Flow characterization and modelling of a South Benin artesian aquifer system: effects of hydraulic and storage properties and recharge on simulated heads across the artesian zone

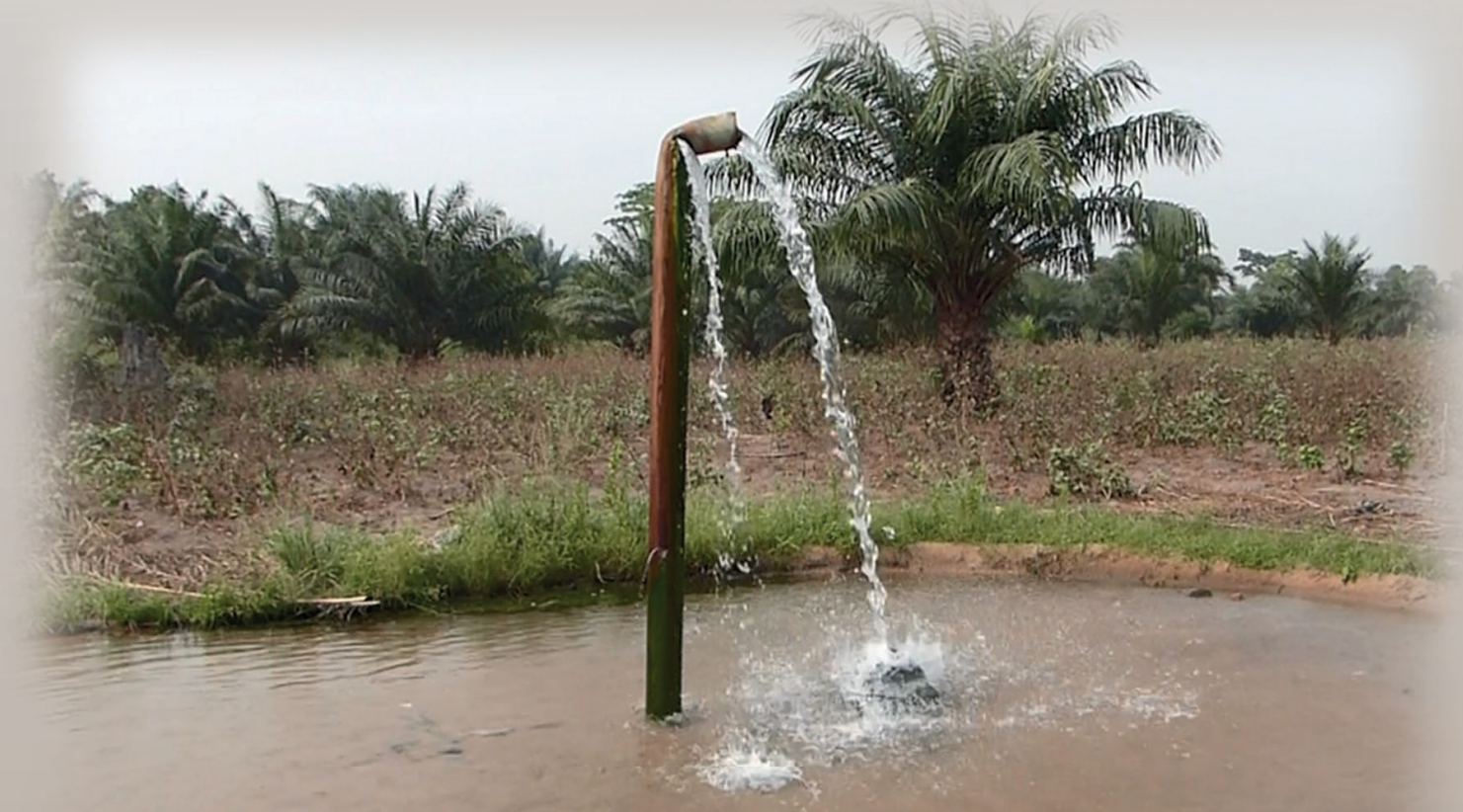

K. A. Raoul Kpegli 
Propositions

1.Artesian systems are structured into peripheral and central artesian zones that react differently to external stresses (this thesis).

2.Artesian heads can temporarily shift to non-artesian heads in the peripheral artesian zone. (this thesis).

3.Developing numerical groundwater flow models is similar to the construction of buildings, except that "what to do" is more straightforward for an architect than for a groundwater modeller.

4. A botanical garden benefits the economy and the environment by conserving biodiversity, endangered plant species, honeybees and birds all of which play an important role in the production of crops.

5.Efficient communication skills and flexibility are undeniable values linked to a successful PhD.

6. Young scientists should not fear the article review process as it is an extra opportunity of learning-by-doing science.

Propositions belonging to the thesis entitled "Flow characterization and modelling of a South Benin artesian aquifer system: effects of hydraulic and storage properties and recharge on simulated heads across the artesian zone"

K.A. Raoul Kpegli,

Wageningen, 04 November 2020 


\section{Thesis committee}

\section{Promotor}

Prof. Dr S.E.A.T.M. van der Zee

Personal chair, Soil Physics and Land Management

Wageningen University \& Research

\section{Co-promotors}

Prof. M. Boukari, Institut National de l'Eau (INE), Université d'Abomey-Calavi, Benin

Dr P.G.B. de Louw, Department of Soil and Groundwater, Deltares, Utrecht, Netherlands

\section{Other members}

Prof. Dr F. Ludwig, Wageningen University \& Research

Prof. Dr S. Silliman, Gonzaga University, Spokane, Washington, USA

Dr G. Houben, Federal Institute for Geosciences and Natural Resources, Hannover, Germany

Dr J.W.A. Foppen, IHE Delft Institute for Water Education

This research was conducted under the auspices of the Research School for SocioEconomic and Natural Sciences of the Environment (SENSE) 


\title{
Flow characterization and modelling of a South Benin artesian aquifer system: effects of hydraulic and storage properties and recharge on simulated heads across the artesian zone
}

\author{
K. A. Raoul Kpegli
}

Thesis

submitted in fulfilment of the requirements for the degree of doctor at Wageningen University

by the authority of the Rector Magnificus,

Prof. Dr A.P.J. Mol, in the presence of the

Thesis Committee appointed by the Academic Board to be defended in public

on Wednesday 4 November 2020

at 11 a.m. in the Aula. 


\section{K. A. Raoul Kpegli}

Flow characterization and modelling of a South Benin artesian aquifer system: effects of hydraulic and storage properties and recharge on simulated heads across the artesian zone, 160 pages.

$\mathrm{PhD}$ thesis, Wageningen University, Wageningen, the Netherlands (2020)

With references, with summaries in English and French

ISBN: 978-94-6395-451-8

DOI: https://doi.org/10.18174/526095 


\section{Table of contents}

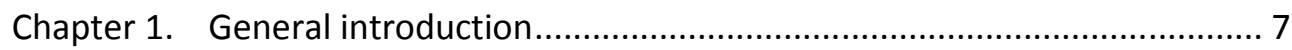

Chapter 2. Development of a conceptual groundwater flow model using a combined hydrogeological, hydrochemical and isotopic approach: a case study from southern Benin

Chapter 3. Impact of hydraulic and storage properties on river leakage estimates: A numerical groundwater flow model case study from southern Benin

Chapter 4. Three-dimensional hydrogeological modelling of head changes of a South Benin artesian aquifer.

Chapter 5. Synthesis

Annexes

Literature cited 125

English summary. 145

French summary (Résumé).. 149

Acknowledgements 153

About the author 157 



\section{General introduction}




\subsection{Problem description}

The world's population is growing fast and in the future, the exploitation of fresh groundwater resources will increase due to its increasing demands for economic growth, intensified agriculture and to loss of surface water resources because of contamination (Ranjan et al., 2006). Water resources are finite and the need to deal with increasing complex water issues has been identified numerous times (see e.g.: Pachepsky et al., 2004). Also, due to climate variability and change, groundwater resources are being threatened worldwide, including developing countries (Bovolo et al., 2009 ; Candela et al., 2009; Green et al., 2011). Climate change effects on groundwater resources are closely linked to other global change drivers, including population growth, urbanization and land-use change, coupled with other socio-economic and political trends. But knowledge about groundwater systems and the impact of climate change on groundwater quantity and quality is limited, especially at large scale (Treidel et al., 2011; Sutanudjaja et al., 2011). Groundwater resources are still poorly understood, and hence poorly managed in many parts of the world (Smith et al., 2016). Some groundwater resources were accumulated hundreds of years ago and are no longer replenished (e.g.: many of the sandstone aquifers of North Africa (see e.g.: Sultan et al., 2013 ; Voss and Soliman, 2014)), thus using them is similar to mining nonrenewable minerals. Unfortunately, groundwater resources management is not simple, because these resources are not all alike and respond differently to stresses and require different management solutions. A vital starting point for improving management of groundwater is to develop a technical understanding of how groundwater systems work. For example: what is the geologic setting, where are the groundwater recharge areas and how much is the recharge, what are the groundwater flow directions, how much water can be sustainably taken from the aquifer, etc.?

Studies that approach all these questions so as to arrive to a comprehensive understanding of the potentiality of an aquifer (for it sustainable management) are rare in the literature. This thesis approaches these questions for the groundwater resource of the Cretaceous (precisely, the Turonian-Coniacian) aquifer in southern Benin. The Turonian-Coniacian (T.C.) aquifer which belongs to the Coastal Sedimentary Basin of Benin, is a valuable water resource in southern Benin. This aquifer is partly artesian, allowing flowing artesian conditions (free-flows) when deep boreholes reach this aquifer. The artesian water keep discharging with great force for many of the artesian wells. But for some of them, the artesian flow has been reduced. Understanding the issue of artesian flow decrease, particularly the future evolution of artesian conditions is key for a sustainable management of this valuable aquifer. A dynamic groundwater flow model of the concerned aquifer system, i.e., a numerical dynamic representation of such a system is recognized as the best tool that can help assess the potentiality of an aquifer system with respect to current and 
future stresses (Lubczynski and Gurwin, 2005). A model requires a considerable amount of data regarding the geometry of the aquifer (including geologic strata and topography), the rivers network and fluxes, location of boreholes and related abstractions rates and fluxes, distributed recharge (spatial zonations and fluxes), the aquifer and its adjacent aquitard spatial properties (hydraulic and storage properties) and system observations (surface and groundwater levels, surface water discharges, etc.). Such considerable amounts of data allow to conceptualize the groundwater flow system and to evaluate its interactions with the surface water system.

Conceptualization means the formulation of a simplified view of the groundwater system. In theory, the closer the conceptual view approximates the real-world system, the more accurate are the groundwater modelling results. However, real-world aquifers systems are complex and parsimony is often desired in practice. Explicitly, the conceptual view should be as simple as possible, as long as it remains adequate to reproduce the system's behavior (Anderson and Woessner 1992 ; Hill 2006). In this thesis, we wish to reproduce the past heads and predict future heads in the artesian aquifer, which requires a good conceptualization of the groundwater system. Conceptualization of a groundwater system usually starts with identifying the hydrostratigraphic units that contain similar hydrogeologic properties in the study area. The hydrostratigraphic units are then categorized as either aquifers or aquitards depending on their capabilities of conveying water. The resulting conceptual view conceives the groundwater system as a series of aquifer and aquitard layers, each with its own aquifer or aquitard properties and water boundary conditions (Yang et al., 2010). A conceptual groundwater flow model is a combination of a conceptual view of the lithostratigraphy and the flow knowledge (recharge areas, flow directions, discharge or downstream areas, boundary conditions, rivers) of the system. Prior to a numerical model development, it is fundamental that a conceptual groundwater flow model of the system be developed (Troldborg et al., 2007; Rojas et al., 2008), because in essence, the numerical flow model is just a translation of the conceptual one. According to Hesch and Chmakov (2011), an increased level of effort in creating the conceptual model reduces the effort calibrating the numerical model. But in practice, errors in the conceptualization of the system occur (Rojas et al., 2008). "How can we extract information from available data on human and water systems in order to inform the building process of socio-hydrological models and conceptualizations?" is the eighteenth of the twenty three unsolved problems in hydrology identified by the community process in 2018 (Bloschl et al., 2019). A specific related question for this study is: how could we build on both the lithostratigraphy and the flow knowledge (derived from approaches such as piezometry, hydrochemistry and isotopes) to arrive at a conceptual groundwater flow model? Hence, a first objective is to develop a conceptual flow model of the study area and 
to assess if both piezometry, hydrochemistry and isotopes are all useful in developing a conceptual flow understanding in such a study area.

In addition to a conceptual groundwater flow model, directions and magnitudes of fluxes between the surface and the groundwater systems are important to capture as accurate as possible for their reasonable inclusion in the numerical model. Accounting for surfacegroundwater interactions contributes to good calibrations of numerical groundwater models (Valerio et al., 2010 ; Rassam et al., 2013). Especially, for the case of the study area where there is an issue of surface water losses (see chapter 3), evaluation of surfacegroundwater fluxes deserves attention. The evaluation of surface-groundwater fluxes is dependent on how accurate the streambed properties and other adjacent subsurface properties are known. Streambed properties are prone to measurement errors because streambed sediments are highly heterogeneous and vary in space (Chen, 2000, 2004; Irvine et al., 2014 ; Liu and Chui, 2018). In addition to the streambed properties, uncertainties in other properties (hydraulic and storage properties) of the subsurface layers may influence the estimated surface-groundwater fluxes. But the question is which of these properties have the largest impact on the simulated fluxes? Hence, the second objective of this thesis is to assess which of these properties have a dominant influence on the estimated surfacegroundwater fluxes.

With a good groundwater flow conceptualization and a reasonable estimation of surfacegroundwater fluxes, the simulation of heads in the artesian system could be performed by means of a numerical groundwater flow model. Previous studies in the literature (Welsh, 2006) found large differences in artesian head declines between areas (e.g.: between south Australia and New South Wales) which could not be explained yet. Also, numerical model exercises, which target a real-world system, deal with hydraulic and storage properties that are uncertain (Mazac et al., 1985 ; Sanchez-Vila et al., 1996; Refsgaard et al., 2012; Nilsson et al., 2001) because limited local scale measurements are usually performed on the field to derive average values which may not accurately represent the reality. Previous studies such as Marchant et al., 2016 and Lin et al., 2017 generated sets of realizations of multiple aquifer properties (e.g.: hydraulic conductivity) to simulate realizations of hydraulic heads and to conduct uncertainty analysis. But, in the artesian studied system, it is not clear which properties if uncertain would more affect the simulated heads. Also, groundwater recharge is known with uncertainties (Ordens et al., 2012; Crosbie et al., 2018) and it is unclear if the impact of recharge and hydraulic and storage properties are the same across the whole artesian zone. So, a set of questions are: how will artesian heads in the T.C. aquifer evolve in the future with respect to future population growth and climate change? which areas of an artesian basin would be more subjected to artesian head declines? what is the impact of recharge and hydraulic and storage properties of the subsurface layers on heads in the 
artesian domain? Hence, the third objective (set of objectives) of this thesis is to investigate the future trends of the heads across the artesian zone considering climate change and increasing water demand, to assess which areas of an artesian basin would be more affected by head instability and to assess the sensitivity of hydraulic and storage properties and recharge on simulated heads in the artesian zone.

\subsection{Research questions and objective}

The problems outlined above lead to research questions that are summarized below:

1) How could we build on both lithostratigraphy, piezometry, hydrochemistry and isotopes data to arrive at a conceptual groundwater flow model?

2) Which of the streambed and subsurface layers properties have a dominant influence on the estimated surface-groundwater fluxes?

3) How will artesian heads in the T.C. aquifer evolve in the future with respect to future population growth and climate change? which areas of an artesian basin would be more subjected to artesian head declines? what is the impact of recharge and hydraulic and storage properties of the subsurface layers on heads in the artesian domain?

The general objective in addressing these questions is to contribute to a better understanding of the functioning of artesian basins and to advance our knowledge regarding modelling such artesian groundwater systems.

\subsection{Thesis outline}

The research questions are addressed in chapters two to four.

In chapter 2, we developed a conceptual groundwater flow model for the case study with an emphasis on how to build on the above mentioned approaches to arrive at a conceptual flow model.

In chapter 3, the obtained conceptual groundwater flow model was translated into a numerical model which is then used to investigate the surface-groundwater interactions, computing the river leakage and assessing how uncertainties in the different hydraulic and storage properties impact the computed river leakage.

In chapter 4, we simulated the heads across the artesian zone so as to understand the reason of current artesian head-drop and to assess the plausible future evolution of heads in the artesian domain under climate change and artesian outflows scenarios. The 
importance of each properties (referred later to as parameters) with respect to simulating heads in an artesian system is examined and discussed. Also, the sensitivity of the computed heads to recharges derived from different rainfall scenarios is discussed.

Chapter one introduces the overall research conducted in this thesis. Chapter 5 is the synthesis of the thesis and it presents the major findings and conclusions of the previous three chapters. In addition, the implications of this study for the society are also discussed. Lastly, limitations of this study and recommendations for future works are highlighted.

As the research chapters (chapters 2 to 4 ) were independently published/submitted to scientific journals, we provided in each of them the background information of the study area to allow that each of them stands alone. 


\section{Development of a conceptual groundwater flow model using a combined hydrogeological, hydrochemical and isotopic approach: a case study from southern Benin}

Study region: The Turonian-Coniacian aquifer system in the North of the Coastal Sedimentary Basin, southern Benin, West Africa.

Study focus: The Turonian-Coniacian aquifer is the major aquifer in southern Benin and is the main source of water supply for the population. The pressure on groundwater resources from the Turonian-Coniacian aquifer is increasing since few artesian wells tapping into this aquifer already show decrease in their yields. Preventing extinction of the artesian outflows requires as a first step a thorough understanding of the groundwater flow system: groundwater recharge areas, downstream areas, and flow directions. In this study, a combined hydrogeological, hydrochemical and isotopic approach was applied to understand the groundwater flow within this aquifer and to develop a coherent conceptual groundwater flow model.

New hydrological insights for the region: The piezometric results indicated three main groundwater flow directions. Stable isotopes results confirmed the piezometry as the most depleted and enriched values in Oxygen-18 and deuterium were found respectively in downstream areas (southern region) and in the recharge areas (northern region) indicated by the piezometry. Similarly, higher tritium contents (up to 3.5 Tritium Unit) characterize recharge areas and low tritium contents ( $<0.12$ Tritium Unit) were found in downstream areas. The combination of these results with the geologic and topographic data led to a coherent conceptual groundwater flow model shown in this paper.

Published as:

K. A. R. Kpegli, A. Alassane, S.E.A.T.M van der Zee, M. Boukari, D. Mama, 2018. Development of a conceptual groundwater flow model using a combined hydrogeological, hydrochemical and isotopic approach: a case study from southern Benin. Journal of Hydrology : Regional Studies, 18, 50-67. 


\subsection{Introduction}

Groundwater is one of the world's most important natural resources. In several parts of the world, it happens that this vital resource is threatened both quantitatively and qualitatively. The example of the Great Artesian Basin which underlies $23 \%$ of the Australia continent (Powel at al., 2015), where several springs have dried out and several artesian wells have stopped flowing, is an illustration of severe threats that occur to groundwater resources. Several other authors (e.g. Idris, 1996; Powell and Fensham, 2015; Roberts and Mitchell, 1987) have reported similar threats on groundwater resources in different parts of the world.

In Benin, especially in the coastal sedimentary basin, groundwater is the major source of freshwater for the population. The major aquifer in this basin (the Turonian-Coniacian aquifer) is artesian in some parts of the basin where artesian wells keep discharging continuously enormous quantity of groundwater to the surface (the artesian wells are freeflowing because they are not pipped and capped, however tapping and capping artesian wells help greatly to reduce water loss and hence aquifer drawdown). It is known from the literature (e.g. Powell and Fensham, 2015) that in some systems, artesian outflows turned out to considerably diminished. Some natural springs have totally dried out and numerous artesian wells have stopped flowing (Powel at al., 2015; Idris, 1996; Powell and Fensham, 2015; Roberts and Mitchell, 1987; Yermani et al., 2003).

Currently in Benin, part of the local population finds the free-artesian outflows beneficial because efforts to manually pump groundwater is not required. However, the other part of the population already express concerns about the sustainability of this groundwater resource (personal communication with the local population) and some artesian wells already show decrease in their yields. So far, no study has investigated the sustainability of this vital resource and therefore groundwater recharge, abstractions rates and free artesian outflow rates required for a sustainable use of this resource, remain completely unclear. To prevent extinction or stoppage of free artesian outflows and drying out of natural springs, it is wise to investigate and identify conditions (recharge and abstractions) that may cause extinction of free artesian outflows and drying out of natural springs. Once the recharge, abstraction rates and free outflow conditions are known, preventive actions could be taken in a short and long term.

Arriving at identifying the conditions that may cause artesian wells outflows to stop and springs to dry out requires as a first step a thorough understanding of the groundwater flow system (groundwater recharge areas, groundwater discharge areas, and flow directions). However, the main problem is that the groundwater head data which is required for the 
understanding of the groundwater flow and the development of conceptual groundwater flow models (Bredehoeft, 2005; Zheng and Bennett, 1995; Kresic and Mikszewski, 2013) is often quite limited in many hydrological systems (Barthel 2014; Candela et al. 2013; Carter et al. 1994; Refstegaard et al. 2010). Data related to groundwater systems are limited or absent, as in ungauged basins, due to their inaccessibility and large costs and huge time involved in long-term experimental characterization and monitoring.

In some hydrological systems, boreholes that could allow the measurements of groundwater levels (GWL) do exist, but they were not designed to allow such measurements even though boreholes for drinking supply could well be designed to allow both groundwater extraction and measurements of GWL (Aranyossy, 2007). Only one GWL data, that was recorded during drilling operations is available for those boreholes, and data recorded during drilling operation may not be reliable. For those boreholes that do not allow GWL measurement, the groundwater mineralization as measured through the TDS (Total Dissolved Solids) could still be obtained as long as groundwater abstraction remain possible from those boreholes. But, this raises the following question: "Can the TDS reliably inform about groundwater flow directions and lead to the development of reliable conceptual groundwater flow models?" Groundwater mineralization has been largely investigated (e.g. Verhagen, 1995; Moussa et al., 2009; Fadili et al., 2015; Dieng et al., 2017; Gning et al., 2017) but its validity in helping develop coherent conceptual groundwater flow models is unclear.

To some extents, stable isotopes (Boronina et al., 2005; Dhaoui et al., 2016) and radioactive isotopes (Izbicki et al., 1995; Szabo et al., 1996), though costly, are proved to provide relevant information on groundwater ages, directions of groundwater flow, aquifer recharge and discharge zones. Hence, isotopes, piezometric and also geologic data are often used to construct conceptual groundwater flow models (Dassi and Tarki, 2014; Pétré et al., 2016; Fernandes et al., 2016; Brikic et al., 2016; Bicalho et al., 2017; Madrala et al., 2017; Segadelli et al., 2017).

Based on the knowledge that hydrochemical patterns are influenced by groundwater flow (Stuyfzand, 1999; Hussein, 2004; Novel et al., 2007) and that high and low mineralization of groundwater are usually correlated to long and short resident time respectively (Wilson et al., 1991; Huneau et al., 2007), we focus on accessing the reliability of the TDS in the development of conceptual groundwater flow models.

So, the main aim of this study is to develop a coherent conceptual groundwater flow model for the research area. We use this case study to access whether the groundwater mineralization as measured through the TDS is a relevant element to consider when it 
comes to developing conceptual flow models in scarce groundwater head data environments, where TDS data could still be obtained. In that sense, we firstly focus on both piezometric and isotopes data to develop a coherent conceptual groundwater flow model using as case study, the Turonian-Coniacian aquifer system in southern Benin. Then, we use data of Tritium and ${ }^{14} \mathrm{C}$ from the same case study to test the reliability of groundwater mineralization with respect to conceptual flow models development.

\subsection{Study area}

\subsubsection{Location, climate and vegetation}

The study area (Figure 2.1) is geographically located between latitudes $6^{\circ} 45 \mathrm{~N}$ and $7^{\circ} 40^{\prime} \mathrm{N}$ and longitudes $1^{\circ} 55^{\prime} \mathrm{E}$ and $2^{\circ} 50^{\prime} \mathrm{E}$ and covers approximately $4600 \mathrm{~km}^{2}$. It is a part of the northern coastal sedimentary basin of Benin republic (Boukari, 2007; Alassane, 2015) and is composed mainly of 3 plateaus (from West to East: Abomey, Zagnanado and Kétou plateaus that are separated respectively by Zou river and Ouémé stream), the Ouémé valley and an East-West belt known regionally as Lama depression (Affaton et al., 1985; Amajor, 1991). The study area is bordered in the North by the crystalline bedrock, in the South by Allada and Sakete plateaus, in the West by Couffo stream and its Eastern border corresponds to the limit between Benin and Nigeria republics (Figure 2.1). It is worthwhile noting that the Kétou plateau extends to the south-western Nigeria (Abeokuta township) where similar geological formations as found in Benin are encountered (Affaton et al., 1985). The topography in the study area varies from -1 to about $270 \mathrm{~m}$ a.s.l. High altitude values are observed in the Northern plateaus. Low altitude values are found in the Ouémé valley and in the Lama depression.

The study area belongs to the sub-equatorial region with a bimodal rainfall distribution (Figure 2.2a). It is characterized by two rainy seasons (a main rainy season: from mid-March to mid-August and a short rainy season: from mid-September to November) and two dry seasons (a short dry season: from mid-August to mid-September and a main dry season: from December to mid-March). The mean annual rainfall recorded at Bohicon meteorological station (from 1922 to 2009) is $1197 \mathrm{~mm}$, with a potential evapotranspiration of about $1500 \mathrm{~mm} /$ year (Achidi et al, 2011; Amoussou, 2005). The relative humidity is high and is comprised between $65 \%$ and $90 \%$. The annual mean temperature is $27^{\circ} \mathrm{C}$ but may rise up to $38^{\circ} \mathrm{C}$ in dry seasons and may decrease down to $19^{\circ} \mathrm{C}$ in rainy seasons.

The original vegetation of the study area is characterized by a mosaic of forest and savannas, but has mostly been replaced by secondary grasslands or savannas due to human 
intervention. However, isolated semi-evergreen rain forest (original vegetation), which are mostly protected for religious reasons, can still be found (Adjakidje, 1984; Adjanohoun, 1989; Houndagba, 2015). The vegetation in urban areas has been removed because of buildings construction and town planning.

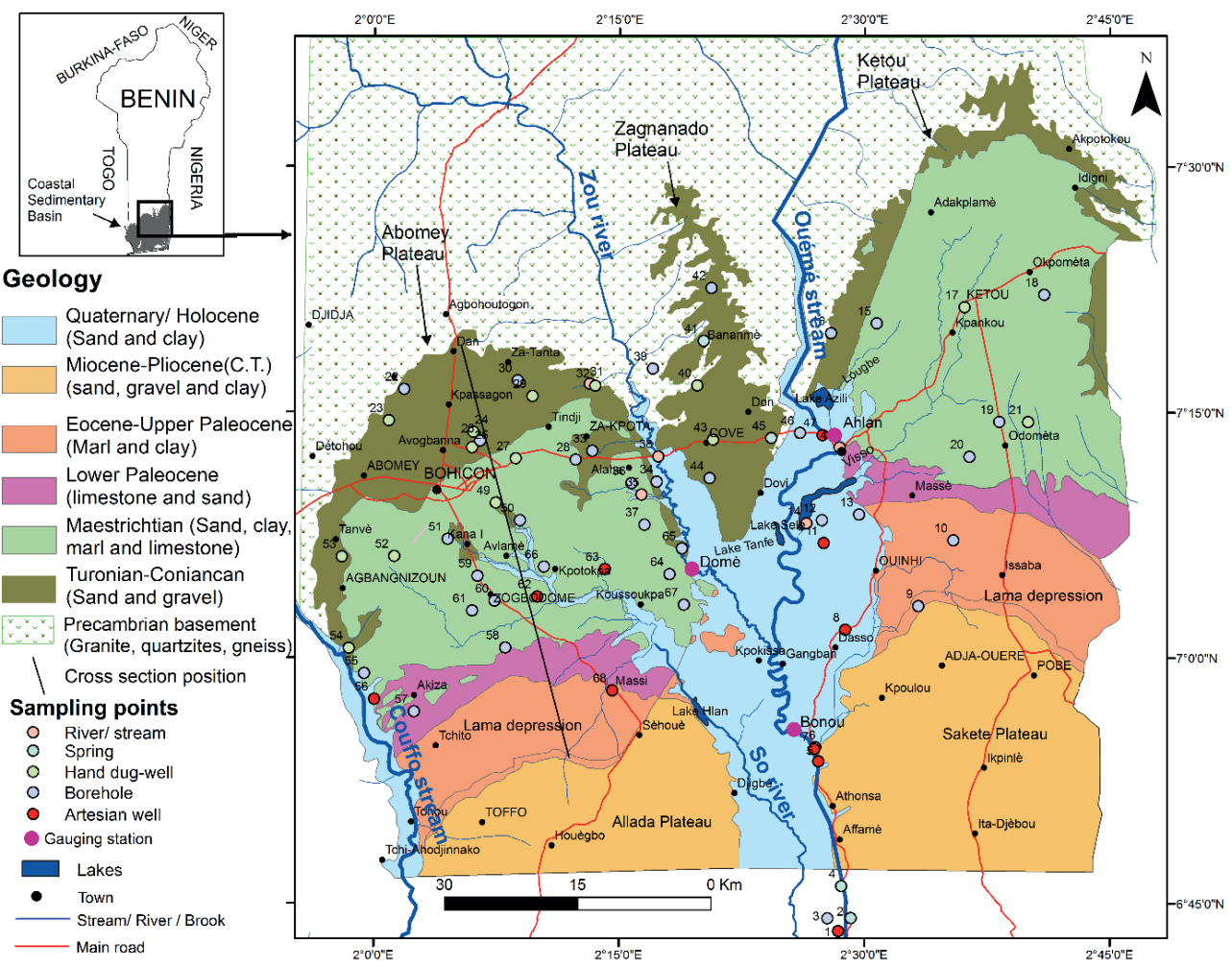

Figure 2.1 Location and geological map of the study area showing sampling points and hydrologic information (modified from IRB (1987)).

\subsubsection{Surface hydrology}

The surface water body is characterized by two main streams (Ouémé and Couffo streams), two main rivers (Zou and Sô rivers), four lakes (Azili, Sele, Tanfè and Hlan lakes), several springs and brooks (Figure 2.1). The Ouémé, Couffo and Zou have their origin outside the study area, in the northern crystalline region (Moniod, 1973; Le Barbe et al., 1993) and flow into the sedimentary basin (Figure 2.1). The Zou river joins up with the Ouémé stream around Kpokissa township which is about $100 \mathrm{~km}$ North of the coast of Benin. These streams and rivers are of permanent flow (Figure 2.2b). The minimum discharges (base flow) occur in dry seasons with about $2 \mathrm{~m}^{3} / \mathrm{s}, 2.5 \mathrm{~m}^{3} / \mathrm{s}$, and $5 \mathrm{~m}^{3} / \mathrm{s}$, respectively for Zou river (at Dome), 
Ouémé stream (at Ahlan) and Ouémé stream (at Bonou). Maximum discharge values are observed in rainy seasons with values of about $140 \mathrm{~m}^{3} / \mathrm{s}, 850 \mathrm{~m}^{3} / \mathrm{s}$ and $850 \mathrm{~m}^{3} / \mathrm{s}$ respectively for Zou river (at Dome), Ouémé stream (at Ahlan) and Ouémé stream (at Bonou). Because Zou and Ouémé merge upstream of Bonou (Figure 2.1), it would be expected that the sum of the discharges of Zou river (at Dome) and Ouémé (at Ahlan) equals the discharge of Ouémé (at Bonou). This expectation is more or less met in dry seasons. In rainy seasons, this expectation is however not met, probably because three lakes (Azili, Sele and Tanfè) are fed by the Ouémé stream during the rainy seasons and these lakes disconnect from the Ouémé stream in dry seasons as observed during field trips. The Sô river has its source in the Lama depression (within the study area), but is fed by free artesian outflow since few decades. The discharges of the Sô river are less than $1 \mathrm{~m}^{3} / \mathrm{s}$ to about $140 \mathrm{~m}^{3} / \mathrm{s}$ respectively in dry and rainy seasons (Colombani et al., 1972). Recent discharge records for the Sô river are unavailable and could not be plotted on Figure 2.2.

Date

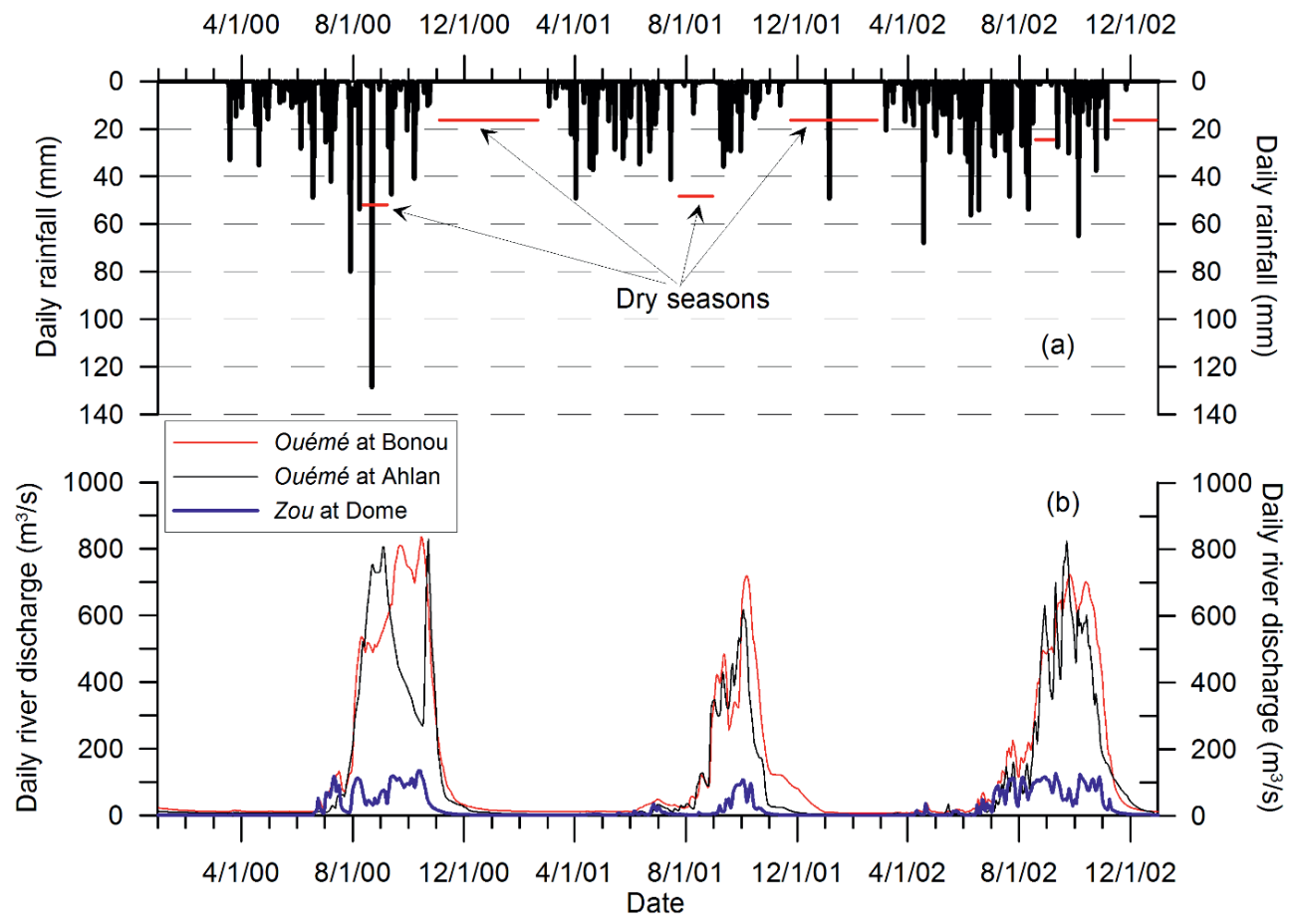

Figure 2.2 Daily rainfall (a) and daily rivers discharges (b) for three selected years (2000 to 2002) that contains no missing data.

Lake Azili, lake Sele (Salzmann and Hoelzmann, 2005) and lake Tanfè which are refilled periodically by the floods of Ouémé stream empty progressively throughout the dry season. Some brooks such as Lougbé and Visso (see Figure 2.1) constitute a constant source of water 
to lake Azili and lake Sele respectively. Lake Hlan (Adite et al., 2013; Sossou-Agbo, 2013) is both refilled and drained by the Sô river.

\subsubsection{Geology and hydrogeology}

Geologically, the study area consists of sedimentary deposits that overlay the Precambrian crystalline rocks (granite, quartzite, and gneiss). These deposits have a monoclinal structure and their thickness generally increases towards the southeast (Slansky, 1962; Houessou, 1974; IRB, 1987). They consist of detrital formations (sand, gravel, and clay), sandstone, marls and limestones. In total, eight stratigraphic units were identified in the whole coastal sedimentary basin and extend from the upper Cretaceous (Turonian-Coniacian (Unit I)) to the Quaternary (Unit VIII). These eight units are described by Boukari and Alassane (2007) and are summarised in Table 2.1. It is worthwhile noting that among these eight units, units $\mathrm{V}$ to $\mathrm{VII}$ are not part of the area of interest. Also, unit VIII is geographically restricted to areas close to rivers, hence absent in the area where the cross section shown on Figure 2.3 is cut (see both Figure 2.1 and Figure 2.3).

Table 2.1 Stratigraphic column of the Coastal Sedimentary Basin of Benin; Source: Géohydraulique, 1985.

\begin{tabular}{|c|c|c|c|c|c|}
\hline Stages & $\begin{array}{l}\text { Lithostratigraphic } \\
\text { units }\end{array}$ & $\begin{array}{l}\text { Thickness } \\
\text { (m) }\end{array}$ & Permeability & $\begin{array}{l}\text { Dominant } \\
\text { lithology }\end{array}$ & Aquifer \\
\hline Holocene & VIII & $\sim 50$ & $\begin{array}{l}\text { Permeable, } \\
\text { Impermeable }\end{array}$ & Clay, Sand** & Quaternary \\
\hline $\begin{array}{l}\text { Miocene- } \\
\text { Pleistocene }\end{array}$ & VII & $\sim 15$ & Semi-permeable & Fine Sand** & \multirow{3}{*}{ C.T. ${ }^{1}$} \\
\hline Upper Miocene & VI & $<120$ & Permeable & Sand** & \\
\hline Lower Miocene & $\mathrm{V}$ & $\sim 145$ & Permeable & Sand** & \\
\hline Middle Eocene & IV & $\sim 170$ & \multirow{3}{*}{ Impermeable } & marls & \multirow{3}{*}{$\begin{array}{l}\text { Impermeable } \\
\text { layer }\end{array}$} \\
\hline Lower Eocene & IIIb & \multirow[b]{2}{*}{$\sim 155$} & & marls & \\
\hline $\begin{array}{l}\text { Upper } \\
\text { Palaeocene }\end{array}$ & IIIa & & & Clays and marls & \\
\hline $\begin{array}{l}\text { Lower } \\
\text { Palaeocene }\end{array}$ & $\mathrm{IIb}$ & $<50$ & Permeable & $\begin{array}{l}\text { Limestone and } \\
\text { sand** }\end{array}$ & L.P. ${ }^{2}$ \\
\hline Maastrichtian & Ila & $<180$ & Impermeable & Clays and marls & $\begin{array}{l}\text { Impermeable } \\
\text { layer }\end{array}$ \\
\hline $\begin{array}{l}\text { Turonian- } \\
\text { Coniacian }\end{array}$ & I & $50 \sim 150$ & Permeable & Sand* & T.C. ${ }^{3}$ \\
\hline \multicolumn{6}{|c|}{ * Main aquifer in the area of study } \\
\hline \multicolumn{6}{|c|}{${ }^{* *}$ Aquifer that is absent or poorly present in the area of study } \\
\hline \multicolumn{6}{|c|}{${ }^{1} \mathrm{C} . \mathrm{T} .=$ Continental Terminal aquifer } \\
\hline \multicolumn{6}{|c|}{${ }^{2}$ L.P. = Lower Palaeocene aquifer } \\
\hline \multicolumn{6}{|c|}{${ }^{3} \mathrm{~T} . \mathrm{C} .=$ Turonian Coniacian aquifer } \\
\hline
\end{tabular}

The area of interest contains three aquifers: the Turonian-Coniacian aquifer (Unit I), the Lower Palaeocene aquifer (Unit IIb), and the Quaternary aquifer (Unit VIII), separated from each other by clay and marls layers (Bouzid, 1971). The most important aquifer in terms of 
extent and thickness is the Turonian-Coniacian aquifer. The Lower Palaeocene aquifer (Figure 2.1) is poorly present at depth as it is discontinuous within the clay and marl materials form the Maastrichtian and the Upper Palaeocene deposits. A simplified hydrogeological cross section (Figure 2.3) illustrates this discontinuity. A fourth aquifer, which is out of focus within this research (the Continental Terminal aquifer: Units V to VII) exists in the south of the study area, on the Allada and the Sakete plateaus (see details on Figure 2.1). Authors such as Boukari (1998), Alassane (2004) and Alassane (2015) have provided detailed knowledge concerning the Continental Terminal aquifer.

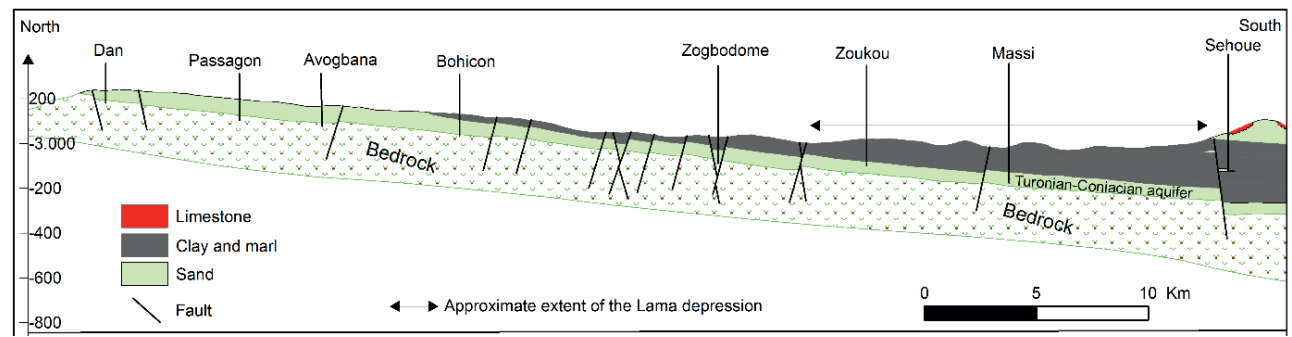

Figure 2.3 Simplified hydrogeological cross-section (IRB, 1987); the position of the cross-section is indicated in Figure 2.1; the enclosed sand and limestone should be searched for in the very right part of the figure.

The Turonian-Coniacian aquifer consists predominantly of sand and secondary of gravel. It outcrops in the northern region and becomes deeper in the South where it is confined by clay and marl materials (Figure 2.3). These clay and marl materials outcrop in the Lama depression (Gomez, 1979) and cause the direct infiltration from rainfall to be limited in this depression (Houndagba, 2015). The depth to the Turonian-Coniacian aquifer varies across the area, so as its thickness. Values of transmissivity reported by Bouzid (1971) and IGIP (1984) are in order of 200 to $750 \mathrm{~m}^{2} /$ day based on groundwater pumping tests carried out in the T.C. aquifer. In the northern region (Northern Abomey plateau, Zagnanado plateau and northern Kétou plateau), hand-dug wells (of up to $70 \mathrm{~m}$ depth) extend into this main aquifer. In the South, it is impossible to exploit the T.C aquifer through hand dug-wells due to the overlaying thick clayey materials and due to the artesian condition that prevails for this aquifer in the South. Hence, only deep boreholes that exploit the T.C. aquifer are found in the South. The Lower Palaeocene aquifer (unit IIb) consists of limestone and is mostly discontinuous and enclosed within the clay and marl materials. Its thickness is usually negligible (from few meters to about 20 to $30 \mathrm{~m}$ ).

The quaternary aquifer is found near rivers and streams in the Ouémé valley (Figure 2.1). It consists of alluvial deposits (coarse and fine sands that alternate with silt and clay materials). The thickness of the quaternary deposits increases gradually from North to South (Boukari, 2002). The Turonian-Coniacian aquifer is the one of main interest in this study. 


\subsection{Materials and Methods}

To acquire groundwater level, isotopes and water quality data, both piezometric surveys and water sampling campaigns were conducted.

\subsubsection{Piezometric surveys}

Two main piezometric surveys were conducted, the first in November 2015 (rainy season) and the second in February 2017 (dry season). The first piezometric survey included 560 wells (see the Electronic Supplementary Material by Kpegli et al., 2018a) and the second included 513 wells. Each of the piezometric surveys was undertaken over the period of a week to ensure groundwater levels were comparable.

Static Water Levels (SWL) also referred to as the depths to water table in Figure 2.4 were measured in the Turonian-Coniacian aquifer across the area of study from existing hand dug-wells and boreholes with a groundwater level sounder (type: WL500). Geographic coordinates of the measurement points were recorded with a GPS (Type: GARMIN GPS 64S). The altitudes (land surface elevation) of the measurement points were extracted from a Digital Elevation Model (DEM, Figure 1 of the Electronic Sepplementary Material by Kpegli et al., 2018a) using ArcGis software. Groundwater heads were determined by subtracting the Static Water Levels from the land surface elevation (i.e., $h_{i}=E l v-S W L$ (Castany, 1998), see Figure 2.4). Applying the equation $h_{i}=z_{i}+h_{p, i}$ (see Castany, 1998; Post and Asmuth, 2013) to determine the groundwater heads is also feasible (see the Electronic Supplementary Material by Kpegli et al., 2018a). However, in that case, the mean depths of the wells screens have to be considered as illustrated on Figure 2.4. The common reference datum used in this study is the mean sea level. The determined groundwater heads data were used to produce piezometric contour maps for the Turonian-Coniacian aquifer using SURFER software. 


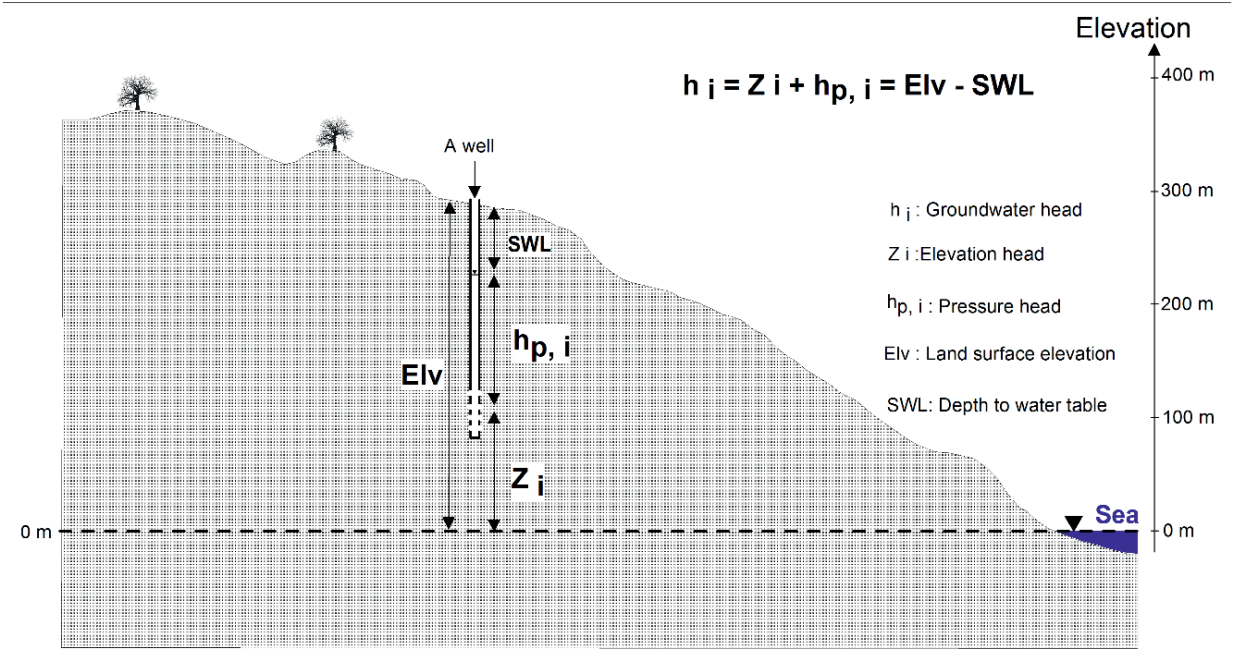

Figure 2.4 Schematic diagram of groundwater head calculation (modified from Post and Asmuth, 2013)

\subsubsection{Water sampling campaigns}

One major water sampling campaign was conducted in September 2015. Both surface water (from the above mentioned rivers and streams) and groundwater (from the existing hand dug-wells, boreholes, and springs) were collected. The sampling points are shown on Figure 2.1.

Prior to sampling, boreholes and dug-wells were purged with a pump until stabilization of $\mathrm{pH}$, Electrical conductivity (EC) and temperature. In average, it took about 6 minutes to purge the wells to make sure that the $\mathrm{pH}$, the EC and the temperature are stabilized. It is also appropriate to pump three well volumes prior to sampling. The purging until stabilization method was preferred to pumping three well volumes because the purging until stabilization method does not require any further calculation (well volume calculation) on the field. It was not necessary to filter groundwater samples. However, surface water samples were filtered when turbid. Water samples were collected and stored in clean highdensity polyethylene bottles (bottles of $60 \mathrm{~mL}$ and bottles of $500 \mathrm{~mL}$ ) with poly-seal caps. Bottles of $60 \mathrm{~mL}$ were used for stable isotopes $\left({ }^{2} \mathrm{H}\right.$ and $\left.{ }^{18} \mathrm{O}\right)$ analysis and bottles of $500 \mathrm{~mL}$ were used for tritium $\left({ }^{3} \mathrm{H}\right),{ }^{14} \mathrm{C}$, and chemical analysis (Major elements: $\mathrm{Ca}^{2+}, \mathrm{Mg}^{2+}, \mathrm{Na}^{+}$, $\mathrm{K}^{+}, \mathrm{Cl}^{-}, \mathrm{SO}_{4}^{2-}, \mathrm{HCO}_{3}^{-}, \mathrm{CO}_{3}^{2-}$, TDS and nitrate: $\mathrm{NO}_{3}^{-}$).

Measurements such as water temperature, $\mathrm{pH}, \mathrm{EC}$, and total alkalinity as $\mathrm{HCO}_{3}^{-}$were carried out onsite. A calibrated $\mathrm{HI} 9828$ multiparameter were used to measure $\mathrm{pH}, \mathrm{EC}$, and 
water temperature. Alkalinity was measured through volumetric titration using chemical available field kits (Model AL-DT). The GARMIN GPS 64S was used to record the coordinates of the sampling points. For surface water sampling, samples were taken from flowing parts of the rivers or streams to avoid sampling river banks waters that may not be well mixed and show effects due to evaporation or pollution (Ryan et al., 2005).

Stable isotopes, tritium and chemical analysis were performed at the Laboratory of RadioAnalysis and Environment (Sfax, Tunisia). Stable isotope ratio $\left(\delta^{2} \mathrm{H}\right.$ and $\left.\delta^{18} \mathrm{O}\right)$ analyses were performed by using the Laser Absorption Spectrometry measurements LGR DLT 100 (Penna et al., 2010). Analyses are reported in per mil (\%o) versus VSMOW standard (ViennaStandard Mean Oceanic Water). Precision of measurement for the analysis for both $\delta^{2} \mathrm{H}$ and $\delta^{18} \mathrm{O}$ is indicated in Table 2.2. Tritium $\left({ }^{3} \mathrm{H}\right)$ analysis were performed using the electrolytic enrichment and liquid scintillation spectrometry (Taylor, 1976) and results are expressed in T.U. (Tritium Unit), with a precision of 0.2 T.U. (with a detection limit of 0.5 T.U.). Major elements except $\mathrm{HCO}_{3}^{-}$and $\mathrm{CO}_{3}^{2-}$ were analyzed by lon-Liquid Chromatography (ILC) equipped with columns IC-Pak TM CM/D for cations, using EDTA and nitric acid as eluent. Anions were analyzed on a Metrohm chromatograph equipped with columns CI SUPER-SEP using phthalic acid and acetonitric as eluent. The test precision of the instrument is about $2 \%$. The total dissolved solids (TDS) was measured by evaporating $100 \mathrm{ml}$ of water sample during 24 hours at 105 degree Celsius. The samples were filtered prior to TDS measurement. The test of charge balance error (Freeze and Cherry (1979)) was run to check the quality of the chemical analyses. The analytical error inferred from the balance between cations and anions did not exceed $5 \%$ which means that the chemical results from lab analyses are valid for interpretation.

In addition to the major water sampling campaign, rain waters were collected monthly (at Bohicon and ITTA rainfall stations) for stable isotopes and tritium analysis. Rainfall is the main input in terms of recharge to the Turonian-Coniacian aquifer. Hence, knowing the isotopic signatures in rainfall will allow comparisons with signatures in groundwaters across the area of interest. Stable isotopes and tritium concerning rain water sampled at these stations were measured and the data are available at the GNIP (IAEA/WMO, 2017). Also, to allow relative age determination, four groundwater samples were taken from TuronianConiacian aquifer, in its artesian part for ${ }^{14} \mathrm{C}$ and ${ }^{13} \mathrm{C}$ analysis. Analysis of ${ }^{14} \mathrm{C}$ and ${ }^{13} \mathrm{C}$ were performed at Groningen University (The Netherlands). Analysis of ${ }^{14} \mathrm{C}$ were done using the AMS method (Saito-Kokubu et al., 2015) and the results are expressed in pmc (percent of modern carbon), with a precision of \pm 0.3 of pmc. Analysis of ${ }^{13} \mathrm{C}$ were performed using a mass spectrometer, with results expressed in \%o values relative to Pee Dee Belemnite (PDB) standard, with a precision of $\pm 0.3 \%$. 
A combination of topographic data, geological data and the groundwater flow directions derived from the piezometric and isotopic data were considered to construct the conceptual flow model using the Surfer software.

\subsection{Results and discussion}

\subsubsection{Piezometry}

The results from the piezometric survey (November 2015) are reported in Table 1 of the Electronic Supplementary Material (ESM, by Kpegli et al., 2018a) and were used to draw the piezometric map of the Turonian-Coniacian aquifer (Figure 2.5). The flow directions for the February 2017 piezometric survey is similar to the one of November 2015, and therefore not shown in this paper.

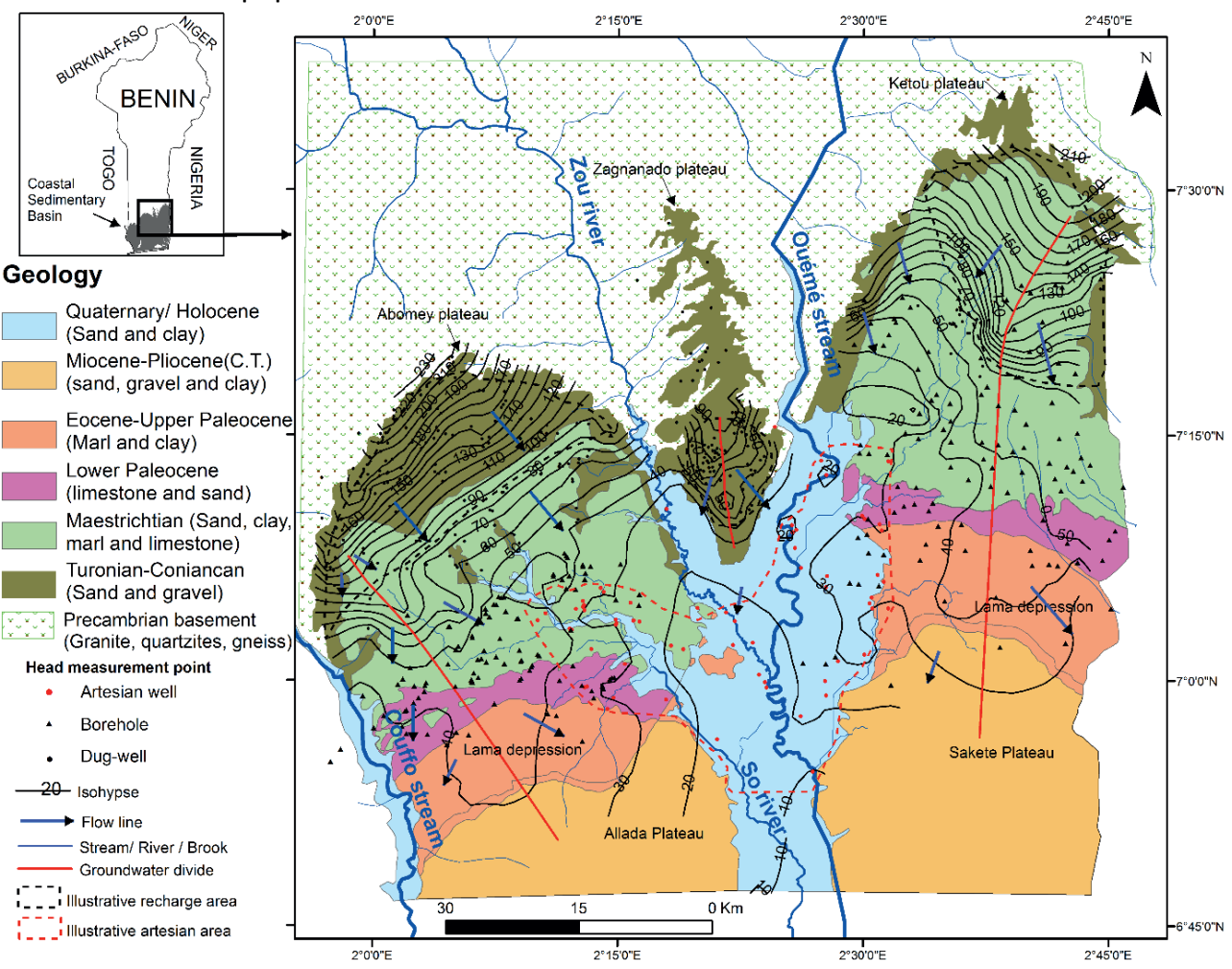

Figure 2.5 Piezometric map of the Turonian-Coniacian aquifer (November 2015) 


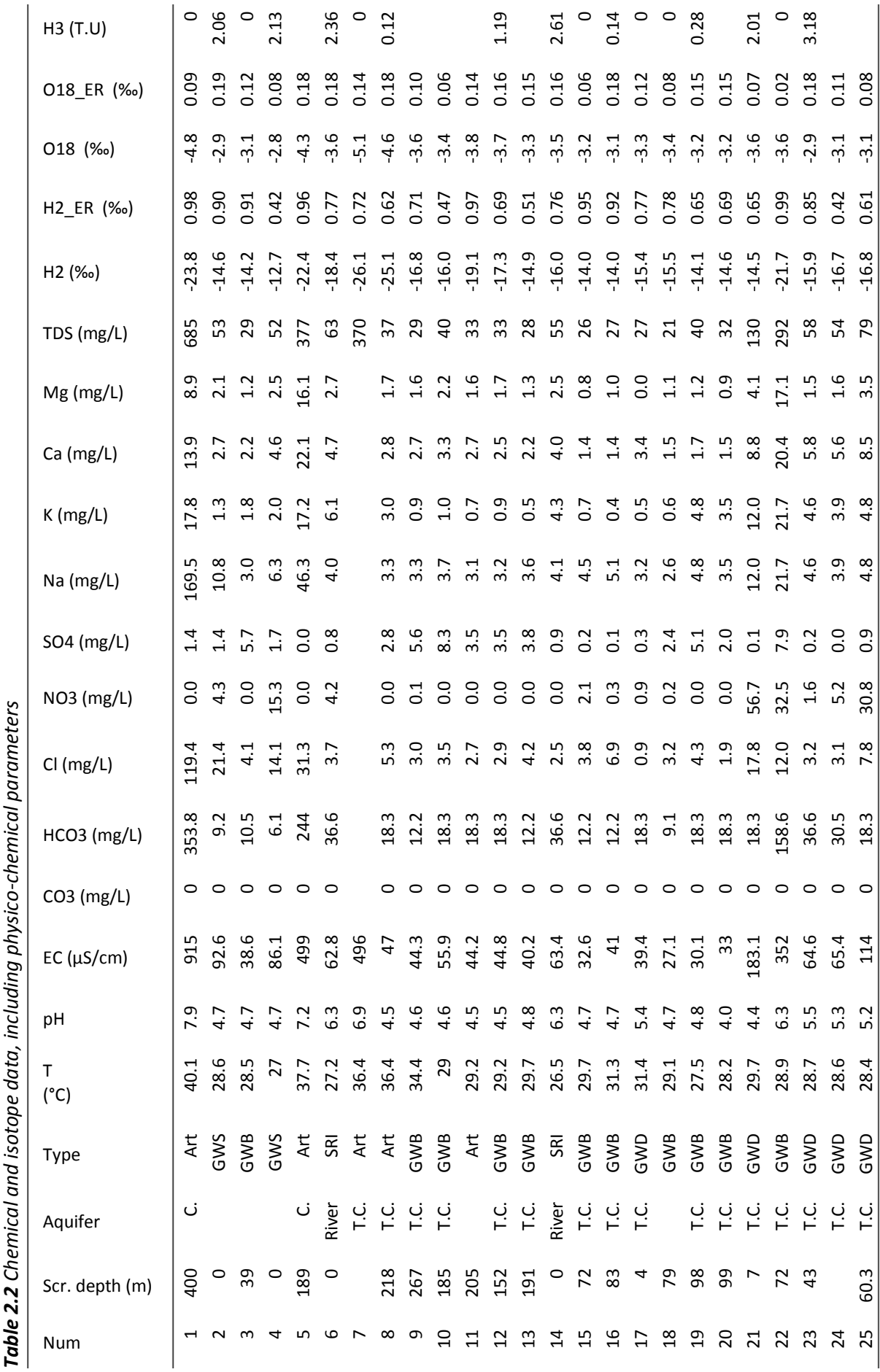




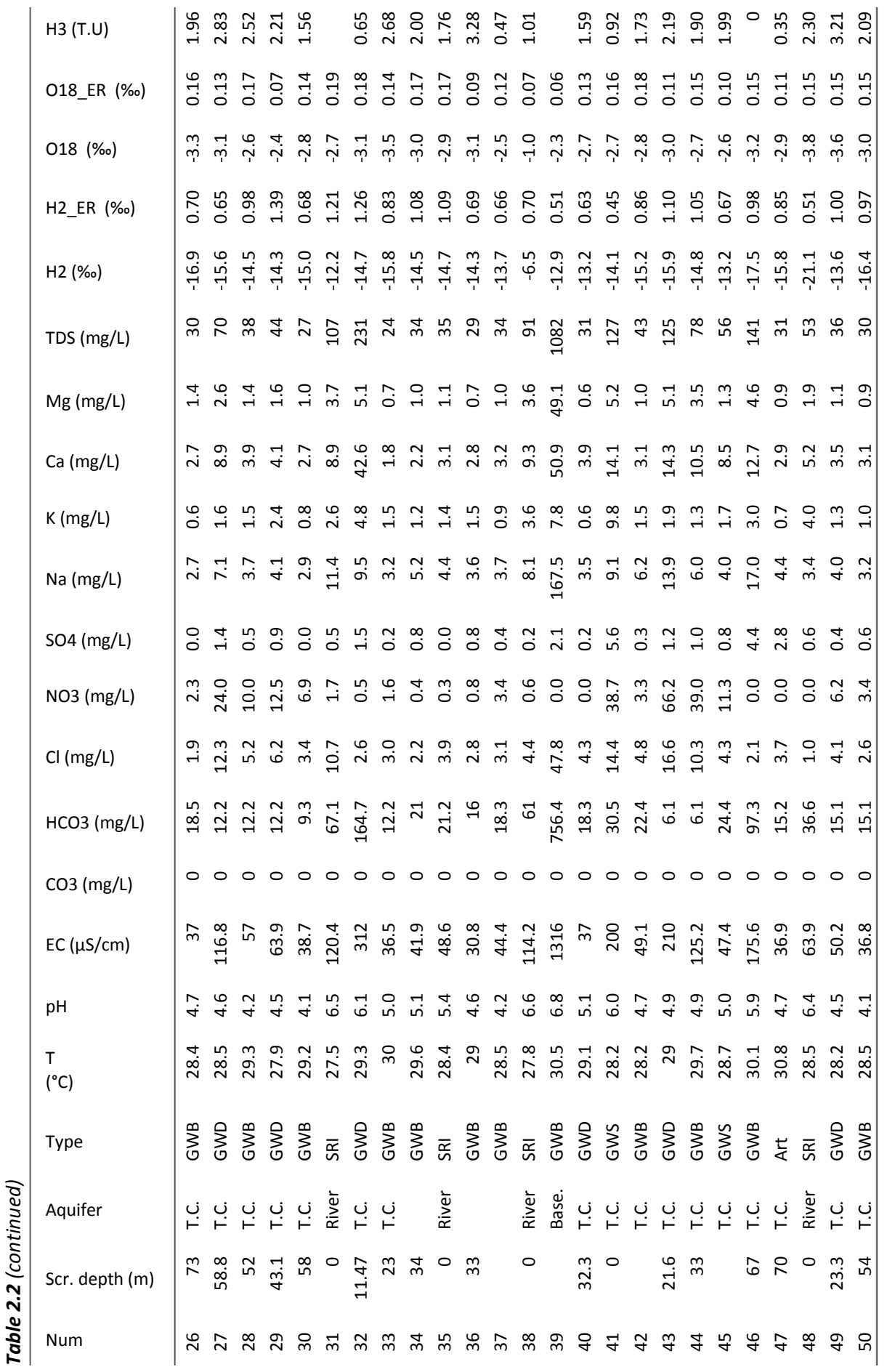




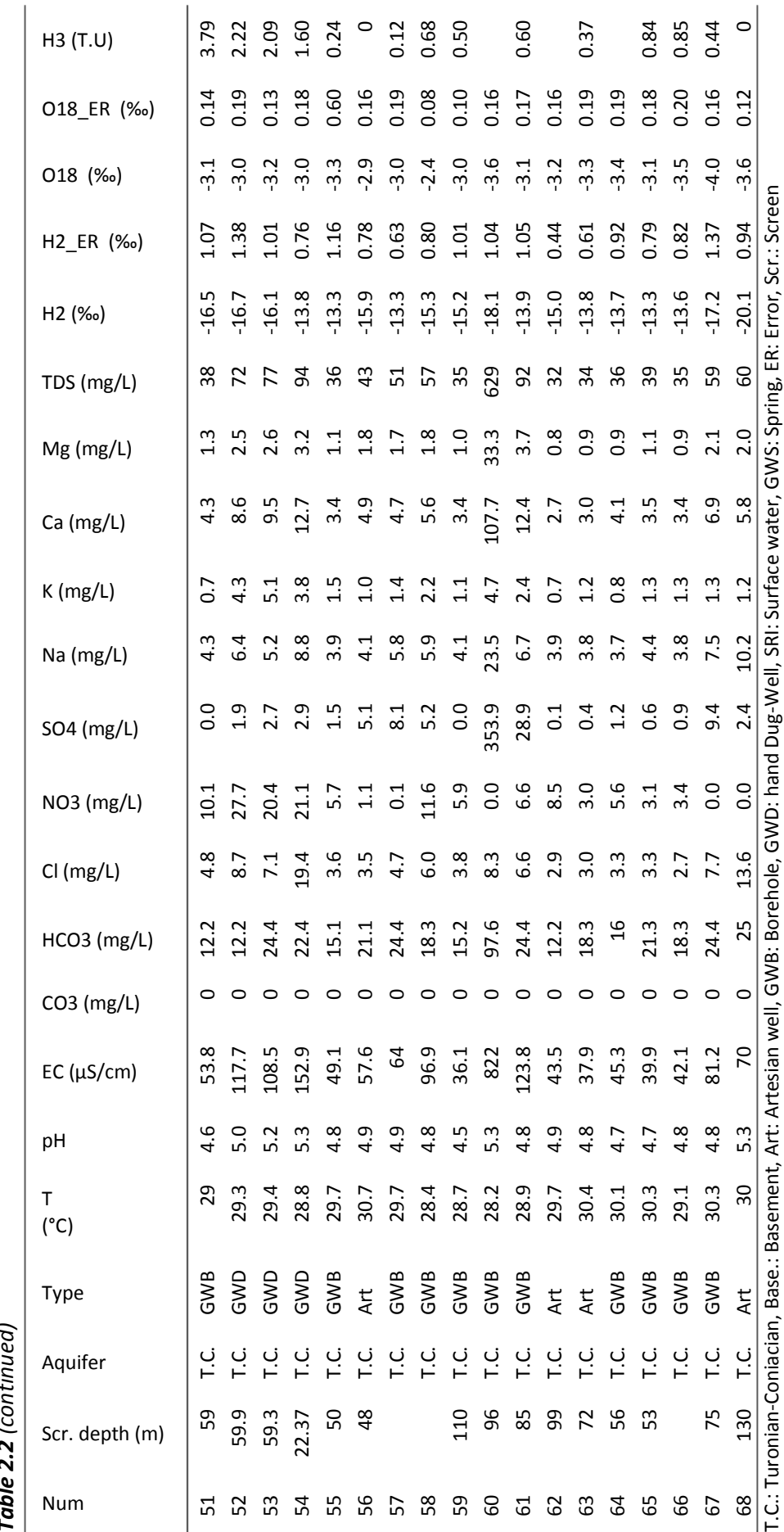


The piezometric map (Figure 2.5), shows that the groundwater flow direction differ from one plateau to the other. This piezometric map highlights a total of three main recharge areas which are all located in the Northern parts of the plateaus.

The first recharge area is located in the North-West of the study area (the northern Abomey plateau) from where groundwater flows generally towards the South-East, with a hydraulic gradient of about $1.3 \%$ in the North-West. This gradient is reduced in the South-East, more than ten times lower (0.08\%) compared to the North of the Abomey plateau.

The second recharge area is located in the North central plateau (the Zagnanado plateau) from where groundwater flows mainly towards the south with an average gradient of $1 \%$. However, groundwater diverges locally from this central plateau towards the Zou river and the Ouémé stream valleys.

The third recharge zone is located in the North-East of the study area (the northern Kétou plateau). Piezometric values are high (about $200 \mathrm{~m}$ ) in this area and these values gradually decrease to about $20 \mathrm{~m}$ towards the South-West. The piezometric contour line of $20 \mathrm{~m}$ (in the south and around the Ouémé stream) are higher than the Ouémé stream stage (less than $15 \mathrm{~m}$ ). This seems to indicate that groundwater from the Turonian-Coniacian aquifer flows into the Quaternary sediments. However, considering that the Turonian-Coniacian aquifer is confined and artesian in this sector (because of the presence of the thick clayey layer) and that the groundwater from the Turonian-Coniacian aquifer is poor in radioactive isotopes in this sector $\left({ }^{3} \mathrm{H} \sim 0 \mathrm{~T}\right.$.U. and ${ }^{14} \mathrm{C} \sim 8 \%$ of modern carbon; see details in section $4.3)$, it is more likely that the Turonian-Coniacian aquifer is disconnected from the Quaternary sediments and surface waters in this sector. Three groundwater divides were derived from the flow pattern of this aquifer. The first is in the west, the second is in the east and the third is on the central plateau as shown on Figure 2.5.

\subsubsection{Groundwater flow evaluation using stable isotopes}

The stable isotopes $\left({ }^{18} \mathrm{O}\right.$ and $\left.{ }^{2} \mathrm{H}\right)$ are part of water molecules and do not interact with the aquifer material (Sidle, 1998; Ette et al., 2017). They are referred to as the "DNA" of water molecules (Ette et al., 2017). In some groundwater flow systems, groundwater in recharge areas is more enriched in stable isotopes while in downstream areas, it tends to be more depleted in stable isotopes (Rozanski, 1985; IAEA, 2008; Dhaoui et al., 2016; SánchezMurillo et al., 2017). Stable isotopes can help identify groundwater recharge zones (Montalvan et al., 2017). Hence, stable isotopes have been used in this study to evaluate the groundwater flow pattern of the Turonian-Coniacian aquifer derived from piezometric surveys. The results from Lab analysis (chemical, stable isotopes and tritium data) 
performed on the water samples collected in the framework of this study are presented in Table 2.2. We have reported all stable isotopes results (from rainfall, surface and groundwater) on the $\delta^{2} \mathrm{H}$ versus $\delta^{18} \mathrm{O}$ diagram where we plotted the Bohicon Meteoric Water Line (BMWL, equation: $\left.{ }^{2} \mathrm{H}=7.2 *{ }^{18} \mathrm{O}+9\right)$. The BMWL was derived from the monthly stable isotope data obtained from monthly rainfall samples analysis, using the least-squarefit linear regression (Celle-Jeonatan et al., 2001) (Figure 2.6). On this diagram the weighted mean annual composition of rainfall in stable isotopes is presented (see MWSI on Figure 2.6). Three main different groups ( $A, B$ and $C$ ) can be distinguished on Figure 2.6: one group (group A) characterized by the most depleted stable isotopes signatures which become more enriched as one moves to the second group (group B) and then to the third group (group C). The blue square (MWSI) represents the weighted mean annual composition of rainfall in stable isotopes belongs to group $\mathrm{C}$, which is a confirmation that the samples from group $\mathrm{C}$ are related to modern recharge.

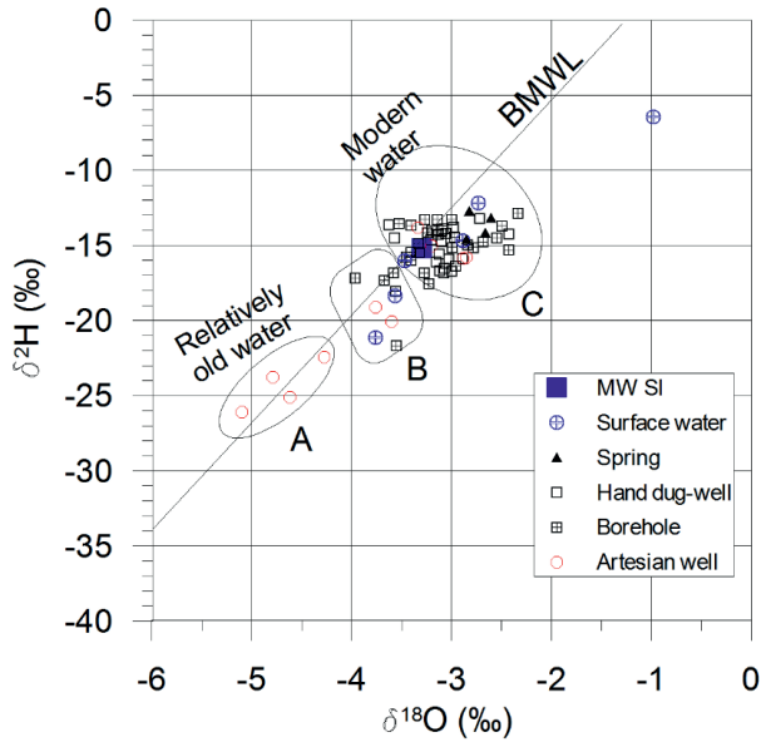

Figure 2.6: Plot of $\delta^{2} \mathrm{H}$ versus $\delta^{18} \mathrm{O}$, showing stable isotope signatures of different type of water samples, with samples in "group $A$ " being the most depleted, samples in "group B" being of intermediate signatures and samples in "group $C$ " being the most enriched in stable isotopes.

Group A (Figure 2.6) is composed only of samples from artesian wells ( samples 01, 05, 07 and 08 ) and shows the most depleted values in stable isotopes $\left(\delta^{18} \mathrm{O}\right.$ ranging from -5.2 to $4.4 \%$ and $\delta^{2} \mathrm{H}$ ranging from -27 to $-23 \%$ ). This group corresponds to stable isotopes signatures of the Turonian-Coniacian aquifer downstream, in the vicinity of Bonou, Afame and Dasso townships (see Figure 2.1 for their geographic location).

Group B (Figure 2.6) is composed of water samples from few (02) artesian wells (samples 11 and 68$)$, boreholes $(12,60,67)$ and surface water $(06,48)$. Samples from hand dug-wells 
are totally absent in group B. This group B shows more enriched values in stable isotopes ( $\delta^{18} \mathrm{O}$ and $\delta^{2} \mathrm{H}$ ranging from -4 to $-3.5 \%$ and from -22 to $-17 \%$, respectively). The absence of samples from hand dug-wells in group $B$ is an indication that the sampling locations corresponding to group $B$ are not a predominant rainfall infiltration zone to the TuronianConiacian aquifer. However, the presence of some samples from surface water in this group suggests that the corresponding sampling areas are intermediate between downstream (Zone of no or insignificant rainfall infiltration to the T.C. aquifer) and upstream (Zone of predominant rainfall infiltration to the T.C. aquifer), where surface-groundwater interactions remain possible.

Group $\mathrm{C}$ shows the most enriched stable isotopes composition $\left(\delta^{18} \mathrm{O}\right.$ and $\delta^{2} \mathrm{H}$ ranging from -3.5 to $-2.2 \%$ and from -23 to $-12 \%$, respectively). All the samples from hand dug-wells are presented in group $\mathrm{C}$, hence confirming that the T.C. aquifer gets recharged predominantly in the corresponding areas (northern plateaus) to this samples, where the local population use hand dug-wells to tap into the T.C. aquifer. According to previous studies (e.g. Dhaoui et al., 2016; Ge et al., 2016), only the most isotopically enriched points of the aquifer system could present a process of current or modern recharge. So, samples in group $C$ (most enriched samples ) being mostly geographically located in the northern plateaus and samples in group A (most depleted) being located towards the south, validate the flow patterns indicated by the piezometry. Stable isotopes are in agreement with the piezometry. So, logically, if the TDS could be useful in developing conceptual flow models in any region characterized by scarce groundwater head data, then the TDS should follow or confirm as well the piezometry. The validation of the piezometry by the TDS is accessed in the next paragraphs. The evaluation of the groundwater flow by stable isotopes performed above is in fact valid only if the stable isotopes compositions are not affected by human activities and by isotope fractionation. To evaluate the effect of human activities on stable isotopes compositions, we removed 24 samples that are contaminated (samples with high $\mathrm{Cl}^{-}$and $\mathrm{NO}_{3}{ }^{-}$contents, i.e.: sample No. 1, 2, 4-6, 15, 21, 22, 24, 25, 27-30, 39, 41, 43$45,49,51,52,54$, and 58; details in section 4.4). This has led to Figure 2.7 which displays the same trend in stable isotopes behaviour from the recharge to downstream areas. This confirms that the interpretations derived from Figure 2.6 remains valid. Isotopes compositions could be in some cases affected due to isotopes fractionation (Mook, 2000), which can occur during evaporation prior to infiltration or after infiltration. Figure 2-6 and Figure 2.7 show that some of the samples from the Turonian-Coniacian aquifer slightly deviate from the Local Meteoric Water Line, meaning that there may be some possible slight evaporation influence in some samples from the Turonian-Coniacian aquifer (Mayr et al., 2007; Kpegli et al., 2015). As such, the evaluation of the groundwater flow by the stable isotopes needs therefore further validations as suggested by previous studies (Faye et al., 
2005; Madioune et al., 2014). The evaluation of the groundwater flow by stable isotopes is hence cross-checked in the next paragraph using radioactive isotopes.

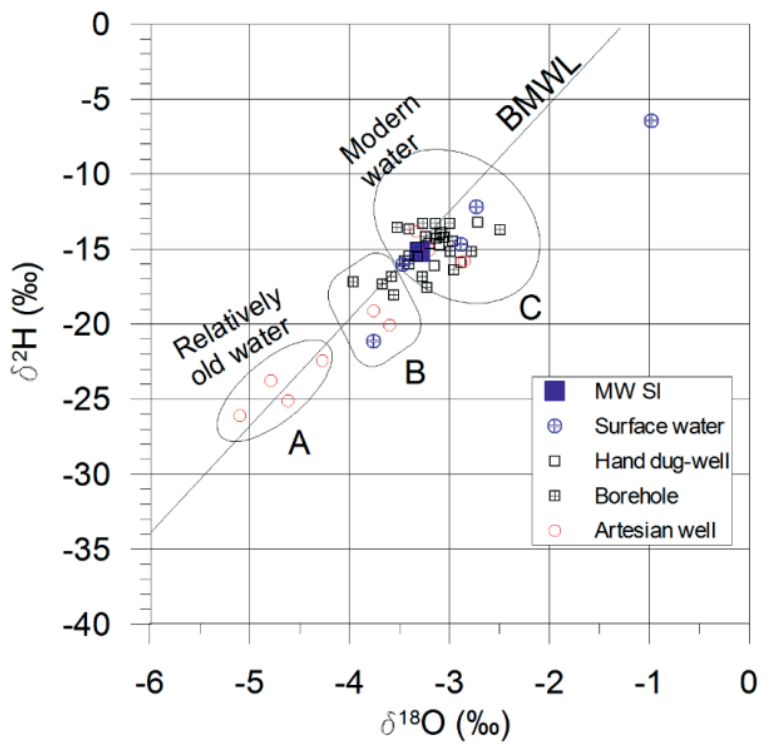

Figure 2.7: Plot of $\delta^{2} \mathrm{H}$ versus $\delta^{18} \mathrm{O}$, showing stable isotope signatures of different type of water samples that are not contaminated by Chloride and Nitrate

\subsubsection{Groundwater flow evaluation using radioactive isotopes}

To validate the piezometry, radioactive tracers (tritium and carbone-14) were used. Figure 2.8 shows the tritium content versus $\delta^{18} \mathrm{O}$ for rainfall, surface water and groundwater (sampled from hand dug-wells, boreholes, natural springs and artesian wells).

Actually, young and old groundwater should be found respectively in the recharge area and the discharge area as groundwater moves from its recharge zone to its discharge one (Craig and Thomas, 2008). Having an indication of the location of young and old groundwater in an aquifer system could help validate or invalidate the flow pattern suggested by the piezometry. Tritium $\left({ }^{3} \mathrm{H}\right)$ and radioactive carbon $\left({ }^{14} \mathrm{C}\right)$ are useful tracers in groundwater dating (IAEA, 2008) and according to Dhaoui et al. (2016), groundwater samples with no tritium are groundwater that the residence time inside the aquifer is pre-1950s. In other words, groundwater samples characterized by no tritium content are groundwater that got recharged prior to 1950, that is the time from which water infiltrates into the soil and got isolated from the atmosphere. The behaviour of water samples collected in the study area is summarized on Figure 2.8 . 

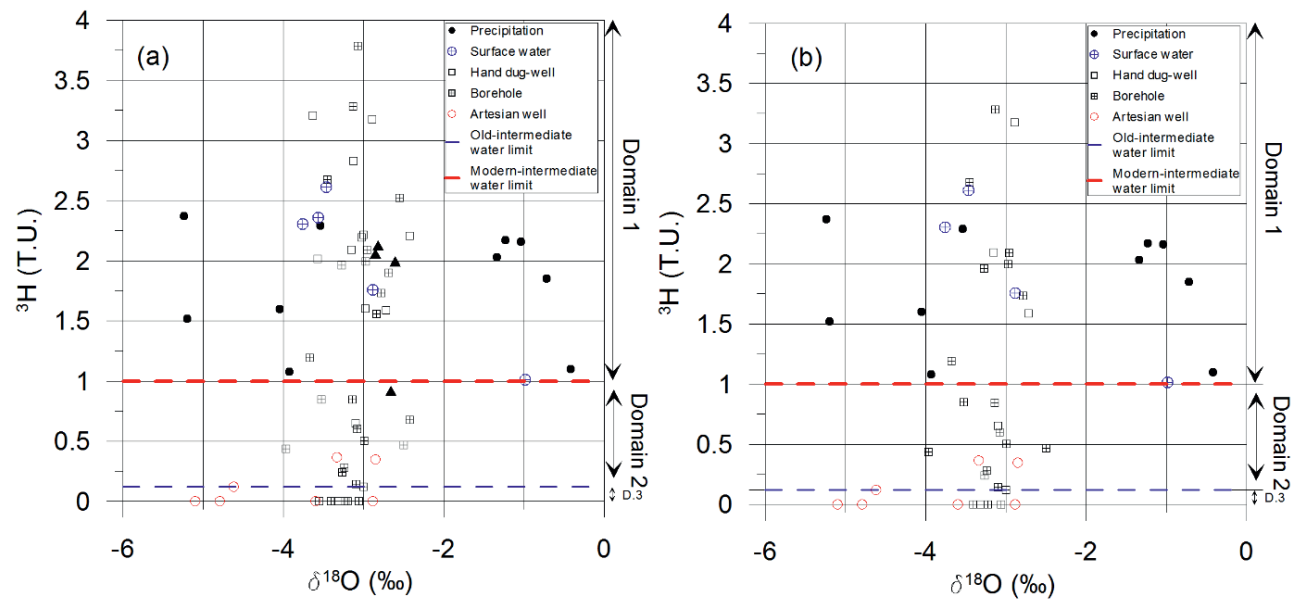

Figure 2.8 Plot of ${ }^{3} \mathrm{H}$ versus ${ }^{18} \mathrm{O}$, differentiating sample types that are of most recent water, intermediate and relatively older water: (a) all samples, (b) samples containing nitrate and chloride are removed)

From Figure 2.8, it can be stated that waters presenting tritium contents greater than 1 T.U. (Tritium Unit) originate from recent precipitations (see the "limit of tritium content" i.e., the red dash on Figure 2.8). This statement is justified because no rainfall sample displays a tritium content below 1 T.U. Hence, groundwater samples that fall in the "domain 1" (as indicated on Figure 2.8) are the most recent water in the Turonian-Coniacian aquifer system, domain 1 being the "domain of precipitation and surface waters".

Groundwater samples that fall in this "domain 1" are only from hand-dug wells, boreholes and springs. None of them is from artesian wells. Moreover, they are geographically mostly located in the northern plateaus (samples 23, 26, 27, 28, 29, 33, 40, 42, 43, ,44, 49, 50, 52, 53, and 54). This is an indication that the corresponding areas to this samples are predominant recharge zones of the Turonian-Coniacian aquifer, which is hence in agreement with the piezometry.

Also, surface water samples belong to domain 1 (Figure 2.8) and are totally absent from "domain 3" (domain of relatively older water, with tritium content less than 0.12 T.U. (the lowest concentration obtained)). It appears that samples from the artesian wells fall mainly in domain 3 (Figure 2.8). This suggests that surface water may communicate with the Turonian-Coniacian aquifer in the northern (around Alahe and Dovi townships; see Figure 2.1 for their geographic location), but this communication is lost downstream (around Bonou, Dasso, and Massi townships) as samples from artesian wells $(05,07,08$, and 63 ) in the vicinity of these townships are with low or no tritium content. 
"Domain 2" is intermediate between recharge zones (modern groundwaters) and downstream areas (relatively older water area). Tritium contents being high in the Turonian-Coniacian aquifer in its recharge areas and low or absent downstream is a confirmation of the groundwater flow pattern indicated by the piezometry. Tritium contents hence appears to be in agreement with the piezometry.

Previous investigations from Dray (1989) and the present study allow comparison of ${ }^{14} \mathrm{C}$ activities at one site (sample 68), in a time scale of three decades. Comparison at this site (see Table 2.3) reveals a slight increase in radiocarbon content in the Turonian Coniacian aquifer system meaning that a shorter groundwater resident time occurs in some part of this aquifer system. A shorter groundwater resident time implies that relatively younger water is found in some parts of the system nowadays compared to 1989. This is a translation that groundwater abstraction, may it be natural (free flows from artesian wells) or not, has caused younger water to be captured within three decades, in at least part of the system. According to Al Faitouri and Sanford (2015), pumping out younger water could be strongly correlated to lowering of the potentiometric surface. In contrary, a decrease in radiocarbon activity (i.e. pumping out older water) could be observed in other systems (Celle-Jeanton et al., 2009) which could mean that older groundwater have moved up gradient, probably under the influence of over-abstraction of the aquifer.

${ }^{14} \mathrm{C}$ activity measured within this study show a decreasing trend from site 8 to site 7 (see Figure 2.1 for geographic location of these sites). An order of sites 8-7 is well in line with the flow directions indicated by the piezometry (because site 8 and 7 are respectively around the contour lines $30 \mathrm{~m}$ and $20 \mathrm{~m}$, see Figure 2.1 and Figure 2.5 for details). ${ }^{14} \mathrm{C}$ activity being the lowest (8.59 pmc, compare to others in Table 2.3) around site 7 reflects the absence of modern water in the Turonian-Coniacian aquifer in this sector, hence confirms again that rivers in the vicinity of site 7 (Bonou township) are totally disconnected from the TuronianConiacian aquifer. Hence, interaction between surface waters and the Turonian Coniacian aquifer should not be allowed in any groundwater flow modeling exercises in this sector.

Table $2.3{ }^{14}$ C activity data (2015), including one data from 1988 (Dray et al., 1989)

\begin{tabular}{ccc}
\hline Sample number & $14 \mathrm{C}(\mathrm{pmc})$ in 2015 & $14 \mathrm{C}(\mathrm{pmc})$ in 1988 \\
\hline 68 & $73.23 \pm 0.2$ & $72.47 \pm 0.3$ \\
8 & $54.49 \pm 0.2$ & $*$ \\
7 & $8.59 \pm 0.1$ & $*$ \\
56 & $84.69 \pm 0.3$ & $*$ \\
\hline
\end{tabular}

\footnotetext{
* Not determined
} 


\subsubsection{Assessment of the suitability of hydrochemistry in revealing groundwater flow directions under groundwater head data scarce environments}

From the flow pattern indicated by the piezometry which is supported by stable and radioactive isotopes, one would expect a gradual increase in groundwater mineralization from recharge to downstream areas. In fact, the TDS of groundwater normally increases (depending on several factors, e.g. geology and resident time) along a given groundwater flow path (Novel et al., 2007). In the case of the present case study, one would expect a gradual evolution of groundwater mineralization from mainly dug-wells samples type towards artesian wells samples type, dug-wells being in the recharge area (See Figure 2.5). This expected mineralization trend is not observed (Figure 2.9) as some of the samples from artesian wells are of low mineralization compared to samples from dug-wells. This is further confirmed by Figure 2.10 which shows that both recent and relatively older groundwater from the Turonian-Coniacian aquifer are of low mineralization. Based on Craig and Thomas (2008), IAEA (2008), Dhaoui et al. (2016), younger groundwater, meaning groundwater samples mainly from hand dug-wells were expected to display low TDS values and were expected to fall in or around the circle of "younger water" (see Figure 2.10). Likewise, relatively older groundwater (especially from artesian wells) were expected to display higher TDS values and fall in or around the circle "old water" (see Figure 2.10). Figure 2.10 rather shows that many samples from artesian wells are characterized by low TDS values just like groundwater samples from hand dug-wells and rivers. It hence appears that groundwater mineralization level does not help discriminate most recent and relatively older water. In other words, the level of groundwater mineralization does not help to clearly discriminate recharge areas from discharge areas, which means that it does not always follow the piezometry. Apparently, depending on the aquifer matrix, which is mainly sandy in this case study, the distance between the recharge and the downstream areas may be a key factor to allow discrimination between modern and relatively older groundwater when using the TDS. The implication of this is that the level of mineralization (TDS) appears not to be a suitable candidate or indicator in developing conceptual groundwater flow models under groundwater head data scarce environments. Probably, insufficient information on well structures may partly explain this finding. 


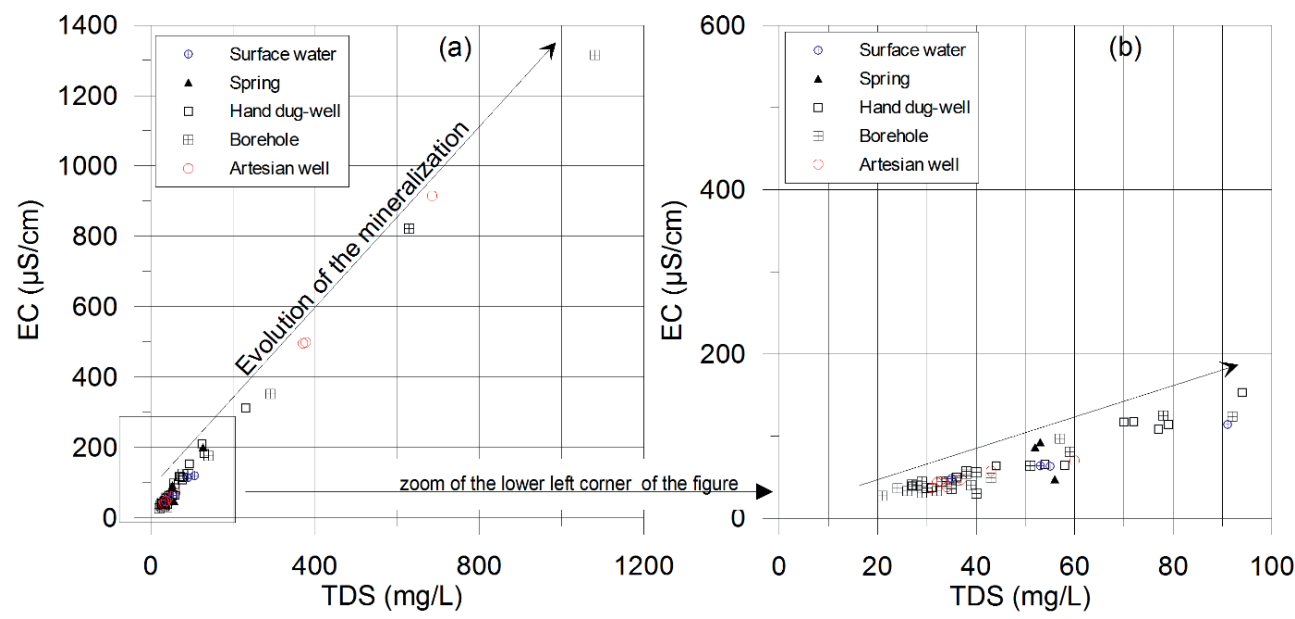

Figure 2.9: Plot of EC versus TDS showing the evolution of the mineralization from different sample types, (b) is a zoom of the lower left corner of (a)

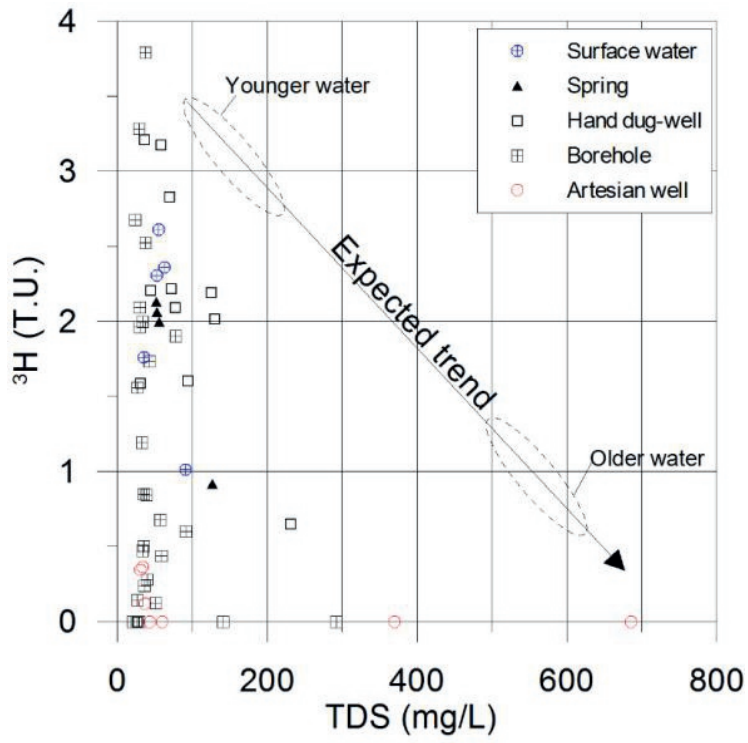

Figure 2.10: Plot of Tritium versus TDS showing an expected trend-line for sample types base on Craig and Thomas (2008), IAEA (2008), Dhaoui et al. (2016).

In some hydrologic systems, anthropogenic activities may influence the natural mineralization and may result in variations of natural nitrate and chloride ions (Appelo and Postma, 2005). From the piper diagram of the study area (Figure 2.11), it appears that some extra chloride and nitrate from human activities at a local scale may be influencing the TDS. 
And these pollution indicators are more reflected in superficial zones (less than 60 meters depth, as shown on Figure 2.12), hence supporting that some extra anthropogenic sources of mainly nitrate, could be present.

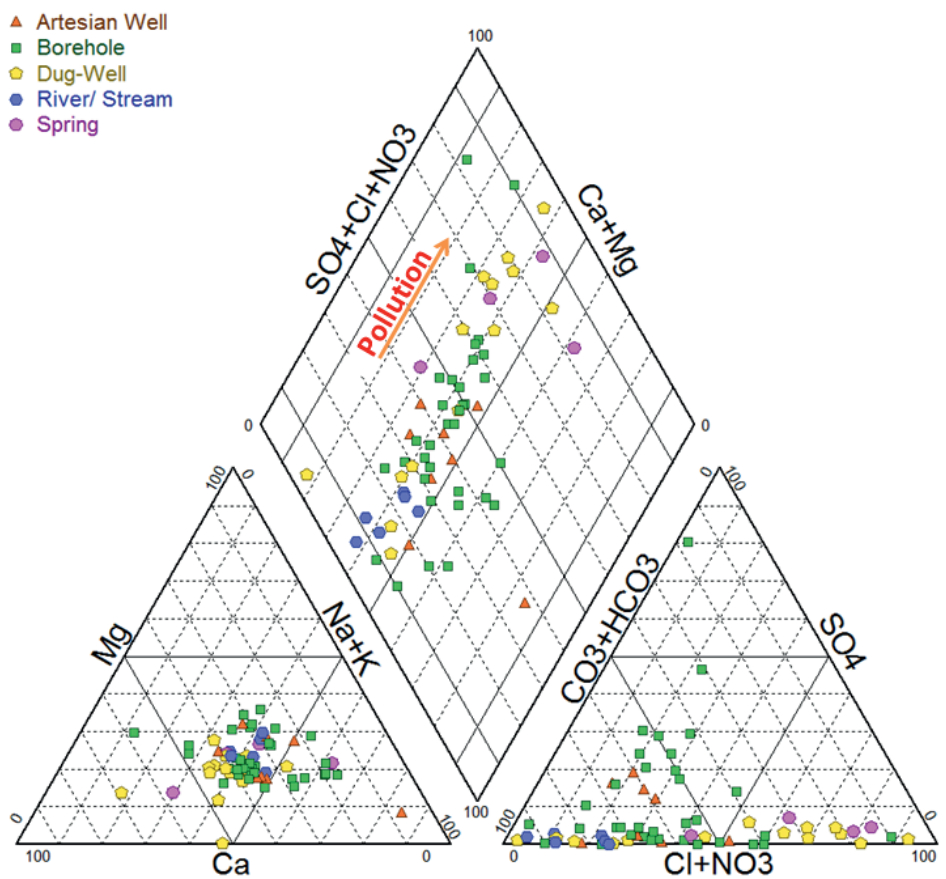

Figure 2.11 Piper diagram showing chemical composition of surface and Groundwater in the study area

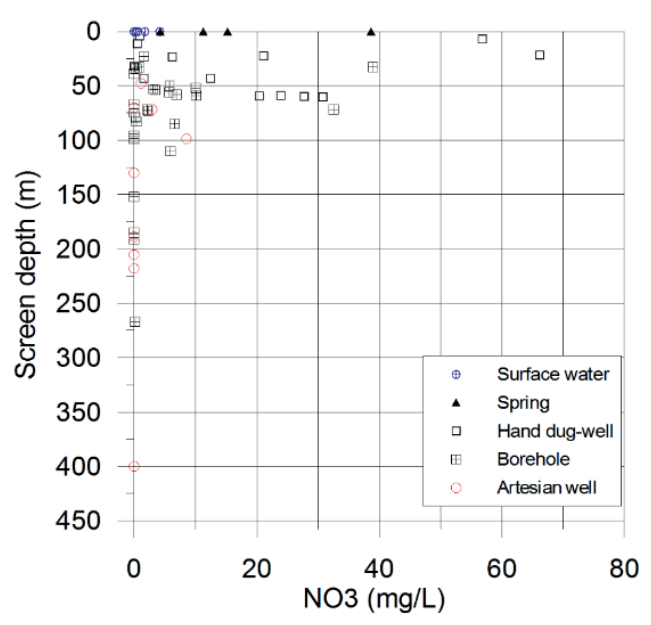

Figure 2.12 Plot of screen depth versus nitrate content in the study area 
Disregarding these possible extra ions sources from the natural groundwater mineralization (i.e. TDS-( $\mathrm{NO}_{3}^{-}$and $\left.\mathrm{Cl}^{-}\right)$, see Figure 2.13 ) has not however lead to different conclusions. So, definitely, the TDS can only mislead with regard to the development of conceptual groundwater flow models in sandy systems similar to the case of the Turonian-Coniacian aquifer system. This could be because the groundwater resident time in this type of aquifer is not long enough to increase the mineralization. Possibly, the available information on wells structure may also have not been sufficient. However, within karstic systems (Novel et al., 2007), where groundwater flows mainly along conduits or underground channels, the mineralization can still provide relevant information regarding the main flow directions.

\subsubsection{Groundwater conceptual flow model of the Turonian-Coniacian aquifer}

The results from the present investigations (hydrogeological and various isotopes) as presented in previous sections of this paper, has allowed to derive a coherent conceptual groundwater flow model which is summarized on the diagram (Figure 2.14). This derived conceptual groundwater flow model (for the T.C. aquifer) is in line with results from previous studies (e.g.: geological cross section presented in Figure 2.3 (IRB, 1987) and Dray et al., 1989).

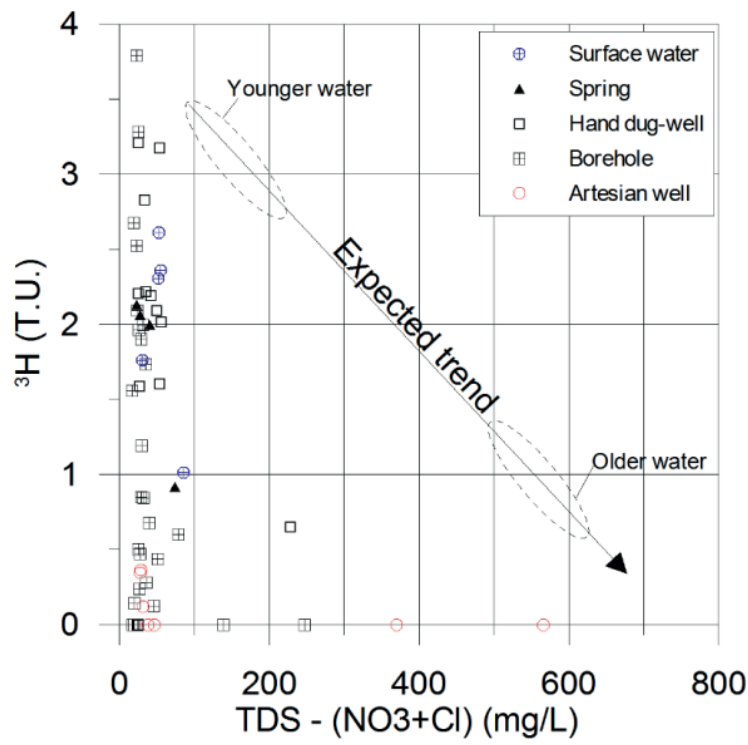

Figure 2.13 Plot of Tritium versus TDS without anthropogenic sources of chloride and nitrate

As indicated on the diagram (Figure 2.14), the T.C. aquifer directly overlays the crystalline bedrocks and outcrops in the Northern research area. This aquifer gets recharged by rainfall predominantly in the Northern study area, since in the Northern part, groundwater samples 
from the T.C. aquifer display isotopic signatures that are in range of those of rainfall samples. From the Northern recharge areas, groundwater flows generally towards the south, with local deviations to the South-East or to the South-West. In the Northern regions, interactions between surface waters (Zou river and Ouémé stream) and the T.C. aquifer is effective (Figure 2.14). In the South, the T.C. aquifer is overlaid by clay and marl materials that are sufficiently low permeable to confine this aquifer. Artesian condition prevails in this southern region for the T.C. aquifer where the samples from the T.C. aquifer are depleted in both stable and radioactive isotopes compared to the recharge areas. Direct recharge from rainfall in the southern region to this aquifer is hence not feasible. Also in this southern region, the T.C. aquifer is hydraulically disconnected from the surface waters (Sô river and Ouémé stream) and the quaternary aquifer (Figure 2.14).

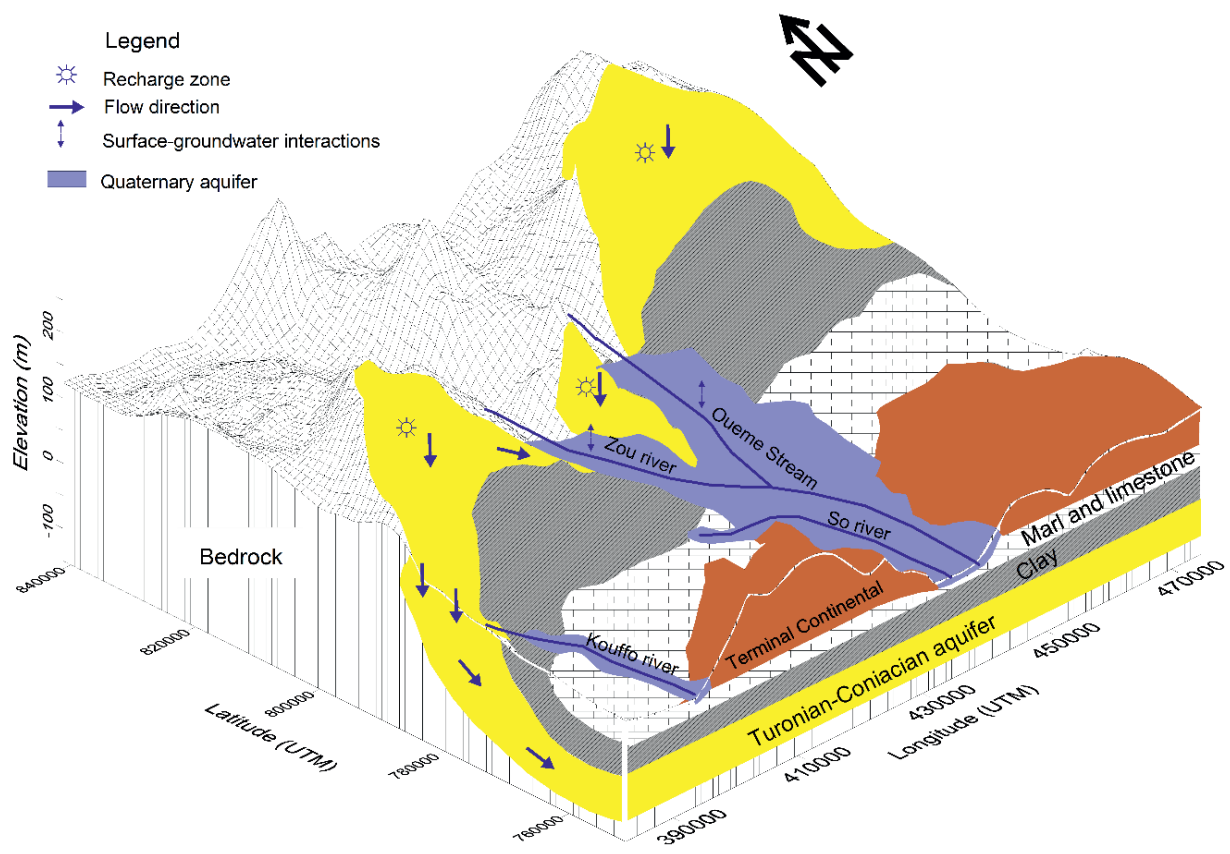

Figure 2.14 Diagram of the first conceptual groundwater flow model of the Turonian-Coniacian aquifer system, with artesian conditions.

In fact, the clay and marl materials constitute a hydraulic barrier between these two. Any numerical model for flow and/or transport modeling should be designed accordingly and treated as such. No or only very limited leakage (river infiltration) could be allowed through these clay and marl materials. The transition between the Northern part of T.C. aquifer that is connected to the Quaternary aquifer and surface waters and its southern part that is disconnected from them is gradual. Actually, between the most enriched samples in isotopic contents that characterized the recharge area of the T.C. aquifer and the most 
depleted samples in downstream areas, there appears a group of intermediate isotopic contents (Figure 2.5) that represents both surface water, boreholes and hand dug-wells. This illustrates that the transition is not abrupt but more gradual. No evaporation effect was observed in the T.C. aquifer flow system as confirmed by stable isotopes signatures. Finally, three groundwater divides are detected in this aquifer system.

\subsection{Conclusion}

In this study, a combined piezometric, hydrochemical and isotopic approach has been used to derive a coherent conceptual groundwater flow model for the Turonian-Coniacian aquifer in southern Benin. Also, this approach has been used to access the ability of the groundwater mineralization as measured through the TDS to develop conceptual groundwater flow models under scarce groundwater head data systems.

The obtained piezometric maps from the conducted hydrogeological investigations revealed three main groundwater flow directions in the Turonian-Coniacian aquifer. A main Northwest to Southeast flow direction is indicated in the western research area while in the Eastern research area, a Northeast to Southwest flow direction is denoted. In the central research area, a North to South flow direction is identified. These results are well confirmed by isotopic techniques. Precisely, stable isotopes displayed more enriched values in recharges areas and more depleted values in downstream areas indicated by the piezometry. Similarly, higher tritium concentrations were observed in recharge areas and low tritium concentrations were found in downstream areas indicated by the piezometry. In addition, the ${ }^{14} \mathrm{C}$ concentrations were shown to decrease from the mentioned recharged to downstream areas. It means that results from hydrogeological and isotopic investigations coherently support each other. Hence a conceptual groundwater flow model for the Turonian-Coniacian aquifer system has been derived. However, the groundwater mineralization as measured through the Total Dissolved Solids (TDS) does not support both the piezometric and isotopic results as expected. As a result, the TDS is not a good candidate in developing conceptual groundwater flow models in environment characterized by scarce groundwater head data.

The conceptual groundwater flow model derived from this study is expected to serve as foundation for further research, especially with respect to hydrogeological modeling exercises which are essential for the sustainable management and preservation of groundwater resources of this aquifer, which is generally of good quality nowadays especially at depth beyond $60 \mathrm{~m}$. This paper has also provided insight on how the existence of interaction between surface and groundwater in hydrological systems could be detected 
using isotope techniques. Finally, this study has demonstrated that it could be tricky to rely only on the TDS in mainly sandy head data scarce systems when it comes to a conceptual understanding of the groundwater flow. In general, we recommend that new boreholes that will be drilled for drinking purposes be systematically designed to allow both groundwater abstraction and groundwater level measurements, especially in rural areas. This way, an increase in the number of boreholes will be positively correlated with available head data and the possibility to acquire fresh head data when needed. In the area that served as case study, it is recommended that the Turonian-Coniacian aquifer be periodically monitored especially in its artesian parts to track changes occurring over time. 


\section{Impact of hydraulic and storage properties on river leakage estimates: A numerical groundwater flow model case study from southern Benin}

Study area: The coastal sedimentary basin including the Zou and Ouémé rivers in Benin.

Study focus: River discharge loss is known to occur on the Zou and Ouémé rivers in southern Benin since a couple of decades ago. The reason behind this discharge reduction remained so far unclear. In this study, we focus on creating a 3D-numerical model of the system and on evaluating the sensitivity of leakage between the rivers and aquifers to various parameters.

New hydrological insights for the region: Results show that leakages along the Zou river and Ouémé stream are tiny (i.e., $3 \%$ of the discharge losses). This implies that the observed water loss from the Zou and Ouémé rivers is not likely caused by the leakage (infiltration) along these rivers into the subsurface. The streambed conductance is found to be among the factors that impact less the computed leakages in the study area. This study has ranked the different hydraulic and storage properties in their order of importance with respect to the computation of river leakages along the concerned rivers. The determined rank of importance of the hydraulic and storage properties can guide river leakage modelling exercises in similar regions elsewhere.

Based on:

K. A. R. Kpegli, S.E.A.T.M van der Zee, A. Alassane, G. Bier, M. Boukari, A. Leijnse, P.G.B. de Louw, D. Mama, 2018. Impact of hydraulic and storage properties on river leakage estimates: A numerical groundwater flow model case study from southern Benin. Journal of Hydrology : Regional Studies, 19, 136-163. 


\subsection{Introduction}

In southern Benin, surface water is hardly exploited for drinking purposes. Rather, for the majority of the population, groundwater is the main source of water supply. Though surface waters are not exploited, Le Barbe et al. (1993) reported losses in water discharge along the Zou river and Ouémé stream (Figure 3.1 and Figure 3.2) which are located in southern Benin. Le Barbe et al. (1993) indicated that upstream discharges on the Zou river (at Atcherigbe gauging station, see Figure 3.2) are higher than the discharges downstream (Dome's gauging station), meaning that there is a loss of water between these two gauging stations (Atchérigbé and Dome gauging stations). In relatively high rainy years (e.g.: 2003, 2007) the discharge loss is well pronounced. The same remark is valid along the Ouémé stream (Le Barbe et al., 1993) between Savè and Ahlan gauging stations (see Figure 3.1 for the gauging stations location).

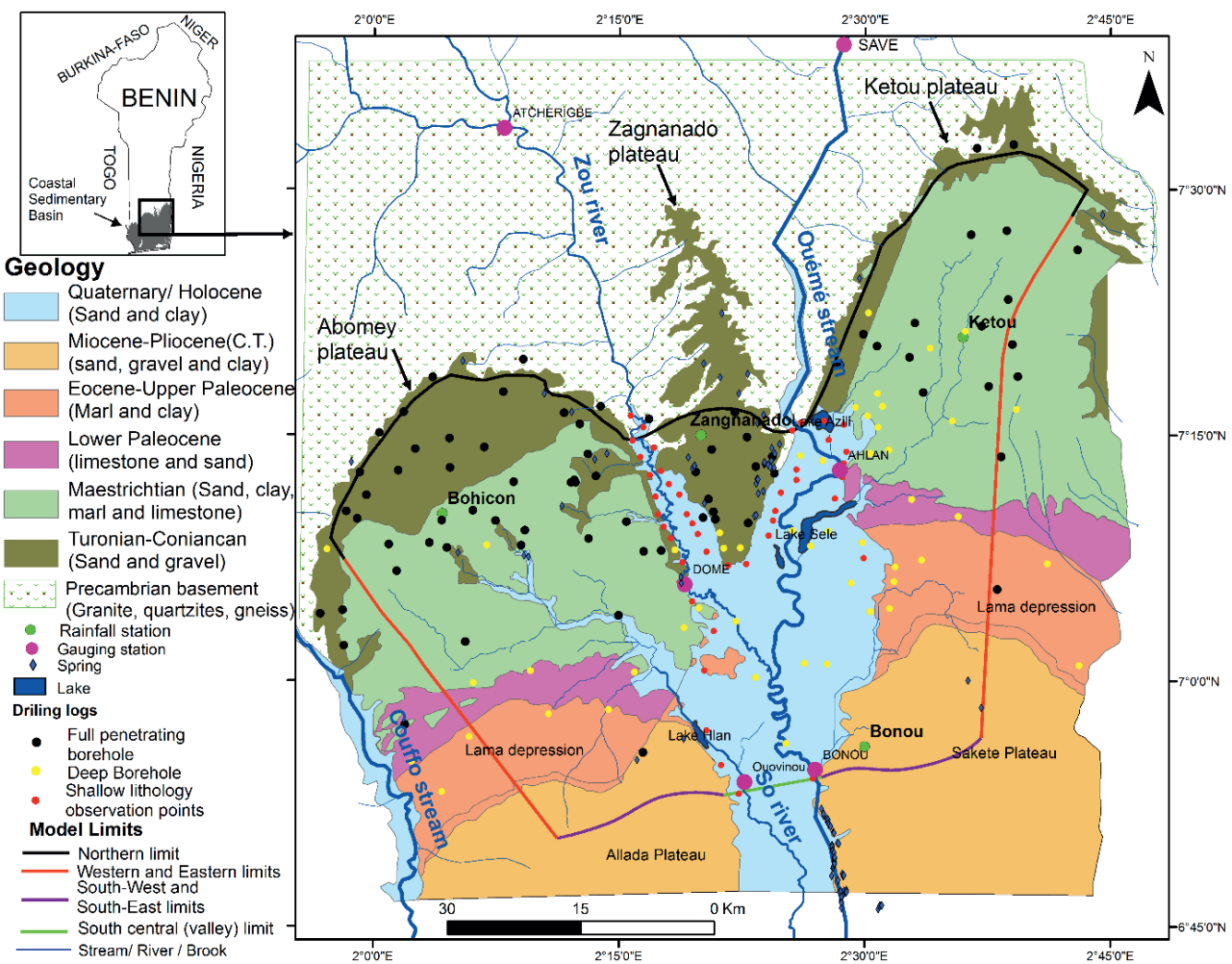

Figure 3.1 Geologic map of the study area showing the location of the drilling logs used for the stratigraphic model, the model limits, rivers, lakes and springs, rainfall stations and gauging stations (modified from Kpegli et al., 2018). 
The cause of this discharge loss is so far unclear and the main motivation of this research is to share light regarding the causes of this water losses from the Zou river and Ouémé stream. Surface-groundwater interactions, mainly river leakage to the subsurface, caused discharge reduction in several hydrological systems (Winter et al., 1998; Lackey et al., 2015; Sophocleous, 2002). Also, groundwater depletion due to abstractions or reduction of recharge by climate or land use changes could cause discharge loss. In this case study, we hypothesize that river leakage in the sedimentary basin is the major cause, since surface water is hardly exploited for both drinking and agriculture. So, the first research question is: how do river leakages compare to the water loss from these rivers? To answer this question, we aim at quantifying the river leakages along these rivers using a 3D numerical flow model. However, the computation of river leakages requires the estimation of the streambed conductance (Hatch et al., 2010; Lackey et al., 2015), which is a parameter that is generally not known accurately. In natural hydrological systems, the streambed conductance varies in space along the rivers/streams because streambed sediments are highly heterogeneous (Chen, 2000; Chen, 2004). Detailed characterization of streambed sediments, at regional scales are not affordable, as they are costly, very time consuming and few tools are available for such tasks (Woessner, 2000). In addition to the streambed conductance, other properties (hydraulic and storage properties) of the adjacent aquifers or aquitards may be influencing the computed river leakages. But, what is unclear is how does each of these properties affect the computed leakages. So, a second question is: which of these different properties control predominantly the computed river leakages? Many models in the literature investigated the estimation of river leakage in hydrological systems but much less is known about the factors that control the leakage estimates in regional hydrogeological systems.

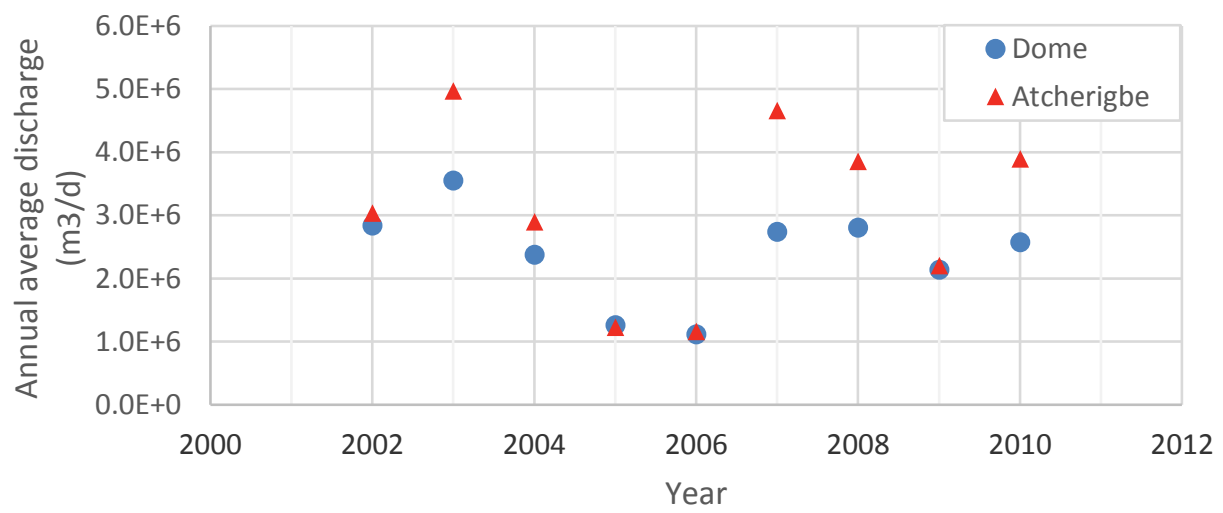

Figure 3.2 Annual river discharge at two gauging stations (Dome and Atcherigbe; data source: DGEau), illustrating loss in water discharge between the two gauging stations, the location of the gauging stations is shown on Figure 3.1 
In this study, we first set up a 3D numerical model for the study area to quantify the river leakages along the Zou river and the Ouémé stream. Second, we compared the computed leakages along these rivers to the water losses from these rivers' conceptual water budget. Finally, we used the developed numerical model to access the impact of the different properties (streambed conductance, hydraulic and storage properties) on the computed river leakages. This helped to determine which properties control predominantly the computed river leakages and to rank the hydraulic and storage properties in their order of importance with the river leakages computation. The 3D groundwater numerical flow model presented in this study is the first developed for the study area and provides insight regarding river leakages estimates that can be used in similar regions elsewhere. The next section (section 3.2) of this paper introduces the study area and its characteristics. Section 3.3 presents the methodology adopted to answer the research questions. The results and discussion are presented in section 3.4.

\subsection{Study area}

\subsubsection{Location, climate and surface hydrology}

The study area (Figure 3.1) is part of the coastal sedimentary basin of southern Benin. It extends from latitudes $06^{\circ} 45^{\prime} \mathrm{N}$ and $7^{\circ} 40^{\prime} \mathrm{N}$ and longitudes $1^{\circ} 55^{\prime} \mathrm{E}$ and $2^{\circ} 50^{\prime} \mathrm{E}$ and covers approximately $4600 \mathrm{~km}^{2}$. The altitude varies between -1 and $271 \mathrm{~m}$ above sea level (Annex 1). It includes in its northern parts, three plateaus which are from West to East the Abomey, Zagnanado and Kétou plateaus. These plateaus are separated from each other by the valleys of Zou river and Ouémé stream respectively. A regional East-West belt known as the Lama depression (Affaton et al., 1985; Amajor, 1991) is found in its southern part and constitutes the southern limits of the Abomey and Kétou plateaus (Figure 3.1). Finally, the study area also includes the northern parts of the Allada palteau and the Sakete plateau (Figure 3.1).

The climate of the study area is characterized by two rainy seasons and two dry seasons. The main rainy season extends from mid-March to mid-August and the short rainy season extends from mid-September to November. The short dry season and the main dry season extend respectively from mid-August to mid-September and from December to mid-March. The mean rainfall is about $1200 \mathrm{~mm} /$ year (Achidi et al., 2012; Houndagba, 2015). The relative humidity vary from 65 to $90 \%$ and the temperature is between 19 and $38^{\circ} \mathrm{C}$.

The surface water network of the study area include one main stream (the Ouémé stream) (Figure 3.1). The Ouémé is the biggest stream in Benin and flows into the sea at a distance of about $120 \mathrm{~km}$ from the South of the study area. The Zou river is the main tributary of the 
Ouémé and joins up the Ouémé at about $10 \mathrm{~km}$ North of Bonou township (Figure 3.1). The water level (water depth) in the Zou river and Ouémé stream vary from $0.3 \mathrm{~m}$ to $7 \mathrm{~m}$ (Figure 3.3). Levels of about $0.3 \mathrm{~m}$ corresponds to the base flow conditions while during extreme flooding periods, the levels can rise up to $7 \mathrm{~m}$.

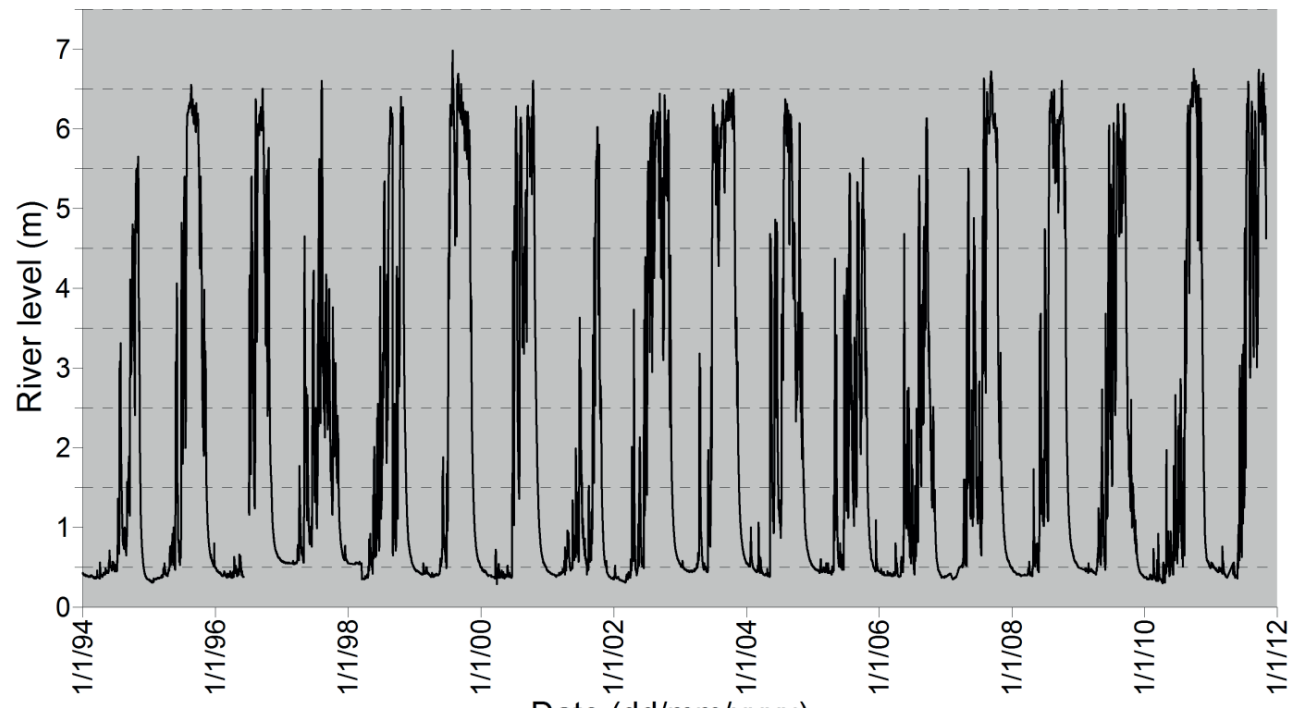

Date (dd/mm/yyyy)

Figure 3.3 Stream/river levels (water depth) in the study area (example of levels at Dome gauging station), data source: DGEau

The surface water network of the study area also include three main lakes (Azili, Sele and Hlan, see Figure 3.1) which are in connection with the rivers, especially in the rainy seasons. There exist also several brooks (the blue lines in Figure 3.1 other than the Zou river and the Ouémé stream) in the study area which are either temporal or permanent.

\subsubsection{Water budget on the Zou river and Ouémé stream}

The water budget on the Zou river and Ouémé stream was first established by Le Barbe et al. (1993) who demonstrated that there is a water loss along these rivers. According to these authors this water loss could be caused by leakage from these rivers into the subsurface in the sedimentary basin or could be caused by connection of these rivers to nearby lakes (mainly Azili, and Sele).

In details, the water budget (for these rivers) in the sedimentary basin is presented in Table 3.1 for few years. $Q$ in $1, Q$ in 2 and $Q$ out are respectively the river inflow to the study area through the Zou river, the inflow to the study area through the Ouémé stream and the 
outflow from the study area through both rivers (see Figure 3.4). The gap between the inflows and the outflow is referred to as water loss in Table 3.1. From the available data, this water loss varies in time between $1.5 \times 10^{6}$ and $8.2 \times 10^{6} \mathrm{~m}^{3} / \mathrm{d}$.

Table 3.1 Conceptual water budget indicating the amounts of water losses along the Zou river and Ouémé stream in the study area (Data source: DGEau and ASECNA-Benin)

\begin{tabular}{lccccc}
\hline Year & Q in $1(\mathrm{m3} / \mathrm{d})$ & $\mathrm{Q}$ in $2(\mathrm{m3} / \mathrm{d})$ & Q out $(\mathrm{m3} / \mathrm{d})$ & Water loss $(\mathrm{m} 3 / \mathrm{d})$ & $\begin{array}{c}\text { Water loss }(\% \\
\text { of total inflow) }\end{array}$ \\
\hline 2002 & $3.92 \mathrm{E}+06$ & $1.10 \mathrm{E}+07$ & $1.35 \mathrm{E}+07$ & $1.50 \mathrm{E}+06$ & 10.5 \\
2003 & $6.55 \mathrm{E}+06$ & $2.38 \mathrm{E}+07$ & $2.43 \mathrm{E}+07$ & $6.03 \mathrm{E}+06$ & 19.9 \\
2004 & $4.43 \mathrm{E}+06$ & $1.62 \mathrm{E}+07$ & $1.65 \mathrm{E}+07$ & $4.06 \mathrm{E}+06$ & 19.7 \\
2005 & - & - & - & - & - \\
2006 & - & - & - & - & - \\
2007 & - & - & - & $3.26 \mathrm{E}+06$ & 12.1 \\
2008 & $5.31 \mathrm{E}+06$ & $2.16 \mathrm{E}+07$ & $2.36 \mathrm{E}+07$ & - & - \\
2009 & - & - & - & $8.23 \mathrm{E}+06$ & 27.7 \\
2010 & $7.43 \mathrm{E}+06$ & $2.23 \mathrm{E}+07$ & $2.15 \mathrm{E}+07$ & - & - \\
\hline
\end{tabular}

$Q$ in 1:River inflow to the study area through the Zou river; $Q$ in 2: Inflow to the study area through the Ouémé stream; $Q$ out: Outflow; $Q$ in $1+Q$ in 2 = total inflow

\subsubsection{Geology and hydrogeology}

Geologically, the study area consists of sedimentary deposits that overlay the Precambrian crystalline rocks (granite, quartzite and gneiss). These deposits have a monoclinal structure and their thickness generally increases towards the southeast (Slansky, 1962; Houessou, 1974; IRB, 1987). They consist of detrital formations (sand, gravel and clay), sandstone, marls and limestones. A total of eight stratigraphic units (Table 3.2) were identified in the whole coastal sedimentary basin and extend from the upper Cretaceous, mainly the Turonian-Coniacian (Unit I) to the Quaternary (Unit VIII).

Four units among these stratigraphic units are aquifers in the study area: the TuronianConiacian aquifer (Unit I), the Lower Paleocene aquifer (Unit IIb), the Continental Terminal aquifer (units V to VII) and the Quaternary aquifer (Unit VIII), separated from each other by clay and marls layers (Bouzid, 1971). The most important aquifer in terms of extent and thickness is the Turonian-Coniacian (T.C.) aquifer that consists predominantly of sand and some gravel. This aquifer outcrops in the North and becomes deeper towards the south where it is confined by clay and marl materials. These clay and marl materials outcrop in the Lama depression (Gomez, 1979) and limit infiltration from rainfall in this depression (Houndagba, 2015). 


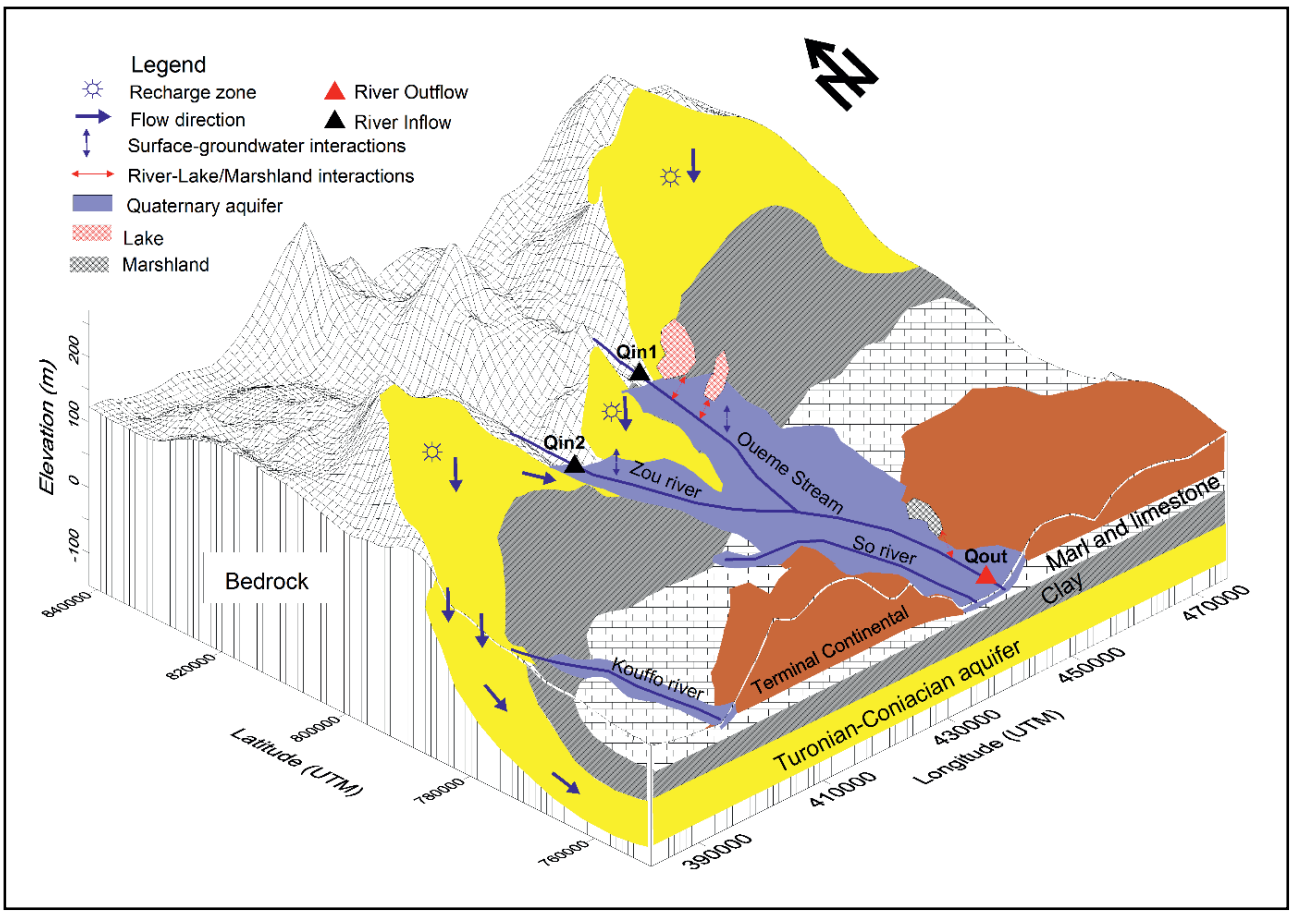

Figure 3.4 Conceptual groundwater flow diagram illustrating water budget along the Zou river and the Ouémé stream (modified from Kpegli et al., 2018)

The depth and the thickness of the Turonian-Coniacian aquifer vary across the area. In the northern region (Northern Abomey plateau, Zagnanado plateau and northern Kétou plateau), hand-dug wells (up to $70 \mathrm{~m}$ depth) extend into this main aquifer. In the South, it is impossible to exploit the T.C aquifer through hand dug-wells due to the overlaying thick clay materials and due to the artesian condition that prevails for this aquifer in the South. Hence, only deep boreholes that exploit the T.C. aquifer are found in the South. The Lower Palaeocene aquifer is discontinuous and enclosed within the clay and marl materials form the Maastrichtian and the Upper Palaeocene deposits. The Continental Terminal aquifer is the upper aquifer and exists in the Allada and Sakete plateaus. The quaternary aquifer consists of alluvial deposits (coarse and fine sands that alternate with silt and clay materials). These deposits are mainly found near rivers and streams in the Ouémé valley (Figure 3.1). However, their thickness along rivers in the North is negligible. Their thickness increases gradually from North to South (Boukari, 2002). The Turonian-Coniacian aquifer is the one of main interest in this study. 
Table 3.2 Stratigraphic column of the Coastal Sedimentary Basin of Benin; Source: Géohydraulique, 1985

\begin{tabular}{|c|c|c|c|c|c|}
\hline Stages & $\begin{array}{l}\text { Lithostratigraphic } \\
\text { units }\end{array}$ & $\begin{array}{l}\text { Thickne } \\
\text { ss (m) }\end{array}$ & Permeability & Dominant lithology & Aquifer \\
\hline Holocene & VIII & $\sim 50$ & $\begin{array}{l}\text { Permeable, } \\
\text { Impermeable }\end{array}$ & Clay, Sand** & Quaternary \\
\hline $\begin{array}{l}\text { Miocene- } \\
\text { Pleistocene }\end{array}$ & VII & $\sim 15$ & Semi-permeable & Fine Sand** & \multirow{3}{*}{ С.T. } \\
\hline Upper Miocene & $\mathrm{VI}$ & $<120$ & Permeable & Sand** & \\
\hline Lower Miocene & V & $\sim 145$ & Permeable & Sand** & \\
\hline Middle Eocene & IV & $\sim 170$ & \multirow{3}{*}{ Impermeable } & marls & \multirow{3}{*}{$\begin{array}{l}\text { Impermeable } \\
\text { layer }\end{array}$} \\
\hline Lower Eocene & IIIb & \multirow{2}{*}{ 155 } & & marls & \\
\hline Upper Paleocene & IIla & & & Clays and marls & \\
\hline Lower Paleocene & $\mathrm{llb}$ & $<50$ & Permeable & Limestone and sand** & L.P. \\
\hline Maestrichtian & Ila & $<180$ & Impermeable & Clays and marls & $\begin{array}{l}\text { Impermeable } \\
\text { layer }\end{array}$ \\
\hline $\begin{array}{l}\text { Turorian- } \\
\text { Coniacian }\end{array}$ & 1 & $\begin{array}{l}50 \sim \\
150\end{array}$ & Permeable & Sand* & T.C. \\
\hline
\end{tabular}

* Main aquifer in the area of study; ${ }^{* *}$ Aquifer that is absent or hardly noticeable in the area of study; C.T.= Continental Terminal aquifer; L.P. = Lower Palaeocene aquifer; T.C. = Turonian Coniacian aquifer; Units Ila up to IV are grouped later into one layer (clay and marl) in Figure 3.5 and Figure 3.6; Units V up to VIII are grouped later into one layer (Fine sand) in Figure 3.5 and Figure 3.6

\subsection{Method}

To quantify the river leakages along the Zou river and the Ouémé stream and to access which parameters mostly affect the estimates of river leakages, we applied a methodology that includes the stratigraphic model construction, the definition of the model flow domain and boundary conditions, the model domain discretization, the implementation of hydraulic properties, recharge estimation and implementation, the steady-state model calibration and the implementation of the transient flow model. Details regarding each of these steps is provided in the following paragraphs.

\subsubsection{Stratigraphic model construction}

To develop a stratigraphic model of the system which is close as possible to the field set up, we considered the existing geological and geophysical data. Geological data include geological maps and drilling logs that were obtained from Slansky (1962), MMEH (2001) and from several hydrogeological consulting reports.

Some of the drilling logs extends to the bedrock and others are partial boreholes. We considered all the drilling logs that reach the bedrock to allow construction of a complete 
3D stratigraphic model. In addition, we considered partial drilling logs that reach the deepest aquifer (i.e. the T.C aquifer). However, for these partial drilling logs, we derived the depths to the bedrock from the bedrock altitude map designed by Pougnet (1955) and Aicard (1959) based on the geophysics investigations (gravimetric and seismic soundings) they conducted across the region. The spatial distribution of the drilling logs used for the stratigraphic model is shown on Figure 3.1. We grouped several adjacent layers similar to clay and marl materials into one main layer representing the clay and marl materials. Also, adjacent layers similar to sand material were grouped into one main sand layer. Table 3.2 provides details regarding the layers that are grouped together. As a result, the sedimentary geologic subsurface is simplified into three distinct stratigraphic layers which are from the bottom to the top: a layer representing the Turonian-Coniacian aquifer, a layer combining the intermediate clay and marls strata and a layer combining the top Quaternary alluvial sediments and the sediments from the Continental Terminal aquifer (Boukari and Alassane, 2007). The intermediate clay and marls strata were combined into one stratigraphic model layer because they are nearly impermeable and behave as an aquitard. The alluvial sediments in the Ouémé valley and the sediment from the Continental Terminal aquifer were combined into one stratigraphic model layer since they are of similar geological facies (Maliki, 1993).

We used the Groundwater Modeling Systems software (GMS) to construct the stratigraphic model (Figure 3.5).We applied the horizon method suggested by Lemon and Jones (2003) due to its simplicity and efficiency in building the stratigraphic model directly from boreholes data and additional cross-sections data. We applied the nearest-neighbour approach (Owen et al., 1996; Tam et al., 2014) in GMS to interpolate the contact between the stratigraphic model layers. The top elevation of the stratigraphic model is the landsurface topography, created from the Shuttle Radar Topography Mission (SRTM) elevation data (EROS, 2002) at 90m-resolution.

The resulting 3D stratigraphic model is shown on Figure 3.5 and cross sections throughout the stratigraphic model are shown on Figure 3.6. The impermeable bedrock (crystalline rocks) below the sediment deposits is excluded in this stratigraphic model, since it plays no role in terms of groundwater flow. 


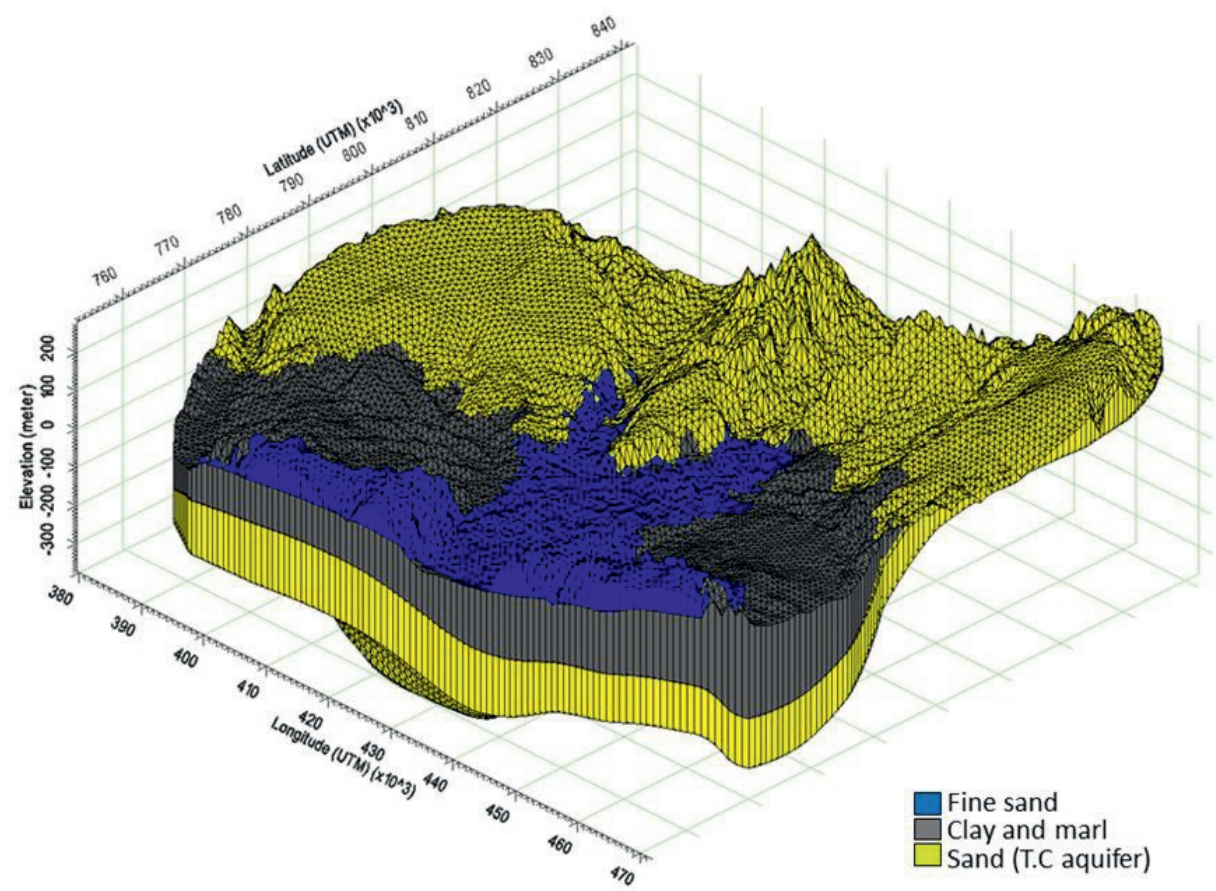

Figure 3.5 3D stratigraphic model of the study area in oblique view, with vertical exaggeration coefficient equal to 50

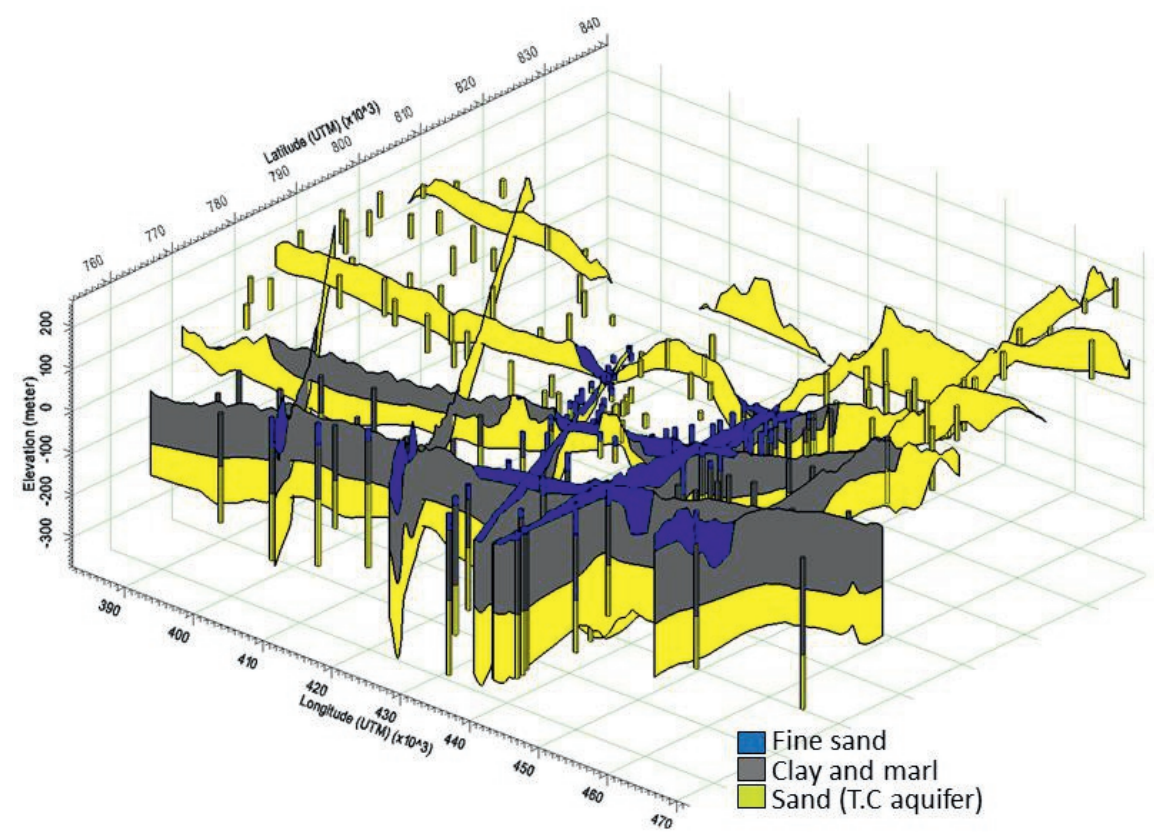

Figure 3.6 Stratigraphic fence diagram of the study area in oblique view showing the drilling logs, with vertical exaggeration coefficient equal to 50 


\subsubsection{Model flow domain and Boundary conditions}

\subsubsection{Flow domain}

The model flow domain is about $3400 \mathrm{~km}^{2}$ (Figure 3.1) and is defined base on the geologic and groundwater divides existing in both the T.C. aquifer and the top aquifer. In detail the boundaries (limits) are as follow:

- The Northern limit: It corresponds to the sediment-bedrock contact. Some complex shapes of the sediment in the northern Zagnanado plateau (Figure 3.1) were not included in the model domain as they are of insignificant thickness $(<1.5 \mathrm{~m})$ and discharge their groundwater through springs. As such, they are of no significance in terms of regional flow and were not included in the model flow domain.

- $\quad$ The Western and Eastern limits: these limits correspond to the identified groundwater divides in the T.C aquifer (see Figure 3.7).

- The South-West and South-East limits (purple lines in Figure 3.1): these limits are positioned along the groundwater divides of the top aquifer (Boukari, 1998; Alassane, 2004). At these limits, different boundary conditions are required for the different layers (the top aquifer, the adjacent impervious clay and marl materials and the T.C. aquifer).

- The South-central limit (the green line in Figure 3.1): this limit is set to cross the Quaternary aquifer in the Ouémé valley (Figure 3.1). Also, at this limit, different types of boundary conditions are required for the Quaternary aquifer, the impervious clay and marl layer, and the deep T.C. aquifer.

\subsubsection{Boundary conditions}

With respect to the explanations in the previous section, a no-flow type of boundary condition is imposed for all layers at the Northern, Western and Eastern limits as suggested by Kresic (2006).

Different types of boundary conditions were applied along the southern model limit, since, at that limit, two main aquifers (the T.C. aquifer and the top aquifer) and one separating aquitard (impermeable layer, mainly clay and marl materials) are to be treated differently.

- $\quad$ For the top aquifer, the South-western and South-eastern limits corresponds to its groundwater divide. Hence, a no-flow type of boundary condition is applied.

- Regarding the South-central limit and for the Quaternary aquifer in the Ouémé valley, an average value of head fluctuation (Dirichlet type of boundary condition) in this aquifer was implemented.

- $\quad$ For the separating aquitard (impervious layer, mainly clay and marl materials), a noflow type of boundary condition is applied based on the knowledge that the horizontal 
hydraulic conductivity of this material is low $\left(\sim 10^{-4} \mathrm{~m} / \mathrm{d}\right)$ and hence nearly no flow occurs horizontally in this layer.

- $\quad$ For the T.C. aquifer, we considered that prescribing a constant head (artesian head) at this limit will imply that the artesian heads could never go below the prescribed head value, which will obviously not be realistic at a transient flow regime. Also, measuring in the field the fluxes ( $Q$ in Figure 3.8) through this limit of the T.C. aquifer is not really feasible, and temporal variations of these fluxes cannot be practically conceived accurately. For these reasons, a Cauchy type of boundary conditions appears to be more realistic because it avoids that inexact prescribed heads and fluxes at this limit influence the model solutions.

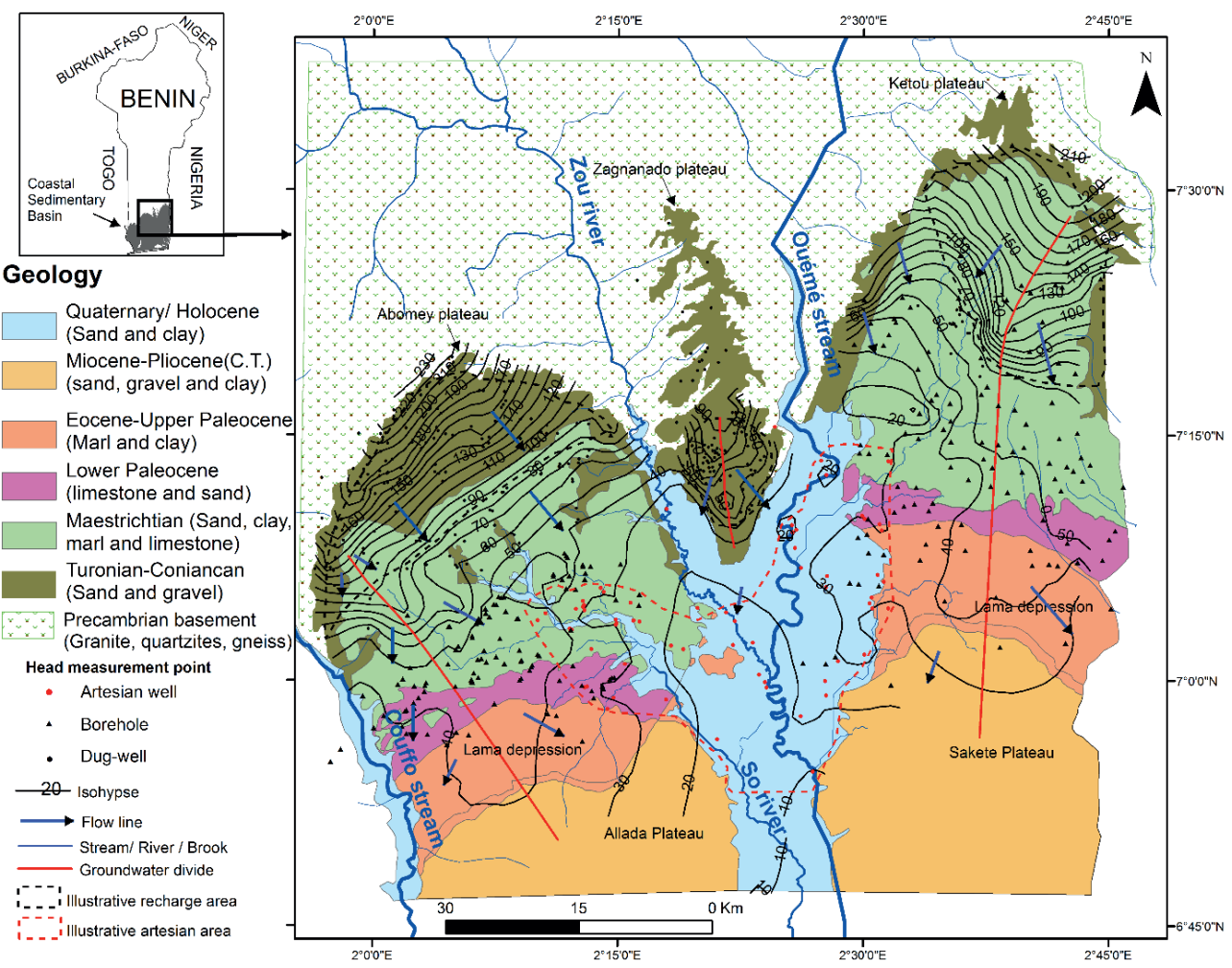

Figure 3.7 Piezometric map of the Turonian-Coniacian aquifer showing groundwater divides locations (from Kpegli et al., 2018)

The different types of boundary conditions at the model limits are summarized in Table 3.3. The model layers introduced in Table 3.3 are explained in the next section. 


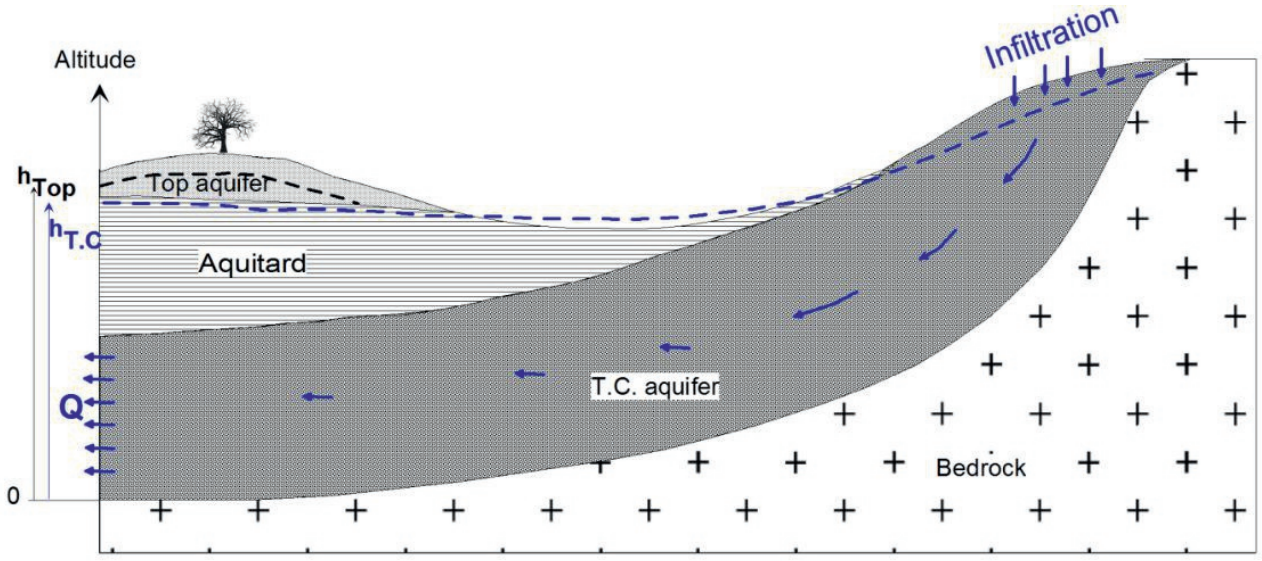

Figure 3.8: Schematic representation of a prescribed head and flux type of boundary condition at the southern limit for the Turonian Coniacian aquifer

Table 3.3 Summary of the Boundary conditions at the model limits

\begin{tabular}{|c|c|c|c|c|}
\hline $\begin{array}{l}\text { Location of the Boundary } \\
\text { conditions }\end{array}$ & Aquifer/aquitard & Model layers & Type of B.C & Parameters \\
\hline $\begin{array}{l}\text { Northern, Western and Eastern } \\
\text { limits }\end{array}$ & $\begin{array}{l}\text { All the aquifers } \\
\text { and the aquitard }\end{array}$ & Layers 1 to 5 & No-flow ${ }^{0}$ & - \\
\hline SW and SE limits & Top aquifer & Layers 1 to 1 & No-flow ${ }^{1}$ & - \\
\hline South-central limit & Top aquifer & Layers 1 to 1 & $\begin{array}{l}\text { Prescribed } \\
\text { average head }{ }^{2}\end{array}$ & - \\
\hline South-central limit & $\begin{array}{l}\text { Impermeable } \\
\text { layer }\end{array}$ & Layers 2 to 2 & No-flow ${ }^{3}$ & - \\
\hline Southern limit & T.C. aquifer & Layers 3 to 5 & Cauchy B.C ${ }^{4}$ & Conductance \\
\hline
\end{tabular}

${ }^{0}$ based on sediment-bedrock impervious contact; ${ }^{1}$ based on groundwater divide in the top aquifer; ${ }^{2}$ based on average head fluctuations in the top aquifer; ${ }^{3}$ based on the knowledge that nearly no flow occurs horizontally in the aquitard; ${ }^{4}$ based on average hydraulic conductivity in the confined part of the T.C. aquifer, implemented as the conductance term in MODFLOW (since there is no physical resistance material at this limit) and based on average hydraulic head $(25 \mathrm{~m})$.

\subsubsection{Model discretization}

We used a Finite-Difference scheme within MODFLOW (McDonald and Harbaugh, 1988) for the model discretization. Horizontally, square cells size of $300 \times 300 \mathrm{~m}$ are implemented and resulted in 283 rows, 312 column and a total of 185194 active cells (see Annex 2 for the $3 \mathrm{D}$ grid model). A dimension of $300 \mathrm{~m}$ is chosen as lower values will cause lengthy model execution time while higher values (coarser model grids) could lead to larger errors in the head and flux simulations. Wildemeersch et al. (2014) suggest that for catchments of few hundred square kilometers, an element size of the order of $500 \mathrm{~m}$ is the best compromise for obtaining good model performance with tractable execution times without significantly increasing prediction uncertainty. The option "boundary matching" within GMS (Jones et 
al., 2002) was used to represent as close as possible the boundaries of the stratigraphic model in the 3-D grid. Vertically, five (05) model layers were defined. In details, the T.C aquifer is subdivided into 3 model layers, the clay and marl materials are considered as one model layer and the top aquifer is also considered as one model layer(Annex 2). The T.C aquifer was subdivided into three (03) model layers to account for vertical heterogeneity in the T.C. aquifer and to allow accurate placement of well screens when required (Kresic, 2006). All the cells within the model boundaries are active cells and were used for simulations.

\subsubsection{Hydraulic properties}

\subsubsection{Hydraulic conductivity}

Hydraulic conductivity for the Turonian-Coniacian aquifer was estimated in previous studies (Bouzid, 1971; IGIP, 1984; BURGEAP-BRGM, 1994; Turkpak International-SCET-Tunisie, 1991) and at different locations based on pumping tests conducted throughout the study area. Clay and marl materials in the study areas are characterized by hydraulic conductivity values of about $10^{-4} \mathrm{~m} / \mathrm{d}$ (Benson and Trast, 1995; Yalo et al., 2014). The hydraulic conductivities of the top aquifer are documented in Barbe et al., 1993 and Boukari, 2002. The hydraulic conductivity values of the different stratigraphic layers are summarized in Table 3.4 and considered during the implementation and calibration of the numerical model.

Table 3.4 Hydraulic conductivities of the different stratigraphic layers (Bouzid, 1971; IGIP, 1984; BURGEAPBRGM, 1994; Turkpak International-SCET-Tunisie, 1991).

\begin{tabular}{lccc}
\hline Location & Y Coordinate (UTM) & X Coordinate (UTM) & Kh (m/day) \\
\hline Regions of top aquifer & Top aquifer & & 2 to 18 \\
Regions of clay material & - & - & $1.00 \mathrm{E}-04$ \\
\multicolumn{5}{c}{ Clay and marl materials } & & \\
Zogbodomey & - & - & 6 \\
Denou & Turonian-Coniacian aquifer & & 6 \\
Ouinhi & 781167.0 & 417119.1 & 6 \\
Kana & 768941.3 & 393090.4 & 21.5 \\
Gbehizankon & 783425.0 & 445984.0 & 31.5 \\
Allahe & 788821.3 & 397819.6 & 66 \\
Assiangbomey & 788556.2 & 416937.8 & 16 \\
Adjido & 790070.5 & 416762.4 & 19 \\
\hline
\end{tabular}

\subsubsection{Conductance parameters}

The conductance is an expression of the ease with which water flows through a resistance layer (e.g.: river bed sediments). When using a conceptual model approach in GMS, the 
manner in which the conductance term should be computed and entered depends on whether the feature object is a polygon (lake for example), arc (river for example) or point (spring for example).

For lakes, rivers/streams and brooks, we defined a conductance based on the average thickness and vertical hydraulic conductivity of the bed-sediments of these hydrologic features. For rivers/streams and brooks, we defined a conductance per unit length (Cond in Equation 3.1) and for lakes, we defined a conductance per unit area (Cond ua $_{\text {in Equation }}$ 3.2). Depending on the lengths of the river-arcs that intersect the grid cells, a corresponding accurate conductance value for the concerned grid cell is calculated by multiplying the value of the conductance per unit length by the length of the river-arcs. Similarly, the area of the cell covered by the lake-polygon is multiplied by the value of the conductance per unit area to obtain the equivalent conductance value for the cells covered by the lake.

$\operatorname{Cond}_{u l}=\frac{k_{v}}{b} w$

Equation 3.1

$\operatorname{Cond}_{u a}=\frac{k_{v}}{b}$

Equation 3.2

where $k_{v}, b$, and $w$ are respectively the vertical hydraulic conductivity of the bed-sediment, the thickness of the bed-sediment and the width of the river.

The obtained average $k_{v}$ values (from few field measurements), thickness of the bed sediments, width of the rivers/stream/brooks as well as the calculated conductances (Cond $_{u l}$ and Cond $_{u a}$ ) are summarized in Table 3.5 and were applied in the numerical model.

Table 3.5 Conductance implemented for rivers/brooks/lakes (Field measurements obtained based on Chen, 2004)

\begin{tabular}{lllll}
\hline Type & $k_{v}(\mathrm{~m} / \mathrm{d})$ & $\mathrm{b}(\mathrm{m})$ & $\mathrm{w}(\mathrm{m})$ & Cond \\
\hline Brooks & 0.8 & 0.3 & 2 & $5.33 \mathrm{~m} / \mathrm{d}$ \\
Rivers & 1.5 & 0.6 & 10 & $25.00 \mathrm{~m} / \mathrm{d}$ \\
Streams & 1.5 & 0.6 & 30 & $75.00 \mathrm{~m} / \mathrm{d}$ \\
Lakes & 0.8 & 1.5 & - & $0.53 / \mathrm{d}$ \\
\hline
\end{tabular}




\subsubsection{Recharge estimation}

Predominant recharge areas (infiltration zones) in the model domain were defined based on the surface geological map developed by the Istito Research Breda (IRB, 1987) and lithological information (from drilling logs). The recharge areas (Figure 3.9) are outcropping regions (Northern) of the Turonian-Coniacian aquifer (see Figure 3.1). For the top aquifer, the whole alluvial plain (along the rivers) represent a recharge area. In regions where clay materials outcrop, recharge is hindered and a dense drainage network is found caused by surficial discharge of precipitation. In contrast, in the recharge areas, the drainage networks are absent or less dense. In total, there are four predominant recharge areas: three in the northern regions for the Turonian Coniacian aquifer and one mainly along the Zou river and the Ouémé stream for the top aquifer. In each of these four recharge areas, there is one rainfall station and data from each of these stations allows recharge estimation for the respective recharge areas.

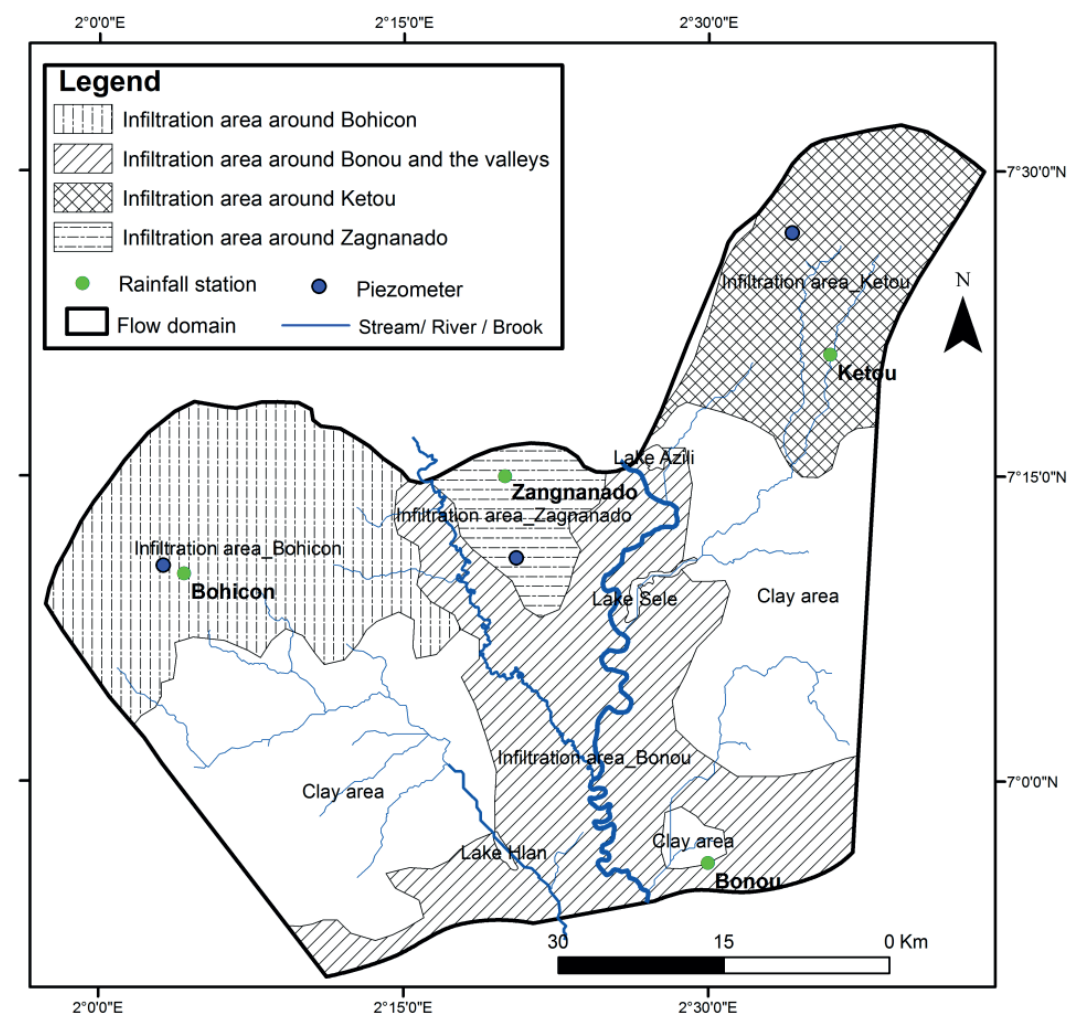

Figure 3.9 Map of Zonal recharge (infiltration) areas showing the rainfall stations and piezometers

Estimating the recharge rate accurately is crucial but remains complex and difficult in view of different parameters that influence infiltration (Dieng, 2017). In this study, we estimated daily groundwater recharge $(R)$ by first using the Penman method (Penman, 1949; Penman, 
1950) to calculate the evapotranspiration. Then, we applied the water budget equation (Equation 3.3). The principle of this equation is that it considers that water is held in store as soil moisture ( $\Delta S$ in equation 3.3), which can be increased by rainfall ( $P$ in equation 3.3) and depleted by the actual evapotranspiration ( $E_{A}$ in equation 3.3). When the soil water storage at field capacity $(\Delta S)$ is attained, excess rainfall is routed to surficial runoff $\left(R_{o f f}\right)$ and to groundwater as recharge. So, the groundwater recharge could be estimated if data of both the soil field capacity and the runoff are available. The actual evapotranspiration is calculated using the weather data available in each of the recharge area. For details regarding the actual evapotranspiration calculation, the reader is referred to Allen et al., 1989 and Allen et al., 1994b.

$P-R_{o f f}=E_{A}+R+\Delta S \rightarrow R=P-\left(R_{o f f}-\Delta S-E_{A}\right)$

Equation 3.3

The reliability of the estimated recharge was judged by comparing the groundwater recharge results (e.g.: Table 3.6) to both the rainfall and the groundwater level fluctuations observed in the same areas (e.g.: Figure 3.10).

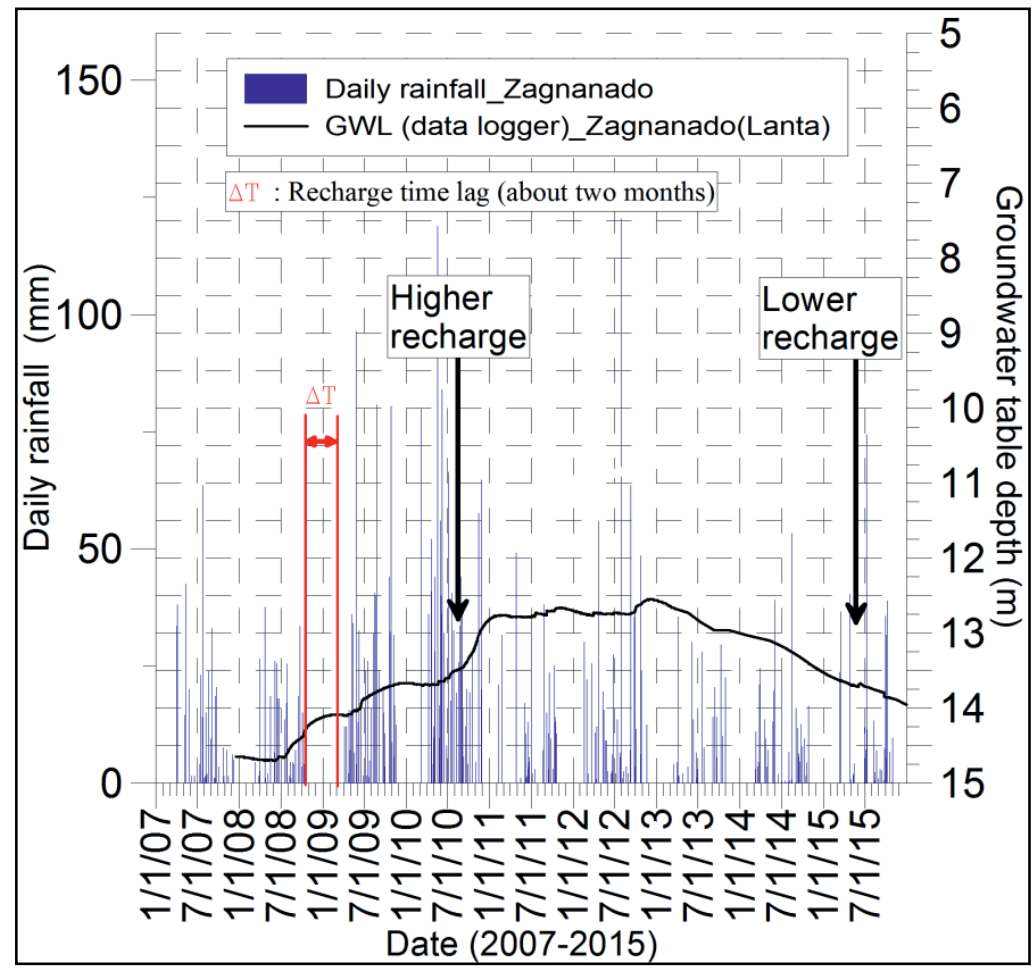

Figure 3.10 Daily rainfall and groundwater level fluctuation at Zagnanado, data source: DGEau and ASECNABenin 
The location of the piezometers is indicated in Figure 3.9. According to the Water Table Fluctuation method (Delin et al., 2007), higher water level rise reflect higher amounts of groundwater recharge. In contrast, lower water level rise reflect of lower amounts of groundwater recharge. For example, from Figure 3.10, it is clear that low recharge occurred in 2015 at Zagnanado compared to the other years (e.g.: Year 2010), since the groundwater level rise is insignificant $(<0.2 \mathrm{~m})$ in 2015 . Accordingly, we would expect the estimated recharge to be low in 2015. The estimated recharge are well in line with this expectation, since the estimated recharge is low for the 2015 (Table 3.6). In contrast, higher recharge is obtained in 2010 (Table 3.6) as expected from Figure 3.10, since in 2010 a high groundwater level rise ( $>1 \mathrm{~m}$ ) occurred. Based on the above comparative groundwater table fluctuation and recharge analysis, the estimated groundwater recharge is judged acceptable and were used as input for the numerical model. The recharge calculated for the other recharge areas (Bohicon, Kétou and Bonou) are summarized in annex 3. Data of soil moisture at field capacity and runoff data required for the recharge calculation in the study area were taken respectively from previous studies (Azontonde, 1991; Schuol et al., 2008 and Biao, 2017).

Table 3.6 Recharge estimates at Zagnanado by a combination of the Penman and the Water Budget methods

\begin{tabular}{cccccc}
\hline Year & Rainfall $(\mathrm{mm})$ & Recharge $(\mathrm{mm})$ & Year & Rainfall $(\mathrm{mm})$ & Recharge $(\mathrm{mm})$ \\
\hline 1970 & 1007 & 176 & 1993 & 978 & 198 \\
1971 & 626 & 21 & 1994 & 770 & 124 \\
1972 & 760 & 148 & 1995 & 1054 & 208 \\
1973 & 647 & 78 & 1996 & 1077 & 206 \\
1974 & 910 & 145 & 1997 & 1168 & 228 \\
1975 & 1077 & 177 & 1998 & 803 & 94 \\
1976 & 759 & 118 & 1999 & 1379 & 407 \\
1977 & 857 & 173 & 2000 & 1074 & 290 \\
1978 & 1195 & 313 & 2001 & 685 & 113 \\
1979 & 1288 & 289 & 2002 & 672 & 75 \\
1980 & 1355 & 364 & 2003 & 1044 & 231 \\
1981 & 840 & 97 & 2004 & 1173 & 290 \\
1982 & 711 & 68 & 2005 & 829 & 167 \\
1983 & 777 & 101 & 2006 & 826 & 157 \\
1984 & 1012 & 175 & 2007 & 1114 & 315 \\
1985 & 901 & 153 & 2008 & 1111 & 346 \\
1986 & 815 & 61 & 2009 & 1725 & 700 \\
1987 & 1075 & 254 & 2010 & 2703 & 1219 \\
1988 & 1532 & 458 & 2011 & 984 & 129 \\
1989 & 948 & 149 & 2012 & 1209 & 312 \\
1990 & 1016 & 223 & 2013 & 786 & 93 \\
1991 & 1088 & 235 & 2014 & 1101 & 261 \\
1992 & 905 & 211 & 2015 & 858 & 174 \\
\hline
\end{tabular}




\subsubsection{Groundwater abstractions and discharge}

According to Slansky (1962) there were already since 1950s few hand-dug wells in the study area. However, groundwater abstractions from these few hand-dug wells were negligible since they were only for domestic use. In addition to this insignificant groundwater abstractions, groundwater also discharges through natural springs in the unconfined part of the Turonian-Coniacian aquifer. During the period 1986-1987, the first artesian wells were installed in the Turonian aquifer. Since then, numerous artesian wells have been installed and constitute continuous and important sources of groundwater discharge of the Turonian-Coniacian aquifer.

\subsubsection{Surface water, recharge, groundwater abstractions and discharge implementation}

The brooks, the Zou river and the Ouémé stream were implemented using the RIV package (McDonald and Harbaugh, 1988) in MODFLOW to simulate the flux into or out of the river through the bed-sediment. The General-Head Boundary (GHB) package was used to represent the three existing lakes in the study area. The estimated recharge was implemented using the recharge $(\mathrm{RCH})$ package.

Springs were implemented in the model using the drain (DRN) package. Three drains were also implemented around Kétou (in layer 05) to account for existing faults that drain the T.C. aquifer and cause this aquifer to be dry in this sector. This is justified as most existing boreholes in this sector are screened in the bedrock and are of low productivity.

\subsubsection{Steady state model calibration}

The model computed head (both in the Turonian-Coniacian aquifer and the top aquifer) was calibrated to the predevelopment (period 1986-1987) conditions, which corresponds to the period when the first artesian wells started to be installed in the area of study. This predevelopment period was considered for the steady state calibration in attempt to limit probable pumping effects on the simulated head and fluxes. Hand-dug wells were not implemented in the steady-state model as abstractions from them were insignificant. Few boreholes that existed in the area were also disregarded for the steady state model for the same reason. 
The fitted parameters are the horizontal hydraulic conductivities of the different stratigraphic layers because these are the less known parameters in terms of accuracy and spatial distribution. The recharge, though estimated based on field data was also verified during calibration so as to identify the recharge zones and the proportion of the estimated recharges that suits the different recharge zones. Note in Table 3.8 that for some parts of the Ketou plateau (infiltration area_Ketou2), 10\% of the estimated recharge appeared suitable. This is also the same for some parts of the Abomey plateau (infiltration area_Kana1 and infiltration area_Kana2). Sensitivity analysis prior to the model calibration indicated that the horizontal hydraulic conductivities and the recharge were the most sensitive parameters to the model computed heads and fluxes. Hence, these two parameters are good candidates to be adjusted (Hill, 1998). The vertical anisotropy (VAN) of the hydraulic conductivity was insensitive to the model outputs and was therefore not adjusted during calibration. In this study, the bed-sediment conductances were not adjusted during calibration. However, the sensitivity of the bed-sediment conductances to the computed heads and fluxes was analyzed and discussed in the results section of this paper.

The manual (trial-and-error) calibration approach was adopted to allow that different zones of hydraulic properties (spatial zonation of the hydraulic properties) are defined based on geologic field knowledge and prior information. Zonation of hydraulic properties is required as hydraulic properties vary in space (Carrera et al., 2005). Also, the manual calibration approach helps to develop practical understanding of the aquifer behaviour with regard to the physical hydrologic and geologic features that exist in the modeled system.

The model is calibrated based on the available groundwater head data which were measured in boreholes during installation in 1986-1987. For both the Kh (horizontal hydraulic conductivity) and the recharge, we began calibration by defining simple and few sub-regions according to the existing hydrologic and geologic features and then we increased slowly the complexity in the sub-regions by applying the principle of parsimony (Yeh and Yoon, 1981; Carrera et al, 1986; Hill, 1986; Madigan and Raftery, 1994; Hill and Tiedeman 2007). The zonal recharge and hydraulic conductivity polygons that lead to a successful calibrated model are shown respectively in Figure 3.11 and Figure 3.12. The associated values of recharge and hydraulic conductivities are summarized respectively in Table 3.7 and in Table 3.8. The obtained hydraulic conductivities values (during calibration) for the T.C aquifer, the clay material and the top aquifer are within the range of values reported by Bouzid, 1971; IGIP, 1984; BURGEAP-BRGM, 1994 and Turkpak InternationalSCET-Tunisie, 1991. 


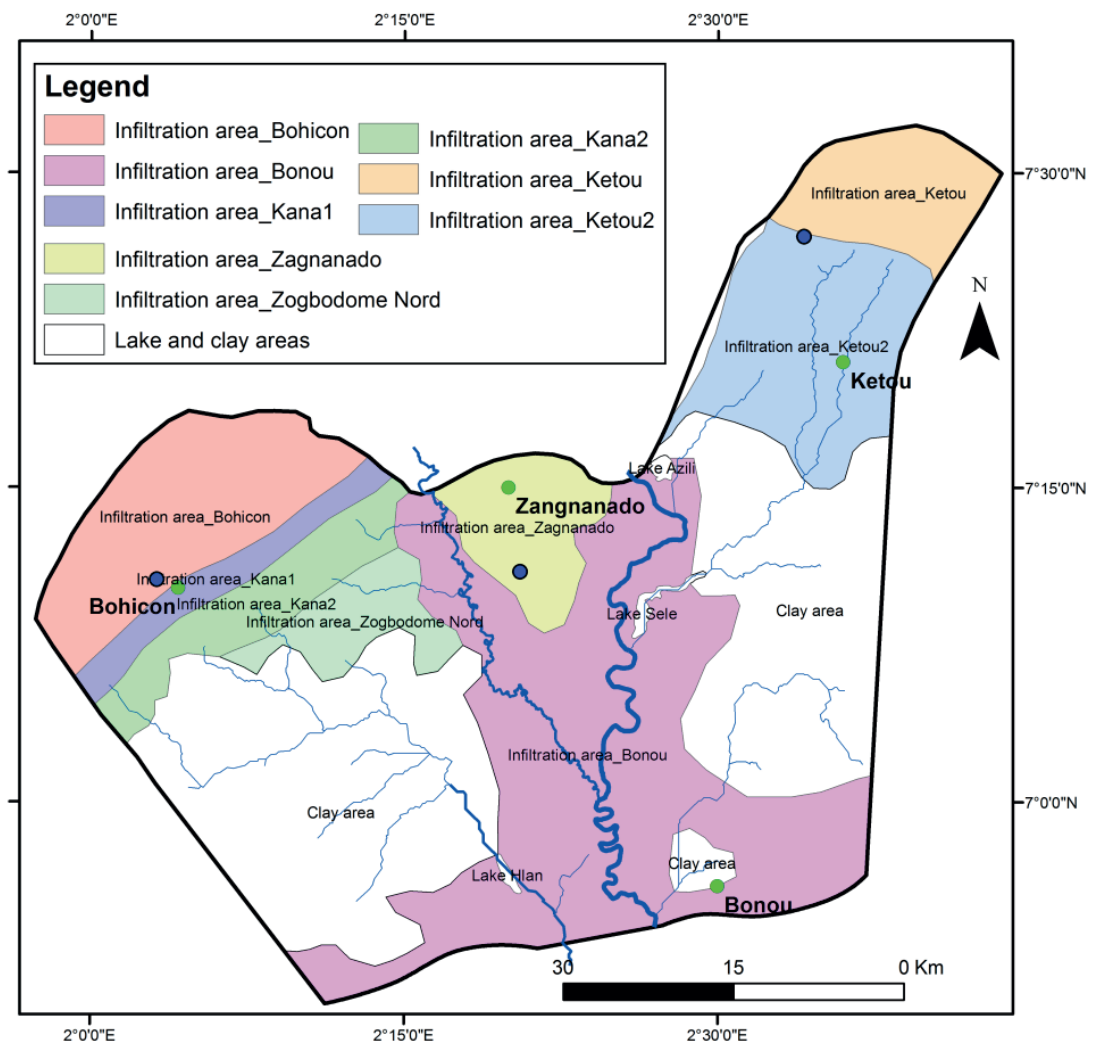

Figure 3.11 Recharge sub-polygons (obtained from calibration)

The model calibration was judged acceptable when the misfit between the observed and the computed heads was less than $10 \mathrm{~m}$. The calibration target (Doherty, 2002) of $10 \mathrm{~m}$ meters was defined based on the standard deviation $(8.5 \mathrm{~m})$ between the SRTM (DEM) data and the data at topographic control points from the field. In addition to the deviation between the DEM and the topographic control points, there are different other sources of imprecision that should not be overlooked. These are: discretization error, measurement error regarding the heads and wells screens elevations and interpolations inaccuracy during the stratigraphic model construction. Also, the recharge calculated and implemented in the model is an average value (year 1987 of Table 3.6 and Annex 3) as well as the observed heads (since the observed heads are not related to a specific month/season), so this could be an additional substantial source of misfit between the computed and observed heads. In that sense, arriving to a perfect calibrated model (highly parametrized) that attempt too close fits with the observed heads is not required (Voss, 2011). 


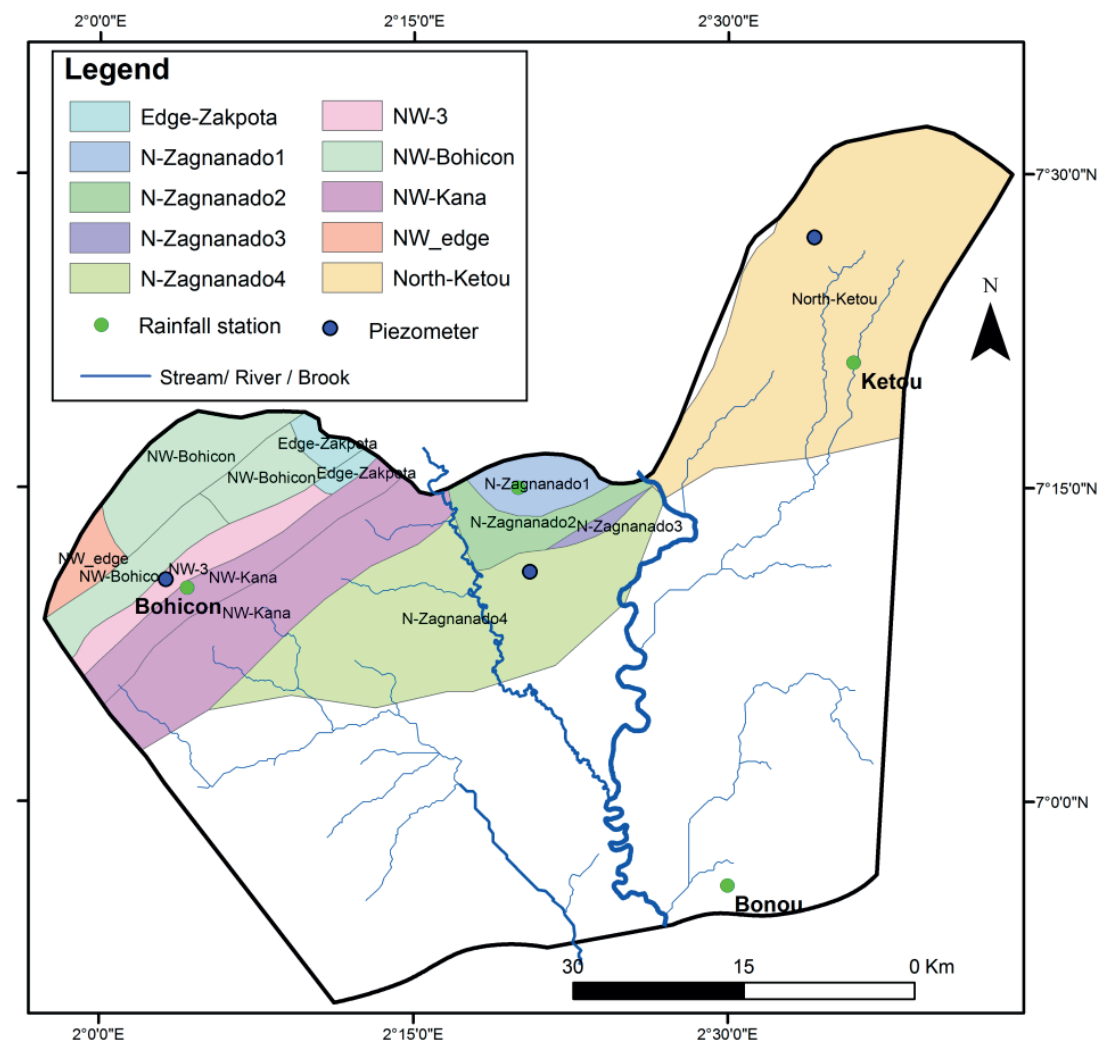

Figure 3.12 Kh sub-polygons from calibration for the T.C aquifer (the zonal Kh of the aquitard and the top aquifer were not adjusted during calibration)

Wildemeersch (2012) suggested that when simulating general variation of piezometric heads, the adequate objective function to consider for the measurement of the goodness of fit between the observed and the computed heads is the RMSE (Root Mean Square Error, see Equation 3.4). The obtained $R^{2}$ is 0.97 and the RMSE is equal to $5.83 \mathrm{~m}$ for the TuronianConiacian aquifer. For the top aquifer, the $R^{2}$ and RMSE are respectively 0.6 and $4.54 \mathrm{~m}$. Also, the residuals are in both cases randomly distributed around the 1:1 line (Figure 3.13a and b) which is an indication that the model is less likely to systematically underestimate or overestimate the heads. 

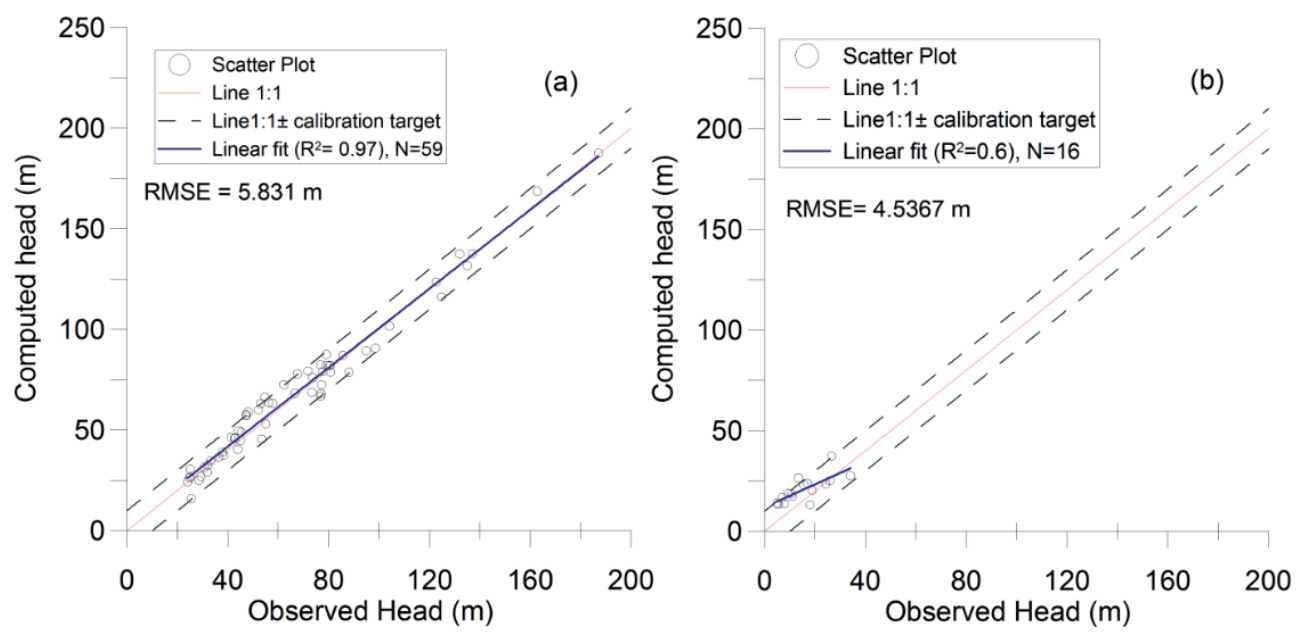

Figure 3.13 Comparison between observed and computed heads after calibration for the period 1986-1987 assuming steady state conditions for the Turonian-Coniatian aquifer (a) and the top aquifer (b).

Table 3.7 Calibrated zonal hydraulic parameters

\begin{tabular}{|c|c|c|c|c|}
\hline Sub-regions & From Layer & To Layer & Horizontal $\mathrm{Kh}(\mathrm{m} / \mathrm{d})$ & Vertical anisotropy (-) \\
\hline \multicolumn{5}{|c|}{ Recharge area of the T.C. aquifer } \\
\hline North-Ketou & 1 & 5 & 40 & 10 \\
\hline N-Zagnanado2 & 1 & 5 & 3 & 10 \\
\hline Edge-Zakpota & 1 & 5 & 5 & 10 \\
\hline Edge-Zakpota & 1 & 5 & 5 & 10 \\
\hline $\mathrm{N}$-Zagnanado4 & 1 & 5 & 25 & 10 \\
\hline N-Zagnanado3 & 1 & 5 & 1 & 10 \\
\hline N-Zagnanado1 & 1 & 5 & 38 & 10 \\
\hline NW-Bohicon & 1 & 5 & 7 & 10 \\
\hline NW-Kana & 1 & 5 & 40 & 10 \\
\hline NW-Bohicon & 1 & 5 & 8 & 10 \\
\hline NW-Kana & 1 & 5 & 40 & 10 \\
\hline NW-3 & 1 & 5 & 30 & 10 \\
\hline NW_edge & 1 & 5 & 2 & 10 \\
\hline NW-Bohicon & 1 & 5 & 8 & 10 \\
\hline \multicolumn{5}{|c|}{ Confined area of the T.C. aquifer } \\
\hline East & 3 & 5 & 6 & 10 \\
\hline central & 3 & 5 & 6 & 10 \\
\hline West & 3 & 5 & 6 & 10 \\
\hline \multicolumn{5}{|c|}{ Top aquifer } \\
\hline South-Central & 1 & 1 & 10 & 10 \\
\hline \multicolumn{5}{|c|}{ Aquitard } \\
\hline South-East & 1 & 1 & 0.007 & 1 \\
\hline South-West & 1 & 1 & 0.007 & 1 \\
\hline South & 2 & 2 & 0.007 & 1 \\
\hline
\end{tabular}

NB: The difference oh Kh between zones in the recharge area of the T.C. aquifer is supported by geologic field observations 


\begin{tabular}{lc}
\hline Sub-regions & Recharge (mm/year) \\
\hline Infiltration area_Ketou & 355.00 \\
Clay area* & 0.00 \\
Infiltration area_Ketou2 & 35.50 \\
Lake Azili* & 0.00 \\
Clay area* & 0.00 \\
Lake Sele* & 0.00 \\
Lake Hlan* & 0.00 \\
Infiltration area_Zagnanado & 254.00 \\
Infiltration area_Bonou & 184.00 \\
Infiltration area_Zogbodome Nord & 222.00 \\
Clay area* & 0.00 \\
Infiltration area_Kana2 & 22.20 \\
Infiltration area_Kana1 & 22.20 \\
Infiltration area_Bohicon & 222.00 \\
\hline recharge was implemented on clay outcropping areas and lakes
\end{tabular}

* No recharge was implemented on clay outcropping areas and lakes

$R M S E=\sqrt{\frac{1}{N} \sum_{i=1}^{N}\left(h_{c}-h_{o}\right)^{2}}$

Equation 3.4

$h_{c}$ and $h_{o}$ are respectively the computed and observed heads

The calibrated steady state model lead to the development of the transient model.

\subsubsection{Transient model implementation and calibration}

The transient model was implemented in an attempt to capture the seasonal behaviour (behaviour in time) of the river leakages. In this study, the simulation time (from January 1988 to October 2011) was chosen because data of rivers levels are available for this period (see Figure 3.14). The levels at Dome's station (Figure 3.14a) and at Ahlan's station (Figure 3.14c) were respectively implemented for the reach of the Zou river and for the reach of the Ouémé stream which is located prior to the junction between the Zou river and the Ouémé stream. The levels at Bonou's station (Figure 3.14b) were implemented for the reach of the Ouémé stream which is located after the junction. The data of the brooks levels are scarce and vary between 0 and 1 meter. Hence, an average value of $0.5 \mathrm{~m}$ is set for the brooks. Also, data of the lakes levels are scarce and average values for lake levels were implemented (i.e., $14 \mathrm{~m}, 9 \mathrm{~m}$ and $6 \mathrm{~m}$ respectively for lake Azili, lake Sele and lake Hlan). 


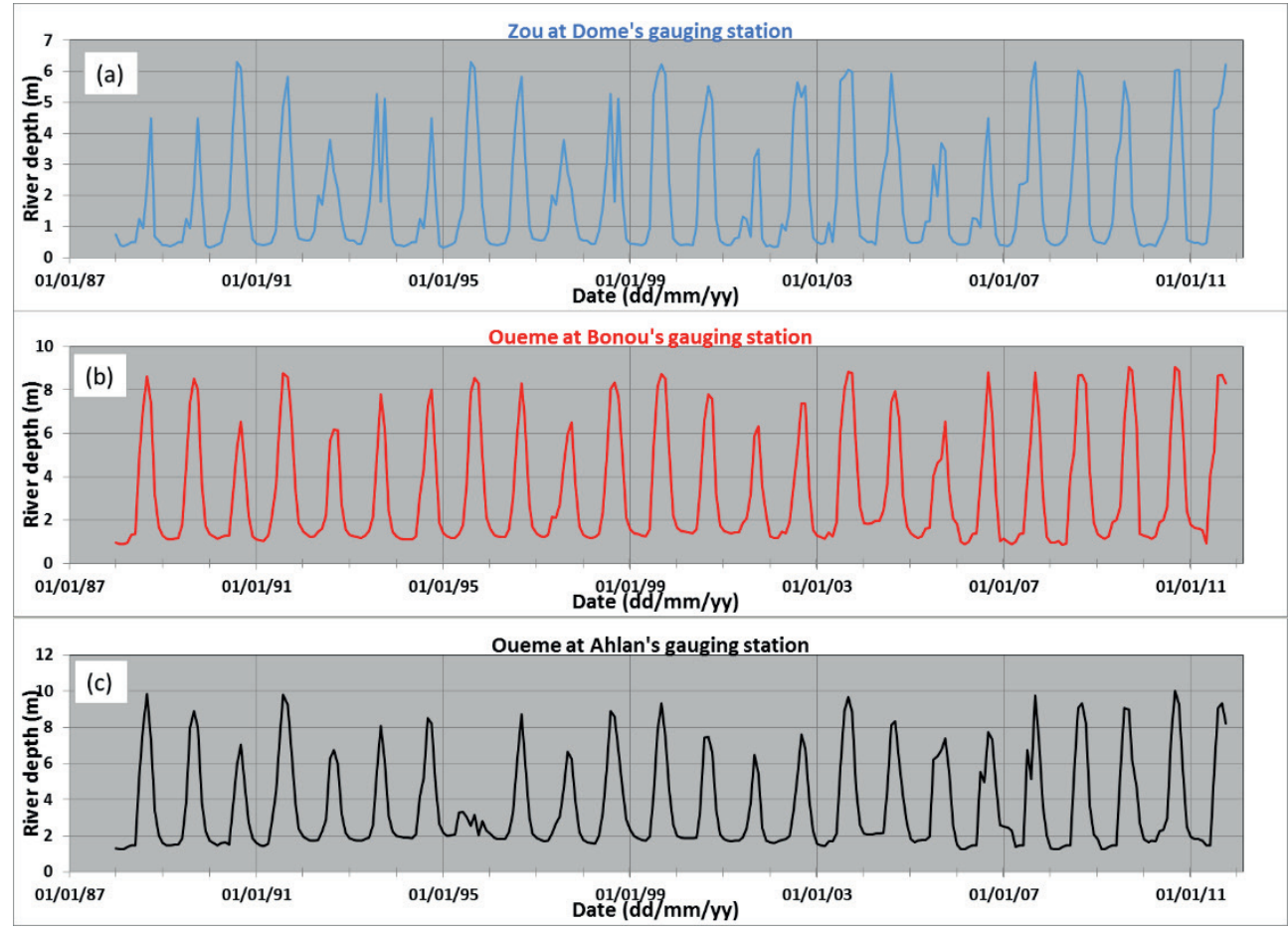

Figure 3.14 Monthly average river depth implemented in the transient model along the Zou and Ouémé

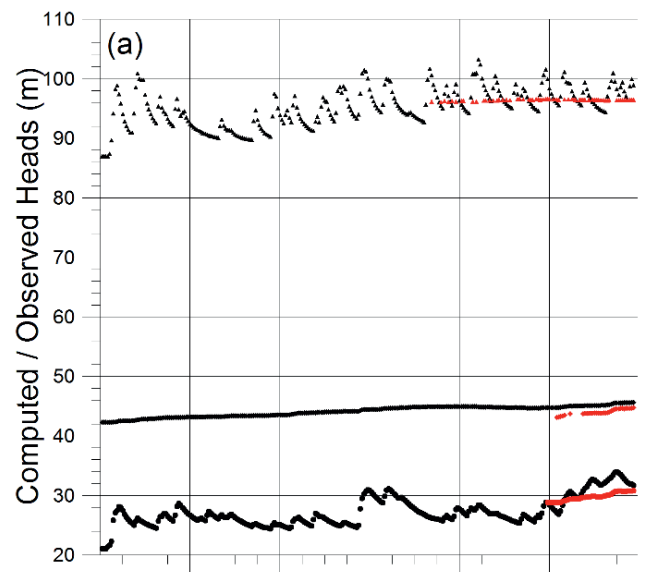

œ

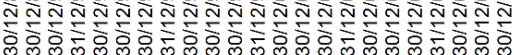
Date (dd/mm/yy)

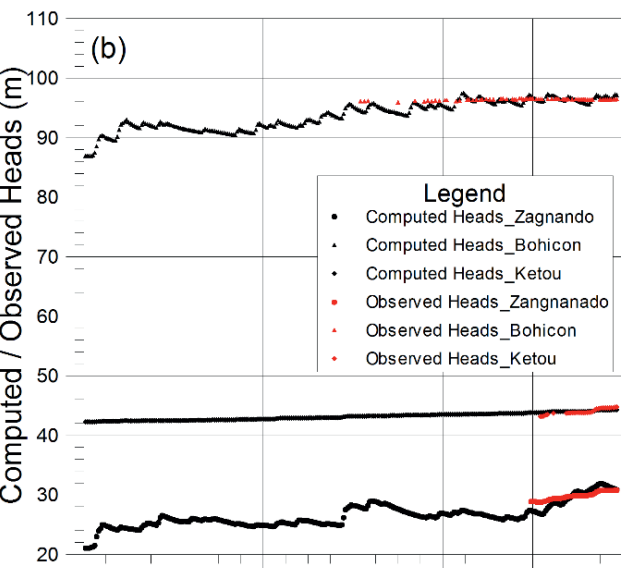

œ ஜ

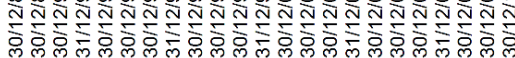
Date $(\mathrm{dd} / \mathrm{mm} / \mathrm{yy})$

Figure 3.15 Transient computed heads versus observed heads prior to calibration (a) and after calibration (b) 
The stress periods were set to be equal to one calendar month with time steps equal to one (only one time step per stress period). A duration of one month as stress period was judged small enough to capture the seasonal leakage behaviour (because the different dry and rainy seasons last for more than one month). This resulted in a total of 285 stress periods. Monthly average river levels, the suitable proportions of estimated recharge for the different recharge zones and abstraction rates were set for each stress period. The storage coefficients implemented for each stratigraphic layer (see Table 3.9) was derived from previous studies and the literature (Bouzid, 1971; Lohman, 1972). The transient model was run (with the heads from the calibrated steady state model being the initial heads) and was calibrated manually (by try-and-error). The transient computed heads were close to the available observed heads (at three locations) after the first model run, except that the computed heads display higher dynamic variability compared to the observed heads (Figure 3.15a). In that sense, only the storage coefficients were adjusted during calibration and the optimal (calibrated) values of storage coefficients are summarized in Table 3.9. At this stage, no further adjustment was required for the implemented recharges. After calibration (storage coefficients), the computed heads became much more closer to the observed heads (Figure 3.15b and Figure 3.16). As explained earlier (Section 3.3.8), there are different sources of imprecisions in the input data that may affect the misfit between the observed and computed heads. So, attempting to match the transient computed heads too closely to the transient observed heads is not realistic, since the transient computed heads respond to estimated monthly recharge events (Voss, 2011). The calibrated transient model is in good agreement with the known groundwater flow patterns in the study area (see Figure 3.16 and Figure 3.17).

The calibrated transient model served to quantify the dynamic river leakages and to access the impact of the conductance, hydraulic and storage properties on the quantified river leakages.

Based on the governing groundwater flow equation (Equation 3.5) and on the equation for the Cauchy boundary condition used to simulate river leakages (Equation 3.6), the parameters to assess are the hydraulic conductivities of the three stratigraphic layers ( $\mathrm{K}_{\mathrm{TC}}$, $\mathrm{K}_{\mathrm{al}}, \mathrm{K}_{\mathrm{clay}}$ ), the storage coefficients (specific yield or specific storage; i.e., Sy or Ss) of the same layers and the streambed conductance. The vertical hydraulic anisotropy being ten (10) and one (1) respectively for the two aquifers and the clay layer (Table 3.7), implies that when varying the horizontal conductivities, the vertical conductivities are also varied accordingly. Based on the knowledge that hydraulic and storage properties in porous medium are often log-normally distributed (Gomez-Hernandez and Gorelick, 1989), these properties were varied within the range of one third (1/3) to three (3) times the base values. The base values of hydraulic and storage properties were multiplied by $1 / 3,2 / 3,3 / 3,4 / 3$ and 3 , leading to 
five model run per parameter and per stratigraphic layer. To account for possible variation in rivers width and streambed vertical hydraulic conductivity, the base values of the streambed conductance were varied within two order of magnitude (i.e., from $0.1 \times$ Cond $_{0}$ to $10 \times \operatorname{Cond}_{0} ;$ Cond $_{0}$ being the stream-bed conductance values from the base model). With this, the impact that each of these properties has on the computed river leakages was assessed.

$K_{x} \frac{\partial^{2} H}{\partial x^{2}}+K_{y} \frac{\partial^{2} H}{\partial y^{2}}+K_{z} \frac{\partial^{2} H}{\partial z^{2}}=S \frac{\partial H}{\partial t}+G$

Equation 3.5

$Q=\operatorname{Cond} \times \Delta H$

Equation 3.6

where $\mathrm{K}, \mathrm{H}, \mathrm{S}, \mathrm{Q}$, Cond and $\Delta H$ are respectively the hydraulic conductivities, the groundwater head, the storage coefficients, the leakage, the stream-bed conductance and head difference between the river and the adjacent aquifer. G stands for sources and sinks terms including leakage.

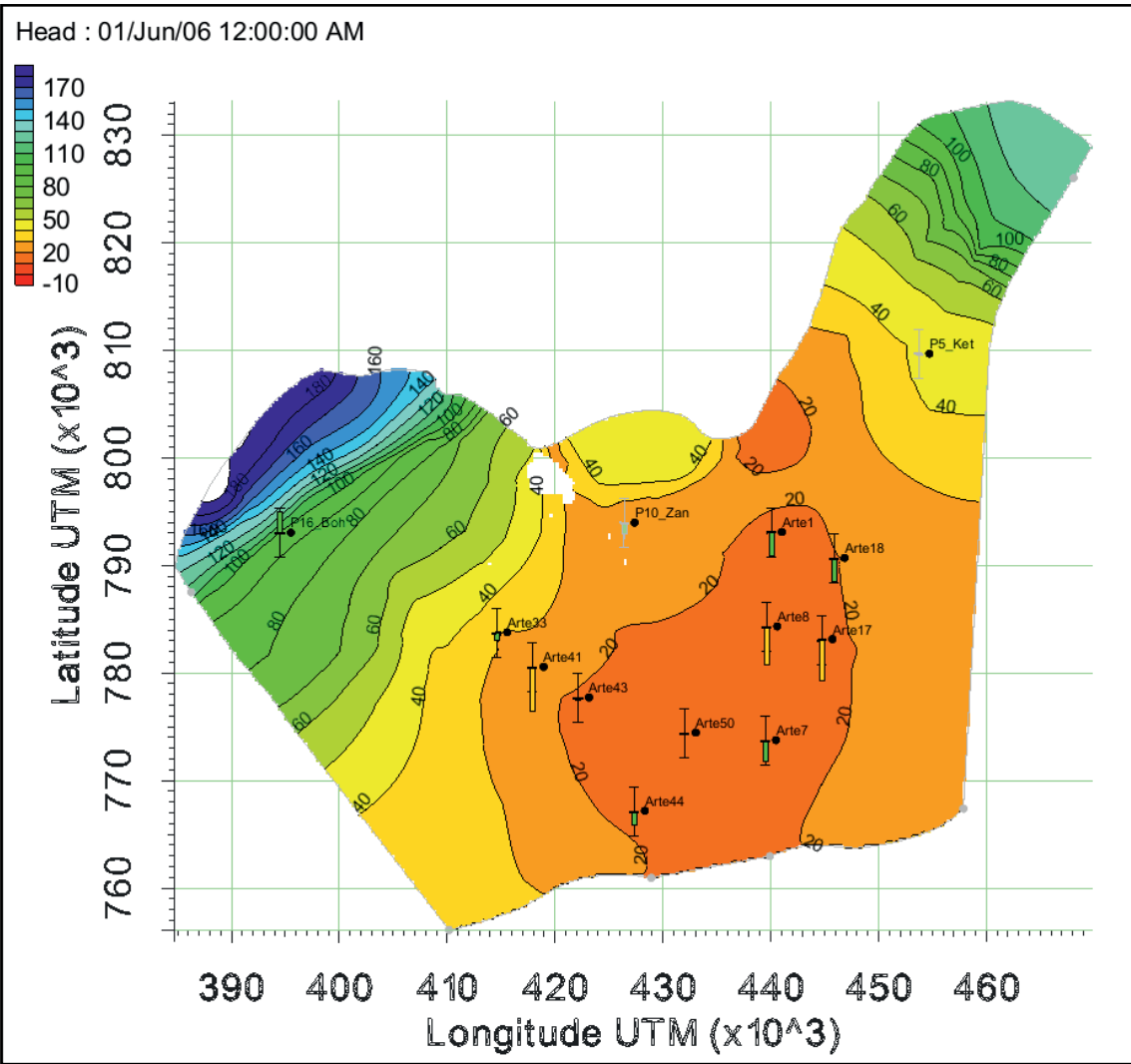

Figure 3.16 Computed heads compared to available observation points (box-plots) in June 2006 (TC aquifer) 


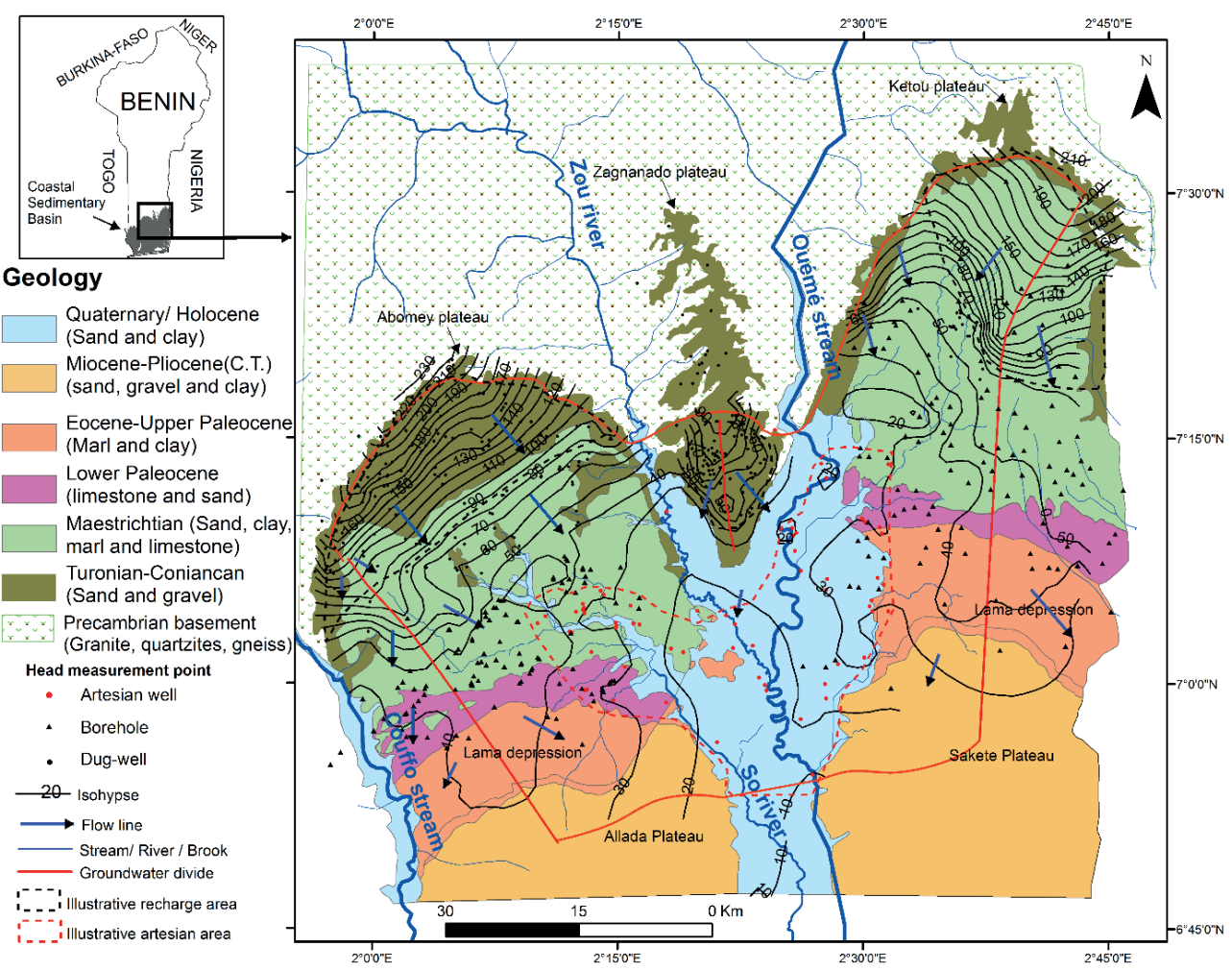

Figure 3.17 Observed piezometric map (November 2015) showing the flow domain (modified from Kpegli et al., 2018).

Table 3.9 Storage coefficients (Data source: Bouzid, 1972; Lohoman, 1972)

\begin{tabular}{|c|c|c|c|}
\hline Geologic Material & $\begin{array}{l}\text { Range of Storage } \\
\text { coefficients }\end{array}$ & $\begin{array}{l}\text { Initial implemented storage } \\
\text { coefficients }\end{array}$ & $\begin{array}{l}\text { Calibrated storage coefficients } \\
\text { (base values) }\end{array}$ \\
\hline Alluvial aquifer & Sy $=[0.1$ to 0.28$]$ & Sy $=0.2$ & Sy $=0.2$ \\
\hline Clay layer & $\begin{array}{l}\text { Ss }=\text { Sy }=[0.02 \text { to } 0.05 \\
]\end{array}$ & Ss $=S y=0.02$ & Ss $=S y=0.02$ \\
\hline \multirow{2}{*}{$\begin{array}{l}\text { Turonian-Coniacian } \\
\text { aquifer }\end{array}$} & Ss $=\left[10^{-5} \text { to } 10^{-3}\right]^{*}$ & Ss $=10^{-4} *$ & Ss $=10^{-3} *$ \\
\hline & Sy $=[0.1 \text { to } 0.3]^{* *}$ & Sy $=0.2^{* *}$ & Sy $=0.2^{* *}$ \\
\hline
\end{tabular}

* Confined part of the T.C aquifer; ${ }^{* *}$ Unconfined part of the T.C aquifer

The next section presents the results and discussion regarding the computed flow budget, the computed river leakages as well as the impact that each of the different properties has on the computed leakages. For the rest of this paper, the term "base-model" and "basevalue" will respectively refer to the calibrated transient model and the optimal parameters values from the calibrated transient model. 


\subsection{Results and discussion}

\subsubsection{Flow budget}

Water budgets (zone-budgets) were calculated for three adjacent sub-zones (named zone0, zone1 and zone2) of the modeled area. Zone0, zone1 and zone2 stand respectively for the top aquifer, the aquitard (clay) and the T.C aquifer (Figure 3.18b, c and d).
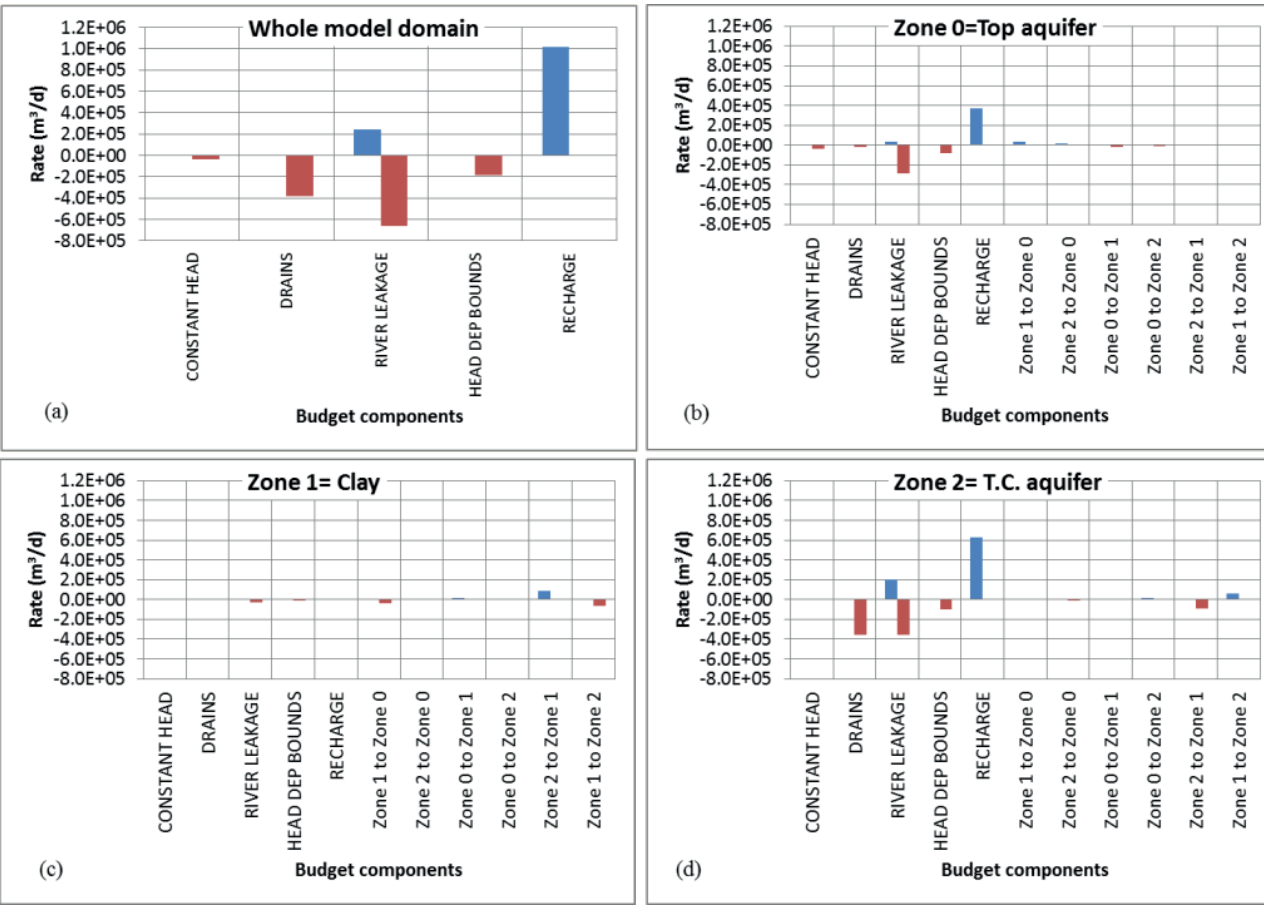

Figure 3.18 Stationary flow budget

It should be underlined that a relatively negligible groundwater $\left(\sim 0.8 \times 10^{5} \mathrm{~m}^{3} / \mathrm{d}\right)$ from the T.C aquifer (Zone2) flows upward to the clay and marl layer (zone1, see Figure 3.18c). And part of it $\left(\sim 0.3 \times 10^{5} \mathrm{~m}^{3} / \mathrm{d}\right.$, see Figure $\left.3.18 \mathrm{~b}\right)$ continues upward to the top aquifer (Zone0). This finding is consistent with the conceptual understanding of the modeled system since the T.C aquifer is known to be artesian in the southern modeled domain (Dray et al., 1989; Achidi et al.,2012; Kpegli et al., 2018).

The stationary flow budget (Figure 3.18a) includes two major inputs (direct groundwater recharge from precipitation and rivers infiltration) and four major outputs (outflows through the southern limit for the top aquifer, springs and faults outflows, river exfiltration and outflows through the southern limit for T.C aquifer combined with lakes exfiltration). 
The total recharge is estimated to be $\sim 10^{6} \mathrm{~m}^{3} / \mathrm{d}$ (Figure 3.18a) which is shared between the T.C aquifer ( $6 \times 10^{5} \mathrm{~m}^{3} / \mathrm{d}$, see Figure $\left.3.18 \mathrm{~d}\right)$ and the top aquifer $\left(\sim 4 \times 10^{5} \mathrm{~m}^{3} / \mathrm{d}\right.$, see Figure $3.18 \mathrm{~b})$. Recharge to the T.C aquifer thus represent $60 \%$ of the total groundwater recharge of the whole system.

The total river infiltration (downward leakage) is $\sim 2.4 \times 10^{5} \mathrm{~m}^{3} / \mathrm{d}$ and more than $83 \%$ of this total river infiltration recharge the T.C aquifer (Figure 3.18a and Figure 3.18d). The remaining $17 \%\left(0.3 \times 10^{5} \mathrm{~m}^{3} / \mathrm{d}\right)$ contributes to the top aquifer recharge. Therefore, rivers contribute to subsurface recharge.

In terms of outflows from the flow domain, river exfiltration (upward river leakage) represents the most important budget component $\left(\sim-6.6 \times 10^{5} \mathrm{~m}^{3} / \mathrm{d}\right)$ followed by the drains ( $-3.8 \times 10^{5} \mathrm{~m}^{3} / \mathrm{d}$ representing springs and faults outflows), the outflows through the southern limit of the T.C. aquifer combined with lakes exfiltration $\left(\sim-1.8 \times 10^{5} \mathrm{~m}^{3} / \mathrm{d}\right.$ termed as "head dep bounds" on Figure 3.18) and the outflows through the southern limit of the top aquifer $\left(-0.33 \times 10^{5} \mathrm{~m}^{3} / \mathrm{d}\right.$, termed as "constant head"). River exfiltration from the T.C aquifer appears to be higher $\left(\sim-3.6 \times 10^{5} \mathrm{~m}^{3} / \mathrm{d}\right)$ than the one from the top aquifer $\left(\sim-2.8 \times 10^{5}\right.$ $\mathrm{m}^{3} / \mathrm{d}$ ). For the T.C aquifer, $\sim-2.1 \times 10^{5} \mathrm{~m}^{3} / \mathrm{d}$, gets recharged from the rivers but $\sim-3.6 \times 10^{5}$ $\mathrm{m}^{3} / \mathrm{d}$ exfiltrate to the surface water. In addition, river exfiltration (upward river leakage) is more than 1.4 time greater than river infiltration (downward river leakage) for both aquifers meaning that rivers remain overall gaining in the flow domain (Figure 3.18). This means that for the stationary condition, rivers are not predominantly recharging the aquifers. However, the dynamic of the river leakages (especially along the Zou river and the Ouémé stream), needs to be examined to cross-check this finding. The dynamic behaviour of the leakages along the Zou river and Ouémé stream is presented in the next section.

\subsubsection{Dynamic of the computed leakages along the Zou river and Ouémé stream}

With regard to the issue of river water loss along the Zou and the Ouémé stream in the study area (Le Barbe et al., 1993), the seasonal river leakage along these rivers was quantified (Figure 3.19). Along the Zou river and the Ouémé stream, it appears that the leakage is upward (groundwater flowing to the river; i.e., gaining stream condition) between November and April yearly (Figure 3.19). Conversely, the leakage is mainly downward in periods of June to October of each year. November to March and June to October are known to include respectively dry and rainy seasons in the study area, meaning that seasonality of the river leakage correlates well with the seasons in the study area. 


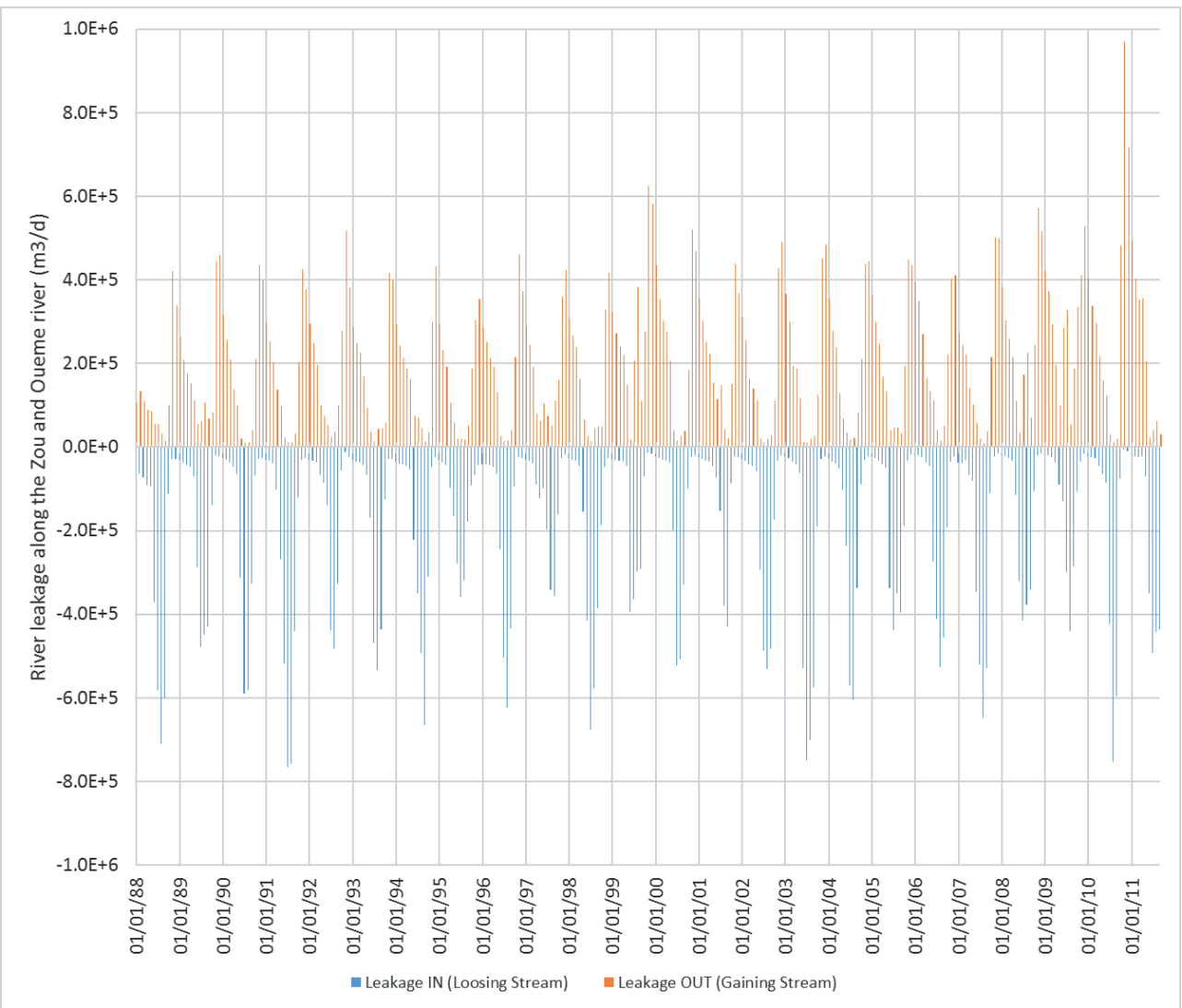

Figure 3.19 Seasonal river leakage along the Zou river and the Ouémé Stream in the sedimentary basin.

The monthly leakage fluxes are comprised between $-8.10^{5}$ and $10^{6} \mathrm{~m}^{3} / \mathrm{d}$ for the simulated period. At the yearly basis, it appears that in some years (e.g.: 1992, 1999; see Figure 3.20a), the upward leakage fluxes are greater compared to the downward leakage fluxes. In some other years (e.g.: 1988, 1991), the upward leakage fluxes are rather less than the downward leakage fluxes. This is an indication that along the concerned sections of the Zou river and the Ouémé stream, the direction of the absolute river leakage is not unique throughout the years. For the simulation period, the differences between the yearly upward and downward leakages are comprised between the $\sim-10^{5}$ and $\sim 2.10^{5} \mathrm{~m}^{3} / \mathrm{d}$ (Figure 3.20b). Compared with the rivers' conceptual water budget along the Zou river and the Ouémé stream (see Table 3.1), the differences between the yearly upward and downward leakages (Figure 3.20b) represent small amounts (i.e., $-0.75 \%,-0.96 \%, 0.35 \%, 3.3 \%$, and $1.66 \%$ ) of the water losses in 2002, 2003, 2004, 2008 and 2010 respectively. For example, from the conceptual water budget, $\sim 6.10^{6} \mathrm{~m}^{3} / \mathrm{d}$ represents the water loss in the year 2003 . However, the absolute leakage fluxes are $\sim-5.810^{4} \mathrm{~m}^{3} / \mathrm{d}$ (i.e., an absolute infiltration of $\sim 0.96 \%$ of the 
water losses). The leakages along the Zou and Ouémé in the study area appear not to be high enough to justify the water losses, given the base-values from the base-model. Uncertainties in flow parameters, hence uncertainties in model results remain so far an issue to consider in hydrological modelling studies (Delhomme, 1979; Du et al., 2018; Ghouili et al., 2017; Zammouri and Ribeiro, 2017). In the next section, we vary each of the parameters within their possible ranges to assess how these parameters impact the computed river leakages.

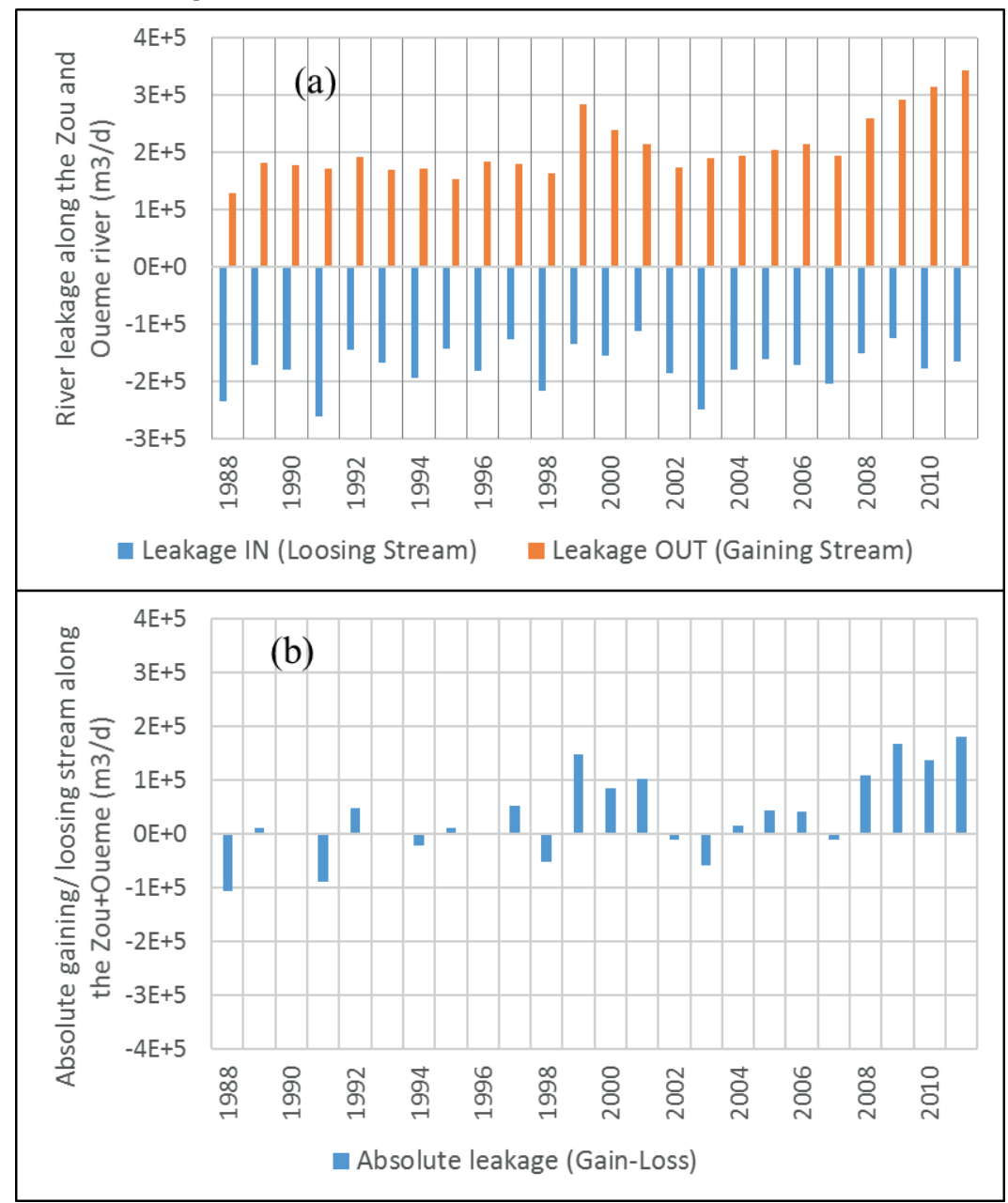

Figure 3.20 River leakage at the yearly basis (a) and difference between yearly upward and downward leakages (absolute leakage).

\subsubsection{Impact of the different parameters on the computed leakage}

\subsubsection{Impact of the streambed conductance}

The streambed conductance was varied within two order of magnitude as indicated in section 3.9. Figure 3.21 shows that throughout the years, the absolute upward/downward 
leakage is similar whether the conductance is equal to five times or ten times the base conductance. In details, only a change of $2.3 \%$ (i.e., $0.039 \times 10^{5} \mathrm{~m}^{3} / \mathrm{d}$ over $1.67 \times 10^{5} \mathrm{~m}^{3} / \mathrm{d}$ ) and $2.6 \%$ (i.e., $0.044 \times 10^{5} \mathrm{~m}^{3} / \mathrm{d}$ over $1.67 \times 10^{5} \mathrm{~m}^{3} / \mathrm{d}$ ) occurred when the base-conductance is multiplied by five and ten respectively (see Figure 3.21, year 2009).

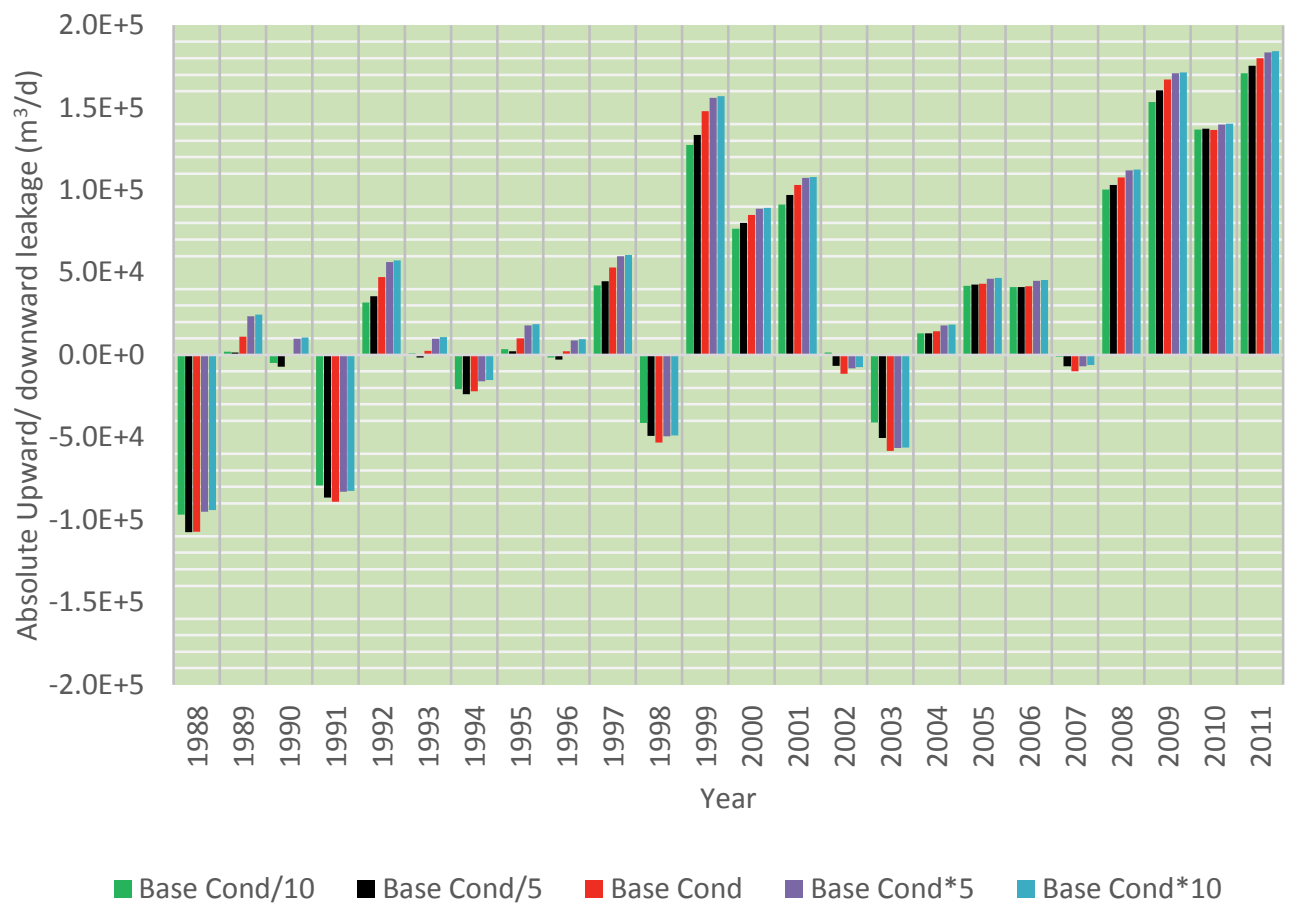

Figure 3.21 Yearly upward/downward leakages under different streambed conductance

This is an indication that a further increase of the conductance will have little influence on the computed leakage. Conversely, when dividing the base-conductance by five or ten, the absolute leakage is relatively more affected $\left(4 \%\right.$ and $8 \%$, i.e., $0.064 \times 10^{5} \mathrm{~m}^{3} / \mathrm{d}$ and $0.14 \times 10^{5}$ $\mathrm{m}^{3} / \mathrm{d}$ over $1.67 \times 10^{5} \mathrm{~m}^{3} / \mathrm{d}$ ) and could be reversed (from upward to downward) for negligible absolute leakage fluxes (fluxes close to zero (e.g.: years 1993,1996 in Figure 3.21)). This suggests that the conductance in areas where the bed-sediments are locally more resistant could be of relative importance regarding the absolute river leakage fluxes. 


\subsubsection{Impact of hydraulic conductivities}

A decrease in the hydraulic conductivity of the alluvial material $\left(\mathrm{K}_{\mathrm{al}}\right)$ resulted in an increase of the absolute upward leakage but in a reduction of the absolute downward leakage. Conversely, when the $K_{a l}$ is increased, the absolute upward leakage is reduced while the downward leakage is increased. For example, dividing the $K_{a l}$ by three only impacted the absolute leakage by $\sim 8 \%$ (i.e., a change of $\sim 0.14 \times 10^{5} \mathrm{~m}^{3} / \mathrm{d}$ over $1.7 \times 10^{5} \mathrm{~m}^{3} / \mathrm{d}$, See for example Figure 3.22a, year 2009).

It can be inferred that in relatively low $\mathrm{Kal}_{\text {al }}$ materials where the range of $\mathrm{K}_{\mathrm{al}}$ uncertainties is likely to be small, $K_{a l}$ would have less impact on the computed leakage, meaning that detailed characterization in low conductive material would not be necessary. However, in highly conductive $K_{a l}$ materials, where the range of $K_{a l}$ uncertainty is likely large, the impact of $K_{a l}$ on absolute leakage would be considerable (e.g.: $0.75 \times 10^{5} \mathrm{~m}^{3} / \mathrm{d}$ over $1.6 \times 10^{5} \mathrm{~m}^{3} / \mathrm{d}$, meaning $\sim 44 \%$ change in leakage when multiplying $K_{a l}$ by three in 2009 , see Figure $3.22 a$ ). This means that the impact of multiplying the $\mathrm{K}_{\text {al }}$ by only three is by far greater than when the streambed conductance is multiplied by ten. This suggests that, compared to the streambed conductance, the $\mathrm{K}_{\mathrm{al}}$ has a greater impact on the computed leakage.
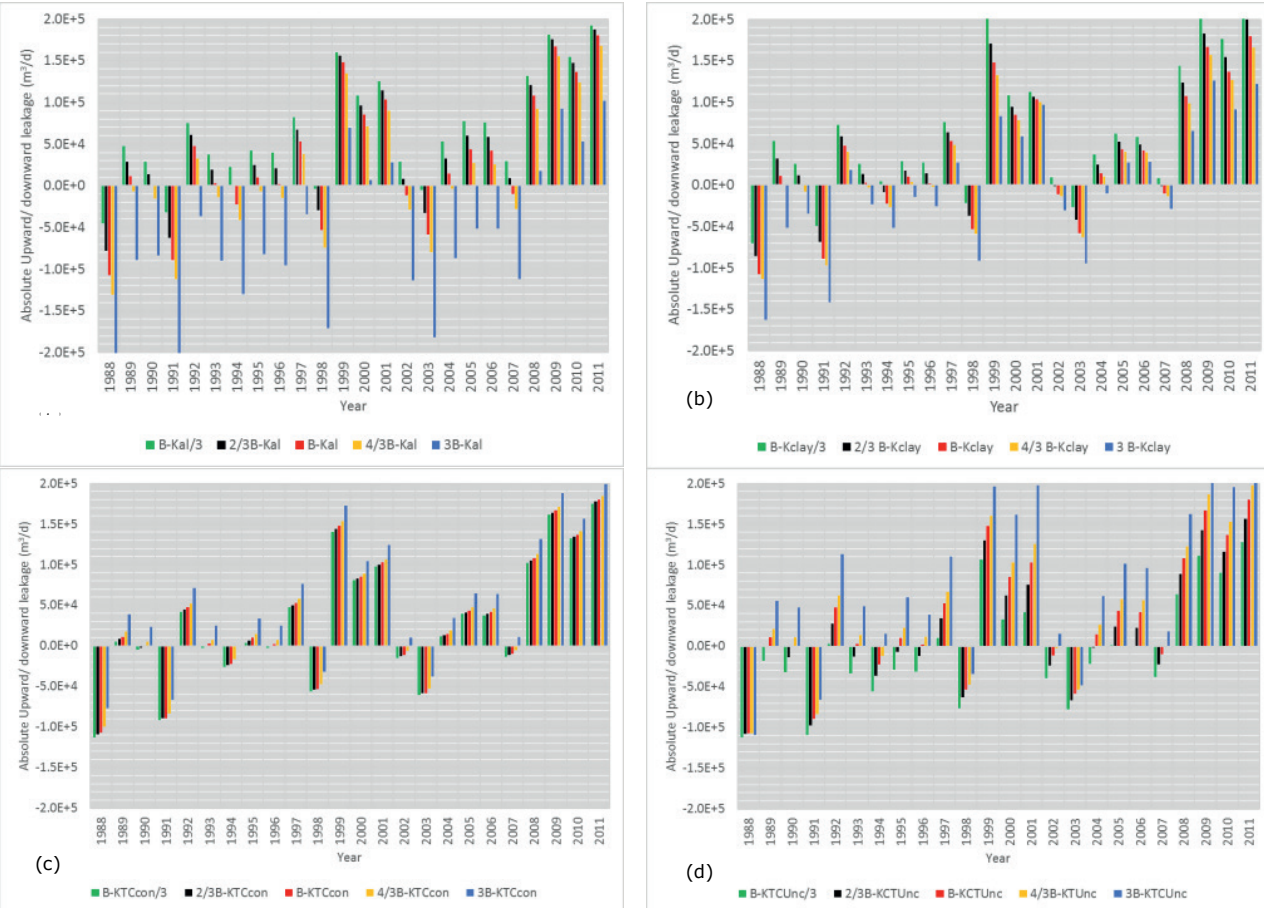

Figure 3.22 Absolute leakages under different hydraulic conductivity of: (a) the alluvial material, (b) clay, (c) unconfined T.C aquifer and (d) confined T.C aquifer. 
Figure $3.22 \mathrm{~b}$ shows that a reduction in the hydraulic conductivity of the clay material ( $\mathrm{K}_{\text {clay }}$ ) caused an increase in the absolute upward leakage. In details, multiplying the $\mathrm{K}_{\text {clay }}$ by three resulted in a change of $\sim 24 \%$ of the absolute leakage (i.e., $0.4 \times 10^{5} \mathrm{~m}^{3} / \mathrm{d}$ over $1.67 \times 10^{5} \mathrm{~m}^{3} / \mathrm{d}$ 2009); which is less compared to the change (44\%) caused by a multiplication by three of the alluvial conductivity. This suggests that the hydraulic conductivity of the clay material has less effect on the computed leakage compared to the conductivity of the alluvial material.

Figure 3.22c shows that multiplying the hydraulic conductivity of the confined part of the T.C aquifer by three has impacted the computed upward leakage only by $12 \%$ (e.i., $0.2 \times 10^{5}$ $\mathrm{m}^{3} / \mathrm{d}$ over $1.67 \times 10^{5} \mathrm{~m}^{3} / \mathrm{d}$ in 2009 , Figure $3.22 \mathrm{c}$ ). A change of $12 \%$ is small compared to the impact related to both the alluvial and the clay hydraulic conductivities which are respectively $44 \%$ and $24 \%$. This illustrates that the hydraulic conductivity of the confined part of the T.C aquifer has less influence on the computed leakage than to the alluvial and clay materials.

Regarding the unconfined part of the T.C aquifer, the impact on leakage of multiplying the base hydraulic conductivities by three is $\sim 45 \%$ (i.e., $0.76 \times 10^{5} \mathrm{~m}^{3} / \mathrm{d}$ over $1.67 \times 10^{5} \mathrm{~m}^{3} / \mathrm{d}$, year 2009 , see Figure $3.22 d$ ). This impact appears to be similar to the case of the alluvial aquifer ( $44 \%)$ and greater than those of the confined T.C aquifer and the clay layer. So, in terms of hydraulic conductivity of the different materials, it appears that the hydraulic conductivities in the alluvial and the unconfined part of the T.C aquifer affect the most the computed leakage, followed by the clay conductivity. The conductivity of the confined part of the T.C aquifer appears to be less important than the conductivity of the clay material. It is worth noting that the streambed conductance is so far the less influencing factor regarding the computed leakage.

\subsubsection{Impact of storage coefficients}

The impact of the storage coefficient of the different geological materials is summarized in Figure 3.23. As shown in Figure 3.23a, increasing three times the storage coefficient in the confined part of the T.C aquifer or dividing it by three has almost no influence on the computed leakage. In details, the change in the computed leakage is $\sim 0.18 \%$ (i.e., a variation of $0.003 \times 10^{5} \mathrm{~m}^{3} / \mathrm{d}$ over $1.67 \times 10^{5} \mathrm{~m}^{3} / \mathrm{d}$ when the base value is multiplied by three).

Regarding the unconfined alluvial material (Figure $3.23 \mathrm{~b}$ ), variations in the storage coefficient (Sy) caused limited impact on the computed leakage ( $5 \%$ when the base value is divided or multiplied three). Also, the impact of the storage coefficient (Sy) in the unconfined part of the T.C aquifer (Figure 3.23c) on the leakage is limited ( 5\% when dividing the storage coefficient by three in 2009). 
$12 \%$ and $15 \%$ (i.e., respectively $0.2 \times 10^{5} \mathrm{~m}^{3} / \mathrm{d}$ and $0.2 \times 10^{5} \mathrm{~m}^{3} / \mathrm{d}$ over $1.67 \times 10^{5} \mathrm{~m}^{3} / \mathrm{d}$ ) represent the changes that occurred in the computed leakage when the base value of the storage coefficient of the clay material is multiplied respectively by one-third and three (Figure 3.23d, year 2009). 12\% and 15\% are relatively high changes compared to the related changes in the alluvial, the confined and the unconfined parts of the T.C aquifer. This suggests that the storage coefficient in the clay layer has a relatively higher impact on the leakages compared to the others. It is worth noting that the clay storage coefficient has a greater impact on the leakage compared to the streambed conductance.
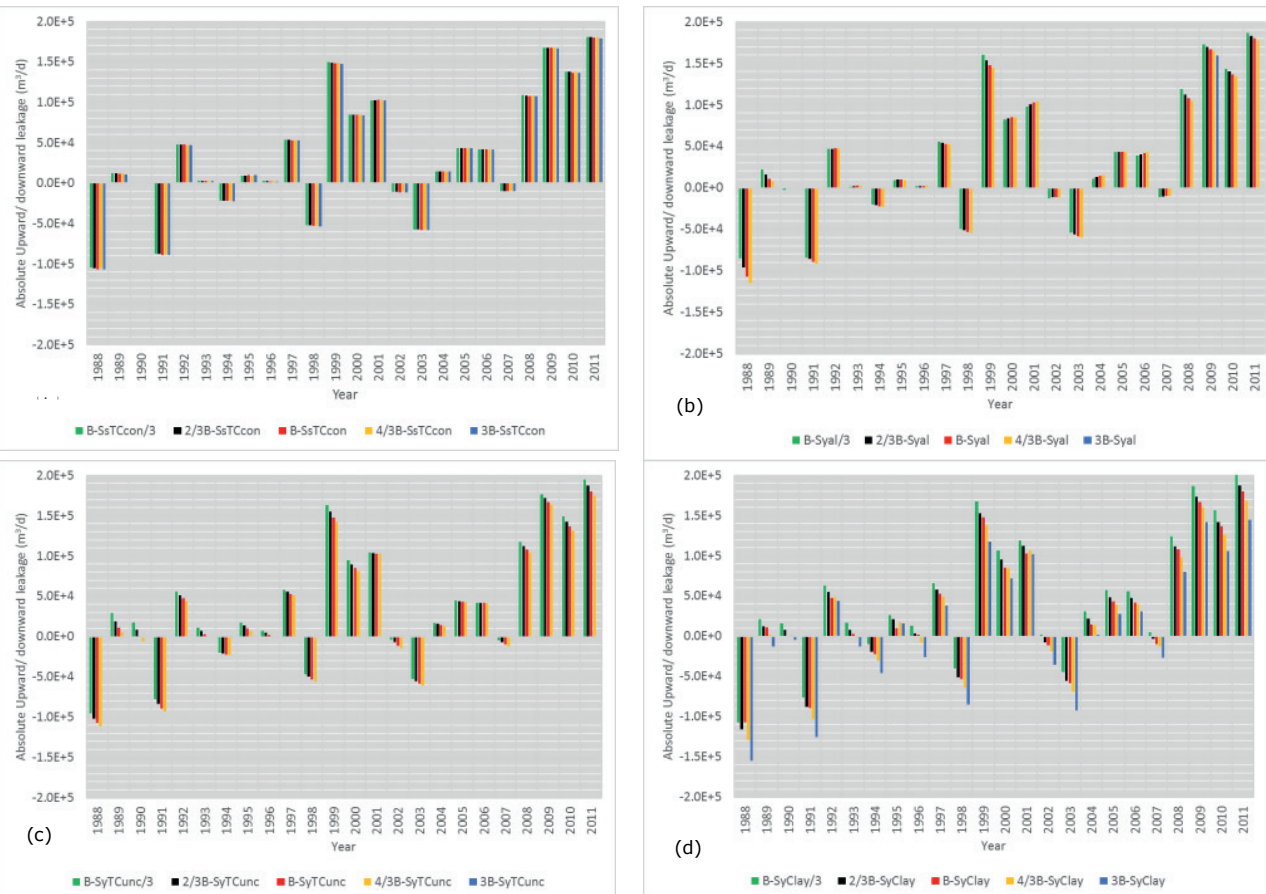

Figure 3.23 Absolute leakages under different storage coefficient of: (a) the confined T.C aquifer, (b) alluvial material, (c) unconfined T.C aquifer and (d) clay

Results presented in this section illustrate that, with regard to the quantification of river leakages in the studied system, the most influencing factors are the hydraulic conductivities in the alluvial and in the unconfined part of the T.C aquifers (which caused $\sim 45 \%$ changes in computed leakages). Then comes the clay's hydraulic conductivity, the storage coefficient of the clay and the hydraulic conductivity of the confined part of the T.C aquifer (which affect the leakage by $12 \%)$. The storage coefficient of the alluvial material, the streambed conductance and the storage coefficient of the unconfined part of the T.C. aquifer only affect the leakage by $5 \%$. The storage coefficient in the confined part of the T.C aquifer is the least important factor that affect the leakage. It should be emphasized that the 
streambed conductance is among the least dominant factors when computing the river leakage.

This finding leads to the conclusion that efforts to measure with high precision streambed conductances with respect to quantifying river leakages are not beneficial. This finding is consistent with Leake et al. (2008) who found that the differences in Colorado river depletion calculated with the original riverbed conductance values and with values that are three orders of magnitude lower are relatively minor.

Based on the different parameters ranges applied in this study, the highest possible leakage values during the simulation period are $-2 \times 10^{5} \mathrm{~m}^{3} / \mathrm{d}$ (absolute downward leakage) and $\sim 2 \times 10^{5} \mathrm{~m}^{3} / \mathrm{d}$ (absolute upward leakage). These values are by far low compared to the water losses from the Zou river and the Ouémé stream (Table 3.1). In details, for example in year 2003 , the water losses are $\sim 60 \times 10^{5} \mathrm{~m}^{3} / \mathrm{d}$ while the highest possible simulated leakage is $\sim 2 \times 10^{5} \mathrm{~m}^{3} / \mathrm{d}$; which represents only $\sim 3 \%$ of the water losses. In relatively high rainy years (with higher groundwater recharge, e.g.: year 2008, 2010, see Figure 3.22), the leakage is absolutely upward, meaning that in these years, leakage along the Zou river and the Ouémé stream have not contributed to the water losses, though the water losses are still important in these years ( $>30 \times 10^{5} \mathrm{~m}^{3} / \mathrm{d}$, see Table 3.1). This finding leads to the conclusion that the observed water loss in the Zou and Ouémé rivers (see Table 3.1 and Figure 3.2) is not likely to be due to their leakage (infiltration) into the subsurface flow domain.

\subsection{Conclusion}

The aim of this study was to quantify river leakage along the Zou river and the Ouémé stream in attempt to understand the role leakages from these rivers play with regard to their water losses. To quantify the leakage, we set-up a 3D-numerical flow model which is based on observations and available data and is close as possible to the field setting. The model served to quantify possible ranges of the leakages along the Zou river and the Ouémé stream, given reasonable ranges of the streambed conductance and of the hydraulic and storage properties. Then, the computed leakages were compared with the water losses from the conceptual water budget on the concerned rivers. The results show that river leakages along the Zou river and the Ouémé stream are tiny, and represent at most 3\% of the water losses. This finding leads to the conclusion that the observed water loss in the Zou and Ouémé rivers is not likely caused by their leakage (infiltration) into the subsurface flow domain. A limitation is that the model in this research does not test the interconnectedness of surface water flows. As such, further research is required to explore other plausible causes such as rivers and other surface water bodies interconnections which 
is beyond the scope of the present modelling research. Alternative explanations of the river water losses are discussed in annex 4 as well as the implication of the outcropping clay layer.

This study strengthens that the streambed conductance is among the properties that has minor influence on the river computed leakages. The most dominant factors are the hydraulic conductivities in the alluvial and in the unconfined part of the Turonian-Coniacian aquifer, followed by storage coefficient in the clay material. This study has allowed to rank the hydraulic and storage properties in their order of importance with regard to the estimation of river leakages. The study hence provides insights regarding the estimation of river leakage in the study area that can be applied in similar regions elsewhere. 


\section{Three-dimensional hydrogeological modelling of head changes of a South Benin artesian aquifer}

Artesian basins include groundwater that may rise above the land surface when tapped with free-flow conditions which makes it possible to exploit groundwater without pumping. The change to non-artesian conditions may therefore have large implications for local people using artesian wells for drinking and various other households usages. We applied a 3D physically base model to assess future head developments in the TuronianConiacian (T.C.) artesian aquifer of southern Benin under different artesian outflows and climate scenarios. A sensitivity analysis of the hydraulic and storage properties of the subsurface layers was performed to determine the importance of each property. The results revealed that artesian basins are structured into peripheral and central zones behaving differently to external stresses. Head amplitudes in the peripheral zones which are adjacent to recharge zones are higher and decrease towards the central artesian zones. This damping of head amplitudes is due to the hydraulic diffusivity of the confined aquifer which is defined as K/S and the leakance of the confining layer. Hence the central artesian zone is found less vulnerable to unstable heads. Lower predicted recharge for the period until 2030 will lead to head drops by about $1 \mathrm{~m}$ at the peripheral artesian zone but will likely recover during the period 2030-2050 for which higher recharge is predicted. It is also found that if the current artesian outflows augment to double by 2050 this would cause heads to reduce by only a few centimeters both in the central and at the periphery of the artesian zone but more pronounced at the center where most artesian wells are located. This suggests that the effect of climate is much more important than the increase of water demand. Among all the subsurface layers properties, the hydraulic conductivity of the confined T.C. aquifer is found to be the most influencing property on the simulated heads across the artesian zone and its specific storage is revealed as the least influencing one. Given the sensitivities of the hydraulic and storage properties as well as recharge, the effect due to climate models is less dominant.

Based on:

K.A.R. Kpegli, P.G.B. de Louw, A. Alassane, D. Mama, M. Boukari, S.E.A.T.M van der Zee. Three-dimensional hydrogeological modelling of head changes of a South Benin artesian aquifer. Submitted to: Hydrogeology Journal 


\subsection{Introduction}

Groundwater has many advantages over surface water resources regarding reliability like the availability during dry periods, ease and low cost of development (installation of wells), and is generally of good quality (MacDonald et al., 2009). Particularly, groundwater from artesian aquifers is advantageous for rural drinking water supply in developing countries, because free-flowing artesian wells make the use of pumps unnecessary. The ever-growing population across the world, including Africa, puts serious stresses (including overexploitation and pollution) on groundwater resources (Wada et al., 2010; Sappa and Rossi, 2010; Aeschbach-Hertig and Gleeson, 2012). The proliferation of groundwater point sources (wells, boreholes, hand dug-wells, artesian wells) is a clear illustration of the increasing stresses on groundwater. Due to such stresses and insufficient recharge, aquifers may undergo severe groundwater depletion (Konikow and Kendy, 2005; Powell and Fensham, 2015). Climate change may be an additional stress on water resources (Dragoni and Sukhija, 2008; Carter and Parker, 2009). Hence, there is a need to understand how future population and climate would affect groundwater resources, including artesian systems. An aquifer is artesian (e.g.: the Great Artesian Basin in Australia, the Baltic Artesian Basin in Latvia and the Nubian Sandstone Aquifer in Northern Africa) when it is enclosed between aquitards and heads rise above the land surface (Meinzer, 1928; Sethi and Di Molfetta, 2019). There are two cases regarding artesian systems: (1) almost no recharge occurs through the confining layer (upper boundaries) which is nearly impermeable and recharge predominantly occurs far away (from an intake area) and groundwater moves slowly down the dip of the aquifer beneath the overlying (semi-) confining beds toward the artesian zone (Mazor, 1995; Virbulis et al., 2013; Newman et al., 2016), (2) significant recharge occurs locally through the confining leaky layer (Sappa and Rossi, 2010; Rushton and Carter, 2012). In southern Benin, groundwater is the main source of water supply for the population where the Turonian-Coniacian (T.C.) aquifer is partly artesian and exploited through hand-dug wells and artesian wells. For this T.C. aquifer, artesian head declines of up to $1 \mathrm{~m}$ have been reported for several artesian wells (Kpegli et al., 2018a). This could be a warning sign of a regional artesian head decline.

The problem of artesian heads declines raised the following first research question: how will artesian heads in the T.C. aquifer evolve in the future with respect to future population growth and climate change? Welsh (2006) found large differences in artesian head declines between areas (e.g.: between south Australia and New South Wales) which could not be explained yet. So, a second research question is: which areas of an artesian basin would be more subjected to artesian head declines? Model parameters like the hydraulic and storage properties of the subsurface layers and recharge are known with uncertainties and their impact on the simulated heads across the artesian zone is of concern. It is unclear if the 
impact of recharge and hydraulic and storage properties are the same across the whole artesian zone. Thus, a third question is: what is the impact of recharge and hydraulic and storage properties of the subsurface layers on heads in the artesian domain?

The objectives of this research are (1) to investigate the future trends of the heads across the artesian zone considering climate change and increasing water demand, (2) to assess which areas of an artesian basin would be more affected by head instability and ( 3 ) to assess the sensitivity of hydraulic and storage properties and recharge on simulated heads in the artesian zone. To answer the above questions, a 3D physically-based numerical model is applied. It is a MODFLOW based transient model that extends up to the year 2050. Plausible climate scenarios were chosen for groundwater recharge estimation and population growth is taken into account to extrapolate future groundwater demands.

\subsection{Study area}

\subsubsection{Location and hydrogeology}

The study area is located in southern Benin (West Africa), about $100 \mathrm{Km}$ from the coast and belongs to the coastal sedimentary basin (Figure 4.1). It consists of sedimentary rocks that overlay crystalline Precambrian bed-rocks, in which two main sandy aquifers exists: the Turonian-Coniacian aquifer and the alluvial aquifer (Quaternary), which are highly heterogeneous. The alluvial aquifer is found basically along the rivers in the valley. Details regarding the sedimentary setting of the study area as well as details about the aquifers are available in Kpegli et al., 2018a. The elevation of the ground surface ranges from approximately -1 (at local depressions) to $270 \mathrm{~m}$ above sea level toward the northern edges of the study area (Weller, 2002). Basically, groundwater for the major aquifer (the T.C. aquifer) gets recharged in the northern regions of the study area which is not covered by clay and marl materials (see the T.C aquifer recharge areas around Bohicon, Zagnanado and Ketou in Figure 4.2) and flows generally to the south, with some local deviances to the South-East and South-West due to the influence of the Ouémé valley (see Kpegli et al., 2018a). In fact, a thick clay and marl layer settled between the Eocene and upper Paleocene (Figure 4.1), with a thickness greater than 150 m (Géohydraulique (1985)) covers a southern part of this aquifer and extends below the alluvial aquifer. Between the Paleocene and Turonian-Coniacian, another clay and marl layer was also settled. The extent of the confining clay and marl layer is shown in Figure 4.2. Below these clay and marl layers (at downstream areas which are in the South), no modern water (<70 years old) was detected in a previous research (see Kpegli et al., 2018a), suggesting that nearly no recharge occurs through these clay layers and that the water existing below these clays basically comes from 
some distance (i.e., recharge areas in the northern study area). The presence of the clays explains why artesian wells (and hence the artesian zone) do not exist in the northern part of the study area but do exist in the south. As such, this clay layer is of very low hydraulic conductivity $\left(\sim 10^{-4} \mathrm{~m} / \mathrm{d}\right)$ but can store water (Sethi and Di Molfetta, 2019).

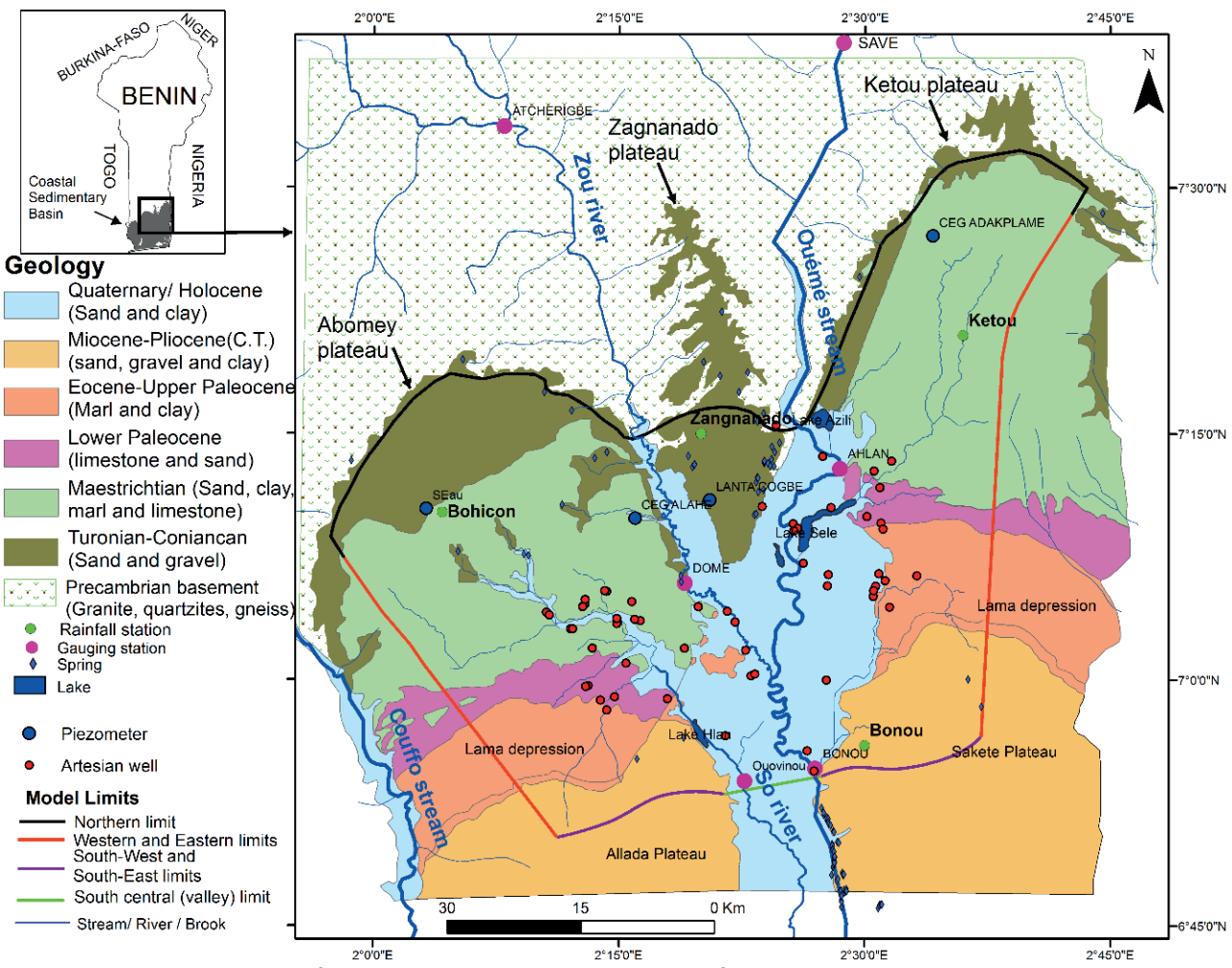

Figure 4.1: Geologic map of the study area showing location of artesian wells and piezometers

\subsubsection{Groundwater development and population growth}

According to Slansky (1962), few individual hand dug-wells was already installed in the T.C. aquifer in 1950s. These few hand dug-wells, with limited abstraction capacities, were installed by the villagers themselves for domestic use in the unconfined T.C. aquifer and in the alluvial aquifer. By 1960, boreholes (deeper than hand dug wells) started to be progressively installed, with higher groundwater abstraction capacities compared to hand dug-wells. Few years later, i.e., in 1980s, the first artesian wells were installed through the clay layer tapping the confined T.C. aquifer at depths of $150 \mathrm{~m}$ and since then, the number of artesian wells keep increasing (Figure 4.3a). According to the national borehole data base (BDI-DGEau), the number of artesian wells reached 52 by 2015 in the study area, with total artesian outflow of about $53 \times 10^{3} \mathrm{~m}^{3} / \mathrm{d}$ (Figure $4.3 \mathrm{~b}$ ). 


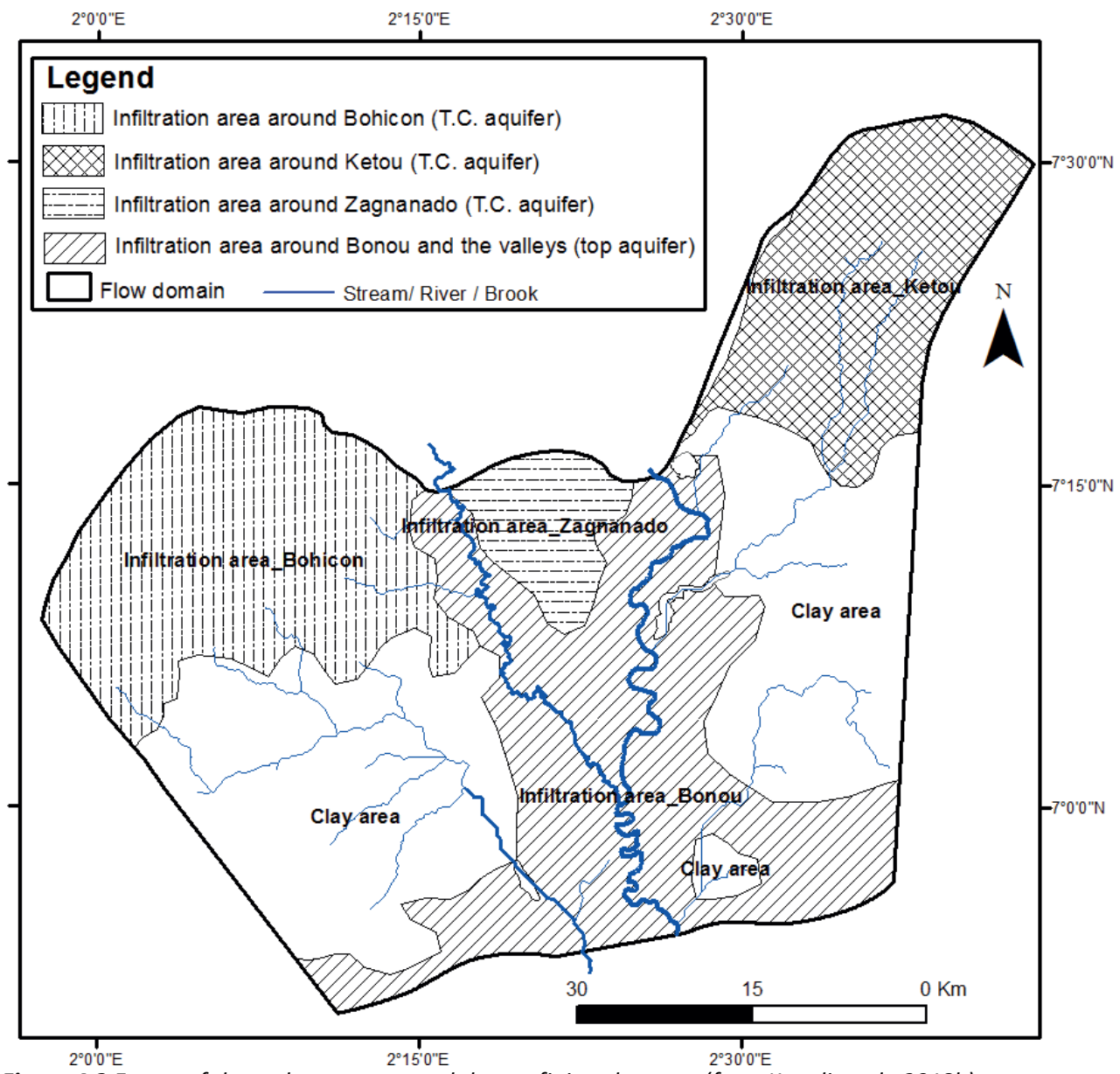

Figure 4.2 Extent of the recharge areas and the confining clay area (from Kpegli et al., 2018b)

Abstraction rates from the individual boreholes and dug-wells could not be monitored and estimated effectively because, some of the individual boreholes and dug-wells locations are unknown. However, all artesian outflows (free-flows) were measured once at installation by the DGEau (the national directorate of water resources in charge of groundwater supply in rural areas) and stored in their data base (BDI-DGEau). Apart from artesian wells, individual boreholes and dug-wells, there are few boreholes drilled and monitored by the SONEB (national water company in charge of water supply in cities). However, the artesian outflows are dominant, i.e., more than five times the abstractions from individual boreholes and SONEB wells (see Figure 4.3c). Future groundwater abstractions including the creation of new artesian wells are basically dependent on the population growth. The population of Benin is growing fast, with nearly $3 \%$ per year, which is assumed to be representative for the study area. According to the official United Nations population estimates and projections (UN, 2017), the population in 2018 is 11.4 million and is expected to double 
by 2048 ( 23 million), and tripled by 2070 ( 33 million). We assume in this study that the increase of future groundwater abstractions (including artesian outflows) would follow the projected trend in the population growth (Figure 4.3c). This will result in artesian outflows of 120 thousands $\mathrm{m}^{3} / \mathrm{d}$ and the impact on artesian conditions by $2050 \mathrm{~s}$ is of concern.
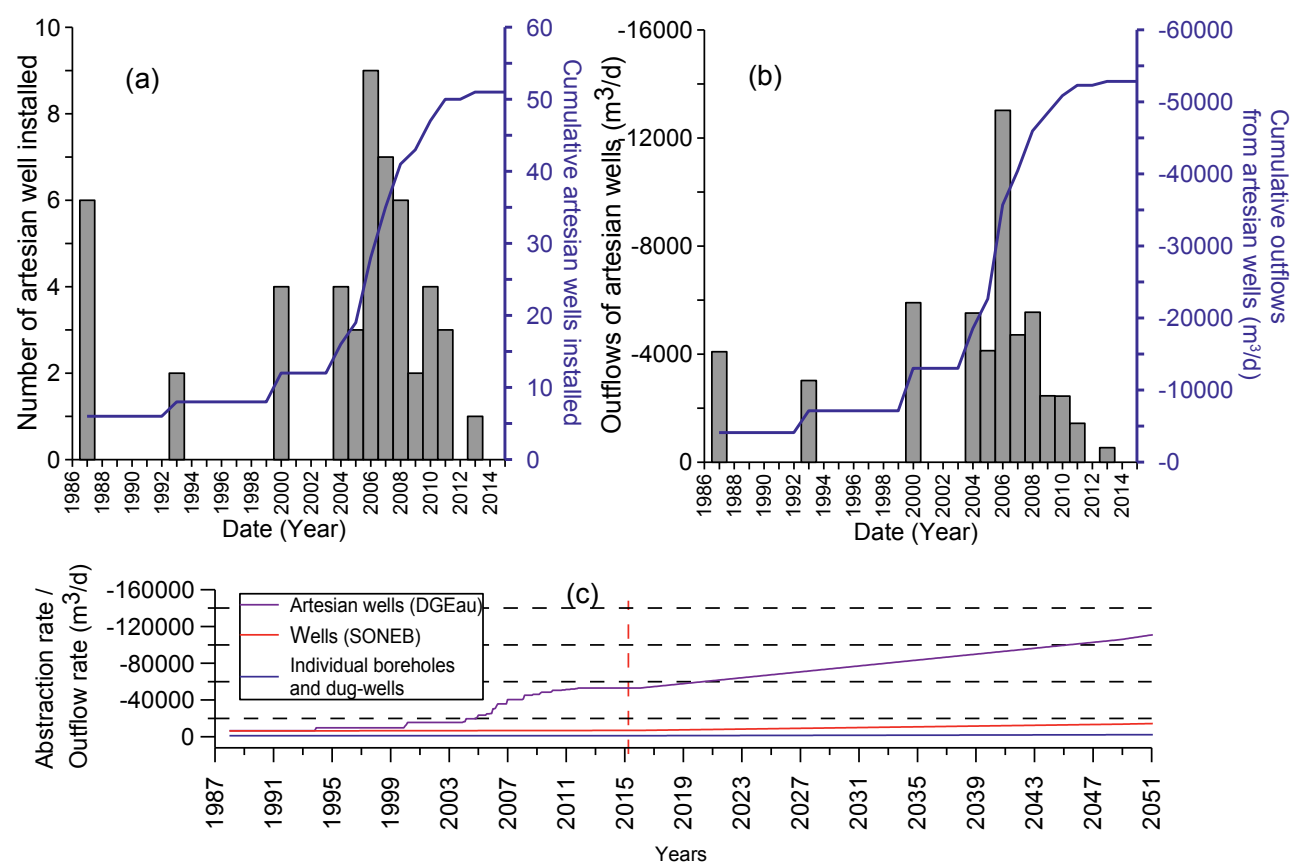

Figure 4.3 Artesian wells proliferation (a) and associated artesian outflows evolution(b) in the study area (Data source: BDI-DGEau); current (SONEB, DGEAU and individual wells) and projected groundwater abstractions (including artesian outflows) in the study area (c). Data source: BDI-DGEau and UN, 2017. The red dashed lines separate the observed data to projected ones

\subsubsection{Conceptual groundwater budget}

The average conceptual groundwater budget for the period $2000-2010$ is presented in Table 4.1. $\mathrm{RCH}, \mathrm{GWA}, \mathrm{GWD}$ are respectively groundwater recharge to the subsurface from rainfall, groundwater abstractions and groundwater discharge through the southern limits of the flow domain (See Figure 4.1). Estimates of the above different groundwater budget components are based on abstractions data from the national data base (BDI-DGEau), recharge calculation based on climatic data and groundwater modelling from previous studies (Kpegli et al., 2018b). The total groundwater input (from both rainfall and net rivers leakage is estimated to be in average $2 \times 10^{8} \mathrm{~m}^{3} /$ year while the total output (through groundwater abstractions/outflows (from wells, boreholes, artesian wells), springs and 
groundwater discharge out of the system (through the southern limits)) is about $1.46 \times 10^{8}$ $\mathrm{m}^{3} /$ year, representing about $73 \%$ of the total input. The difference is assumed to be stored in the subsoil leading to a net groundwater level increase. Figure 4.4 shows net storage for the years 2008-2010, which resulted in a groundwater level increase as confirmed by groundwater level observations (Figure 4.7). Groundwater level declines are found during periods when outputs are higher than inputs, e.g. 2005-2006.

Table 4.1 Conceptual groundwater budget for the study area (average values for the period 2000-2010)

\begin{tabular}{lcc}
\hline & $\mathrm{IN}\left(\mathrm{m}^{3} /\right.$ year) & OUT $\left(\mathrm{m}^{3} /\right.$ Year $)$ \\
\hline RCH & $1.88 \mathrm{E}+08$ & \\
River (drainage minus infiltration)* & $1.30 \mathrm{E}+07$ & \\
GWA** $^{* *}$ & & $1.53 \mathrm{E}+07$ \\
GWD* $^{*}$ & & $7.14 \mathrm{E}+07$ \\
Spring outflows & & $5.96 \mathrm{E}+07$ \\
\hline Total & $2.01 \mathrm{E}+08$ & $1.46 \mathrm{E} 8$ \\
Discrepancy = storage ? & & $5.49 \mathrm{E}+07$ \\
\hline$*$ : from Kpegli et al., 2018b & \\
$* *$ : data source: BDI-DGEau and SONEB &
\end{tabular}

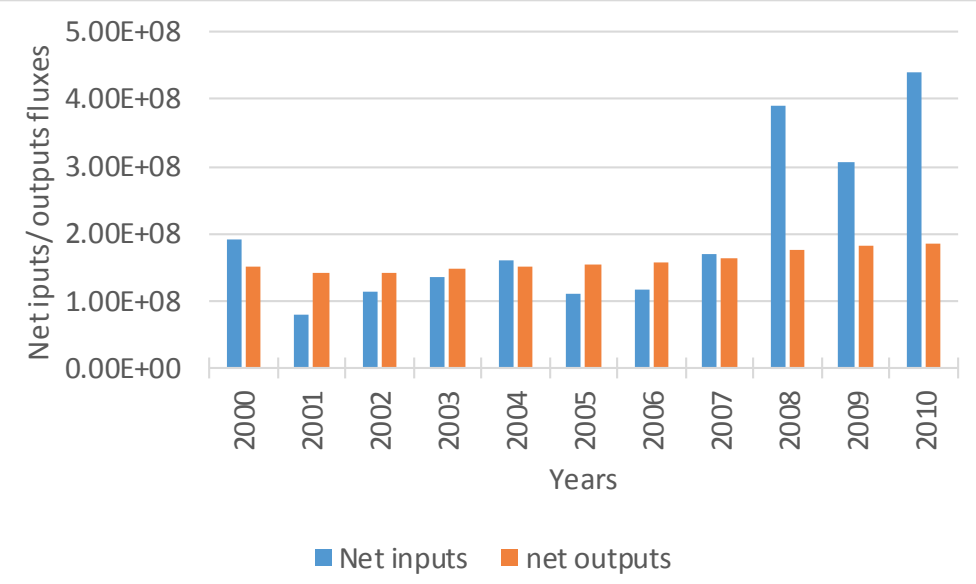

Figure 4.4 Net inputs and net outputs fluxes from the groundwater balance during the period 2000-2010 


\subsection{Methodology}

To investigate future artesian heads development and to understand the impact of uncertainty in recharge, hydraulic and storage properties of the subsurface layers on simulated artesian conditions, we applied the following three main steps: (1) estimation of future groundwater recharge and artesian outflows, (2) numerical model calibration and validation and (3) scenarios implementation.

\subsubsection{Estimation of future groundwater recharge and artesian outflows}

Groundwater recharge is the main driver for groundwater flow dynamics. Its future longterm estimation requires climate projection data. The average annual rainfall is $\sim 1100$ $\mathrm{mm} /$ year and $1050 \mathrm{~mm} /$ year for the period (1970-2015) at Bohicon and Kétou stations respectively (see Figure 4.1 for the location of the rainfall stations). Climate projection data (temperature, rainfall, wind speed, relative humidity, solar radiation) for the region and for the period 2016-2050 were from the CORDEX-Africa (Giorgi et al., 2009) of which details are provided by ESGF grid (http://esg-dn1.nsc.liu.se/esgf-web-fe/). Among the considered regional models (RACMO, CCLM and REMO, see Table 4.2 and M'Po (2016) for their description), RACMO appears to better reproduce the historical rainfall over West Africa including the study area (Diallo et al., 2012; M'Po et al., 2016) and will therefore be used in this study. RACMO8.5 suggests that annual rainfall amounts (for Bohicon station) would vary between $\sim 700$ and $\sim 1800 \mathrm{~mm} / \mathrm{y}$ (Figure 4.5a), with an average value of $1190 \mathrm{~mm} /$ year (for the period 2016-2050) which is higher and hence positive effect on heads due to this climate scenario is expected. RACM08.5 scenario assumes a general slight increase in the average yearly rainfall by 2050s, with periodic decreases (in average lower predicted rainfall for 2020-2030 compared to the year 2030s and 2040s). Apart from the most plausible RACMO scenario, the sensitivity of other possible climate scenarios such as REMO and CCLM to heads will be assessed. Precipitation projections data present significant bias (Piani et al., 2010; Wilcke et al., 2013), defined as long term average difference between models and observations. The bias was corrected using the Adjusted Quantile Mapping method ( $\mathrm{M}^{\prime} \mathrm{Po}$ et al., 2016). According to M'Po et al. (2016), the Adjusted Quantile Mapping method is the most effective method in correcting the bias in daily precipitations in the study area. After bias corrections, the projected rainfall data of RACMO8.5 were considered to estimate groundwater recharge applying a combination of the Penman (for potential evapotranspiration estimation) and the water balance method (see Kpegli et al., 2018b and Appendix A). The temperature is projected to slightly increase by 2050 (Jalloh et al., 2013) and therefore higher potential evapotranspiration is expected (Figure 4.5b). A more detailed explanation of the recharge calculation is provided in Appendix $A$, including short 
time series of the calculated potential evapotranspiration as well as the climatic data for illustrative purposes. Such explanation applies both for observed and projected climatic data regarding recharge estimation.

Table 4.2 List of Regional Climate Models used.

\begin{tabular}{|c|c|c|}
\hline Model Name & Institute & Driving Model \\
\hline CCLM4-8-17 & Climate Limited-area Modelling Community (CLM-Community) & MPI-M-MPI-ESM-LR \\
\hline REMO2009 & $\begin{array}{l}\text { Helmholtz-Zentrum Geesthacht, Climate Service Center, Max Planck } \\
\text { Institute for Meteorology }\end{array}$ & MPI-M-MPI-ESM-LR \\
\hline RACMO22T & Royal Netherlands Meteorological Institute, De Bilt, The Netherlands & ICHEC-EC-EARTH \\
\hline
\end{tabular}

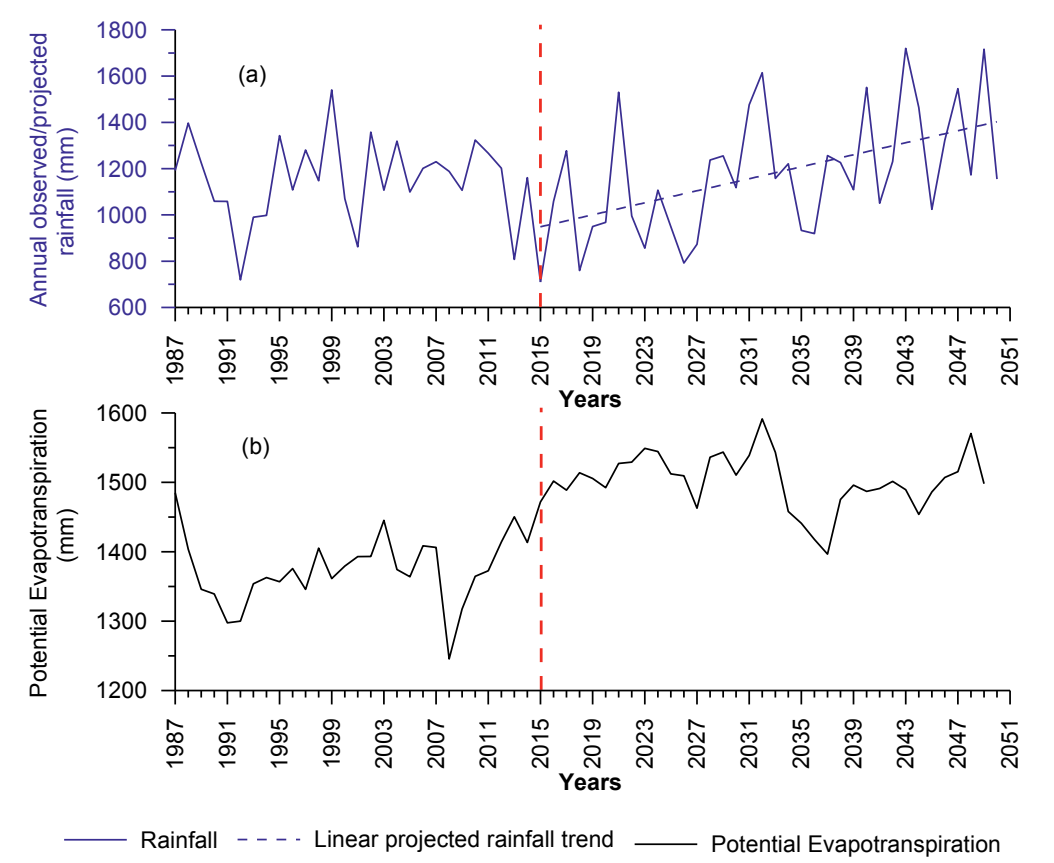

Figure 4.5 Annual observed (period 1987-2015) and projected-RACMO 8.5 (2016-2050) rainfalls (a) and potential evapotranspiration (b) at Bohicon station

The plausible estimated future groundwater recharge for RACMO8.5 is presented on Figure 4.6 showing that precipitation and recharge will be relatively low during some years (e.g.: 2020s). 

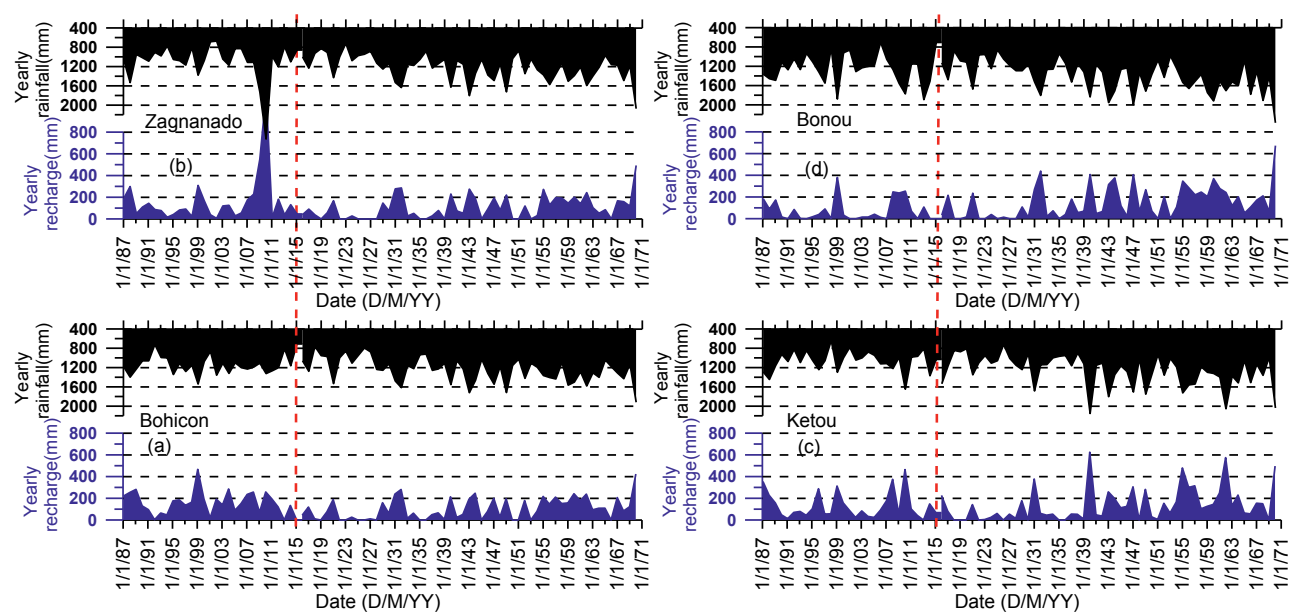

Figure 4.6 Projected groundwater recharge based on RACMO8.5 at (a) Bohicon, (b) Zagnanado, (c) Ketou, and (d) Bonou stations. See Figure 4.1 for the location of the stations. The vertical red dashed lines separate the period for which observed climatic data are used for recharge calculation and the period for which projected climatic data are used.

The estimated future artesian outflows (period 2015-2050) as explained in section 4.2.2 were implemented using the WELL package. In artesian outflows context, there is a feedback mechanism. Namely, the installation of an artesian well would locally cause lower heads resulting in lower artesian outflows per wells. By applying fixed outflow rates in the WELL-package, this feedback mechanism is not considered in the model. As implemented, doubling the artesian outflows implies doubling the number of artesian wells whereas in reality slightly more wells should be drilled to obtain the same doubling amount. Abstractions from individual and SONEB wells were not considered because they are negligible compared to the artesian wells outflows (Figure 4.3c) and difficult to monitor accurately. Because river leakage is not a dominant process in the study area and future river levels are not available, average rivers levels (period 2000-2010) were implemented for the period 2015-2050.

\subsubsection{Numerical model calibration and validation}

The conceptual groundwater flow model (Kpegli et al., 2018a) of the study area was translated into a numerical MODFLOW (McDonald and Harbaugh, 1988) model which was constructed by Kpegli et al. (2018b). The numerical model is a 3D-model with a total of five model layers. The bottom three layers represent the deep aquifer (the T.C. aquifer) which is covered in the southern part by a thick clay layer and outcropping in its northern region where it is recharged. The clay layer (see Figure 4.2 for its extension) with very low hydraulic conductivity is represented by one model layer. The alluvial aquifer forms partially the top- 
layer. Estimated groundwater recharge rates were implemented in the northern region where the T.C. aquifer outcrops and on top of the alluvial aquifer. Recharge is assumed to be zero for the outcropping clay areas due to the very low permeability of this clay layer and based on previous studies (Kpegli et al., 2018a). The subsurface layers properties (hydraulic and storage properties), obtained from previous studies (Bouzid, 1971; IGIP, 1984; BURGEAP-BRGM, 1994; Turkpak International-SCET-Tunisie, 1991) were implemented (see Table 4.3 for the properties values), the known groundwater abstractions (from wells) were applied and the model was calibrated (stationary and transient calibrations) by Kpegli et al. (2018b). For further details about the numerical model, the reader is referred to Kpegli et al. (2018b). The calibrated hydraulic and storage properties by Kpegli et al. (2018b) were validated with additional set of observed heads available for only three locations. This is a data-scarce related problem that is well known in hydrology (e.g.: Wu et al., 2011; de Kloe, 2014; Näschen et al., 2018). The model was calibrated for the period 2000-2011 (in previous studies by Kpegli et al., 2018b) and validated during this study for the period 2011-2015 (Figure 4.7) using the calibrated values of hydraulic and storage properties by Kpegli et al., 2018b (see Table 4.3). The computed heads for the period 20112015 remain in good agreement with the available three time series observations (Figure 4.7). In case insufficient long time series data is available for transient calibration and validation, an alternative is to consider sets of stationary data taken during a same time period to improve the calibration (Baalousha, 2012). So, in addition to the available three long time series, stationary head measurements for September 2015 were considered and were close to the corresponding computed heads ( 61 observations, with RMSE $=3.5 \mathrm{~m}$ ) see Appendix B). Hence, the model was considered calibrated and validated and was used to assess the evolution of the heads in the artesian sector of the study area by 2050 with respect to future population growth and climate change. Finally, the validated model served to analyze the impact of uncertainties of recharge, hydraulic and storage properties and climate models on the simulated heads in the artesian zone. As a rule of thumb, we consider a distance (to southern model boundary) according to the leakage factor $(\lambda)$ of about $4 \mathrm{Km}$ based on the previous work by Mazure (1932) and we focus more on results in areas far as about $3 \lambda$ (i.e., about $12 \mathrm{Km}$ ) from the southern limit to avoid boundary effects. 


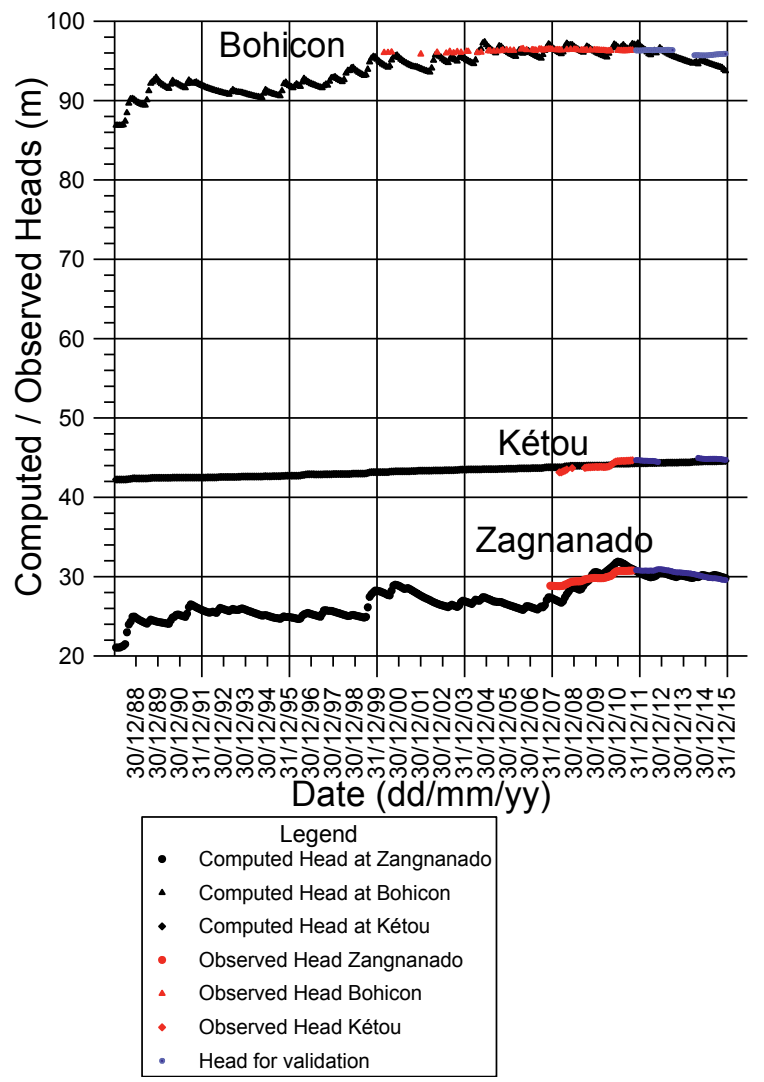

Figure 4.7 Computed and observed heads during calibration (2000-2011; Kpegli et al., 2018b) and validation (2011-2015) periods

\subsubsection{Scenarios implementation}

Three scenarios regarding artesian outflows were considered in this study for the period 2016 to 2050. The first scenario (the no-change abstraction scenario), is a baseline scenario that maintained the free-outflows constant at year 2015 rates. For the second scenario (the increase abstraction scenario), projected increase in artesian outflow rates is met to evolve linear with population growth, which is projected to be doubled by 2050 . New wells are implemented near existing ones. This is a worst-case scenario compared to a situation where the new artesian wells are spread across the artesian zone because grouping of wells will result in larger cone of depressions. The third scenario (the zero-scenario) considers the impact of capping all the artesian wells by 2025, with the period 2015 to 2025 set as the nochange abstraction scenario. For all the above three outflow scenarios, RACMO8.5 previously described in section 4.3.1 is implemented. 
The impact of uncertainties in recharge, hydraulic and storage properties and climate change models on the artesian conditions are studied by means of sensitivity analysis. Previous studies (e.g. Gomez-Hernandez and Gorelick, 1989; Song et al., 2011) indicated that, confidence intervals in hydraulic and storage properties likely range from one-third to three times the base values, as these properties are often log-normally distributed, and this was applied for each layer. In this research, we focus on the properties of the confined part of the Turonian-Coniacian aquifer and the properties of its adjacent clay layer because this confined part of the aquifer and the clay layer are directly linked to the artesian zone. Finally, the effect of the outflow and climate scenarios is assessed.

Table 4.3 Hydraulic and storage base values of aquifers and the clay layer (form Kpegli et al., 2018b)

\begin{tabular}{|c|c|c|c|}
\hline Geologic Material & Hydraulic conductivity (m/day) & Thickness (m) & Storage coefficients \\
\hline & 10 & 10 to 50 & Sy $=0.2$ \\
\hline Clay layer & 0.007 & 19 to 201 & Ss $=S y=0.02$ \\
\hline \multirow{2}{*}{ Turonian-Coniacian aquifer } & $6 *$ & \multirow{2}{*}{10 to 214} & Ss $=10^{-3 *}$ \\
\hline & 2 to $40^{* *}$ & & Sy $=0.2^{* *}$ \\
\hline
\end{tabular}

* Confined part of the T.C aquifer

${ }^{* *}$ Unconfined part of the T.C aquifer

\subsection{Results and discussion}

\subsubsection{Assessment of the causes of the artesian head drops}

The position of the artesian zone with the average heads above the land surface is shown on Figure 4.8a and has an average surface area (spatial extension) of about $900 \mathrm{Km}^{2}$ which varies with time by about $60 \mathrm{Km}^{2}$ (mainly in the northern regions). This illustrates that some areas that are artesian can change to non-artesian temporarily and the spatial extension of this area is approximately $60 \mathrm{~km}^{2}$ (indicated by the grey-colored area in Figure $4.8 \mathrm{~b}$ ). The maximum deviations between the average and the maximum heads in the artesian zone (Figure 4.8b) are low ( 0 to $2 \mathrm{~m}$ ); values close to zero and higher values (about $2 \mathrm{~m}$ ) are found respectively in the southern artesian zone and in the northern artesian zone (Figure 4.8b). This suggests that the area that can shift from artesian to non-artesian is also the area with higher heads deviation as reference to average head values. 


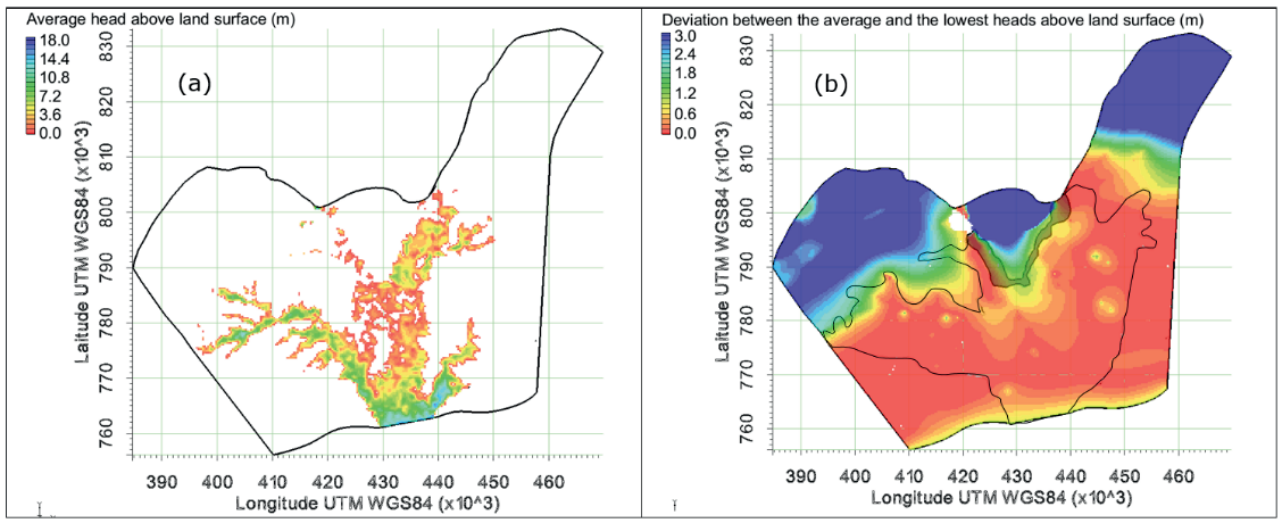

Figure 4.8: Average heads above land surface (a), deviation between the average and the lowest heads including the approximate limit (black contour lines) of the maximum artesian zone (b)

Model results illustrate that only in some parts of the artesian zone heads fluctuate seasonally (e.g. P69 and P70 : Figure 4.9b). Close to the artesian zone border (within 4 km), heads seasonally fall below the land surface due to the influence of recharge (Figure 4.9 a and b). Proliferation of artesian wells with its associated transient artesian outflows did not significantly affect the heads until 2005 , explained by the relatively low artesian outflows until 2005 with less than twenty artesian wells ( $25 \times 10^{3} \mathrm{~m}^{3} / \mathrm{d}$, see Figure $\left.4.3 \mathrm{c}\right)$. However, increase of artesian wells after 2006 to $\sim 40 \times 10^{3} \mathrm{~m}^{3} / \mathrm{d}$ caused locally noticeable drawdowns at some places (e.g.: P94 in Figure 4.9). As shown on Figure 4.10, head amplitudes generally decrease with distance from the northern artesian zone border toward the south where these amplitudes become nearly zero. For a coastal aquifer system, it has been demonstrated (White and Roberts, 1994; Liu et al., 2016) that attenuation of the tidal response with distance occur both in confined and unconfined coastal aquifers, but is more profound in unconfined aquifers (White and Roberts, 1994; Liu et al., 2016). This is due to much larger storage capacity of unconfined aquifers which is usually several orders of magnitude larger than for confined aquifers (Erskine, 1991). Besides the storativity of an aquifer or multi-aquifer system, the aquifer outflow/inflow (through the confining layer) is another factor determining the attenuation of head fluctuations. In a leaky aquifer, groundwater may leak toward the surface (or from the top system) dampening the propagation of head changes controlled by both the hydraulic transmissivity and storativity of the aquifer. These hydraulic and storage properties, together with the leakance of the semi-confining layer cause head fluctuations to attenuate and damp with distance (Jiao and Tang, 1999). This implies that the downstream areas of the artesian zone would not display high head-fluctuations (and it will be much more stable or reliable in terms of artesian heads) compared to the other areas that are near the recharge areas. 


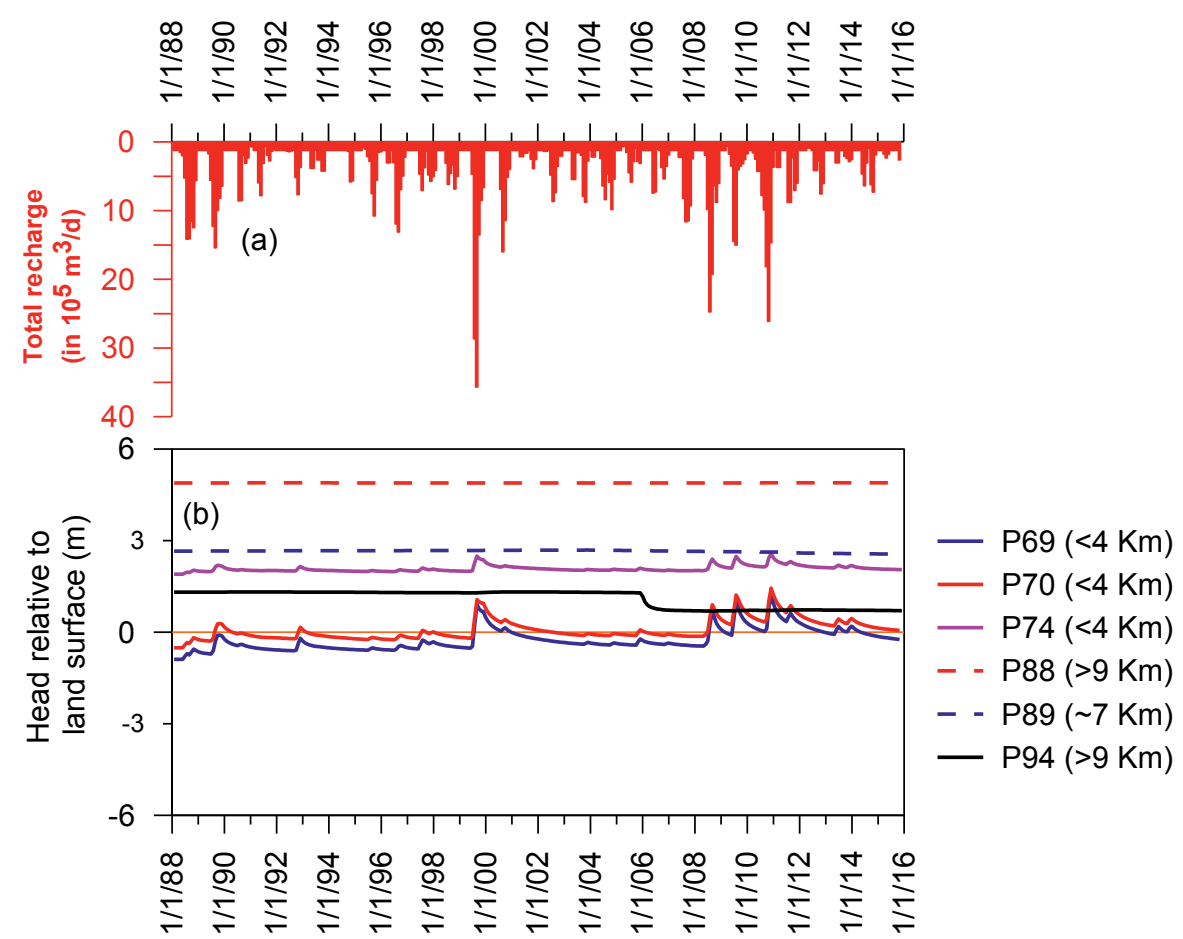

Figure 4.9 Evolution of the simulated heads relative to surface level compared to recharge and artesian outflows (as shown on Figure 4.3). The distance of the head calculation points to the artesian zone border is included in the legend; the location of the head calculation point is shown in Figure 4.11

The artesian zone where the head amplitudes exceed $0.5 \mathrm{~m}$ is vulnerable to head fluctuations in the sense of changing from artesian to non-artesian. This zone is located around the upstream border of the artesian zone (which is the Northern border of the artesian zone in this study area). The message is that areas with higher head amplitudes are located around the northern border of the artesian zone, although the value of $0.5 \mathrm{~m}$ is indeed arbitrary. The region close to the northern artesian zone border with head fluctuations greater than $0.5 \mathrm{~m}$ is referred to as peripheral artesian region in this study. The other region characterized by relatively low head amplitudes $(<0.5 \mathrm{~m})$ is a more stable artesian zone and is located toward the south and is referred to as the center of the artesian zone (Figure 4.10). We remarked (see Figure 4.11) that the artesian wells for which headdrops were noted on the field ( $<1 \mathrm{~m}$ according to the local population and the BDI-DGEau) were installed recently (after the year 2005) and fall in the periphery of the artesian zone. But in the central artesian region, the artesian wells have not displayed a noticeable headdrop (BDI-DGEau). 
Artesian head amplitude in meter (Maximum head-Minimum head)

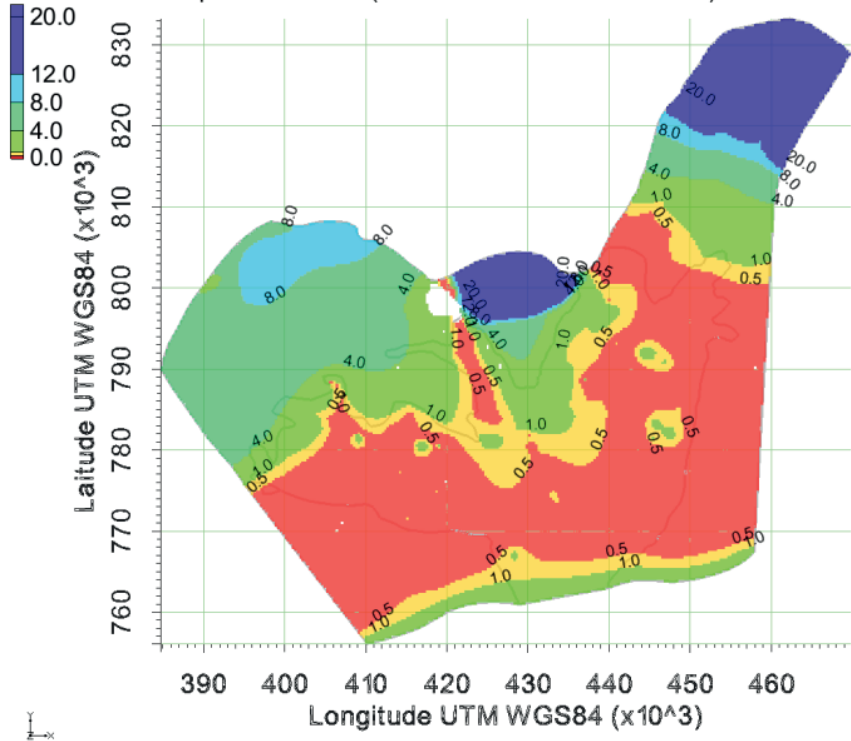

Figure 4.10: Map of artesian heads amplitude across the flow domain including the approximate contour of the artesian zone (black line)

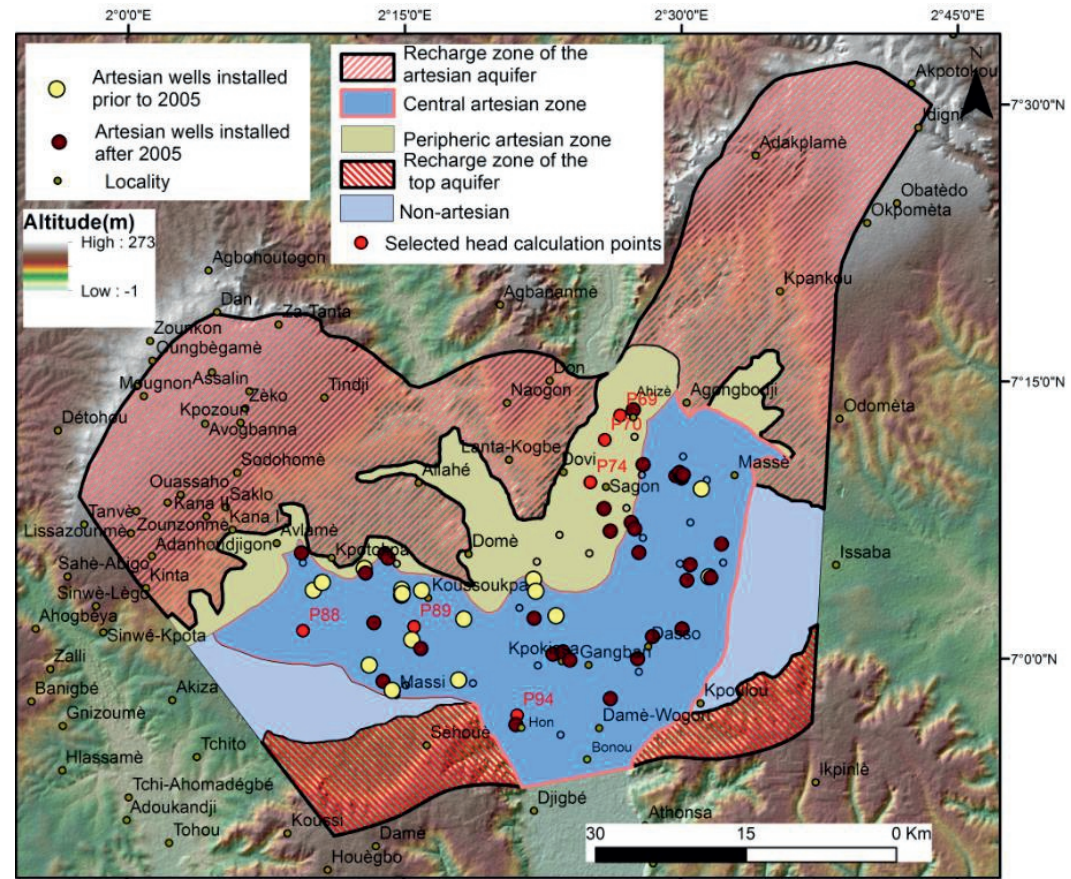

Figure 4.11.: Map showing the periphery and central artesian zones with the spatial proliferation of artesian wells (installed prior and after 2005) in the artesian zone; the periphery and central artesian zones are where the heads amplitudes are respectively large $(>0.5 \mathrm{~m})$ and small $(<0.5 \mathrm{~m})$. Red dots represent selected head calculation points. 


\subsubsection{Outflow scenarios analysis}

\section{Increase and Zero-outflow scenarios}

The effects of the different outflow scenarios for the future (as described in section 4.3.3) are compared with the reference case which is 'artesian outflows remains constant' and are summarized in Figure 4.12. The effects of capping the artesian wells (Figure 4.12a) is much more remarkable compared to the increase of artesian outflows (Figure 4.12b). The increase of artesian wells is progressive (following the expected population growth) while the capping of all artesian wells is a sudden action that will first lead to a relatively abrupt head-gain (e.g.: see P94 on Figure 4.13b) in the near vicinities of the artesian wells. This explains why the effect of capping all the artesian wells is much more remarkable compared to the effect of increasing them. Also, the amount of outflow is important as in this case, capping all wells by 2025 implies that the total outflows moved suddenly from $\sim 68 \times 10 \mathrm{~m}^{3}$ to zero (Figure 4-3) but increasing of artesian wells as implemented leads to a total outflow increase of $\sim 24 \times 10 \mathrm{~m}^{3}$ after 15 years. Obviously, this higher change in outflows amounts due to the capping of all artesian wells also leads to a higher effect. Spatially, heads increase of up to approximately $3.5 \mathrm{~m}$ might occur for the case of capping the artesian wells (Figure 4.12a). The heads changes are higher around the artesian wells in the central artesian zone than near the periphery of the artesian zone due to the higher concentration of artesian wells and the heads changes are close to zero in the recharge zone. For the case of the increase scenario (Figure 4.12b), heads-drops of up to $1.5 \mathrm{~m}$ might occur in the vicinity of the artesian wells in the central artesian zone. The effect due to the increase scenario is two to three times lower than the effect due to capping because the amounts involved in the capping $\left(\sim 68 \times 10 \mathrm{~m}^{3}\right)$ are two to three times higher than the ones involved in increase scenario $\left(\sim 24 \times 10 \mathrm{~m}^{3}\right)$. As such, the changes of the extent of the artesian zone (expansion or shrinking) due to the implemented outflow scenarios is insignificant $\left(<20 \mathrm{~km}^{2}\right)$.

In detail, in case the current artesian outflows double by 2050 (i.e., the "increase scenario"), results show that heads differences may reach few centimeters (about $10 \mathrm{~cm}$ by 2050) in the periphery as shown on Figure 4.13a (P69, P70 and P74, see Figure 4.11 for the location of the head calculation points). As given the fact that heads at the periphery are only slightly above surface level, the periphery is very vulnerable for small head changes, "vulnerable" in the sense that artesian conditions disappear. But higher head variations are needed further downstream (in the central artesian zone) before heads can move below the land surface. Under the same increase scenario, the associated heads differences appear greater at the center (about $70 \mathrm{~cm}$, see Figure 4.13a, namely P94 and P89) and could be explained by the proximity of artesian wells. As the outflows involved in the capping scenario are higher compared to the amounts involved in the increase scenario, the effect is much more 
important for the capping, especially in the central zone having much more artesian wells (e.g.: P94 and P89 on Figure 4.13b).

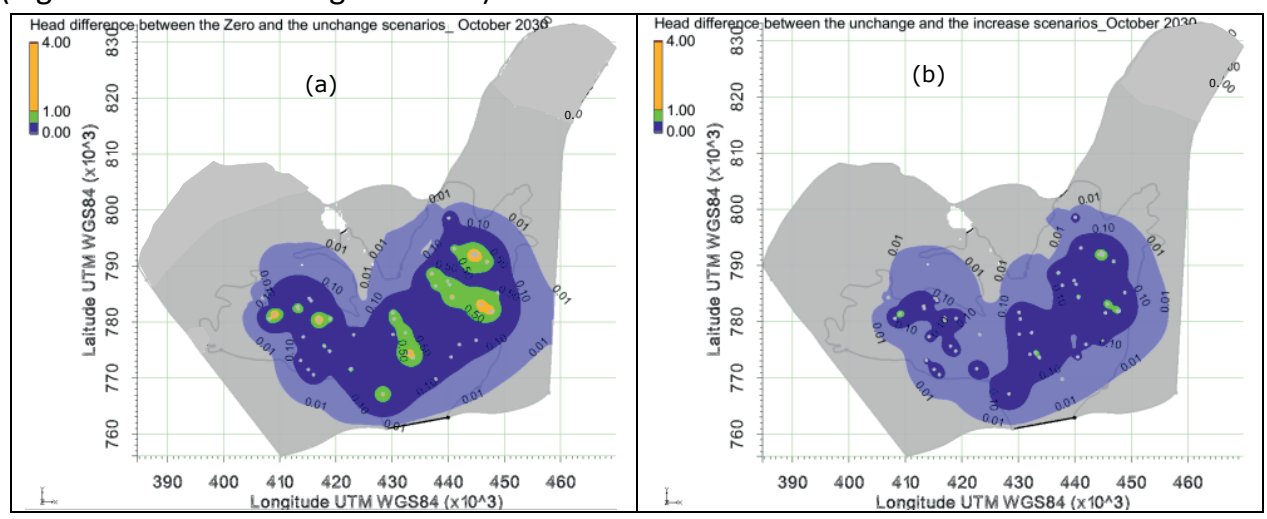

Figure 4.12: Map showing the effect (in meter) of outflow scenarios on hydraulic heads (after 15 years) for (a) zero-scenario 'capping all wells' (b) increase scenario 'increase of artesian outflows. Grey dots represent artesian wells and grey line indicates the approximate contour of the artesian zone.
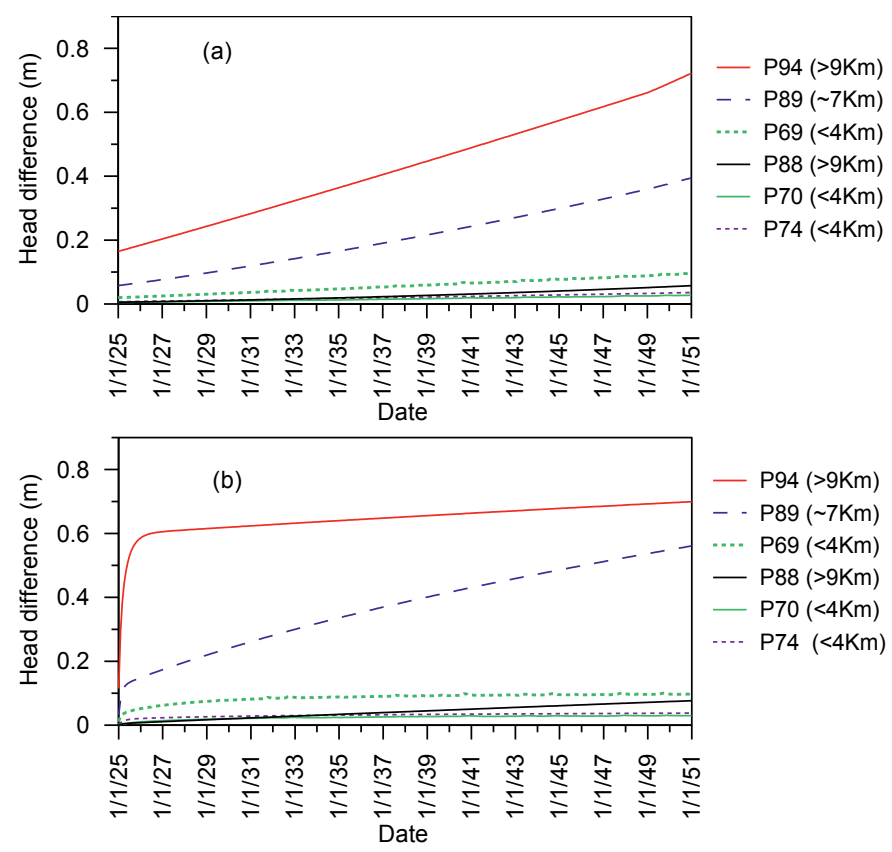

Figure 4.13 Effects on heads due to different outflow scenarios ; (a) the effect of doubling the artesian wells compared to current situation (increase of wells); (b) the effect of capping all artesian wells compared to current situation. See Figure 4.11 for the location of the head calculation points, the distance of the head calculation point to the boundary of artesian zone is included in the legend in bracket. 


\section{No-change outflow scenario}

It is noted that under the current artesian outflows, the heads relative to land surface (artesian heads) would drop (Figure 4.14) in future (by $1 \mathrm{~m}$ below land surface) in the peripheral artesian zone including localities of Ahizè and Massè (see Figure 4.11) between 2020s and 2030s (see P69 and P70 for the periods of 2020s and 2030s on Figure 4.14). This is due to the relatively low projected recharge in 2020s and 2030s compared to the years after (Figure 4.6). However, during 2040s, heads recovery in those areas is expected, due to higher predicted recharge during 2040s (Figure 4.6), suggesting that changes in recharge have much more impact than current artesian outflows, if current outflows are maintained in the future. Furthermore, the impact of recharge is more important in the periphery than in the center and the impact of the outflow scenarios is more important in the center where most of the artesian wells are. Toward the center of the artesian zone (which includes the localities of Kpokissa, Hon, Bonou, Dasso (see Figure 4.11 for the location of the localities)), artesian heads are relatively stable (see P88, P89, P94 on Figure 4.14). This result is well supported by the artesian wells installed in this area since 1987 (locality called Hon and nearby, see Figure 4.11) which did not show changes in heads and flow rates, as observed by the local population.

When it comes to the functioning of an artesian zone, it can be understood from the above results that the peripheries of artesian zones that are near the recharge areas are more sensitive to head fluctuations as opposed to the heart of the artesian zones that would be less vulnerable to seasonal head fluctuations, thus more stable in terms of heads in artesian wells.

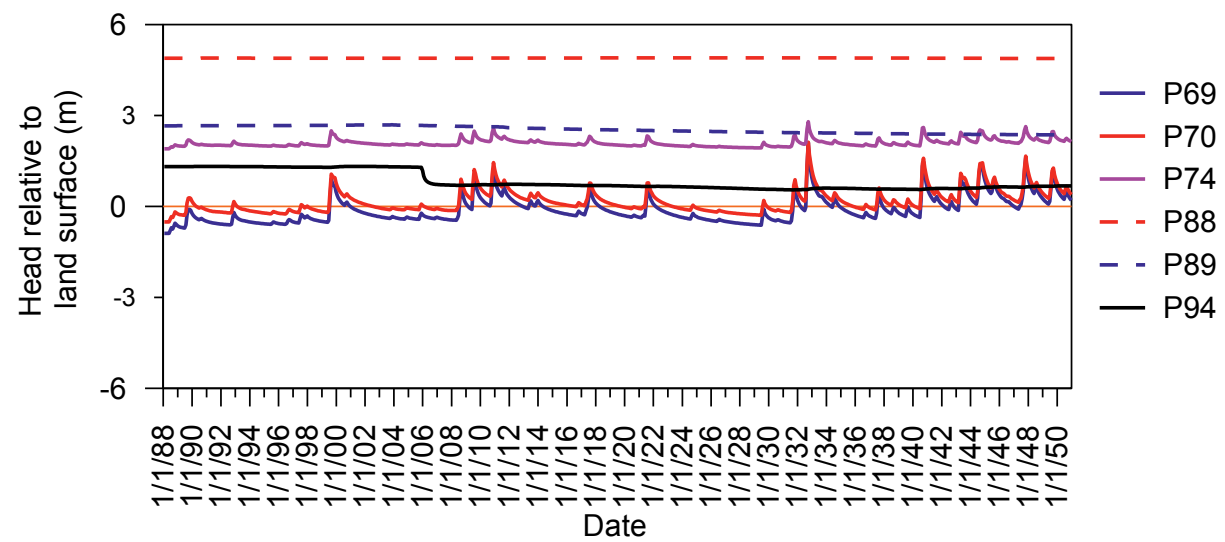

Figure 4.14 Head relative to land surface (for the "no-change outflow scenario") at selected points of the artesian zone, the location of the selected head calculation points is shown on Figure 4.11 


\subsubsection{Sensitivity of the heads in the artesian zone to hydraulic and storage properties and to recharge}

\subsubsection{Sensitivity to hydraulic and storage properties}

The heads across the artesian zone appear to have low sensitivity to the specific storage of the confined part of the T.C. aquifer, with effects on heads (Table 4.4) smaller than $1 \mathrm{~cm}$. Compared to the specific storage of the confined part of the T.C. aquifer, uncertainties in the storage properties of the confining clay layer have greater impact on the computed heads in the artesian zone (Table 4.4). This is due to the larger specific storage coefficient for a clay (i.e., $2 \times 10^{-3}$ to $2 \times 10^{-2}$ (Batu (1998)) compared to the specific storage coefficient of a confined aquifer (i.e., $10^{-4}$ to $10^{-2}$ (Todd, 1980)). The impact is even greater when it comes to uncertainties in the hydraulic conductivities of the confined T.C. aquifer and of the clay layer. Average heads differences of $\sim 4 \mathrm{~m}$ and $\sim 2 \mathrm{~m}$ occurred respectively when the base conductivities of the confined T.C. aquifer and the confining clay layer are multiplied by 3 (Table 4.4); the base conductivities being respectively $6 \mathrm{~m} /$ day and $7 \times 10^{-3} \mathrm{~m} /$ day for the confined T.C. aquifer and the confining clay layer. These effects on heads are largest in the center compared to the periphery while the effects on amplitudes are largest for the periphery. This is because this part of the aquifer is confined and that recharge occurs far away.

Also, the head fluctuations are attenuated and are damped with distance due to the influence of hydraulic transmissivity of the aquifer, its storativity and leakance of the semiconfining layer (see section 4.4.1). Overall, the sensitivity for heads amplitudes and the sensitivity for head are low for storage coefficient of the confined part of the T.C. aquifer (Table 4.4) and higher for the hydraulic conductivity of the confining clay layer and the hydraulic conductivity of the confined part of the T.C. aquifer. This implies that when modelling artesian systems similar to the one in southern Benin, the hydraulic conductivity of the artesian aquifer is the first key factor to investigate critically for reliable head simulation in the artesian zone. The second key factor is the hydraulic conductivity of the confining clay layer. The storage properties of both the artesian aquifer and the confining clay layer are of less importance compared to the $\mathrm{K}$ of the confined aquifer and the $\mathrm{K}$ of its confining layer. As both $\mathrm{K}$ and $\mathrm{Ss}$ influence the damping of heads amplitudes, it can be stated that this damping is sensitive to the hydraulic diffusivity (K/Ss) of the confined aquifer. 
Table 4.4 Sensitivity of hydraulic conductivity and storage coefficients to average heads and head amplitudes differences (in meter) in the center and periphery of the artesian zone

\begin{tabular}{|c|c|c|c|c|}
\hline & \multicolumn{2}{|c|}{ Current period (2015-2020) } & \multicolumn{2}{|c|}{ Current period (2015-2020) } \\
\hline & $\begin{array}{c}\text { Average head } \\
\text { difference in the } \\
\text { center }\end{array}$ & $\begin{array}{c}\text { Average head } \\
\text { difference at } \\
\text { periphery }\end{array}$ & $\begin{array}{c}\text { Head amplitude } \\
\text { difference in the } \\
\text { center }\end{array}$ & $\begin{array}{c}\text { Head amplitude } \\
\text { difference at } \\
\text { periphery }\end{array}$ \\
\hline & \multicolumn{4}{|c|}{ Hydraulic conductivity of the confined part of the T.C. aquifer } \\
\hline A (1/3)-Base & -4.36 & 0.37 & -0.04 & -0.09 \\
\hline B (2/3)-Base & -1.65 & 0.22 & -0.02 & -0.05 \\
\hline D (4/3)-Base & 1.13 & 0.05 & 0.02 & -0.04 \\
\hline$E(6 / 3)$-Base & 2.61 & -0.04 & 0.05 & -0.05 \\
\hline \multirow[t]{2}{*}{ F (3)-Base } & 3.89 & -0.11 & 0.09 & -0.08 \\
\hline & \multicolumn{4}{|c|}{ Hydraulic conductivity of the confining clay layer } \\
\hline A (1/3)-Base & - & - & - & - \\
\hline B (2/3)-Base & 0.96 & -0.07 & 0.02 & -0.09 \\
\hline D (4/3)-Base & -0.66 & 0.03 & -0.01 & -0.15 \\
\hline E (6/3)-Base & -1.58 & 0.07 & -0.02 & -0.18 \\
\hline \multirow[t]{2}{*}{ F (3)-Base } & -2.44 & 0.11 & -0.02 & -0.22 \\
\hline & \multicolumn{4}{|c|}{ Specific storage coefficient of the confined part of the T.C. aquifer } \\
\hline A (1/3)-Base & 0.00 & -0.01 & 0.00 & 0.10 \\
\hline B (2/3)-Base & 0.00 & 0.00 & 0.00 & 0.08 \\
\hline D (4/3)-Base & 0.00 & 0.00 & 0.00 & 0.06 \\
\hline$E(6 / 3)$-Base & 0.00 & 0.00 & 0.00 & 0.04 \\
\hline \multirow[t]{2}{*}{ F (3)-Base } & 0.01 & 0.00 & 0.00 & 0.01 \\
\hline & \multicolumn{4}{|c|}{ Specific storage coefficient of the confining clay layer } \\
\hline A (1/3)-Base & 0.38 & -0.12 & 0.04 & -0.09 \\
\hline B (2/3)-Base & 0.11 & -0.04 & 0.01 & -0.16 \\
\hline D (4/3)-Base & -0.06 & 0.08 & 0.00 & -0.28 \\
\hline$E(6 / 3)$-Base & -0.12 & 0.14 & 0.00 & -0.37 \\
\hline F (3)-Base & -0.17 & 0.17 & 0.00 & -0.48 \\
\hline
\end{tabular}

\subsubsection{Sensitivity to recharge}

In practice, it is difficult to estimate groundwater recharge accurately (Scanlon et al., 2006; Kikuchi and Ferré, 2014). Previous studies (e.g.: Lanini and Caballero, 2016) indicated that uncertainties in groundwater recharge estimation may reach $42 \%$. Therefore, we explored the effect of varying the recharge between $-40 \%$ and $+40 \%$ (from the base-recharge values) to heads across the artesian zone.

It appears that when the recharge is increased average heads rise up to two times higher at the periphery of the artesian (compared to the center (Table 4.5). Basically, this response is linear at both locations. This is also true for head amplitude difference (Table 4.5). This implies that the recharge uncertainties would have greater impacts on the simulated heads in the peripheral artesian zone and would have relatively limited influence on the computed heads in the central artesian domain. 
Table 4.5 Sensitivity of average heads and heads amplitudes differences (in meter) to recharge

\begin{tabular}{|c|c|c|}
\hline & \multicolumn{2}{|c|}{ Current period (2015-2020) } \\
\hline & \multicolumn{2}{|c|}{ Average Head differences (m) } \\
\hline & $\begin{array}{l}\text { Average Head difference } \\
\text { in the center }(\mathrm{m})\end{array}$ & $\begin{array}{c}\text { Average Head difference at } \\
\text { the periphery }(\mathrm{m})\end{array}$ \\
\hline$+10 \% \mathrm{RCH}$ & 0.03 & 0.07 \\
\hline$+20 \% \mathrm{RCH}$ & 0.06 & 0.14 \\
\hline$+30 \% \mathrm{RCH}$ & 0.10 & 0.21 \\
\hline$+40 \% \mathrm{RCH}$ & 0.13 & 0.28 \\
\hline$-10 \% \mathrm{RCH}$ & -0.03 & -0.07 \\
\hline$-20 \% \mathrm{RCH}$ & -0.06 & -0.15 \\
\hline$-30 \% \mathrm{RCH}$ & -0.10 & -0.22 \\
\hline \multirow[t]{3}{*}{$-40 \% \mathrm{RCH}$} & -0.13 & -0.30 \\
\hline & \multicolumn{2}{|c|}{ Head amplitude differences (m) } \\
\hline & $\begin{array}{l}\text { Head amplitude } \\
\text { difference in the center } \\
\qquad(\mathrm{m})\end{array}$ & $\begin{array}{l}\text { Head amplitude difference } \\
\text { at the periphery }(\mathrm{m})\end{array}$ \\
\hline$+10 \% \mathrm{RCH}$ & 0.00 & 0.10 \\
\hline$+20 \% \mathrm{RCH}$ & 0.01 & 0.19 \\
\hline$+30 \% \mathrm{RCH}$ & 0.01 & 0.29 \\
\hline$+40 \% \mathrm{RCH}$ & 0.01 & 0.38 \\
\hline$-10 \% \mathrm{RCH}$ & 0.00 & -0.09 \\
\hline$-20 \% \mathrm{RCH}$ & -0.01 & -0.19 \\
\hline$-30 \% \mathrm{RCH}$ & -0.01 & -0.28 \\
\hline$-40 \% \mathrm{RCH}$ & -0.01 & -0.37 \\
\hline
\end{tabular}

\subsubsection{Effect of other possible climate scenarios on simulated heads}

Table 4.6 summarizes the effect of the three climate scenarios (recharge estimates) on the heads, in which the most plausible climate model RACMO is compared to three other climate scenarios which are described in section 4.3.1. The head differences obtained due to these climate scenarios are higher at upstream locations (i.e., at the periphery, e.g. P69) than in downstream locations (e.g.: P94, see Table 4.6), which is explained by its closer position to the recharge areas. It appears that differences in heads due to the different climate scenarios (Table 4.6) are smaller compared to heads differences due to hydraulic conductivities of both the aquifer and its confining layer as shown in sections 4.4.3.1 and 4.4.3.2. This implies that it is much more important to work on minimizing uncertainties linked to hydraulic parameters or to uncertainties linked to the estimated recharge from a chosen climate scenario than to identify the climate scenario that reproduces the best possible rainfall pattern of a modelled flow domain. Storage of both the aquifer and its confining layers is not so sensitive as shown in section 4.4.3.2. 
Table 4.6 Sensitivity of average heads and heads amplitudes differences (in meter) to three different climate scenarios compared to the most plausible scenario RACMO.

\begin{tabular}{|l|c|c|c|c|}
\cline { 2 - 5 } \multicolumn{1}{c|}{} & $\begin{array}{c}\text { Average head } \\
\text { difference in } \\
\text { the center }\end{array}$ & $\begin{array}{c}\text { Average head } \\
\text { difference at } \\
\text { periphery }\end{array}$ & $\begin{array}{c}\text { Head } \\
\text { amplitude } \\
\text { difference in } \\
\text { the center }\end{array}$ & $\begin{array}{c}\text { Head } \\
\text { amplitude } \\
\text { difference at } \\
\text { periphery }\end{array}$ \\
\hline RACMO-CCLM & 0.38 & 0.81 & 0.54 & 5.22 \\
\hline RACMO-REMO & 0.37 & 1.05 & 55 & 3.99 \\
\hline REMO-CCLM & 0.01 & 0.23 & 0.35 & 6.04 \\
\hline
\end{tabular}

\subsection{Conclusion}

Artesian heads are important for local populations as pumping is not required for them to get access to such a groundwater. The aims of this study were to investigate the future artesian head evolution in the Turonian-Coniacian (T.C.) aquifer of southern Benin under different artesian outflow and climate scenarios, and to assess which areas of the artesian zone would be vulnerable to head fluctuations. Additionally, the impacts of uncertainties in hydraulic and storage properties of the subsurface layers on hydraulic heads were assessed by means of a sensitivity analysis. A 3D numerical groundwater flow model was developed and served for the scenario and sensitivity analysis. The study revealed that artesian basins are structured into peripheral and central zones, which react differently to stresses. Heads would tend to be more stable at the central artesian zones as opposed to the periphery that is more subjected to seasonal head fluctuations because recharge-related head fluctuations are only generated from far away, i.e., in the recharge area which is closer to the peripheral artesian zone. But due to leakage into/out of the confining layer, head amplitudes will damp with distance toward the central artesian zone. Thus, artesian wells for which head-drops were noticed on the field appear to be in the peripheral artesian zone.

We found that under the current artesian outflows and the predicted recharge (estimated based on the most plausible climate model, i.e., RACMO), artesian heads would seasonally drop by up to $1 \mathrm{~m}$ below land surface from present days until 2030 at the peripheral artesian zone which corresponds in the study area to localities including Ahizè and Massè. However, heads-recovery will occur during 2030 to 2050 for which the estimated recharge is higher. Results indicated that if the current artesian outflows double by 2050 due to the expected increase of water demand by population growth, this might cause heads to reduce by only few centimeters both in the central and at the periphery of the artesian zone. This shows that the effect of climate change is much more important than the increase of water demand. Furthermore, the impact of recharge is more important in the periphery than in the center and the impact of the outflow scenarios is more important in the center where 
most of the artesian wells are. Capping all the artesian wells by 2025 would only slightly recover artesian heads.

The results of the sensitivity analysis show that hydraulic conductivities of the confined T.C. aquifer has the greatest impact on the computed heads across the artesian zone followed by the hydraulic conductivity of the confining clay layer, the specific storage of the confining clay layer and the specific storage of the confined T.C. aquifer. The effects on heads are largest in the center compared to the periphery while the effects on amplitudes are largest for the periphery because this part of the aquifer is confined and that recharge occurs far away.

For the study area, it is feasible that the local population and NGOs rely on the artesian wells located in the central artesian zone for various water usages. Under the most plausible future climate scenario, there is likely no risk of substantial artesian head-drop in the central artesian zone if the current artesian wells are maintained (with no installation of new artesian wells), at least by 2050 as demonstrated in this paper.

\subsection{Appendixes}

\section{Appendix A: Explanation of recharge calculation}

Weather data (Sun radiation (SR), Wind speed (WS), temperature (T), relative humidity (H) and rainfall) were collected for the study area. For illustrative purposes, a short time series of daily weather data as well as calculated evapotranspiration and recharge are presented in the table below.

SR, WS, T and $\mathrm{H}$ served for the potential evapotranspiration (PET) calculation based on the Penman method (Penman, 1949; Penman, 1950) recommended by the FAO. For details regarding the PET calculation, the reader is referred to Allen et al. (1989). The potential evapotranspiration and the soil water content at field capacity were subtracted from the effective rainfall (Eff. Rain; i.e., rainfall minus runoff) to obtain recharge $(\mathrm{RCH})$. Data of the soil water content at field capacity and runoff were taken respectively from Azontonde (1991) and Schuol et al. (2008). For the recharge area around Bohicon, soil water content at field capacity and runoff are respectively $70 \mathrm{~mm}$ and $\sim 15 \%$ of rainfall. The recharge for the other years and for the recharges areas were calculated the same way, taking into account the soil water content, runoff and rainfall of each recharge area. 
Table showing raw climatic data, calculated PET and recharge around Bohicon

\begin{tabular}{|c|c|c|c|c|c|c|c|c|c|}
\hline Date & $\mathrm{T}$ (Degree) & Humidity (\%) & WS $(\mathrm{m} / \mathrm{s})$ & SR (hour) & PET (mm) & $\mathrm{ETR}(\mathrm{mm})$ & Stock $(\mathrm{mm})$ & Rain (mm) & $\mathrm{RCH}(\mathrm{mm})$ \\
\hline 01/Aug/87 & 27.7 & 78 & 0.3 & 7 & 4.2 & 4.2 & 1.465 & 0 & 0 \\
\hline 02/Aug/87 & 27.85 & 78 & 2.1 & 5.6 & 4.3 & 4.3 & 19.945 & 26.8 & 0 \\
\hline 03/Aug/87 & 26.35 & 84.5 & 1.3 & 2.4 & 3 & 3 & 20.94 & 4.7 & 0 \\
\hline 04/Aug/87 & 25.85 & 87 & 1.4 & 0.9 & 2.6 & 2.6 & 21.4 & 3.6 & 0 \\
\hline 05/Aug/87 & 26.95 & 78.5 & 1.4 & 9.3 & 4.9 & 4.9 & 16.5 & 0 & 0 \\
\hline 06/Aug/87 & 27.4 & 82.5 & 1.9 & 10 & 5.1 & 5.1 & 12.59 & 1.4 & 0 \\
\hline 07/Aug/87 & 27.25 & 82 & 2.3 & 5 & 3.9 & 3.9 & 10.9 & 2.6 & 0 \\
\hline 08/Aug/87 & 26.9 & 78.5 & 2.9 & 6.8 & 4.5 & 4.5 & 34.96 & 33.6 & 0 \\
\hline 09/Aug/87 & 26.2 & 81.5 & 0.7 & 4.7 & 3.5 & 3.5 & 31.46 & 0 & 0 \\
\hline 10/Aug/87 & 25.65 & 82 & 2.1 & 2.2 & 3.1 & 3.1 & 70 & 55.9 & 5.875 \\
\hline 11/Aug/87 & 25.55 & 86 & 1.4 & 1.1 & 2.6 & 2.6 & 70 & 7.9 & 4.115 \\
\hline 12/Aug/87 & 26.6 & 82.5 & 1.3 & 4.2 & 3.5 & 3.5 & 66.925 & 0.5 & 0 \\
\hline 13/Aug/87 & 25.7 & 83.5 & 1.7 & 2.9 & 3.1 & 3.1 & 70 & 19.9 & 10.74 \\
\hline 14/Aug/87 & 26.25 & 84 & 1.3 & 6.1 & 3.9 & 3.9 & 69.245 & 3.7 & 0 \\
\hline 15/Aug/87 & 25.6 & 88 & 1.9 & 1.5 & 2.7 & 2.7 & 70 & 7.9 & 3.26 \\
\hline 16/Aug/87 & 27 & 82.5 & 1.4 & 6.6 & 4.1 & 4.1 & 70 & 36.4 & 26.84 \\
\hline 17/Aug/87 & 25.45 & 88 & 1.1 & 1.7 & 2.6 & 2.6 & 67.655 & 0.3 & 0 \\
\hline 18/Aug/87 & 26.1 & 84 & 2.1 & 5.3 & 3.7 & 3.7 & 63.955 & 0 & 0 \\
\hline 19/Aug/87 & 27.05 & 79 & 2.4 & 6.8 & 4.4 & 4.4 & 59.98 & 0.5 & 0 \\
\hline 20/Aug/87 & 27.6 & 79 & 1.3 & 5.6 & 4 & 4 & 55.98 & 0 & 0 \\
\hline 21/Aug/87 & 27.05 & 80.5 & 3 & 1.8 & 3.3 & 3.3 & 52.68 & 0 & 0 \\
\hline 22/Aug/87 & 25.7 & 85 & 1.4 & 0.7 & 2.5 & 2.5 & 58.34 & 9.6 & 0 \\
\hline 23/Aug/87 & 25.25 & 87 & 1 & 0.9 & 2.4 & 2.4 & 63.675 & 9.1 & 0 \\
\hline 24/Aug/87 & 26 & 83.5 & 0.6 & 1.6 & 2.6 & 2.6 & 68.045 & 8.2 & 0 \\
\hline 25/Aug/87 & 25.75 & 87 & 2.3 & 1.9 & 2.8 & 2.8 & 67.54 & 2.7 & 0 \\
\hline 26/Aug/87 & 25.8 & 85.5 & 1.4 & 1.7 & 2.7 & 2.7 & 70 & 7.4 & 1.13 \\
\hline 27/Aug/87 & 26.25 & 85.5 & 1.6 & 1.8 & 2.8 & 2.8 & 68.305 & 1.3 & 0 \\
\hline 28/Aug/87 & 26.05 & 84.5 & 1.3 & 1.8 & 2.8 & 2.8 & 70 & 34.2 & 24.575 \\
\hline 29/Aug/87 & 26.35 & 82.5 & 1.1 & 3.2 & 3.1 & 3.1 & 68.175 & 1.5 & 0 \\
\hline 30/Aug/87 & 26.75 & 82.5 & 3 & 2.9 & 3.4 & 3.4 & 64.775 & 0 & 0 \\
\hline 31/Aug/87 & 26.3 & 86 & 2.1 & 0.4 & 2.5 & 2.5 & 70 & 17.4 & 7.065 \\
\hline 01/Sep/87 & 24.15 & 90 & 0 & 0 & 2 & 2 & 68.51 & 0.6 & 0 \\
\hline 02/Sep/87 & 26.85 & 82.5 & 1.6 & 3.9 & 3.4 & 3.4 & 66.13 & 1.2 & 0 \\
\hline 03/Sep/87 & 26.75 & 81.5 & 2.1 & 7.6 & 4.3 & 4.3 & 61.83 & 0 & 0 \\
\hline 04/Sep/87 & 26.75 & 81 & 1.4 & 6.1 & 3.9 & 3.9 & 57.93 & 0 & 0 \\
\hline 05/Sep/87 & 26.15 & 88 & 1.7 & 1.5 & 2.6 & 2.6 & 60.6 & 6.2 & 0 \\
\hline 06/Sep/87 & 27.9 & 81 & 0.7 & 7.2 & 4.1 & 4.1 & 70 & 17.5 & 1.375 \\
\hline 07/Sep/87 & 27.75 & 79.5 & 1.4 & 6.9 & 4.2 & 4.2 & 65.8 & 0 & 0 \\
\hline 08/Sep/87 & 25.95 & 82.5 & 1.4 & 2.9 & 3 & 3 & 70 & 33.4 & 21.19 \\
\hline 09/Sep/87 & 25.7 & 82 & 0.3 & 4.6 & 3.2 & 3.2 & 67.225 & 0.5 & 0 \\
\hline $10 / \mathrm{Sep} / 87$ & 27.75 & 78.5 & 0.3 & 6.7 & 3.9 & 3.9 & 63.665 & 0.4 & 0 \\
\hline $11 / \mathrm{Sep} / 87$ & 27.7 & 75.5 & 1.9 & 7.7 & 4.5 & 4.5 & 70 & 21.5 & 7.44 \\
\hline $12 / \mathrm{Sep} / 87$ & 24.95 & 84 & 2.1 & 3.9 & 3.1 & 3.1 & 66.9 & 0 & 0 \\
\hline
\end{tabular}




\begin{tabular}{|c|c|c|c|c|c|c|c|c|c|}
\hline Date & $\mathrm{T}$ (Degree) & Humidity (\%) & WS $(\mathrm{m} / \mathrm{s})$ & SR (hour) & PET $(\mathrm{mm})$ & $\operatorname{ETR}(\mathrm{mm})$ & Stock $(\mathrm{mm})$ & Rain (mm) & $\mathrm{RCH}(\mathrm{mm})$ \\
\hline 13/Sep/87 & 27.1 & 77 & 1.1 & 6.1 & 3.8 & 3.8 & 63.1 & 0 & 0 \\
\hline $14 / \mathrm{Sep} / 87$ & 27.25 & 78.5 & 1.1 & 6.3 & 3.9 & 3.9 & 68.125 & 10.5 & 0 \\
\hline 15/Sep/87 & 27.6 & 79.5 & 1.9 & 6.5 & 4.1 & 4.1 & 64.62 & 0.7 & 0 \\
\hline $16 / \mathrm{Sep} / 87$ & 24.9 & 85.5 & 0.9 & 2.4 & 2.6 & 2.6 & 63.04 & 1.2 & 0 \\
\hline 17/Sep/87 & 27.35 & 79.5 & 0.6 & 5.3 & 3.5 & 3.5 & 61.24 & 2 & 0 \\
\hline $18 / \mathrm{Sep} / 87$ & 25.2 & 80.5 & 1.9 & 1.3 & 2.7 & 2.7 & 58.71 & 0.2 & 0 \\
\hline 19/Sep/87 & 27.4 & 79.5 & 1.7 & 5.9 & 3.8 & 3.8 & 54.91 & 0 & 0 \\
\hline 20/Sep/87 & 27.3 & 80 & 1.7 & 4.1 & 3.4 & 3.4 & 55.505 & 4.7 & 0 \\
\hline $21 / \operatorname{Sep} / 87$ & 26.75 & 80.5 & 1.7 & 3.8 & 3.3 & 3.3 & 70 & 55.8 & 29.635 \\
\hline 22/Sep/87 & 22.85 & 81.5 & 0.9 & 0 & 2 & 2 & 70 & 34 & 26.9 \\
\hline $23 / \mathrm{Sep} / 87$ & 26.5 & 83.5 & 1.3 & 5.1 & 3.3 & 3.3 & 66.7 & 0 & 0 \\
\hline 24/Sep/87 & 27.5 & 83 & 1.3 & 6.9 & 3.8 & 3.8 & 70 & 11.5 & 2.675 \\
\hline $25 / \mathrm{Sep} / 87$ & 26.2 & 83.5 & 1.9 & 2.8 & 2.9 & 2.9 & 70 & 13.1 & 8.235 \\
\hline 26/Sep/87 & 27.4 & 77.5 & 1.7 & 7.4 & 4.1 & 4.1 & 65.9 & 0 & 0 \\
\hline $27 / \operatorname{Sep} / 87$ & 26.35 & 82 & 1 & 5.1 & 3.3 & 3.3 & 70 & 18.4 & 8.24 \\
\hline $28 /$ Sep/87 & 25.45 & 81 & 1 & 5.7 & 3.3 & 3.3 & 66.7 & 0 & 0 \\
\hline $29 / \mathrm{Sep} / 87$ & 27.15 & 81.5 & 1.6 & 7.8 & 4 & 4 & 62.785 & 0.1 & 0 \\
\hline $30 / \mathrm{Sep} / 87$ & 27.6 & 80 & 1.6 & 8.5 & 4.2 & 4.2 & 58.585 & 0 & 0 \\
\hline $01 /$ oct/87 & 27.6 & 80.5 & 1 & 9.1 & 4.2 & 4.2 & 70 & 34.7 & 13.88 \\
\hline $02 / O c t / 87$ & 24.95 & 83.5 & 1.6 & 5.7 & 3.2 & 3.2 & 66.885 & 0.1 & 0 \\
\hline 03/Oct/87 & 26.5 & 80.5 & 0.4 & 9.5 & 4.1 & 4.1 & 62.785 & 0 & 0 \\
\hline 04/Oct/87 & 27.55 & 79.5 & 1.1 & 9.1 & 4.2 & 4.2 & 70 & 13.6 & 0.145 \\
\hline 05/Oct/87 & 26.85 & 81 & 1.4 & 3.9 & 3 & 3 & 67 & 0 & 0 \\
\hline 06/Oct/87 & 22.4 & 88.5 & 1.9 & 0 & 1.8 & 1.8 & 70 & 17 & 9.65 \\
\hline $07 / O c t / 87$ & 25 & 85 & 0.6 & 2 & 2.3 & 2.3 & 67.7 & 0 & 0 \\
\hline $08 /$ Oct/87 & 27.4 & 79 & 1.1 & 6.8 & 3.6 & 3.6 & 70 & 7.6 & 0.56 \\
\hline 09/Oct/87 & 25.75 & 82.5 & 0.4 & 6.2 & 3.2 & 3.2 & 67.055 & 0.3 & 0 \\
\hline $10 / O c t / 87$ & 27.75 & 81.5 & 1.1 & 8.7 & 4 & 4 & 68.07 & 5.9 & 0 \\
\hline $11 / O c t / 87$ & 27.05 & 81.5 & 1 & 6.3 & 3.4 & 3.4 & 70 & 15.8 & 8.1 \\
\hline $12 / \mathrm{Oct} / 87$ & 25.25 & 84.5 & 0.9 & 2.9 & 2.5 & 2.5 & 68.265 & 0.9 & 0 \\
\hline
\end{tabular}


Appendix B: Additional stationary head observations used to assess model calibration (Computed versus Observed head for the period September 2015)

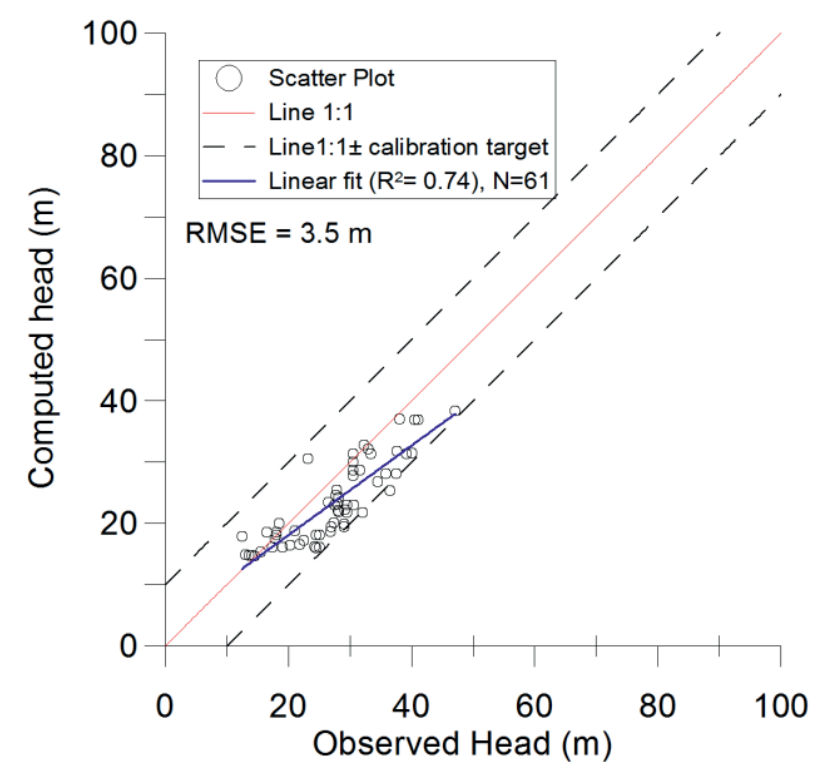




\section{Synthesis}




\subsection{Introduction}

As indicated in the general introduction (chapter 1 ) of this thesis, water resources in general and particularly groundwater resources are under increasing threats at many places worldwide. The threats to groundwater resources might worsen in the future due to population growth and future climate, and managing sustainably such vital resources requires a good knowledge of aquifers structures, functioning and behaviour with respect to present and future stresses. Hydrogeological models are tools to simulate present and future groundwater systems behaviour and have been used worldwide under different hydrogeological contexts (e.g.: in coastal sedimentary regions (de Louw et al., 2010; Kallioras et al., 2010), in arid sedimentary regions (Babiker and Gudmundsson, 2004; Gossel et al., 2004; Yao et al., 2014), in basement rocks contexts (Huyakorn et al., 1983; Matyjasik et al., 2002) and in karstic regions (Froukh, 2002; Ghasemizadeh et al., 2012; Xu et al., 2019)). There are studies where numerical models were set up to simulate artesian systems (eg: Welsh, 2006; Virbulis et al., 2013; Pétré et al., 2019) and Welsh (2006) found large differences in artesian head declines between areas (e.g.: between south Australia and New South Wales) which could not be explained yet. Also, it is unclear which properties would be much more sensitive to the simulated heads in the artesian zones. This research contributes to improve knowledge regarding the structure of artesian systems (based on a case study of the Cretaceous aquifer of southern Benin), regarding the relevance of surfacegroundwater interactions in such systems, regarding reactions of such systems to future stresses and regarding the parameters that are key when modelling such systems.

\subsection{Major findings}

The findings summarized below are based on the results presented in chapters two to four.

\subsubsection{Groundwater flow conceptualization in the studied artesian system}

In chapter two, the groundwater flow directions were studied based on piezometric surveys and helped to identify the flow directions and to develop a conceptual groundwater flow model of the study area. Also, hydrochemistry (including isotopes) studies were conducted with respect to understanding the flow directions. Stable and radioactive isotopes spatial distributions indicated that the recharge areas are located in the northern region and that downstream areas are toward the south, with higher and lower isotopic signatures respectively associated to the recharge and downstream areas. Stable and especially radioactive isotopes were identified as good indicators that can be used in similar artesian 
systems elsewhere to pinpoint recharge and downstream areas and to conceptualize the general groundwater flow of such systems. A conceptual flow model is proposed (in chapter 2) for the case study and can serve as foundation for future numerical exercises. The groundwater mineralization as measured through the TDS (Total Dissolved Solids) was found not effective in such flow conceptualization, as no robust and no logical TDS trend was found in the flow system.

\subsubsection{Surface-groundwater interactions in the studied artesian system}

In chapter 3, we have investigated surface-groundwater interactions in the studied artesian system. River leakage to the subsurface was unknown in the studied system. We have addressed this issue with a numerical model, with a focus on the hydraulic and storage properties that are important in simulating river leakage. We found that the contribution of surface-groundwater fluxes to recharging the artesian aquifer is negligible. We also found that when modelling surface-groundwater interaction, the riverbed conductance is not the key or the most influencing factor affecting the computed leakage in the studied system. Actually, even when three times the based-conductance value was implemented, this resulted in little changes (less than $3 \%$ of the based computed leakage). But, this changes might be significant in other systems. Rather, for the studied system, the riverbed conductance is found to be among the least influencing factors. But the hydraulic conductivity of the alluvial and of the unconfined part of the artesian aquifer are key factors. We arrived at ranking the different hydraulic and storage properties with respect to computing river leakage in such a system. This rank of properties can guide modelling exercises (computations) of river leakage in other similar systems.

\subsubsection{Past and future head assessment across the artesian zone under artesian outflows and climate scenarios}

Chapter 4 was dedicated to investigating the past head evolution and to assess the future head evolution across the artesian zone, using the previously developed numerical model. Additionally, the impacts of uncertainties in hydraulic and storage properties of the subsurface layers on hydraulic heads were assessed by means of a sensitivity analysis. With this modelling exercise, we found that the artesian basin is structured into peripheral and central parts, with different reactions to external stresses (groundwater recharge mainly). The peripheral artesian zone was found adjacent to groundwater recharge areas and is more subjected to easy-head fluctuations than the central artesian zones, where seasonal head-fluctuations are attenuated. In fact, head amplitudes generally decrease with distance 
from the northern artesian zone border toward the South where these amplitudes become nearly zero. This is because heads fluctuations (recharge-related) are generated from far away (recharge area in the North) and due to the aquifer inflow/outflow through the confining layer (leakage), these fluctuations which are controlled by the hydraulic transmissivity and storativity of the aquifer, will attenuate with distance. The assessment of past head evolutions revealed that artesian head-drop is not a new process in the system. It used to occur especially at the peripheral artesian zone, but was not noticed on the field earlier as the first artesian wells installed until the year 2005 were located at the central artesian zone where seasonal head fluctuations are somewhat attenuated. Modelling results indicated that head-drop might be more pronounced during the period 2020s under the current artesian outflows, due to plausible lower recharge for that period. But during 2030s, results suggest a slight recovery of heads (head-gain), especially in the peripheral artesian zone due to plausible higher recharge for that period. In case the current artesian outflows double by 2050 due to the expected increase of water demand by population growth, this might cause heads to reduce by only few centimeters both in the central and at the periphery of the artesian zone, suggesting that the effect of climate change is much more important than this increase of water demand. Furthermore, results show that the impact of recharge is more important in the periphery than in the center and the impact of the outflow scenarios is more important in the center where most of the artesian wells are. Capping all the artesian wells by 2025 would only slightly recover artesian heads. When modelling heads in the artesian system, we found that the hydraulic conductivity of the confined part of the aquifer is the most sensitive parameter to the computed heads, followed by the hydraulic conductivity of the confining layer, the specific storage of the confining clay layer and the specific storage of the confined aquifer. The effects on heads are largest in the center compared to the periphery while the effects on amplitudes are largest for the periphery because this part of the aquifer is confined and that recharge occurs far away.

\subsection{General discussion}

The main focus of this thesis is about assessing which of the hydraulic and storage properties are dominant in heads computation in the artesian zone. A numerical groundwater flow model is setup in that respect, using MODFLOW and based on the conceptual knowledge of the real-world system. We have shown in chapter two that a combined use of lithostratigraphic information and isotopes (mainly radioactive: ${ }^{3} \mathrm{H}$ and ${ }^{14} \mathrm{C}$ ) can lead to a conceptual groundwater flow model. Hence, to limit errors and inconsistencies in groundwater conceptual flow models, we suggest the inclusion of radioactive isotopes in flow investigations. In fact, the groundwater dating ability of these tracers is the ingredient 
in contributing to conceptual flow model development. As explained by Mook et al., 2000, when groundwater infiltrates the soil and is hence isolated from the atmosphere, decay starts for these tracers and the duration between water infiltration point and sampling point can be estimated. However, in some systems, it might be possible that these tracers are secondary produced (Münnich, 1957). In such cases, the secondary produced tracer should be taken into account when developing a flow knowledge of the real-world system (conceptual flow model). In other discontinuous flow systems (e.g.: karst and basement rocks (fractured) aquifers), the application of these radioactive isotopes with respect to flow conceptualization of a real-world system might not be worthy (Zhao et al., 2018), as groundwater circulates faster through complex discontinuous systems leading to expectable mixing of groundwater from various origins

Due to complexities that are inherent to real world including subsurface, it is challenging to take into account all details of a real-world system in a numerical model, especially at large scales (de Marsily et al., 1998; Gabaix, and Laibson, 2008; Hurkmans, 2009). This is illustrated by the most commonly used models of the earth: flat, spherical, and ellipsoid. These models do not account for the bumps and grooves. A perfect replica of the earth would reproduce every contour and details, but such a representation would be impossible. As a consequence, translating a conceptual knowledge of the real-world system into a numerical model comes along with uncertainties (Wu and Zeng, 2013), which are from different origins including simplifications in stratigraphic representations, imprecisions linked to discretization (both spatial and temporal), elevation errors (inaccuracy in DEM (Digital Elevation Model)) and model parameters uncertainties.

Studies regarding the stratigraphic representations of the subsurface have drawn much attention in recent decades (Jones and Wright, 1993; Lemon and Jones, 2003; Wu et al., 2005; de Rienzo et al., 2008; Tonini et al., 2008; Zhu et al., 2012). Such stratigraphic representations (known as the "layer cake" models (Turner, 2006)) are simplified as they are generated from different types of data (e.g.: boreholes, cross-sections) that are often scarce (Touch et al., 2014). In addition to simplifications in stratigraphic representations, there are imprecisions linked to discretization. For example, for large-scale models with greater grid sizes, landscape (topography, land-use, pedology) heterogeneity cannot be represented explicitly. However, the smaller the grid size is the higher is the computation burden (Wildemeersch et al., 2014). Hence, too small grid sizes in large scale models are not desired, calling again for simplifications, which is a point of introducing imprecisions in numerical models. For example, if a numerical model squared grid size is $1 \mathrm{Km} \times 1 \mathrm{Km}$, then a unique topographic value, unique values of soil properties and unique observed values (e.g.: observed head) will be attached to such a grid cell. This is a typical example of simplifications that occur in numerical modelling exercises, causing deviations from the 
reality. This same issue applies to Digital Elevation Models (DEMs) used to define the top elevations of hydrogeological models (see for example Li, 1992; Wise, 2000; Pike, 2002; Wechsler, 2003). However, simplifications cannot be totally avoided and this applies not only to the model setup in this study but also to many other scientific fields such as economics and applied physics (to describe the aggregate behaviour of systems as opposed to the behaviour of their individual parts (e.g.: Daganzo et al., 2012)).

When the model is set-up with reasonable stratigraphic, discretization and topographic simplifications, another important source of uncertainties concerns the model parameters which may influence the modelling results. Uncertainties in model parameters do not influence modelling results the same way (Korving et al., 2002). Focusing on the evaluation of river leakage to the subsurface in chapter three, we have shown that uncertainties in some parameters appear to have dominant influence on the computed river leakage. Namely, the hydraulic conductivity $(K)$ of the alluvial aquifer and the $K$ of the unconfined part of the artesian aquifer have dominant influence on the computed leakage. Conversely, the riverbed conductance, a parameter which is difficult to determine accurately (because of highly heterogeneous riverbed sediments (Chen, 2000)) is among the parameters having less influence on the computed river leakages. Similar results were obtained when modelling surface-groundwater interactions in the Ruataniwha basin in New Zealand (Baalousha, 2012). This author (Baalousha, 2012), based on sensitivity analysis found that the model results (leakage) are highly sensitive to aquifers hydraulic conductivity and nearly not to riverbed conductance. The study by Rushton (2007) also supports that the hydraulic conductivity of the aquifer is usually a more important factor. This implies that when computing river leakages in systems similar to the case concerned by this thesis, there is therefore a need for more investigation on aquifers hydraulic conductivities than the river bed conductance, as the model results are more sensitive to changes in aquifers hydraulic conductivities than any other parameter.

In chapter four, we investigated the historical and future heads evolution in the artesian domain and we found that the first three parameters that control the results (computed heads) are respectively the hydraulic conductivity of the confined aquifer, the conductivity of the confining clay layer and the specific storage of the confining layer. The conductivity of the clay layer is found even much more important than the storage properties of the aquifers in artesian systems. Previous studies (e.g.: Shuwei et al., 2015) rather found that, in the unconfined system, the model result (computed head) is mostly responsive to recharge. This implies that which model parameter is most sensitive will depend on the system we are dealing with, i.e., it is unconfined or confined problem dependent. In unconfined and confined systems, results (computed heads) are most responsive to recharge and hydraulic conductivities respectively as opposed to storage properties. Hence 
we suggest that when modelling artesian basins, especially during calibration, aquifer zonation (zones with different aquifer properties) should be defined based mainly on hydraulic conductivities, which are the parameters having large sensitivity. Other parameters are less important and may not contribute to additional aquifer zonation. Hence, heads can be modelled using the smallest number of parameters and zones (Jiao and Lerner, 1996).

Recharge estimation is difficult as it cannot be measured directly (Bakker et al., 2013) and is as well prone to uncertainties, regardless of the method of estimation (Ordens et al., 2012; Crosbie et al., 2018). In this thesis, the water balance method is applied and requires various type of data including runoff and soil water content at field capacity. Both runoff and soil water content at field capacity that were available for the study area were limited. Hence, the later were assumed uniform over large areas in this study implying that the estimated recharge might not be precise enough. However, a spatially detailed knowledge of runoff and soil water content would increase the reliability of the developed model. In addition, the artesian outflows scenarios that were implemented in the study (chapter four) could be further elaborated. Namely, the "increased" scenario that considers (based on the projected population growth by the UN) doubling the current artesian outflows (and hence doubling the artesian wells in theory) by 2050 may be subjected to several adjustments. In the study, we assumed a linear increase of artesian outflows at places where the artesian wells already exist. However, exponential and unevenly distributed increases might be considered as well. In addition, the "increased" scenario might consider that new artesian wells are installed in areas where no artesian wells existed, instead of implementing new artesian wells near the existing ones. The model set up in this study is a tool that can help implement these alternative scenarios and many other scenarios, hence helping in decision making regarding groundwater resources management of the studied region. For the study area, we found that, in the central artesian zone and under the current artesian wells configurations, artesian heads will likely be stable for the next three decades (i.e., by the year 2050). This implies that the local populations and NGOs can rely on the free-flows of the artesian wells in the central artesian zone to develop activities such as intensive rice and other crop production. There are many other artesian basins worldwide for which the groundwater resource potentiality is unknown, though they are exploited for various purposes. The research presented in this thesis offers a basis to explore the potential of groundwater resources of artesian basin elsewhere, which is a key starting point for their sustainable management. 


\subsection{Limitations and recommendations}

The modelling approach applied in this thesis certainly has some limitations.

One of the limitations concerns the scarce availability of hydraulic and storage properties data in the study area. Although field pumping tests are most recommended for the evaluation of such properties (Zech et al., 2015), they may not be feasible in some field conditions prone to recirculation of pumped water back to the aquifer. Alternatively, laboratory tests (e.g.: Hao et al., 2012) and geophysical techniques (e.g.: Magnetic Resonance and Vertical Electrical soundings) could be used to derive hydraulic and storage properties of the subsurface layers (Gunther and Muller-Petke, 2012; Chen et al., 2018; Perdomo et al., 2018). However, it should be kept in mind that properties derived from both laboratory and non-invasive methods do not necessary reflect field conditions (Picornell et al., 1992; Bagarello, and Provenzano, 1996).

Another limitation concerns groundwater recharge which is the driven force of the modelled system. Its magnitude depends on several parameters including precipitation amounts, evapotranspiration, runoff amounts and soil properties. In chapters three and four of this thesis, we used soil properties that are available, namely, the soil water content at field capacity to evaluate groundwater recharge. Also, we used the limited runoff data that is available locally. However, both runoff and soil properties data were not available at small scale. Hence, the evaluated recharge may be improved in several ways, namely: (i) evaluating runoff that reflects field conditions at small scale and (ii) estimating soil properties at small scale.

Typically for artesian groundwater systems modelling, the location of the downstream model boundary could be an issue if, due to computational burdens, it is not feasible to place such a boundary at natural hydrologic boundaries which may be very far (hundreds of kilometers) away (sea coastline, large rivers, etc.) as the case of the GABFLOW (the Great Artesian Basin flow) model for which the downstream boundary is set to coincide with the Gulf of Carpentaria coastline (Welsh, 2006). Such a model boundary can be placed at a certain distance from the interested area and specified heads or fluxes can be applied at such model boundary. However, the distance to which the downstream boundary can be placed so as to limit its influence on the computed heads in the artesian domain is not discussed in the literature. More research is needed to investigate this issue and to elaborate on the impact that the distance of the downstream boundary would have on the computed heads in the artesian zones and to arrive at recommendable distances that could minimize this downstream boundary effect on the artesian states simulations. Also, we used in this research the WELL package (which uses fixed fluxes) to implement artesian outflows. However, it might be possible that outflows creates lower heads which may also cause 
lower outflows. Although such a feedback mechanism is not physically noticed clearly in the studied system and not included in this modelling, further research is needed to elaborate on how such a feedback mechanism could be accounted for in modelling artesian systems. 


\section{Annexes}

\section{Annex 1: Altitude map of the study area}

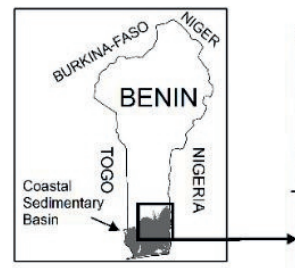

\section{Altitude(m) High : 273}

- Rainfall station

- Gauging station

Spring

Driling logs

- Full penetrating

- borehole

Deep Borehole

Shallow lithology

- observation points

Model Limits

Vestern and Eastern limit South-West and

South-East limits

South central (valley) limit

- Stream/ River/Brook

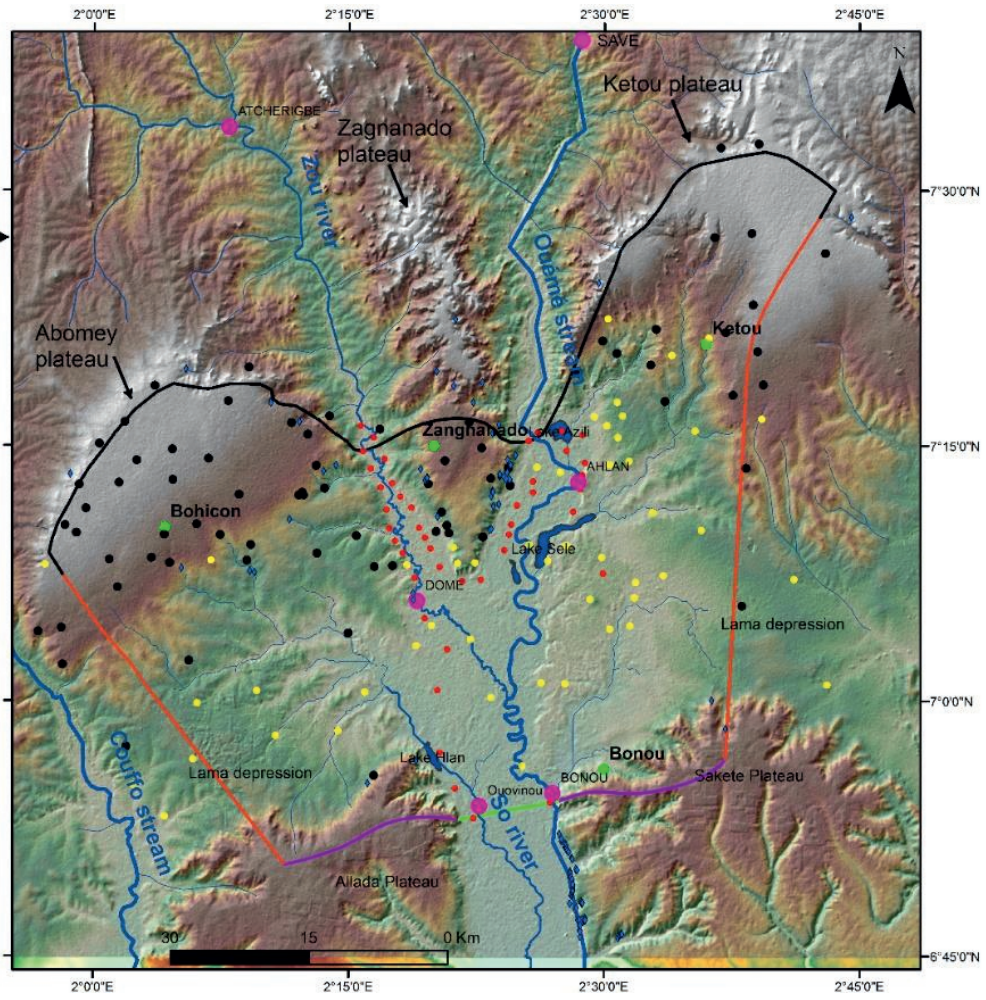




\section{Annex 2: The 3D model grid}

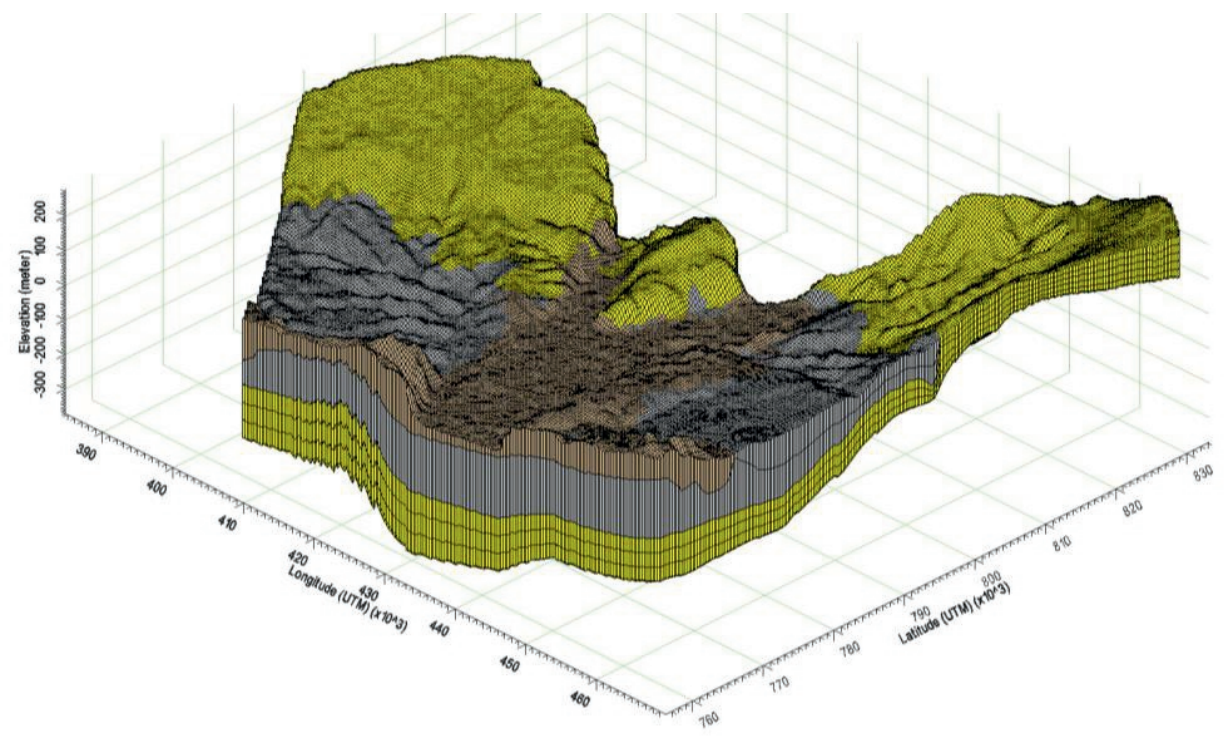

Annex 3: Recharge estimated for the three other recharge zones by a combination of the Penman and the Water Budget methods.

\begin{tabular}{|c|c|c|c|c|c|c|}
\cline { 2 - 7 } \multicolumn{1}{c|}{} & \multicolumn{2}{c|}{ Bohicon } & \multicolumn{2}{c|}{ Ketou } & \multicolumn{2}{c|}{ Bonou } \\
\hline Year & Rainfall $(\mathrm{mm})$ & Recharge $(\mathrm{mm})$ & Rainfall $(\mathrm{mm})$ & Recharge $(\mathrm{mm})$ & Rainfall $(\mathrm{mm})$ & Recharge $(\mathrm{mm})$ \\
\hline 1970 & 1221 & 173 & 1181 & 126 & 1235 & 8 \\
\hline 1971 & 1013 & 57 & 783 & 52 & 710 & 0 \\
\hline 1972 & 1200 & 120 & 997 & 52 & 1043 & 2 \\
\hline 1973 & 972 & 85 & 836 & 9 & 1199 & 6 \\
\hline 1974 & 1085 & 106 & 1049 & 143 & 767 & 0 \\
\hline 1975 & 1135 & 86 & 949 & 38 & 1220 & 0 \\
\hline 1976 & 848 & 26 & 730 & 0 & 763 & 0 \\
\hline 1977 & 552 & 13 & 999 & 40 & 857 & 0 \\
\hline 1978 & 1267 & 217 & 1415 & 321 & 1164 & 40 \\
\hline 1979 & 1448 & 344 & 1429 & 268 & 1519 & 166 \\
\hline 1980 & 1308 & 206 & 1028 & 117 & 1444 & 138 \\
\hline 1981 & 993 & 103 & 1077 & 121 & 1246 & 56 \\
\hline 1982 & 766 & 10 & 962 & 84 & 1031 & 3 \\
\hline 1983 & 679 & 41 & 587 & 5 & 918 & 10 \\
\hline 1984 & 1008 & 63 & 1153 & 156 & 1220 & 15 \\
\hline 1985 & 897 & 24 & 1126 & 178 & 1184 & 31 \\
\hline 1986 & 1053 & 49 & 869 & 13 & 997 & 0 \\
\hline 1987 & 1192 & 222 & 1291 & 355 & 1361 & 184 \\
\hline
\end{tabular}




\begin{tabular}{|c|c|c|c|c|c|c|}
\hline \multirow[b]{2}{*}{ Year } & \multicolumn{2}{|c|}{ Bohicon } & \multicolumn{2}{|c|}{ Ketou } & \multicolumn{2}{|c|}{ Bonou } \\
\hline & Rainfall (mm) & Recharge $(\mathrm{mm})$ & Rainfall (mm) & Recharge (mm) & Rainfall (mm) & Recharge $(\mathrm{mm})$ \\
\hline 1988 & 1397 & 254 & 1446 & 229 & 1456 & 89 \\
\hline 1989 & 1225 & 282 & 1158 & 157 & 1491 & 173 \\
\hline 1990 & 1059 & 130 & 923 & 48 & 1118 & 16 \\
\hline 1991 & 1058 & 96 & 1073 & 13 & 1271 & 0 \\
\hline 1992 & 720 & 3 & 821 & 71 & 1042 & 86 \\
\hline 1993 & 990 & 64 & 1095 & 79 & 1268 & 3 \\
\hline 1994 & 998 & 47 & 845 & 43 & 930 & 0 \\
\hline 1995 & 1343 & 177 & 1051 & 103 & 1108 & 18 \\
\hline 1996 & 1108 & 186 & 1242 & 289 & 1317 & 39 \\
\hline 1997 & 1280 & 136 & 1056 & 56 & 1548 & 91 \\
\hline 1998 & 1148 & 164 & 635 & 58 & 823 & 0 \\
\hline 1999 & 1540 & 467 & 1297 & 314 & 1877 & 381 \\
\hline 2000 & 1071 & 194 & 996 & 159 & 918 & 33 \\
\hline 2001 & 862 & 20 & 777 & 90 & 863 & 0 \\
\hline 2002 & 1358 & 192 & 1044 & 24 & 1310 & 0 \\
\hline 2003 & 1107 & 139 & 998 & 84 & 1230 & 15 \\
\hline 2004 & 1319 & 287 & 876 & 34 & 1202 & 16 \\
\hline 2005 & 1099 & 89 & 946 & 24 & 1177 & 42 \\
\hline 2006 & 1201 & 151 & 1122 & 89 & 700 & 13 \\
\hline 2007 & 1230 & 236 & 1114 & 176 & 1055 & 0 \\
\hline 2008 & 1188 & 257 & 1219 & 375 & 1266 & 247 \\
\hline 2009 & 1106 & 72 & 984 & 54 & 1555 & 237 \\
\hline 2010 & 1324 & 259 & 1648 & 465 & 1772 & 255 \\
\hline 2011 & 1266 & 194 & 982 & 103 & 1148 & 68 \\
\hline 2012 & 1202 & 121 & 966 & 42 & 1154 & 0 \\
\hline 2013 & 808 & 0 & 804 & 0 & 1891 & 108 \\
\hline 2014 & 1161 & 135 & 1368 & 149 & 1509 & 0 \\
\hline 2015 & 710 & 1 & 1029 & 68 & 706 & 0 \\
\hline
\end{tabular}

\section{Annex 4: Alternative explanations of the river water losses and implications of the outcropping clay layer}

According to Le Barbe et al. (1993), the Zou and the Ouémé lose water and Kpegli et al. (2018b) found that these losses could not be attributed to their leakage to the subsurface (because their results showed that at most, only up to $3 \%$ of the river losses could leak to the subsurface). If not leaking predominantly to the subsurface, then, other possible causes could be: (1) losses due to probable intermittent connections of these rivers to two brooks (based on data by Colombani et al. (1972), (2) evaporation from the open water surface and evapotranspiration, (3) discharge measurement errors and (4) leakage in flooding areas during flooding periods. Each of the above possible causes is described below with respect to their likelihood. 
As far as the probable losses through brooks is concerned, the available records back to 1950s and 1960s (Colombani et al., 1972) have shown that two brooks in the system (named Zounga and Agbagbe) allow the Zou and the Ouémé rivers to intermittently communicate with the Sô river in the western study area (Fig. A4.1). It is worth noting that the Sô river also drains precipitations that fall on the outcropping clay area in the South-West prior to its junction with these two brooks (Fig. A4.1). It appears that most of the Zou and Ouémé rivers losses occur predominantly between June and October (Fig. A4.2 a), with these brooks fluxes accounting for nearly $\sim 97 \%$ of the losses (Fig. A4.2 c).

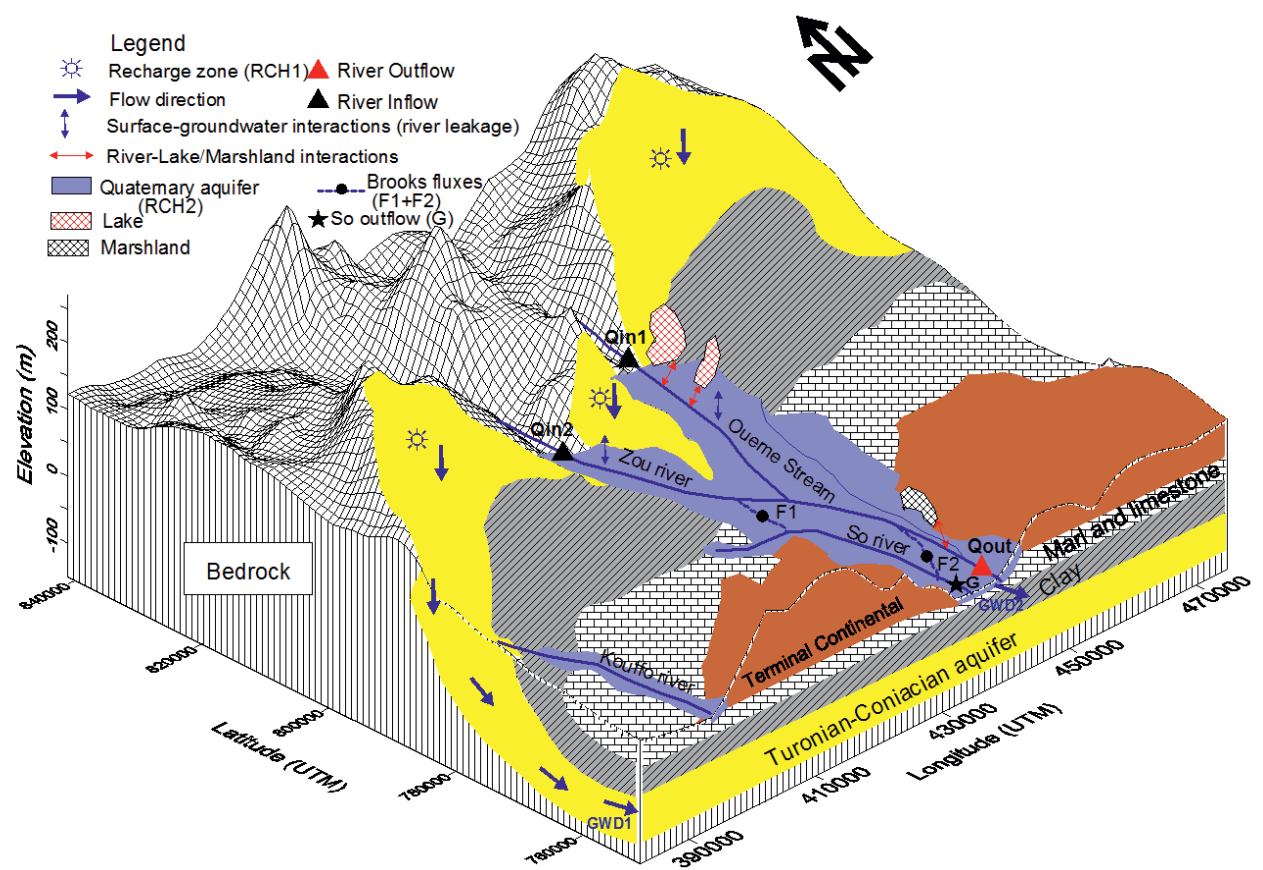

Fig. A4.1 Conceptual flow diagram of the study area showing the intermittent brooks and illustrating groundwater and surface water budgets (modified from Kpegli et al., 2018a and based on Colombani et al., 1972) 


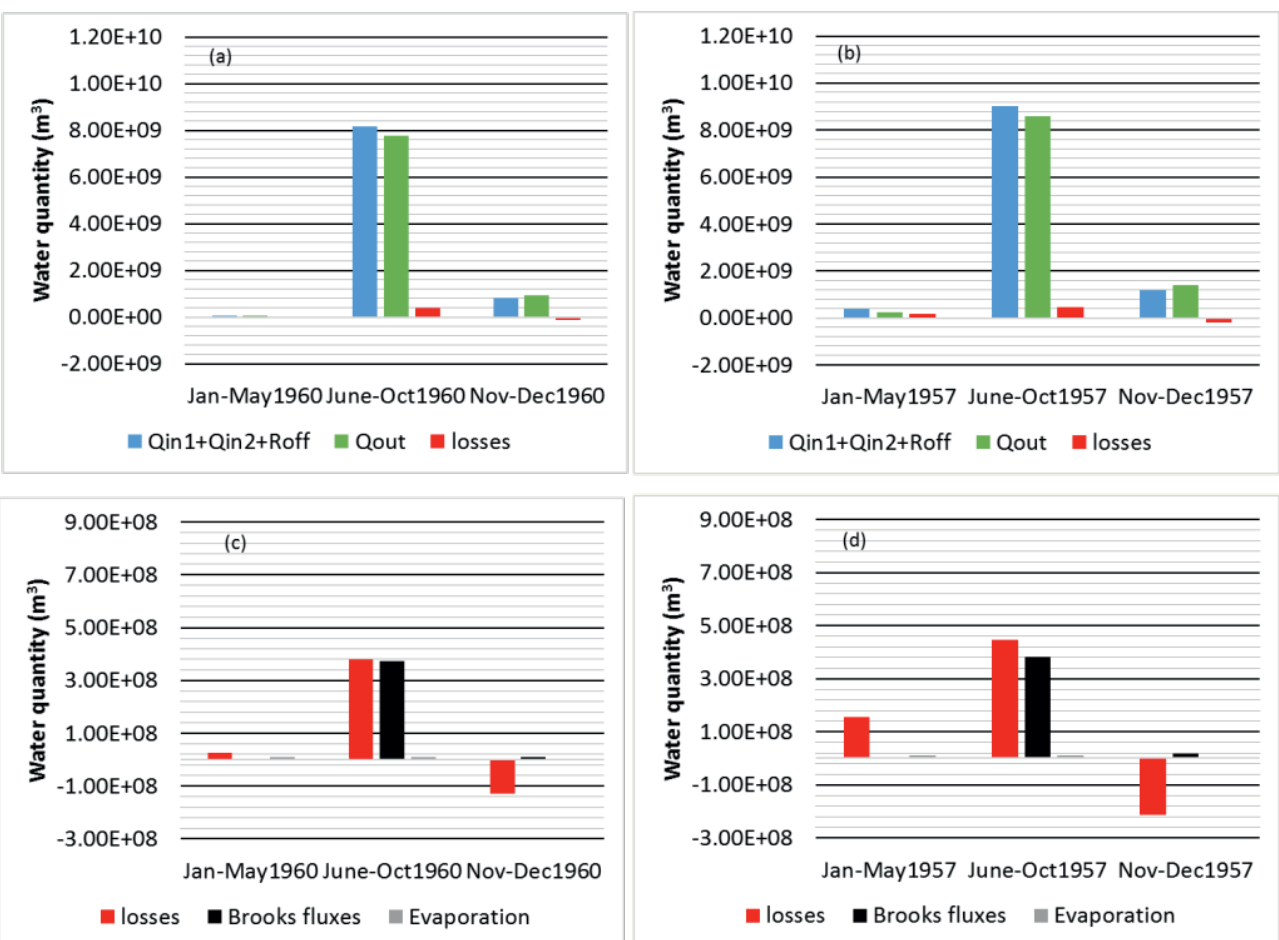

Fig. A4.2 Distribution of total river input, output and water losses ( $a$ and $b$ ) and losses compared to brooks fluxes and evaporation ( $c$ and d) for the different periods of the years 1960 and 1957 for which data is fully available; data source: Colombani et al., 1972; Le barbe et al., 1993

Based on Brunel and Bouron (1992), evaporation from the open water is insignificant (less than $\sim 2 \%$ of the losses). Evapotranspiration in the study area is about $1500 \mathrm{~mm} /$ year (Achidi et al., 2012), i.e., about $4.10 \times 10^{-3} \mathrm{~m} / \mathrm{d}$ (and about $0.247 \mathrm{~m}$ for the flooding period JuneOctober). With a flooding area of approximately $5.3 \times 10^{7} \mathrm{~m}^{2}$ (Colombani et al., 1972), the amount of evapotranspiration approximates $0.13 \times 10^{8} \mathrm{~m}^{3}$ during June-October. This suggests that evapotranspiration might reach $3 \%$ of the losses in the flooding area (i.e., $0.13 \times 10^{8} \mathrm{~m}^{3}$ over $4 \times 10^{8} \mathrm{~m}^{3}$ during June-October), which is by far low to be the main responsible cause of the losses. From the above, other plausible processes (including leakage to the subsurface during flooding periods) that could be linked to the losses would be negligible processes. This is in line with previous findings (Kpegli et al., 2018b) that indicated that the Ouémé and the Zou rivers leakage to the subsurface is tiny and could not predominantly explain their losses. Also, it appears that the Sô river's total outflows after its junction with both brooks (see " $G$ " on Fig. A4.1) account for approximately $6.27 \times 10^{7} \mathrm{~m}^{3}$ during November to December 1957 (Colombani et al., 1972), with both brooks contributing for $\sim 1.66 \times 10^{7} \mathrm{~m}^{3}$. This implies that precipitations $(0.10 \mathrm{~m})$ falling during this period on the Western clay outcropping area $\left(\sim 4.8 \times 10^{8} \mathrm{~m}^{2}\right)$ and resulting in an amount of $\sim 4.8 \times 10^{7} \mathrm{~m}^{3}$ moves out through mainly the Sô river ( $96 \%$ of the total rainfall amount) and 
evapotranspiration ( $3 \%$; i.e., $4.10 \times 10^{-3} \mathrm{~m} / \mathrm{d}$ over the Sô surface of $\sim 6.10 \times 10^{6} \mathrm{~m}^{2}$ during November to December). This suggests that possible infiltration of rainfall amount on the outcropping clay, if any, appears negligible and could be explained by the very low hydraulic conductivity of this outcropping clay $\left(\sim 10^{-4} \mathrm{~m} /\right.$ day, see Pedersen and Boukari, 2009; Sethi and Di Molfetta, 2019).

River discharges were measured using ADCP (Acoustic Doppler Current Profiler), an instrument based on Doppler effect, which measures discharge of a river in a short time while crossing it (Nihei and Kimizu, 2008). There are uncertainties attached to such discharge measurements. According to Lang et al. (2006), the standard uncertainties are up to $5 \%$ of discharge measurements, with larger values when flow velocity or gradient of water raising are important. In order words, discharge measurements are more uncertain under unsteady flow conditions that might prevail in years of relatively higher river flows (Baldassarre and Montanari, 2009). Uncertainties in the discharge measurements may thus affect the accuracy of surface water budget, leading to the conclusion that parts of the surface water is lost. As shown on Fig. A4.2 ( $a$ and b), fluxes recorded in 1957 are greater than fluxes in 1960 and would thus relatively be more uncertain (compared to 1960). During the year 1960, the Zou and Ouémé rivers water losses are mainly explained by the brooks fluxes and evapotranspiration (including open water evaporation). However, this is not the case for the year 1957 (Fig. A4.2 (c and d)) for which fluxes are relatively more uncertain, meaning that higher unsteady river flows may be problematic in explaining river losses accurately.

Fig. A4.3 provides insight on the functioning of the alluvial system in the study area. During the periods November to December (post rainy period), the rivers rather gain some water (Fig. A4.3 c and d) that were temporarily stored in the alluvial during previous rainy periods. This gaining is related to the previous recharge (to the alluvial aquifer) that occurred during previous rainy events and which is progressively flushed out of the alluvial to the surface water system during post-rainy periods (Fig. A4.3). As illustrated on Fig. A4- 3, the alluvial get recharged from rainfalls during June-October and discharge to the rivers from November, with a short time delay (less than five days) between recharge and discharge to the surface water system. It appears that not all rainfall recharge the alluvial aquifer, since its water table is insensitive to several rainfall events. In fact, the soil water content at field capacity needs to be satisfied first before excess rainfall can be routed to the groundwater table. 


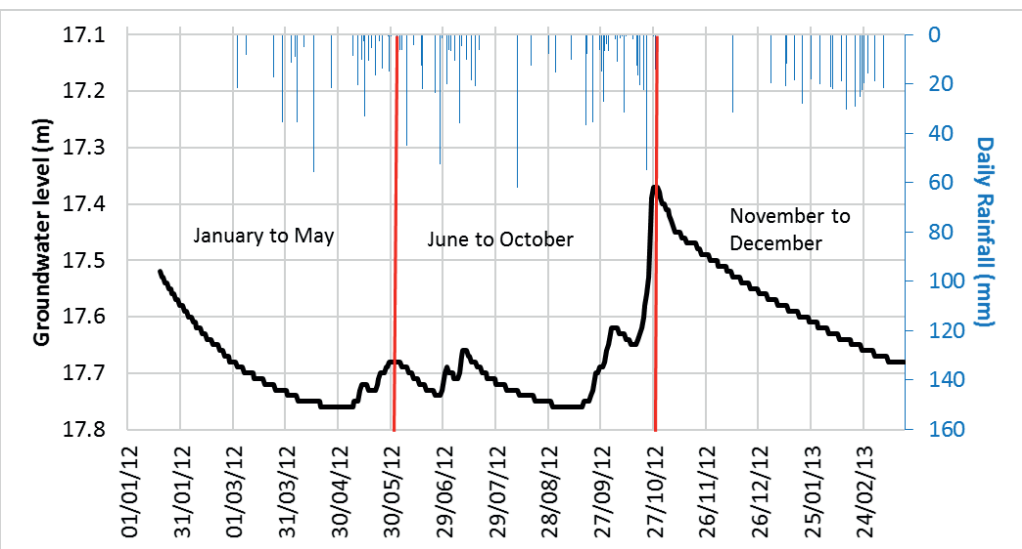

Fig. A4.3 Groundwater level fluctuation and rainfall in the alluvial plain showing different periods of a year, the delay in response to alluvium water level is less than five days

From the above described possibilities, the intermittent connection of the Zou and Ouémé rivers to the brooks is likely the predominant cause of the Ouémé and the Zou rivers water losses. However, the link between the intermittent brooks and the Zou and Ouémé rivers losses might be illustrated more strongly if fresher and longer time series data than the ones available nowadays and presented in this Annex become available. Discharge measurement errors could be an issue when explaining accurately the river water losses. But leakage to the subsurface (from these rivers), evaporation from the open water and evapotranspiration are negligible processes. 


\section{Literature cited}

Achidi, J., Bourguet, L., Elsaesser, R., Legier, A., Paulvé, E., Tribouillard, N., 2012. Notice explicative de la carte hydrogéologique du Bénin : carte du bassin sédimentaire cotier à l'échelle 1/200 000. Technical report. DGEau, Cotonou, Benin, p. 77.

Adite A., Gbankoto, A., Toko, I. I., Fiogbe, E. F, 2013. Diet breadth variation and trophic plasticity behavior of the African bonytongue Heterotis niloticus (Cuvier, 1829) in the Sô River-Lake Hlan aquatic system (Benin, West Africa): Implications for species conservation and aquaculture development. Natural Science, 5, 1219-1229.

Adjakidje, V., 1984. Contribution à l'étude botanique de savanes guineennes de la Republique Populaire du Benin. PhD thesis, Universite de Bordeaux III, Bordeaux, 284 pp.

Adjanohoun, E., 1989. Contribution aux études ethnobotaniques et floristiques en République Populaire du Benin. Agence de Cooperation Culturelle et Technique, Paris, $\mathrm{v}, 895 \mathrm{p}$.

Aeschbach-Hertig, W., Gleeson, T., 2012. Regional strategies for the accelerating global problem of groundwater depletion. Nature Geoscience, 5: 853-861.

Affaton, P., Houessou, A., Gomez, G., 1985. La formation d'Adakplame (Benin, OuestAfrique) n'appartient pas au Continental Terminal. Journal of African Earth Sciences, 3, 359-364.

Aicard, P., 1959. Le précambrien du Togo et du Nord-Ouest du Dahomey. PhD thesis, Université de Nancy, France.

Al Faitouri M., Sanford W. E., 2015. Stable and radio-isotope analysis to determine recharge timing and paleoclimate of sandstone aquifer in central and southeast Libya. Hydrogeology Journal, 23, 707-717.

Alassane A., Trabelsi, R., Dovonon, L. F., Odeloui, D. J., Boukari, M., Zouari, K., Mama, D., 2015. Chemical evolution of the Continental Terminal shallow aquifer in the south of the coastal sedimentary basin of Benin (West Africa) using multivariate factor analysis. Journal of Water Resource and Protection, 7, 496-515.

Alassane, A., 2004. Etude hydrogéologique du Continental Terminal et des formations de la plaine littorale dans la région de Porto-Novo: Identification des aquifères et vulnérabilité à la pollution de la nappe superficielle. PhD thesis, Université C. A. Diop de Dakar, Sénégal.

Allen, R. G., Jensen, M. E., Wright, J. L., and Burman, R. D. 1989. Operational estimates of reference evapotranspiration. Agron. J. 81, 650-662.

Allen, R. G., Smith, M., Pereira, L. S., and Perrier, A. 1994b. An update for the calculation of reference evapotranspiration. ICID Bulletin, 43 (2), 35-92. 
Alsumaiei, A. A., Bailey, R. T., 2018. Quantifying threats to groundwater resources in the Republic of Maldives Part I: Future rainfall patterns and sea level-rise. Hydrological Processes, 32, 1137-1153.

Amajor L. C., 1991. Aquifers in the Benin Formation (Miocene Recent), Eastern Niger Delta, Nigeria: Lithostratigraphy, Hydraulics, and Water Quality. Environ Geol Water Sci, 17, 85-101.

Amoussou H.S., 2005. Morpho-Dynamique du delta de la Sô, Mémoire de Maîtrise, DGAT, FLASH, UAC, $108 \mathrm{p}$.

Anderson, M.P., Woessner W.W., 1992. The role of postaudit in model validation. Advances in Water Resources 15, 167-173.

Anderson, M.R. and Woessner, W.W., 1992. Applied groundwater modeling: simulation of flow and advective transport, First Edition. San Diego, CA: Academic Press.

Apello. C. A. J., Postma. D., 2005. Geochemistry, groundwater and pollution 2nd edition. Balkema publisher, USA. 649p.

Aranyossy, J. F., 2007. First results of the isotopic study of the Doula Quaternary (Cameroun). IAEA, Proceedings of the symposium: Advances in Isotope Hydrology and its Role in Sustainable Water Resources Management, 2, 37-48.

Azontonde, H. A., 1991. Propriétés physiques et hydrauliques des sols au Bénin. Soil Water Balance in the Sudano Sahelian Zone ( Proceedings of the Niamey Workshop, February 1991). IAHS Publ. no. 199,1991.

Baalousha, H.M, 2012. Modelling surface-groundwater interaction in the Ruataniwha basin, Hawke's Bay, New Zealand. Environ Earth Sci, 66, 285-294.

Babiker, M., Gudmundsson, A., 2004. The effects of dykes and faults on groundwater flow in an arid land: the Red Sea Hills, Sudan. Journal of Hydrology, 297, 256-273.

Bagarello, V., Provenzano, G., 1996. Factors affecting field and laboratory measurement of saturated hydraulic conductivity. Transactions of the American Society of Agricultural Engineers, 39, 153-159.

Bakker, M., Bartholomeus, R., Ferre, T., 2013. Groundwater recharge: processes and quantification. Hydrol. Earth Syst. Sci. 17, 2653-2655.

Baldassarre, G. D., Montanari, A., 2009. Uncertainty in river discharge observations: a quantitative analysis. Hydrol. Earth Syst. Sci., 13, 913-921.

Barthel R., 2014. A call for more fundamental science in regional hydrogeology. Hydrogeology journal, 22, 507-510. DOI 10.1007/s10040-014-1101-9.

Basu, N. B., Rao, P. S. C., Winzeler, H. E., Kumar, S., Owens, P., Merwade, V., 2010. Parsimonious modeling of hydrologic responses in engineered watersheds: Structural heterogeneity versus functional homogeneity, Water Resour. Res., 46, W04501.

Batu, V., 1998. Aquifer Hydraulics: A Comprehensive Guide to Hydrogeologic Data Analysis, John Wiley \& Sons, New York, 727p. 
Benson, C.H., Trast, J.M., 1995. Hydraulic Conductivity of Thirteen Compacted Clays. Clays Clay Miner. 43, 669-681.

Biao, E. I, 2017. Assessing the Impacts of Climate Change on River Discharge Dynamics in Ouémé River Basin (Benin, West Africa). Hydrology, 4, 47; doi:10.3390/hydrology4040047.

Bicalho, C.C., Batiot-Guilhe, C., Taupin, J.D., Patris, N., Van Exter, S., Jourde, H., 2017. A conceptual model for groundwater circulation using isotopes and geochemical tracers coupled with hydrodynamics: A case study of the Lez karst system, France. Chemical Geology, in press.

Blöschl, G., et al., 2019. Twenty-three unsolved problems in hydrology (UPH) - a community perspective, Hydrological Sciences Journal, 64:10, 1141-1158.

Boronina, A., Balderer, W., Renard, P., Stichler, W., 2005. Study of stable isotopes in the Kouris catchment (Cyprus) for the description of the regional groundwater flow. Journal of Hydrology, 308, 214-226.

Boukari, M., 1998. Fonctionnement du système aquifère exploité pour l'approvisionnement en eau de la ville de Cotonou sur le littoral béninois. Impact du développement urbain sur la qualité des ressources. PhD thesis, Université Cheikh Anta Diop, Dakar, Sénégal.

Boukari, M., 2002. Réactualisation des connaissances hydrogéologiques relatives au bassin sédimentaire côtier du Benin, Report, 134p, Direction de l'Hydraulique. Appui á la Gestion des Ressources en Eau (AGRE), Cotonou, Benin.

Boukari, M., 2007. Hydrogeologie de la republique du Benin (Afrique de l'ouest). Africa geosciences revue, 14, 303-328.

Boukari, M., Alassane, A., 2007. Les ressources en eaux souterraines du bassin sédimentaire côtier de la République du Bénin. Africa Geoscience Review, 14, 283-301.

Bouzid M., 1971. Développement de l'utilisation des eaux souterraines, Dahomey : hydrogéologie. Rapport technique 1, PNUD -FAO. SF/DAH3. Rome, Italie. $88 \mathrm{p}$

Bovolo, C.I., Parkin, G., Sophocleous, M., 2009. Groundwater resources, climate and vulnerability. Environ. Res. Lett. 4 (3), 035001.

Bredehoeft, J., 2005. The conceptualization model problem: surprise. Hydrogeol Journal, 13, 37-46.

Brikic, Z., Briski, M., Markovic, T., 2016. Use of hydrochemistry and isotopes for improving the knowledge of groundwater flow in a semiconfined aquifer system of the Eastern Slavonia (Croatia). Catena, 142, 153-165.

Brown, G. O., 2002. Henry Darcy and the making of a law. Water Resources Research, 38:7, 1106.

Brunel, J.P., Bouron, B., 1992. Evaporation des nappes d'eau libre en Afrique sahelienne et tropicale. ORSTOM, Paris, France. 
BURGEAP-BRGM. 1994. Projet d'alimentation en eau potable des areas lacustres des Départements de l'Atlantique et de l'Ouémé. Rapport final, 64 p. Direction de I'Hydraulique, Cotonou, Bénin.

Candela L., Elorza F.J., Tamoh K., 2013. Groundwater modelling with limited data sets: the Chari-Logone area (Lake Chad Basin, Chad). Hydrol Processes, 28, 3714-3727. doi:10.1002/hyp.9901.

Candela, L., von Igel, W., Javier Elorza, F., Aronica, G., 2009. Impact assessment of combined climate and management scenarios on groundwater resources and associated wetland (Majorca, Spain). J. Hydrol. 376 (3-4), 510-527.

Carrera, J., Alcolea, A., Medina, A., Hidalgo, J., Slooten, L. J., 2005. Inverse problem in hydrogeology. Hydrogeol J, 13, 206-222

Carrera, J.,, Neuman, S. P., 1986. Estimation of aquifer parameters under transient and steady state conditions: 1. Maximum-likelihood method incorporating prior information, Water Resour. Res., 22(2), 199-210, doi:10.1029/WR022i002p00199.

Carter R. C., Morgulis E. D., Dottridge J., Agbo J. U., 1994. Groundwater modelling with limited data: a case study in a semi-arid dune field of northeast Nigeria. Quarterly Journal of Engineering Geology, 27, S85-S94.

Carter, R. C., Parker, A., 2009. Climate change, population trends and groundwater in Africa, Hydrological Sciences Journal, 54:4, 676-689, DOI: 10.1623/ hysj.54.4.676.

Castany, G., 1988. Hydrogéologie : principes et méthodes. Dunod, Paris. 236p.

Celle-Jeanton, H., Huneau, F., Travi, Y., Edmunds, W. M., 2009. Twenty years of groundwater evolution in the Triassic sandstone aquifer of Lorraine: impacts on baseline water quality. Applied Geochemistry, 24, 1198-1213.

Celle-Jeanton, H., Zouari, K., Travi, Y., Daoued, A., 2001. Caractérisation isotopique des pluies en Tunisie. Essaie de typologie dans la région de Sfax. C.R. Acad. Sci. Paris Sci. Terre Planètes 333, 625-631.

Chen, X., 2000. Measurement of streambed hydraulic conductivity and its anisotropy. Environmental Geology 39, 1-8.

Chen, X., 2004. Streambed hydraulic conductivity for rivers in South-central Nebraska. Journal of the American Water Resources Association, 03012, 561-573.

Chen, Y.C., Tsai, J.P., Chang, L.C., Chang, P.Y., Lin, H., 2018. Estimating hydraulic conductivity fields in composite fan delta using vertical electrical sounding. Water, 10, 1620.

Colombani, J., Sircoulon, J., Moniod, F., Rodier, J., 1972. Monographie du delta de l'Ouémé (Tome 1\&2). ORSTOM, Paris, France.

Craig, M. B., Thomas, M. J., 2008. Groundwater Age and Groundwater Age Dating. Annu. Rev. Earth Planet. Sci., 36, 121-152.

Crosbie, R.S., Peeters, L.J.M., Herron, N., McVicar, T.R., Herr, A., 2018. Estimating groundwater recharge and its associated uncertainty: Use of regression kriging and the chloride mass balance method. Journal of Hydrology, 561, 1063-1080. 
Daganzo, C. F., Gayah, V. V., Gonzales, E. J., 2012. The potential of parsimonious models for understanding large scale transportation systems and answering big picture questions. Euro J Transp Logist, 1, 47-65.

Dassi, L. and Tarki, M., 2014. Isotopic tracing for conceptual models of groundwater hydrodynamics in multilayer aquifer systems of central and southern Tunisia. Hydrological Sciences Journal, 59:6, 1240-1258.

de Kloe, A., 2014. Calibrating a rainfall-runoff model in a data scarce catchment in Mozambique. Master thesis, Delft University of Technology.

de Louw, P.G.B., Oude Essink, G.H.P., Stuyfzand, P.J., van der Zee, S.E.A.T.M., 2010. Upward groundwater flow in boils as the dominant mechanism of salinization in deep polders, The Netherlands. Journal of Hydrology, 394, 494-506.

de Marsily, G., Delay, F., Teles, V., Schafmeister, M. T., 1998. Some current methods to represent the heterogeneity of natural media in hydrogeology. Hydrogeology Journal, 6 , 115-130.

de Rienzo, F., Oreste, P., Pelizza, S., 2008. Subsurface geological-geotechnical modelling to sustain underground civil planning. Eng. Geol. 96, 187-204. http://dx.doi.org/10. 1016/j.enggeo.2007.11.002.

Delhomme J.P., 1979. Spatial Variability and Uncertainty in Groundwater Flow Parameters: A Geostatistical Approach. Water Resources Research, 15, 269-280.

Delin, G.N., Healy, R.W., Lorenz, D.L., Nimmo, J.R., 2007. Comparison of local- to regionalscale estimates of ground-water recharge in Minnesota, USA. J. Hydrol. 334, 231-249. doi:10.1016/j.jhydrol.2006.10.010

Dhaoui, Z., Zouari, K., Taupin, J.D., Farouni, R., 2016. Hydrochemical and isotopic investigations as indicators of recharge processes of the Continental Intercalaire aquifer (eastern piedmont of Dahar, southern Tunisia). Environmental Earth Sciences, 75: 1186, doi:10.1007/s12665-016-5990-x.

Diallo, I., Sylla, M. B., Giorgi, F., Gaye, A. T., Camara, M., 2012. Multimodel GCM-RCM Ensemble-Based Projections of Temperature and Precipitation over West Africa for the Early 21st Century, International Journal of Geophysics, 2012, 1-19.

Dieng, M., 2017. Etude de la relation eaux de surface-eaux souterraines dans un contexte de changements climatiques dans la zone Sud du bassin du Saloum (Sénégal). PhD thesis, Univeristé de Liège, Belgium.

Dieng, N. M., Orban, P., Otten, J., Stumpp, C, Faye, S., Dassargues, A., 2017. Temporal changes in groundwater quality of the Saloum coastal aquifer. Journal of Hydrology: Regional Studies, 9, 163-182.

Doherty, J., 2002. Manual for PEST, $5^{\text {th }}$ edition. Brisbane, Australia: Water Numerical Computing.

Dragoni, W., Sukhija, B.S., 2008. Climate change and groundwater: a short review. Special Publication No. 288. The Geological Society, London, pp. 1-12. 
Dray, M., Giachello, L., Lazzaroto, V., Mancini, M., Roman, E. and Zuppi, G. M., 1989. Etude isotopique de l'aquifère crétacé du bassin sédimentaire côtier béninois. Hydrogeologie, 3, 167-177.

Du, X., Lu, X., Hou, J., Ye, X., 2018. Improving the reliability of numerical groundwater modeling in a data-sparse region. Water, 10, 289.

Engelhardt, I, De Aguinaga, J.G., Mikat, H., Schüth, C., Liedl, R., 2014. Complexity vs. Simplicity: Groundwater model ranking using information criteria. Groundwater, 52, 4, 573-583.

EROS, 2002. Shuttle Radar Topography Mission (SRTM) elevation data set. National and Aeronautics and Space Administration (NASA), From: the National Center for Earth Observations and Science, U.S. Geological Survey, Sioux Falls, SD.

Erskine, A. D., 1991. The effect of tidal fluctuation on a coastal aquifer in the U. K., Ground Water, 29, 556-562.

Ette O. J., Okuofu C. A., Adie D.B., Igboro S. B., Alagbe S. A., Etteh C. C., 2017. Application of environmental isotope to access the renewability of groundwater of continental intercalaire aquifer of Sokoto basin in Northweastern Nigeria. Groundwater for Sustainable Development, 4, 35-41.

Fadilah, T., Gross, L., Schaa, R., 2018. Estimation of aquifer properties using surface based electrical resistivity tomography. EAGE-HAGI 1st Asia Pacific Meeting on Near Surface Geoscience and Engineering; Yogyakarta; Indonesia; Code 137601.

Fadili, A., Mehdi, K., Riss, J., Najib, S., Makan, A., Boutayab, K., 2015. Evaluation of groundwater mineralization processes and seawater intrusion extension in the coastal aquifer of Oualidia, Morocco: hydrochemical and geophysical approach. Arabian Journal of Geosciences, 8, 8567-8582.

Faye, S., Maloszewski, P., Stichler, W., Trimborn, P., Faye, S.C., Gaye, C.B., 2005. Groundwater salinisation in the Saloum (Senegal) delta aquifer: minor elements and isotopic indicators. Science of the Total Environment, 343, 243-259.

Fernandes, A. J. , Maldaner, C. H., Negri, F., Rouleau, A., Wahnfried, I. D., 2016. Aspects of a conceptual groundwater flow model of the Serra Geral basalt aquifer (Sao Paulo, Brazil) from physical and structural geology data. Hydrogeol Journal, 24,1199-1212.

Fraust, C. R., Silka, L.R., Mercer, J.M., 1981. Computer modeling and groundwater protection. Groundwater, 19, 362-365

Freeze, R. A., 1994. Henry Darcy and the fountains of Dijon. Ground Water. 32, 23-30.

Freeze, R.A., Cherry, J.A., 1979. Groundwater. Prentice-Hall, Inc, Englewood Cliffs, NJ, p. 604.

Froukh, L.J., 2002. Groundwater Modelling in Aquifers with highly Karstic and Heterogeneous Characteristics (KHC) in Palestine. Water Resour. Manag., 16, 369-379. 
Gabaix, X., Laibson, D., 2008. "The Seven Properties of Good Models." In The foundations of positive and normative economics: A handbook, edited by A. Caplin and A. Schotter, (pp. 292-299). New York, NY: Oxford University Press.

Ge, J., Chen, J., Ge, L., Wang, T., Wang, C., 2016. Isotopic and hydrochemical evidence of groundwater recharge in the Hopq Desert, NW China. J Radioanal Nucl Chem, 310, 761775.

Géohydraulique, 1985. Notice explicative de la carte hydrogéologique á l'échelle 1/200 000 du Bassin Sédimentaire Côtier du Benin. Report, 23p, Direction Générale de I'Hydraulique, Cotonou, Benin.

Ghasemizadeh, R., Hellweger, F., Butscher, C., Padilla I., Vesper, D., Field, M., Alshawabkeh, A., 2012. Review: Groundwater flow and transport modeling of karst aquifers, with particular reference to the North Coast Limestone aquifer system of Puerto Rico. Hydrogeology Journal, 20, 1441-1461.

Ghouili, N., Ribeiro, L., Zammouri, M., Horriche, F.J., 2017. Effect of the spatial variability of transmissivity on the groundwater flow and budget of the Takelsa multilayer aquifer, Tunisia. Environmental Earth Sciences, 76, 699.

Giorgi, F., Jones, C., Asrar, G., 2009. Addressing climate information needs at the regional level: the CORDEX framework. World Meteorological Organization (WMO) Bulletin 58:175-183.

Gning, A. A., Orban, P., Gesels, J., Ngom, D. N., Dassargues, A., Malou, R., Brouyère, S., 2017. Factors controlling the evolution of groundwater dynamics and chemistry in the Senegal River Delta. Journal of Hydrology: Regional Studies, 10, 133-144.

Gomez G., 1979. Contribution á l'étude des formations superficielles au Nord-Est de la dépression de la Lama. Essai d'interprétation géodynamique de cette dépression. PhD thesis, Université Paris VII, France.

Gomez-Hernandez, J.J., Gorelick, S.M., 1989. Effective Groundwater Model Parameter Values' Influence of Spatial Variability of Hydraulic Conductivity, Leakance, and Recharge. Water Resources Research, 25, 405-419

Gossel, W., Ebraheem, A. M., Wycisk, P., 2004. A very large scale GIS-based groundwater flow model for the Nubian sandstone aquifer in Eastern Sahara (Egypt, northern Sudan and eastern Libya). Hydrogeology Journal, 12, 698-713.

Green, T.R., Taniguchi, M., Kooi, H., Gurdak, J. J., Allen, D. M., Hiscock, K. M., Treidel, H., Aureli, A., 2011. Beneath the surface of global change: Impacts of climate change on groundwater. Journal of Hydrology, 405, 532-560.

Green, T.R., Taniguchi, M., Kooi, H., Gurdak, J. J., Allen, D. M., Hiscock, K. M., Treidel, H., Aureli, A., 2011. Beneath the surface of global change: Impacts of climate change on groundwater. Journal of Hydrology, 405, 532-560. 
Gunther, T., Muller-Petke, M., 2012. Hydraulic properties at the North Sea island of Borkum derived from joint inversion of magnetic resonance and electrical resistivity soundings. Hydrology and Earth System Sciences, 16, 3279-3291.

Hao, Z.C., An, G.Y., Wang, J.H., Li, L., Meng, J., 2012. Laboratory measurement of soil saturated hydraulic conductivity in source region of Yellow River. Journal of Hohai University, 40, 9-12.

Hatch, C.E., Fisher, A.T., Ruehl, C.R., Stemler, G., 2010. Spatial and temporal variations in streambed hydraulic conductivity quantified with time-series thermal methods. J. Hydrol. 389, 276-288.

Hesch, W., Chmakov, S., 2011. A Unified Modeler's Workbench: Workflow-Driven Conceptual and Numerical Modeling. Proceedings ModelCARE2011 held at Leipzig, Germany, in September 2011.

Hill, M. C, 1986. The Practical Use of Simplicity in Developing Ground Water Models. Groundwater, 44, 775-781.

Hill, M.C, Tiedeman, C.R., 2007. Effective groundwater model calibration: with analysis of data, sensitivities, predictions, and uncertainty. Hoboken, New Jersey: John Wiley and Sons.

Hill, M.C., 1998. Methods and Guidelines for Effective Model Calibration. Water Resource Investigations Report 98-4005, US Geological Survey, Water Resources Division, Denver.

Hill, M.C., 2006. The practical use of simplicity in developing groundwater models. GroundWater, 44, 775-781.

Holger Treidel, Jose Luis Martin-Bordes, Jason J. Gurdak, 2011. Climate Change Effects on Groundwater Resources: A Global Synthesis of Findings and Recommendations, CRC Press, $414 \mathrm{p}$.

Houessou, A., 1974. Etudes des formations détritiques de l'ouest du bassin sédimentaire côtier du Dahomey. PhD thesis, Université de Lille, France. $138 \mathrm{p}$

Houndagba, J. C., 2015. Dynamique des paysages naturels dans le centre du Benin. PhD thesis, Université d'Abomey-Calavi, Abomey-Calavi. 349p.

Hu, R. L., Yue, Z. Q., Wang L. C. , Wang, S. J., 2004. Review on current status and challenging issues of land subsidence in China. Eng Geol 76:65-77. Review on current status and challenging issues of land subsidence in China. Eng Geol 76: 65-77.

Hubbert, M.K., 1957. Darcy's law and the field equations of the flow of underground fluids, Hydrological Sciences Journal, 2, 23-59.

Huneau, F., Rey, F., Riss, J., Pretou, F., Celle-Jeanton, H., 2007. Groundwater resources from carbonate rocks in mountainous regions: hydrochemical and isotopic survey of groundwaters in the western Pyrenees (France). IAEA, Proceedings of the symposium: Advances in Isotope Hydrology and its Role in Sustainable Water Resources Management, 2, 67-75. 
Hurkmans, R.T.W.L., 2009. Effects of climate variability and land use change on the water budget of large river basins. PhD thesis, Wageningen University, Wageningen, the Netherlands.

Hussein, M. T., 2004. Hydrochemical evaluation of groundwater in the Blue Nile Basin, eastern Sudan, using conventional and multivariate techniques. Hydrogeology Journal 12, 144-158.

Huyakorn, P.S., Lester, B.H., Faust, C.R., 1983.. Finite element techniques for modeling groundwater flow in fractured aquifers. Water Resources Research, 19, 1019-1035.

IAEA. (2008). Isotopes de l'environnement dans le cycle hydrologique. Book, IAEA, Vienna, $588 p$.

IAEA/WMO, 2017. Global Network of Isotopes in Precipitation. The GNIP Database. Accessible at: http://www.iaea.org/water.

Idris, H., 1996. Springs in Egypt. Environmental Geology, 27, 99-104.

IGIP, 1984. Adduction d'eau dans 13 chefs-lieux de district. Ministère de I'Industrie des Mines et de l'Energie, SBEE, Rapport de fin de travaux.

INSAE, 2013. Recensement Général de la Population et de l'Habitat. MDAEP, INSAE : Cotonou, Bénin

IRB, 1987. Etude de cartographie géologique et prospection minérale de reconnaissance au Sud du 9ème parallèle. Report. Istituto Recerche Breda, FED-OBEMINES.

Irvine, D. J., Cranswick, R. H., Simmons, C. T., Shanafield, M. A., Lautz, L. K., 2014. The effect of streambed heterogeneity on groundwater-surface water exchange fluxes inferred from temperature time series. Water Resour. Res.,51, 198-212.

Izbicki, J.A., Martin, P., Michel, R.L., 1995. Source, movement and age of groundwater in the upper part of the Mojave River Basin, California, USA. Proceedings of the 1994 International Symposium on Application of Tracers in Arid Zone Hydrology, 232, 43-56.

Jalloh, A., Nelson, G., Thomas, T., Zougmoré, R.B., Roy-Macauley, H., 2013. West African Agriculture and Climate Change: A Comprehensive Analysis. Free Downloads from IFPRI. Jiao, J. J., Lerner, D. N., 1996. Using Sensitivity Analysis to Assist Parameter Zonation in Ground Water Flow Model. Water Resources Bulletin, American Water Resources Association, 32, 1.

Jiao J. J., Tang, Z., 1999. An analytical solution of groundwater response to tidal fluctuation in a leaky confined aquifer. Water Resources Research, 35, 747-751.

Jones, N. L., Budge, T. J., Lemon, A. M., Zundel, A. K., 2002. Generating MODFLOW Grids from Boundary Representation Solid Models. Groundwater, 40 (2), 194-200.

Jones, N.L., Wright, S.G., 1993. Subsurface characterization with solid models. J.Geotech. Eng. 119, 1823-1839.

Kallioras, A., Pliakas, F., Diamantis, I., 2010. Simulation of groundwater flow in a sedimentary aquifer system subjected to overexploitation. Water Air Soil Pollut., 211, 177-201. 
Kikuchi, C., Ferré, T. P. A., 2014. Quantifying Groundwater Recharge Uncertainty: A Multiple-Model Framework and Case Study. Proceedings of the American Geophysical Union Fall Meeting, 2014. abstract id. H33C-0818.

Kinzelbach, W., Bauer, P., Siegfried, T., Brunne, P., 2003. Sustainable groundwater management problems and scientific tools. Episodes, 26, 4.

Konikow, L.F., Kendy, E., 2005. Groundwater depletion: A global problem. Hydrogeol Journal, 13: 317-320. https://doi.org/10.1007/s10040-004-0411-8

Korving, H., van Gelder, P., van Noortwijk, J., Clemens, F., 2002. Influence of model parameter uncertainties on decision-making for sewer system management. Proceedings of the Fifth International Conference on Hydroinformatics, Cardiff, UK.

Kpegli, K. A. R., Alassane, A., van der Zee, S.E.A.T.M, Boukari, M., Mama, D., 2018a. Development of a conceptual groundwater flow model using a combined hydrogeological, hydrochemical and isotopic approach: a case study from southern Benin. Journal of Hydrology : Regional Studies, 18, 50-67.

Kpegli, K. A. R., van der Zee, S.E.A.T.M, Alassane, A., Bier, G., Boukari, M., Leijnse, A., de Louw, P.G.B., Mama, D., 2018b. Impact of hydraulic and storage properties on river leakage estimates: A numerical groundwater flow model case study from southern Benin. Journal of Hydrology : Regional Studies, 19, 136-163.

Kpegli, K.A.R., Alassane, A., Trabelsi, R., Zouari, K., Boukari, M., Mama, D., Dovonon, F.L., Yoxi, Y.V., Toro-Espitia, L.E., 2015. Geochemical processes in Kandi Basin, Benin, West Africa: A combined hydrochemistry and stable isotopes approach. Quaternary International, 369, 99-109.

Kresic N., Mikszewski, A., 2013. Hydrogeological conceptual site models: data analysis and visualization. CRC Press, Boca Raton FLA, 584 pp.

Kresic, N., 2006. Hydrogeology and groundwater modeling. CRC Press book, second edition, $807 p$.

Kumar, C.P., 2012. Groundwater Modelling Software - Capabilities and Limitations. Journal of Environmental Science, Toxicology and Food Technology, 1, 46-57.

Lackey, G., Neupauer, R.M., Pitlick, J., 2015. Effects of streambed conductance on stream depletion. Water, 7, 271-287

Lang, M., Perret, C., Renouf, E., Sauquet, E., Paquier, A., 2006. Uncertainty of flood discharge estimates. La Houille Blanche, 6, 33-41.

Lanini, S., Caballero, Y., 2016. Groundwater recharge and associated uncertainty estimation combining multi-method and multiscale approaches. International Congress on Environmental Modelling and Software 25.

Le Barbe, L., Ale, G., Millet, B., Texier, H., Borel, Y., Gualde, R., 1993. Les ressources en eau superficielles de la république du Benin. Edition Orstom, Paris, France, 540p.

Leake, S.A.; Greer, W.; Watt, D.; Weghorst, P. Use of Superposition Models to Simulate Possible Depletion of Colorado River Water by Ground-Water Withdrawal; USGS, 
Scientific Investigations Report 2008-5189; U.S. Geological Survey (USGS): Reston, VA, USA, 2008.

Lemon, A.M., Jones, N.L., 2003. Building solid models from boreholes and user-defined cross-sections. Comput. Geosci. 29, 547-555.

Li, Z., 1992. Variation of the Accuracy of Digital Terrain Models With Sampling Interval, Photogramm. Rec., 14, 113-128.

Lin, Y. P., Chen, Y. W., Chang, L. C., Yeh, M.S., Huang, G.H., Petway, J.R., 2017. Groundwater Simulations and Uncertainty Analysis Using MODFLOW and Geostatistical Approach with Conditioning Multi-Aquifer Spatial Covariance. Water, 9, 164.

Liu, S., Chui, T.F.M., 2018. Impacts of Streambed Heterogeneity and Anisotropy on Residence Time of Hyporheic Zone. GroundWater, 56 (3), 425-436.

Lohman, S. W., 1972. Groundwater hydraulics. Report, Geological Survey professional paper 708.

Liu, Y., Jiao, J. J., Luo, X., 2016. Effects of inland water level oscillation on groundwater dynamics and land-sourced solute transport in a coastal aquifer. Coastal Engineering ,114, 347-360.

Lubczynski, M.W., Gurwin, J., 2005. Integration of various data sources for transient groundwater modeling with spatio-temporally variable fluxes-Sardon study case, Spain. J. Hydrol., 306, 71-96.

Luckey, R.R., Becker, M.F., 1999. Hydrogeology, water use, and simulation of flow in the High Plains aquifer in northwestern Oklahoma, southeastern Colorado, southwestern Kansas, northeastern New Mexico, and northwestern Texas. USGS, Water-Resources Investigations Report 99-4104.

M'Po, N. Y., Lawin, A. E., Oyerinde, G. T., Yao, B. K., Afouda, A. A., 2016. Comparison of Daily Precipitation Bias Correction Methods Based on Four Regional Climate Model Outputs in Ouémé Basin, Benin. Hydrology. 4, 6, 58-71.

Macdonald, A. M., Calow, R. C., Macdonald, D. M. J., Darling, W. G., Dochartaigh, B. É. Ó., 2009. What impact will climate change have on rural groundwater supplies in Africa?, Hydrological Sciences Journal, 54:4, 690-703, DOI: 10.1623/hysj.54.4.690.

Madigan, D., Raftery, A. E., 1994. Model selection and accounting for model uncertainty in graphical models using Occam's window. J. Am. Stat. Assoc., 89(428), 1535 - 1546, doi:10.2307/2291017.

Madioune, D. H., Faye, F., Orban, P., Brouyère, S., Dassargues, A., Mudry, J., Stumpp, C., Maloszewski, P., 2014. Application of isotopic tracers as a tool for understanding hydrodynamic behavior of the highly exploited Diass aquifer system (Senegal). Journal of Hydrology, 511, 443-459.

Madrala, M., Wasik, M., Maloszewski, P., 2017. Interpretation of environmental tracer data for conceptual understanding of groundwater flow: an application for fractured aquifer 
systems in the Kłodzko Basin, Sudetes, Poland. Isotopes in Environmental and Health Studies, 53, 466-483.

Maliki, A.R., 1993. Etude hydrogeologique du littoral Béninois dans la région de Cotonou et ses environs. Fac. des Sci. Tech. Géologie. PhD thesis, Université de Dakar, Senegal.

Marchant, B., Mackay, J., Bloomfield, J., 2016. Quantifying uncertainty in predictions of groundwater levels using formal likelihood methods. J. Hydrol., 540, 699-711.

Matyjasik, M., Yonkee, W.A., Barnett, D.A., 2002. Groundwater flow in fractured aquifers in the sevier thrust belt, Wasatch Mountains, Utah, USA.. Biuletyn - Panstwowego Instytutu Geologicznego, 404, 85-106.

Mayr, C., Lücke, A., Stichler, W., Trimborn, P., Ercolano, B., Oliva, G., Ohlendorf, C., Soto, J., Fey, M., Haberzettl, T., Janssen, S., Schäbitz, F., Schleser, G.H., Wille, M., Zolitschka, B., 2007. Precipitation origin and evaporation of lakes in semi-arid Patagonia (Argentina) inferred from stable isotopes $(\delta 180, \delta 2 H)$. Journal of Hydrology, 1, 53-63.

Mazac, O., Kelly, W.E., Landa, I., 1985. A hydrogeophysical model for relations between electrical and hydraulic properties of aquifers. Journal of Hydrology, 79, 1-19.

Mazor, E., 1995. Stagnant aquifer concept Part 1. Large-scale artesian systems- Great Artesian Basin, Australia. Journal of Hydrology, 173, 219-240.

Mazure J.P., 1932 in Bakker M., 1999. Simulating groundwater flow in multi-aquifer systems with analytical and numerical Dupuit-models. Journal of hydrology, 222, 55-64.

McDonald, M.G., Harbaugh, A.W., 1988. A modular three-dimensional finite-difference groundwater flow model. U.S. Geological Survey Techniques of Water-Resources Investigations, Book 6, Chp A1, 586 p.

Meinzer, O E , 1928. Compressibility and elasticity of artesian aquifers. Econ Geol, 23, 263291

MMEH (Ministère des Mines de l' Energie et de l'Hydraulique), 2001. Synthèse géologique du Bassin Sédimentaire Côtier du Bénin. Report, Projet de Redéfinition du Socle du bassin sédimentaire Côtier du Bénin. CEPRA, Cotonou, Benin, 141p.

Moniod F., 1973. Régime hydrologique de I'Ouémé (Dahomey). Cah. O.R.S.T.O.M., sér. Hydrol., 2, Tome 1.

Montalvan, F. J., Heredia, J., Ruiz, J. M., Pardo-Iguzquiza, E., Garcia de Domingo, A., Elorza, F. J., 2017. Hydrochemical and isotopes studies in a hypersaline wetland to define the hydrogeological conceptual model : Fuente de Piedra Lake (Malaga, Spain). Science of Total Environment, 576, 335-346.

Mook, W. G., 2000. Environmental isotopes in the hydrological cycle, Principles and Applications. International Atomic Energy Agency, Vienna.

Moussa, B. A., Zouari, K., Oueslati, N., 2009. Geochemical study of groundwater mineralization in the Grombalia shallow aquifer, north-eastern Tunisia: implication of irrigation and industrial waste water accounting. Environmental Geology, 58, 555-566. 
Münnich, K.O., 1957. Messung des 14C-Gehaltes von hartem Grundwasser. Naturwiss. 44: 32-39. In: Mook, W. G., 2000. Environmental Isotopes in the Hydrological Cycle, Principles and Applications. International Atomic Energy Agency, Vienna.

N'Tcha M'Po, Y., 2018. Évaluation de l'impact des changements climatiques et d'utilisation des terres sur les ressources en eau du bassin de l'Ouémé a Beterou à l'horizon 2050. PhD thesis, Institut National Polytechnique Félix Houphouët-Boigny, Côte d'Ivoire.

Näschen, K., Diekkrüger, B., Leemhuis, C., Steinbach, S., Seregina, L. S., Thonfeld, F., van der Linden, R., 2018. Hydrological Modeling in Data-Scarce Catchments: The Kilombero Floodplain in Tanzania. Water, 10, 599.

Newman, B. D.; Havenor, K. C., Longmire, P., 2016. Identification of hydrochemical facies in the Roswell Artesian Basin, New Mexico (USA), using graphical and statistical methods. Hydrogeol J, 24, 819-839.

Nfor, B.N., Chukwuemeka, L.O., Ogala, J.E., Olobaniyi, S.B., 2006. An Evaluation of the Artesian System of the Anambra Basin Southeastern Nigeria. European Journal of Scientific Research, 15, 140-150.

Nihei, Y., Kimizu, A., 2008. A new monitoring system for river discharge with horizontal acoustic Doppler current profiler measurements and river flow simulation. Water Resources Research, 44, W00D20, doi:10.1029/2008WR006970

Nilsson, B., Sidle, R. C., Klint, K. E., Bøggild, C. E., and Broholm, K.: Mass transport and scaledependent hydraulic tests in a heterogeneous glacial till-sandy aquifer system, J. Hydrol., 243, 162-179, 2001.

Novel, J. P., Dimadi, A., Zervopoulous, A., Bakalowiks, M., 2007. The aggitis karst system, Eastern Macedonia, Greece: Hydrologic functioning and development of the karst structure. Journal of Hydrology, 334, 477-492.

Ordens, C.M., Werner, A.D., Post, V.E.A., Hutson, J.L., Simmons, C.T., Irvine, B.M., 2012. Groundwater recharge to a sedimentary aquifer in the topographically closed Uley South Basin, South Australia. Hydrogeol. J., 20, 61-72.

Owen, S.J., Jones, N.L., Holland, J.P., 1996. A comprehensive Modeling Environment for simulation of Groundwater Flow and Transport. Engineering with Computers, 12, 235242.

Pachepsky, Y., Smettem, K., Vanderborght, J., Herbstm M., Vereecken, H., Wosten, J.H.M., 2004. Reality and fiction of models and data in soil Hydrology. Unsaturated-zone Model. Progress, challenges Appl. 231-260. Available at https://library.wur.nl/ojs/index.php/frontis/issue/view/197, accessed last in June 2018.

Pedersen, B.I., Boukari, M., 2009. Mise au point professionelle de la modelisation de la gestion des eaux souterraines de la zone de captage de Godomey, Cotonou, Benin. Report, Henrik Chritensen, Cowi A/S.

Penman, H.L., 1949. The dependence of transpiration on weather and soil conditions. J.Soil. Sci., 1, 74-89 
Penman, H.L., 1950. The water balance of the Stour catchment area. J.Inst. Water Engrs., 4, 457-469

Penna, D., Stenni, B., Wrede, S., Bogaard, T.A., Gobbi, A., Borga, M., Fischer, B.M.C., Bonazza, M., Charova, Z., 2010. On the reproducibility and repeatability of laser absorption spectroscopy measurements for delta ${ }^{2} \mathrm{H}$ and delta ${ }^{18} \mathrm{O}$ isotopic analysis. Hydrol. Earth Syst. Sci. 7, 2975-3014.

Perdomo, S., Kruse, E.E., Ainchil, J.E., 2018. Estimation of hydraulic parameters using electrical resistivity tomography (ERT) and empirical laws in a semi-confined aquifer. Near Surface Geophysics, 16, 627-641.

Pétré, M. A., Rivera, A., Lefebvre, R., 2019. Numerical modeling of a regional groundwater flow system to assess groundwater storage loss, capture and sustainable exploitation of the transboundary Milk River Aquifer (Canada - USA). Journal of Hydrology, 575, 656670

Pétré, M.A., Rivera, A., Lefebvre, R., Hendry, M.J., Folnagy, A.J.B, 2016. A unified hydrogeological conceptual model of the Milk River transboundary aquifer, traversing Alberta (Canada) and Montana (USA). Hydrogeology Journal, 24, 1847-1871.

Piani, C., Haerter, J. O., Coppola E., 2010. Statistical bias correction for daily precipitation in regional climate models over Europe. Theor. Appl. Climatol., 99: 187-192.

Picornell, Miguel, Guerra, Antonio, 1992. Comparison of field and laboratory measurements of hydraulic conductivity. ASTM Special Technical Publication, 1118, 346-361.

Pike, R., 2002. A Bibliography of Terrain Modeling (Geomorphometry), the Quantitative Representation of Topography-Supplement 4.0, USGS, 158 pp.

Post, V.E.A., Asmuth, J.R., 2013. Review: Hydraulic head measurement-new technologies, classic pitfalls. Hydrogeology Journal, 21, 737-750.

Pougnet, R., 1955. Le précambrien du Dahomey. PhD thesis, Université Clermont-Ferrand, France. $186 \mathrm{p}$

Powell, O., Fensham, R., 2015. The history and fate of the Nubian Sandstone Aquifer Springs in the oasis depressions of the Western Desert, Egypt. Hydrogeology Journal, 24, 395406.

Powell, O., Silcock, J., Fensham, R., 2015. Oases to Oblivion: The rapid demise of springs in the south-eastern Great Artesian Basin, Australia. Groundwater, 53, 171-178.

Ranjan, P., Kazama, S., Sawamoto, M., 2006. Effects of climate change on coastal fresh groundwater resources. Global Environmental Change 16, 388-399.

Rassam, D. W., Peeters, L., Pickett, T., Jolly, I., Holz, L., 2013. Accounting for surfacegroundwater interactions and their uncertainty in river and groundwater models: A case study in the Namoi River, Australia. Environmental Modelling \& Software, 50, 108-119.

Refsgaard, J. C., Christensen, S., Sonnenborg, T. O., Seifert, D., Hojberg, A. L., Troldborg, L., 2012. Review of strategies for handling geological uncertainty in groundwater flow and transport modeling. Advances in Water Resources, 36, 36-50. 
Refstegaard J.C., Hojberg A.L., Moller I., 2010. Groundwater modeling in integrated water resources management: visions for 2020. Ground Water 48, 633-648.

Roberts, C.R., Mitchell, C.W., 1987. Spring mounds in southern Tunisia. Geological Society Special Publication, 35, 321-334.

Rojas, R., Feyen, L., Dassargues, A., 2008 Conceptual model uncertainty in groundwater modeling: Combining generalized likelihood uncertainty estimation and Bayesian model averaging. Water Resour Res, 44, W12418.

Rozanski, K., 1985. Deuterium and oxygen-18 in European groundwaters-links to atmospheric circulation in the past . Chemical Geology (Isotope Geoscience Section), 52, 349-363.

Ruelland, D., Ardoin-Bardin, S., Collet, L., Roucou, P., 2012. Simulating future trends in hydrological regime of a large Sudano-Sahelian catchment under climate change. Journal of Hydrology, 424-425, 207-216

Rushton, K., 2007. Representation in regional models of saturated river-aquifer interaction for gaining/losing rivers. Journal of Hydrology, 334, $262-281$.

Rushton, K. R. , Carter, R. C., 2012. Groundwater resources of aquifers with extensive confined regions illustrated by the Woburn Sands, Bedfordshire, UK. Quarterly Journal of Engineering Geology and Hydrogeology, 45, 31-44.

Ryan, A.L., Yeow, A., Swain, L., Webber, T., 2005. Water sampling procedures, safety and quality assurance report. Ministry of Water, Land and Air Protection, Province of British Colombia, Canada. 48p.

Saito-Kokubu, Y., Matsubara, A., Miyake, M., Nishizawa, A., Ohwaki, Y., Nishio, T., Sanada, K., Hanaki, T., 2015. Progress on multi-nuclide AMS of JAEA-AMS-TONO. Nuclear Instruments and Methods in Physics Research, Section B: Beam Interactions with Materials and Atoms, 361, 48-53.

Salzmann U., Hoelzmann P., 2005. The Dahomey Gap: an abrupt climatically induced rain forest fragmentation in West Africa during the late Holocene. The Holocene 15, 190199.

Sánchez-Murillo, R., Esquivel-Hernández, G., Sáenz-Rosales, O., Piedra-Marín, G., FonsecaSánchez, A., Madrigal-Solís, H., Ulloa-Chaverri, F., Rojas-Jiménez, L.D., Vargas-Víquez, J.A., 2017. Isotopic composition in precipitation and groundwater in the northern mountainous region of the Central Valley of Costa Rica. Isotopes in Environmental and Health Studies, 53, 1, 1-17.

Sanchez-Vila, X., Girardi, J., and Carrera, J.: Scale effects in transmissivity, J. Hydrol., 183, 122, 1996.

Sappa, G., Rossi, M., 2012. Numerical modeling to estimate the artesianism evolution in north-western sahara aquifer system. Italian Journal of Engineering Geology and Environment, 1, 81-94. 
Scanlon, B. R., Keese, K. E., Flint, A. L., Flint, L. E., Gaye, C. B., Edmunds, W. M., Simmers, I., 2006. Global synthesis of groundwater recharge in semiarid and arid regions. Hydrol.Process, 20, 3335-3370.

Schuol, J., Abbaspour, K. C., Srinivasan, R., Yang, H., 2008. Estimation of freshwater availability in the West African sub-continent using the SWAT hydrologic model. Journal of Hydrology, 352, 30-49.

Segadelli, S., Vescovi, P., Ogata, K., Chelli, A., Zanini, A., Boschetti, T., Petrella, E., Toscani, L., Gargini, A., Celico, F., 2017. A conceptual hydrogeological model of ophiolitic aquifers (serpent inised peridotite): The test example of Mt. Prinzera (Northern Italy). Hydrological Processes, 31, 1058-1073.

Sethi R., Di Molfetta A., 2019. Groundwater Engineering: A Technical Approach to Hydrogeology, Contaminant Transport and Groundwater Remediation. Book, Springer Tracts in Civil Engineering, Springer, Cham.

Shuwei, Q., Xiujuan, L., Changlai, X., He, H., Zhang, F., Fengchao, L., 2015. Numerical Simulation of Groundwater Flow in a River Valley Basin in Jilin Urban Area, China. Water, 7, 5768-5787.

Sidle, W. C., 1998. Environmental isotopes for resolution of hydrology problems. Environmental Monitoring and Assessment, 52, 389-410.

Slansky M., 1962. Contribution à l'étude géologique du bassin sédimentaire côtier du Dahomey et du Togo. PhD thesis, Université de Nancy, France.

Smith, M., Cross, K., Paden, M. and Laban, P. 2016. Spring - Managing groundwater sustainably. IUCN, Gland, Switzerland.

Song, I., Rathbun, A. P., Saffer, D. M., 2011. Uncertainty of permeability and specific storage due to experimental error during data acquisition for pulse-transient technique. Proceedings of the American Geophysical Union Fall Meeting, 2011.

Sophocleous, M., 2002. Interactions between groundwater and surface water: the state of the science. Hydrogeolgy Journal, 20, 52-67.

Sossou-Agbo A. L., 2013. La mobilité dans le complexe fuvio-lagunaire de la basse vallée de I'Ouémé au Bénin, en Afrique de l'Ouest. Histoire. PhD thesis, Université de Grenoble, France.

Stuyfzand, P. J., 1999. Patterns in groundwater chemistry resulting from groundwater flow. Hydrogeology Journal, 7, 15-27.

Suganthi, S., Elango, L., Subramanian, S. K., 2017. Microwave D-InSAR technique for assessment of land subsidence in Kolkata city, India. Arab J Geosci, 10:458.

Sultan, M., Ahmed, M., Sturchio, N., Yan, Y.E., Milewski, A., Becker, R., Wahr, J., Becker, D., Chouinard, K., 2013. Assessment of the Vulnerabilities of the Nubian Sandstone Fossil Aquifer, North Africa. Climate Vulnerability: Understanding and Addressing Threats to Essential Resources, 5, 311-333. 
Sutanudjaja, E. H., van Beek, L. P. H., de Jong, S. M., van Geer, F. C., Bierkens, M. F. P., 2011. Large-scale groundwater modeling using global datasets: a test case for the RhineMeuse basin. Hydrol. Earth Syst. Sci., 15, 2913-2935.

Szabo, Z., Rice, D. E., Plummer, L. N., Busenberg, E., Drenkard, S., Schlosser, P., 1996. Age Dating of Shallow Groundwater with Chlorofluorocarbons, Tritium/Helium: 3, and Flow Path Analysis, Southern New Jersey Coastal Plain. Water resource research, 32, 10231038.

Tam, V.T., Batelaan, O., Le, T.T., Nhan, P.Q., 2014. Three-dimensional hydrostratigraphical modelling to support evaluation of recharge and saltwater intrusion in a coastal groundwater system in Vietnam. Hydrogeology Journal, 22, 1749-1762.

Taylor, C.B., 1976. IAEA Isotope Hydrology Laboratory, Technical Procedure Note No. 19. International Atomic Energy Agency, Vienna.

Todd, D.K., 1980. Groundwater Hydrology, 2nd ed., John Wiley \& Sons, New York, 535p.

Tonini, A., Guastaldi, E., Massa, G., Conti, P., 2008. 3D geo-mapping based on surface data for preliminary study of underground works: a case study in Val Topina (Central Italy). Eng. Geol. 99, 61-69.

Touch, S., Likitlersuang, S., Pipatpongsa, T., 2014. 3D geological modelling and geotechnical characteristics of Phnom Penh subsoils in Cambodia. Engineering Geology, 178, 58-69.

Toure, A., Diekkrüger, B., Mariko, A., Cissé, A. S., 2017. Assessment of Groundwater Resources in the Context of Climate Change and Population Growth: Case of the Klela Basin in Southern Mali. Climate 2017, 5, 45; doi:10.3390.

Troldborg, L., Refsgaard, J. C., Jensen, K. H., 2007. The importance of alternative conceptual models for simulation of concentrations in a multi-aquifer system. Hydrogeol J, 15, 843860.

Turkpak International-SCET-Tunisie, 1991. Inventaire des ressources en eaux souterraines au Bénin. Rapport final, Direction de l'Hydraulique, Cotonou, Bénin. 1. 284 p.

Turner, A.K., 2006. Challenges and trends for geological modelling and visualisation. Bull. Eng. Geol. Environ. 65, 109-127.

UN., 2017. World Population Prospects: The 2017 Revision. New York: United Nations.

Valerio, A., Rajaram, H., Zagona, E., 2010. Incorporating groundwater-surface water interaction into river management models. Groundwater 48 (5), 661-673.

Verhagen, B. T., 1995. Semiarid zone groundwater mineralization processes as revealed by environmental isotope studies. Application of Tracers in Arid Zone Hydrology (Proceedings of the Vienna Symposium, August 1994). IAHS Publ. no. 232.

Virbulis, J., Bethers, U., Saks, T., Sennikovs, J., Timuhins, A., 2013. Hydrogeological model of the Baltic Artesian Basin(Article) [Modèle hydrogéologique du bassin artésien de la Baltique]. Hydrogeology Journal, 21, 845-862. 
Voss, C.I., Soliman, S.M., 2014. The transboundary non-renewable Nubian Aquifer System of Chad, Egypt, Libya and Sudan: Classical groundwater questions and parsimonious hydrogeologic analysis and modeling. Hydrogeology Journal, 22, 441-468.

Voss, I.C., 2011. Editor's message: Groundwater modeling fantasies-part 2, down on earth. Hydrogeology Journal, 19, 1455-1458.

Wada, Y., van Beek, L. P. H., van Kempen, C. M., Reckman, J. W. T. M., Vasak, S., Bierkens, M. F. P., 2010. Global depletion of groundwater resources. Geophysical Research Letters, 37, L20402.

Wang, Q., Zhan, H., 2017. Intrawellbore kinematic and frictional losses in a horizontal well in a bounded confined aquifer. Water Resources Research, 53, 127-141.

Wechsler, S. P., 2003. Perceptions of Digital Elevation Model Uncertainty by DEM Users, URISA Journal, 15, 57-64.

Weller, U., 2002. Land Evaluation and Land Use Planning for Southern Benin (West Africa). PhD thesis, University of Hohenheim, Stuttgart, Gemany.

Welsh, W.D., 2006. Great Artesian Basin Transient Groundwater Model. Bureau of Rural Sciences, Department of Agriculture, Fisheries and Forestry, Australia.

White, J. K., Roberts, T. O. L., 1994. The significance of groundwater tidal fluctuations, in Groundwater Problems in Urban Areas: Proceeding of the International Conference Organized by the Institution of Civil Engineers and Held in London, 2-3 June 1993, edited by W. B. Wilkinson, pp. 31-42, Thomas Telford, London.

Wilcke, R., Mendlik, T., Gobiet, A., 2013. Multi-variable error correction of regional climate Models. Climatic Change, 120, 871-887.

Wildemeersch, S., 2012. Assessing the impact of technical structure choices on groundwater model performance using complex sythetic case. PhD thesis, Université de Liege, Belgium.

Wildemeersch, S., Goderniaux, P., Orban, P., Brouyère, S., Dassargues A., 2014. Assessing the effects of spatial discretization on large-scale flow model performance and prediction uncertainty. Journal of Hydrology, 510, 10-25.

Wilson, G. V., Jardine, P.M., Luxmoore, R. J., Todd, D. E., Lietzke, D. A., 1991. Hydrogeochemical processes controlling subsurface transport from an upper subcatchment of Walker Branch Watershed during storm events, 2, Solute transport processes, J. Hydrol., 123, 317-336.

Winter, T.C., Harvey, J.W., Franke, O.L., Alley, W.M., 1998. Ground water and surface water: a single resource, US Geological Survey Circular 1139

Wise, S., 2000. Assessing the quality for hydrological applications of digital elevation models derived from contours, Hydrol. Processes, 14, 1909-1929.

Woessner W.W., 2000. Stream and fluvial plain ground water interactions: rescaling hydrogeologic thought. Ground Water, 38, 423-9. 
Wu, Y., Wang, W., Toll, M., Alkhoury, W., Sauter, M., Kolditz, O., 2011. Development of a 3D groundwater model based on scarce data: the Wadi Kafrein catchment/Jordan. Environ Earth Sci, 64, 771-785.

Wu, Q., Xu, H., Zou, X., 2005. An effective method for 3D geological modeling with multisource data integrationComput. Geosci. 31, 35-43.

Wu, J.C., Zeng, X.K., 2013. Review of the uncertainty analysis of groundwater numerical. Chin Sci Bull, 58, 3044-3052.

$\mathrm{Xu}$, Z., Hu, B.X., Xu, Z., Wu, X., 2019. Simulating seawater intrusion in a complex coastal karst aquifer using an improved variable-density flow and solute transport-conduit flow process model. Hydrogeology Journal, in press.

Yalo, N., d'almeida, G.F., Dovonou, F., 2014. Estimation of an unconfined sandy aquifer parameters using gravimetric and geoelectrical methods. International Research Journal of Geology and Mining, 4, 20-28.

Yang, X., Steward, D. R., de Lange, W. J., Lauwo, S. Y., Chubb, R. M., Bernard, E. A., 2010. Data model for system conceptualization in groundwater studies. International Journal of Geographical Information Science, 24:5, 677-694.

Yao, Y., Zheng, C., Liu, J., Cao, G., Xiao, H., Li, H., Li, W., 2014. Conceptual and numerical models for groundwater flow in an arid inland river basin. Hydrological processes, 29, 1480-1492.

Yeh, W. G., Yoon, Y. S., 1981. Aquifer parameter-identification with optimum dimension in parameterization, Water Resour. Res., 17(3), 664-672, doi:10.1029/WR017i003p00664.

Yermani, M., Zouari, K., Michelot, J. L., Mamou, A., Moumni, L., 2003. Approche géochimique du fonctionnement de la nappe profonde de Gafsa Nord (Tunisie centrale), Hydrological Sciences Journal, 48, 95-108. DOI: 10.1623/hysj.48.1.95.43482.

Zammouri, M., Ribeiro, L., 2017. 2017. Analyzing the effect of transmissivity uncertainty on the reliability of a model of the northwestern Sahara aquifer system. Journal of African Earth Sciences, 129, 910-922.

Zech, A., Arnold, S., Schneider, C., Attinger, S., 2015. Estimating parameters of aquifer heterogeneity using pumping tests - implications for field applications. Advances in Water Resources, 83, 137-147.

Zhao, L.J., Eastoe, C.J., Liu, X.H., Wang, L.X., Wang, N.L., Xie, C., Song, Y.X., 2018. Origin and residence time of groundwater based on stable and radioactive isotopes in the Heihe River Basin, northwestern China. Journal of Hydrology: Regional Studies, 18, 31-49.

Zheng, C., Bennett, G., 1995. Applied contaminant transport modeling. Wiley, NewYork.

Zhu, L., Zhang, C., Li, M., Pan, X., Sun, J., 2012. Building 3D solid models of sedimentary stratigraphic systems from borehole data: an automatic method and case studies. Eng. Geol. 127, 1-13. 


\section{English summary}

Water resources in general and groundwater resources particularly are vital to mankind in most places on earth. The security of groundwater resources supply to feed a growing population will become increasingly uncertain. Groundwater resources are finite and there is a need to deal with complex groundwater systems and manage them sustainably. Managing them sustainably can significantly contribute to water security for various purposes including domestic usages and food security.

Quantitative threats to groundwater resources are expressed in terms of continuous groundwater heads declines, meaning that when an aquifer displays a constant decrease in its hydraulic head, then this may become alarming for water managers. Examples of aquifers displaying some depletions are numerous across the world. The case of the Cretaceous aquifer in southern Benin, where some artesian wells display decrease in their flow rates, has drawn attention in this PhD research. In fact, the literature indicates that artesian free-flow cessations (due to artesian head-drops) have occurred in other basins including the Great Artesian Basin in Australia. So, some questions that need to be elucidated for the case of southern Benin are: how will artesian head evolve during the next decades? Are there risks for complete cessation of artesian wells free-flows?

Addressing such questions requires a deep knowledge regarding the aquifer's flow setting, its interactions with the surface water and its reactions to present and future stresses. Conceptualizing the flow setting of the concerned aquifer is fundamental with regard to the above questions but can be attached to errors. Hence, the first question we addressed in this thesis is: how could we build on both the lithostratigraphy, piezometry, hydrochemistry and isotopes data to arrive at a conceptual groundwater flow model? Understanding the surface-groundwater interactions is vital to investigating how present and future stresses affect hydraulic heads in the studied system. However, simulations of river leakage are parameters-dependent, with uncertain knowledge of the parameters themselves and with no clear knowledge of how uncertainties in the parameters (including the streambed conductance which is the most problematic parameter) affect the computed leakage. So, the second question we investigated is: which of the streambed and subsurface layers properties have a dominant influence on the estimated surface-groundwater fluxes? In addition, Welsh (2006) found large differences in artesian head declines between areas (e.g.: between south Australia and New South Wales) which could not be explained yet. Furthermore, there are many parameters (including recharge and hydraulic properties) involved in the computation of heads in the artesian system and which of the parameters 
are key in such investigations are not clearly known. It is also unclear if the impact of recharge and hydraulic and storage properties are the same across the whole artesian zone. Hence, a third question (set of questions) that we addressed are: how will artesian heads in the T.C. aquifer evolve in the future with respect to future population growth and climate change? which areas of an artesian basin would be more subjected to artesian head declines? what is the impact of recharge and hydraulic and storage properties of the subsurface layers on heads across the artesian domain?

In chapter two of this thesis, we addressed the above first question. Namely, we conducted piezometric and hydrochemical (including stable and radioactive isotopes) surveys, taking into account the existing lithostratigraphic information to elucidate the groundwater flow in the studied aquifer and to arrive at a conceptual groundwater flow model. We found that, for the concerned aquifer, recharge occurs in the northern region and that groundwater flows generally towards the southern areas. Stable and radioactive isotopes spatial distributions illustrate well the recharge areas, with higher and lower signatures respectively associated to the recharge and downstream areas. Radioactive isotopes were found to be good indicators that can be used in similar artesian systems elsewhere to pinpoint recharge and downstream areas and to conceptualize the general groundwater flow of such systems. However, the groundwater mineralization as measured through the TDS (Total Dissolved Solids) was found not effective in such flow conceptualization, as no robust and logical TDS trend was found in the flow system. A conceptual flow model is proposed in chapter 2 for the case study and can serve as foundation for future numerical modelling exercises.

In chapter three, we investigated the river leakage in the studied artesian system, using a numerical model based on the previously developed conceptual flow model. We found that in the confined part of such a system, the contribution of surface-groundwater fluxes (leakage) to recharging the artesian aquifer is negligible. We also found that when modelling surface-groundwater interaction, the streambed conductance is not the key or the most influencing factor affecting the computed leakage. Rather, the streambed conductance is found to be among the least influencing factors in this system, but the hydraulic conductivity of the alluvial and of the unconfined part of the artesian aquifer are key factors. We arrived at ranking the different hydraulic and storage properties with respect to computing river leakage in such a system. We hope that this rank of properties can guide modelling exercise (computation) of river leakage in other similar systems.

In chapter four, we simulated the present and future groundwater heads in the artesian zone so as to understand the cause of the current artesian head-drops and to predict the future evolution of the heads, given the projected recharge and population growth. We 
found that the artesian basin is structured into peripheral and central parts, which have different reactions to external stresses. The peripheral artesian zone was found adjacent to groundwater recharge areas and is more subjected to higher head-fluctuations compared to the central artesian zones. In fact, head fluctuations (recharge-related) are only generated from far away, i.e., in the recharge area which is closer to the peripheral artesian zone. But due to leakage into/out of the confining layer that exists in the south, head amplitudes will damp with distance toward the central artesian zone. The assessment of past head evolutions reveals that artesian head-drop is not a new process in the studied system. It used to occur especially at the peripheral artesian zone, but was not noticed on the field (in the study area) earlier as the first artesian wells installed until 2005 were located at the central artesian zone where head amplitudes are negligible as explained in chapter four. The heads in the central artesian part will likely be stable till 2050, implying that the local population and NGOs can reply on artesian wells free-flow in those areas for food production and various other purposes. We also found that, due to lower-predicted recharge in 2020s, head-drop might be more pronounced (down to $1 \mathrm{~m}$ below surface level) in the peripheral artesian zone for that period. But during 2030-2050, results suggest a slight recovery (head-gain) especially in the peripheral artesian zone due to higher expected recharge for that period. Results indicated that in case the current artesian outflows double by 2050 due to the expected increase of water demand by population growth, this might cause heads to reduce by only few centimeters both in the central and at the periphery of the artesian zone. This shows that the effect of climate change is much more important than the increase of water demand. Furthermore, we found that the impact of recharge is more important in the periphery than in the center and the impact of the outflow scenarios is more important in the center where most of the artesian wells are. Capping all the artesian wells by 2025 would only slightly recover artesian heads. The hydraulic conductivity of the confined part of the aquifer proved to be the most sensitive parameter to the computed heads, followed by the hydraulic conductivity of the clay layer, the specific storage of the confining clay layer, and the specific storage of the confined aquifer. The effects on heads are largest in the center compared to the periphery while the effects on amplitudes are largest for the periphery because this part of the aquifer is confined and that recharge occurs far away.

Chapters one and five of this thesis respectively introduces and synthetizes the research work-flow presented in chapter two to four. The research certainly has limitations, which first concern the hydraulic and storage properties of the subsurface strata that were not available on small scale. However, such data at small scale are desirable to account more for heterogeneity. Second, groundwater recharge is the driver of the modelled system and its magnitude depends on several parameters including precipitation amounts, runoff amounts, evapotranspiration and soil properties. In this thesis (chapters three and four), we 
used the soil water content and runoff data available from previous studies. However, the laters were again not available at small scale, meaning that the evaluated recharge could be further improved by evaluating runoff and soil water contents that reflect field conditions and at small scale. Typically for artesian groundwater system modelling, the location of the downstream model boundary could be an issue if, due to computational burdens, it is not feasible to place such a boundary at natural hydrologic boundaries which may be very far (hundreds of kilometers) away (sea coastline, large rivers, etc.). Such a downstream model boundary can be placed at a certain distance from the interested area and specified heads or fluxes can be applied at such a model boundary. However, the distance to which such a downstream boundary could be placed so as to limit its influence on the computed heads in the artesian domain is not discussed in the literature. More research is needed to investigate this issue and to elaborate on the impact that the distance of the downstream boundary would have on the computed heads in the artesian zones. 


\section{French summary (Résumé)}

Les ressources en eau en générale et en particulier les ressources en eau souterraines demeurent vitales pour l'homme. La disponibilité de ces ressources pour assurer l'approvisionnement en eau des populations sans cesse croissante, n'est pas certaine. Les ressources en eaux souterraines sont limitées et il est nécessaire de comprendre le fonctionnement des aquifères en vue de leur gestion durable, ce qui peut contribuer à assurer la disponibilité en eau pour diverses fins incluant les usages domestiques et de sécurité alimentaire.

Les menaces quantitatives sur la ressource en eau souterraine s'expriment par une baisse continue des charges hydrauliques, ce qui peut être alarmant pour les gestionnaires de la ressource. Plusieurs aquifères de par le monde sont affectés par des baisses piézométriques continues, et périodiques pour d'autre. Le cas de l'aquifère du Crétacé au Sud du Bénin retient l'attention dans ce travail du fait que des baisses de débits sont notées au niveau de certain forages artésiens. En effet plusieurs forages artésiens ont cessé de couler dans d'autres bassins, c'est le cas par exemple du GAB (Great Artesian Basin) en Australie. Ceci suscite quelques interrogations pour le cas du sud du Bénin. Notamment, comment évolueront les charges artésiennes au cours des prochaines décennies? Y a-t-il de risques d'extinction des forages artésiens existants?

Aborder les questions susmentionnées requiert une connaissance approfondie relative à l'écoulement de l'aquifère, à ses interactions avec les eaux de surface et à son comportement hydrodynamique vis-à-vis des pressions présentes et futures. Conceptualiser l'écoulement de l'aquifère au vu des interrogations susmentionnées est fondamentale, mais peut être entaché d'erreurs. Ainsi la première question spécifique abordée dans cette thèse est: Comment peut-on se baser sur les informations lithostratigraphiques et d'écoulement (basées sur plusieurs approches) pour définir un modèle conceptuel d'écoulement des eaux souterraines? Autrement, les approches de piézométrie, d'hydrochimie et isotopiques sont-elles toute utiles pour le développement d'un modèle conceptuel d'écoulement? La compréhension des interactions eaux souterraines-eaux de surface est aussi indispensable pour examiner l'impact que les pressions actuelles et futures auraient sur les charges artésiennes. Cependant, la simulation des flux eaux souterraines-eaux de surface fait appel à des paramètres qui sont connus avec incertitudes. L'influence de l'incertitude de ces paramètres (dont la conductance des sédiments de fonds de rivières, paramètre le plus complexe à évaluer) sur ces flux n'est pas bien cernée. Ainsi, la seconde question spécifique abordée dans ce travail est: quels sont les paramètres qui influencent le plus les flux eaux souterraines-eaux de surface simulés ? En outre, Welsh (2006) a observé que le degré de baisses de charges varie selon les régions de la zone artésienne, une observation qui n'a pas été encore expliqué. Aussi, plusieurs 
paramètres interviennent dans la simulation des charges hydrauliques des bassins artésiens. Lequel de ces paramètres reste déterminant pour de pareils simulations reste inconnue. Ainsi, une troisième question (série de questions) spécifique qu'aborde la présente étude est: Comment évolueraient les charges artésiennes en fonction du climat et de la croissance démographique? Quels parties de la zones artésienne seraient plus vulnérables aux baisses de charges artésiennes ? quels impacts la recharge, les propriétés hydrauliques et d'emmagasinement des formations géologiques ont sur les charges hydrauliques simulées en zone artésienne?

Le chapitre deux de cette thèse est consacré à la première question spécifique. Notamment, nous avons conduit de campagnes piézométriques et hydrochimiques (incluant les isotopes stables et radioactives) en tenant compte des informations lithostratigraphiques existantes pour élucider l'écoulement souterrain de l'aquifère du Crétacé et parvenir à un modèle conceptuel d'écoulement du système étudié. Les résultats ont montré que les zones de recharge du système artésien sont localisées dans la partie Nord de la zone d'étude et l'écoulement des eaux souterraines se fait en générale du Nord vers le Sud. La distribution spatiale des isotopes stables et radioactives notamment illustrent bien les zones de recharge et les directions d'écoulement, avec de fortes signatures isotopiques en zones de recharge et de faibles signatures en direction des zones de décharge. Les résultats démontrent que les isotopes radioactifs sont de bons traceurs pouvant être utiles dans d'autres bassins similaires pour l'identification des zones de recharge et de décharge, pour la compréhension des sens d'écoulement et pour conceptualiser l'écoulement générale des systèmes similaires. Un modèle conceptuel est établit au chapitre deux pour le système étudié et peut servir de base pour des exercices de simulations numériques futures. En revanche, l'hydrochimie classique, notamment le TDS, ne semble pas être en cohérence avec les résultats issus de la piézométrie et des isotopes.

Le chapitre trois a traité d'interactions eaux souterraines-eaux de surface dans le système artésien étudié. Un modèle numérique d'écoulement est élaboré à cet effet et est basé sur le modèle conceptuel précédemment établie. II en ressort que dans la partie sud du système étudié, la contribution issue des eaux de surface pour la recharge de l'aquifère est insignifiante. Les résultats indiquent par ailleurs que la conductance des sédiments de fond de rivières n'est pas le facteur clé ou le facteur affectant le plus les flux eaux souterraineseaux de surface simulés. Plutôt, la conductance des sédiments de fonds de rivières figure parmi les facteurs les moins influençant. Par contre, la conductivité hydraulique des alluvions et de la partie libre de l'aquifère artésien sont les facteurs dominants. Une classifications des propriétés hydrauliques et d'emmagasinement est proposée pour le cas des simulations de flux eaux souterraines-eaux de surface. Cette classification restera utile 
pour l'estimation de ces flux dans des systèmes artésiens similaires à celui étudié dans ce travail.

Au chapitre quatre, une simulation de l'évolution des charges hydrauliques à l'horizon 2050 a été effectué dans la partie artésienne de la zone d'étude. Les résultats ont montré que le bassin artésien est structuré en parties périphérique et centrale, qui n’ont pas les mêmes réactions vis à vis des pressions externes. La zone périphérique se trouve adjacente aux zones de recharge et est plus sujette aux fluctuations piézométriques. Ces fluctuations piézométriques en périphérie ne se propagent pas jusqu'à la zone artésienne centrale. En effet, les amplitudes piézométriques diminuent en fonction de la distance (de la zone de recharge vers le sud) et deviennent pratiquement nulles dans la partie centrale artésienne. Cette atténuation des amplitudes de charges artésiennes de la zone de recharge vers la zone centrale artésienne est due au fait que les fluctuations de charges (causées par la recharge) sont uniquement générées dans la zone de recharge (dans la partie Nord). En se propageant vers le sud, ces fluctuations sont influencées par des suintements d'eau provenant de la couche argileuse sus-jacente. L'analyse des charges hydrauliques simulées révèle que les baisses de charges artésiennes ne constituent pas un processus nouveau dans le système étudié. II s'agit plutôt d'un processus périodique qui a surtout lieu dans la partie périphérique artésienne mais qui n'avait pas été constaté tôt sur le terrain (par les populations locales) du fait que les forages artésiens existants jusqu'en 2005 se révèlent avoir été tous installé dans la partie centrale artésienne. Les charges hydrauliques dans la partie centrale artésienne resteraient stables jusqu'à I'horizon 2050. Ceci implique que le populations locales de même que les ONG intéressées peuvent se fier aux forages artésiens jaillissants dans cette partie centrale (incluant les localités de Hon, Bonou, Ouinhi) pour la production agricole et pour d'autres usages. Les résultats révèlent aussi que les baisses de charges artésiennes pourraient s'accentuer (de l'ordre de $1 \mathrm{~m}$ ) dans la partie artésienne périphérique au cours des années 2020 du fait d'une recharge relativement faibles prévue pour cette période. Cependant, au cours de la période 2030-2050, un léger regain piézométrique toujours dans la partie artésienne périphérique se produirait du fait des recharges relativement élevées prévues pour cette période. Si les débits artésiens doublaient d'ici 2050 en liaison étroite avec la croissance démographique, ceci causerait une baisse légère de quelques centimètres seulement aussi bien dans les parties périphérique que dans la centrale artésienne, suggérant que l'impact du climat est plus important que la celui lié à cette croissance démographique. Par ailleurs, l'impact de la recharge est plus important en zone artésienne périphérique que centrale mais les scenarii de débits artésiens impactent plus la zone artésienne centrale que périphérique. Un scénario de fermeture des tous les forages artésiens en 2025 indique un léger regain de charges artésienne. Les charges artésiennes simulées sont le plus sensibles à la conductivité hydrauliques de la partie confinée de l'aquifère artésien. Viennent ensuite la conductivité 
hydraulique de la couche argileuse, le coefficient d'emmagasinement de la couche argileuse et le coefficient d'emmagasinement de la partie confinée de l'aquifère artésien. L'effet de ces propriétés sur les charges hydrauliques est important en zone centrale comparativement à la zone périphérique pendant que leurs effets sur les amplitudes de charges hydrauliques est plus large en zone périphérique du fait que l'aquifère en zone centrale est confiné et que la recharge provient de très loin.

Le chapitre un de la thèse introduit la problématique du sujet et présente les questions de recherche. Le chapitre cinq fait la synthèse des résultats principaux présentés aux chapitres deux, trois et quatre puis présente leurs implications du point de vue social et scientifique. L'approche de modélisation numérique adoptée dans ce travail a certainement des limites ou insuffisances. La première insuffisance concerne les couches géologiques du modèle dont les propriétés hydrauliques et d'emmagasinement ne sont disponibles qu'à des échelles macroscopiques. Cependant, il serait meilleur de disposer de ces propriétés à petites échelles pour mieux prendre en compte les hétérogénéités intrinsèques au milieu réel. Deuxièmement, la recharge est le flux d'entrée qui conditionne l'état hydrodynamique du système. Mais cette dernière dépend de plusieurs paramètres dont la quantité de pluie, de ruissellement, l'évapotranspiration et les propriétés du sol, notamment la teneur en eau du sol. Dans ce travail (chapitres trois et quatre), nous avons exploité des valeurs de teneur en eau de sols et de ruissellement estimées par des études précédentes. Cependant, ces dernières ne sont pas toujours disponibles à petites échelles. Les recharges estimées au cours de ce travail pourraient donc être affinées à partir des teneurs en eau de sols et de ruissellement estimés à petites échelles.

Typiquement, pour la modélisation des systèmes artésiens, le positionnement spatial de la frontière avale du modèle peut être problématique au cas où, du fait du temps de calcul très onéreux, cette frontière ne peut pas être repoussé pour coïncider avec des limites hydrologiques naturelles (grand cours d'eau, grand lacs ou océans) se trouvant très éloignées, à des centaines de kilomètres. Une telle limite peut être alors positionnée à une certaine distance de la zone d'intérêt avec des conditions aux limites (charges hydrauliques ou flux) qui y sont imposées. Cependant, la distance à laquelle une telle frontière peut être positionnée de façon à minimiser son influence sur la zone d'intérêt n'est pas discutée dans la littérature et, l'impact de la distance de cette frontière sur les charges hydrauliques simulées dans la zone d'intérêt n'est pas connue. En ce sens, de futures travaux de recherches peuvent être initié pour élucider l'impact de la distance de cette frontière avale sur les charges artésiennes simulées. 


\section{Acknowledgements}

Throughout this PhD journey, numerous people provided supports.

I would like to thank Prof. Dr. Ir. Sjoerd van der Zee, that I met for the very first time in Benin in February 2010 when I was still undertaking the Bachelor program. A couple of years later, he became my main promotor and supervised this thesis. Thank you for your strong support and careful reading of the various manuscripts I produced and for your suggestions for their improvement. Thank you for having given me the opportunity to pursue my doctoral studies at Wageningen University.

My profound gratitude to Prof. Moussa Boukari, my local co-promotor for the long supervising commitment he started since I was at the Bachelor level. Thank you for locally supervising this $\mathrm{PhD}$ research. I vividly remember with found some field trips we carried out together across the study area in southern Benin, observing the geology and other hydrologic features that justify parts of the model border. Thank you for this long support.

I would also like to thank Dr. Perry de Louw who lately joined the supervision team of my $\mathrm{PhD}$ research. Although you joined the supervision team latter, your contributions to this are undeniable. Thanks for the workspace you offered me several times at Deltares (Utrecht), for the time you dedicated and for the constructive comments you provided on the manuscripts I produced. I think your strong encouragements kept me motivated at times I felt very down.

Special thanks to Prof. Anton Leijnse and to Ir. George Bier for the several discussions we had had, especially regarding the hydrological setting of the study area and regarding the definition of the boundary conditions of the numerical model. Technical guidance in GMSsoftware from Ir. George Bier was appreciated.

I thank the team of Prof. Alain Dassargues including Dr. Phillippe Orban and Serge Brouyere for giving me the opportunity to spend a three-month stay in their group at Liege University, deepening my modelling knowledge and for inspiring me regarding groundwater recharge estimation and numerical model calibration.

I am grateful to Prof. Daouda Mama, Prof. Abel Afouda, Prof. Abdoukarim Alassane, Prof. Nelly Kelome, Prof. Nicaise Yalo, Prof. Emmanuel Lawin, Prof. Eric Alamou, Prof. Flavien Dovonou and Prof. Julien Adoukpe for their constant attention to my research progress. 
I thank all the people who helped me to obtain various data I used for the model developed during my PhD studies. Namely, I would like to mention Mr. Philippe Adjomayi, Dr. Raoufou Maliki, Mr. Martin Kpomasse, Dr. Jonas N'cha M'po, Dr. Rita Houngue, Dr. Joel Tossou and Dr. Japhet Kodja.

My profound gratitude to Mr. Erik Frederiks, Mr. Bert Bruins, Mr. Steven Starmans, Prof. Marc Kpodekon, Prof. Michelline Agassounon and Prof. Euloge Agbossou for all the administrative arrangements within the NICHE project.

Special thanks to the secretaries Marnella van der Tol, Rianne Maasen and formerly (Annelies van de Bunte) and the financial department (formerly including Siawash, Geert Belgers and Randy Binneveld) for smoothly handling the administrative issues during my studies at WUR.

Thanks go to my drivers for the numerous safe-drivings across the study area in southern Benin and for their practical helps on the field, including water sampling campaigns.

$\mathrm{I}$ also thank my former Bachelor and Master students Mr Amos Agossou, Mr Brian Bamigbotche, Mr Justin Hayaka and Ms Mellone Glessougbe, who contributed to piezometric surveys and other field investigations including spring discharge measurements.

I also thank Mr Gafoudou Sakpoho, my volunteer English Teacher for helping upgrade my English level, which has been a great asset throughout this PhD journey.

I appreciate feedbacks I received from various scientists that I got to know from the Hydrogeology literature and conferences. They include Prof. Kresic Neven, Prof. Roland Barthel, Prof. Romain Chestnaux and Prof. Vu Thanh Tam who, based on their modelling experience, provided guidance toward solving some modelling issues that I encountered such as model convergence. Thank you for your time and for the long emails explanations.

My gratitude goes to my friends and colleagues at Wageningen University. I will mention Verra, Lington, Pavan, Samuale, Belyse, Goddy, Chakaphon, Corjan, Coleen, Dr. Xiaomei, Dr. Karrar, Dr. Kaveh, Dr. Celia, Marina Kim and the others for the refreshing activities we enjoyed together.

My gratitude also goes to all the members of the Beninese community at Wageningen University for the warm welcome and friendship during my various stays in the Netherlands. I thank particularly Dr. Folachodé Akogou, Dr. Waliou Yessoufou, Dr. Charles Tamou, Dr. Deedi Sogbohossou, Dr. Falylath Babah Daouda, Dr. Fernande Honfo, Dr. Souleimane 
Adekambi, Marius Assogba, Deo-Gratias Hougni, Dr. Edmond Totin and Landry Fanou to whom I kept in contact with during my PhD journey.

My gratitude goes to Mr Raoul Adjobo and Ms Rosemarie Merz for making sure that I am well settled in Wageningen and for some cities we visited together in the Netherlands. I recall with pleasure the visits througout the cities of Maastricht, Apeldorrn, Almelo,...

I would like to thank Klaas Oostindie for outling the thesis as well as designing its s cover. I thank my Paranymphs (Verra Felix da Graca Silva and Pavan Cornelissen) for organizing my PhD defence.

I would like to thank the reading committee for their time and helpful comments.

Last but certainly not the least, I would express warm thanks to my Father (Koffi Kpegli) and my Mother (Denise Gnanga) for their unconditional supports and for being always there for me, both in the best and worst times of my life. I also thank my wife (Chantal Hounkpatin), my siblings Honoré and Thibaut for their understanding and supports during my PhD journey.

Thanks to all of you.

K. A. Raoul Kpegli, Wageningen 
The research described in this thesis was financially supported by the NICHE/BEN167 project. Financial supports from the IAEA (International Atomic Energy Agency) and IFS (International Foundation for Science) for contributing to some of my trainings (including GIS and modelling), field trips, lab analysis and an open access publication fees are gratefully acknowledged. Financial supports from the LEB founds for supporting my attendance to the conference in Croatia and to my modelling training in Germany are appreciated.

Cover design by klaas Oostindie 


\section{About the author}

Kpegli K.A. Raoul was born on December 31, 1988 at Kouvènafide (in Benin). He obtained his bachelor's degree in Hydrogeology in February 2011 at the University of Abomey-Calavi (Faculté des Sciences et Techniques) in Benin. In November 2012, he acquired his master's degree in the field of Hydrogeology at the same University. During the bachelor and the Master accademic studies, he did internships at various institutions in Benin (including DGEau) and abroad (including the Ghana Water Research Institute) to acquire practical field experience.

Afterward, he worked as a research assistant for the IRD (Institut de Recherche pour le Développement) under the GRIBA (Groundwater Resources In Basement rocks of Africa) project and participated in several geological, geophysical (ERT, RMP) and pumping tests surveys across northern Benin. In late 2012, he joined the Laboratoire d'Hydrologie Appliquée of the University of Abomey-Calavi as a research assistant and participated actively in the implementation of several research projects such as the IAEA-RAF7013 and RAF7011 projects, which aimed at assessing the groundwater quality and their vulnerability to pollution, mainly in transboundary aquifers of the Sahel region (Northern Africa). In 2014, he was awarded a PhD grant (NICHE/BEN167) to pursue his PhD studies at Wageningen University, the Netherlands. For formal admission to the PhD program, he successfully completed the qualifying exams. He effectively started his PhD studies in January 2015 with a general aim of characterizing and modelling the flow in a giant aquifer of southern Benin in view of assessing its future artesian heads evolution.

Mr Kpegli attended several training courses abroad related to GIS, isotopes and modelling tools and has participated in several international conferences, with both oral and poster presentations. He also published scientific results in high impact factor peer review journals. He is perfectly bilingual (French and English) and was awarded two IFS grants (5570-1 and 5570-2) as supports to his research initiatives. He can be contacted via the email addresses below.

Email: raoulkpegli@gmail.com ; raoulkpegli@yahoo.fr 


\section{Scientific publications}

In peer review journals

K. A. R. Kpegli, P.G.B. de Louw, A. Alassane, D. Mama, M. Boukari, S.E.A.T.M van der Zee. Three-dimensional hydrogeological modelling of head changes of a South Benin artesian aquifer. Under review in the Hydrogeology Journal.

K. A. R. Kpegli, S.E.A.T.M van der Zee, A. Alassane, G. Bier, M. Boukari, A. Leijnse, P.G.B. de Louw, D. Mama, 2018. Impact of hydraulic and storage properties on river leakage estimates: A numerical groundwater flow model case study from southern Benin. Journal of Hydrology: Regional Studies, 19, 136-163.

K. A. R. Kpegli, A. Alassane, S.E.A.T.M van der Zee, M. Boukari, D. Mama, 2018. Development of a conceptual groundwater flow model using a combined hydrogeological, hydrochemical and isotopic approach: a case study from southern Benin. Journal of Hydrology: Regional Studies, 18, 50-67.

K. A. R. Kpegli, A. Alassane, R. Trabelsi, K. Zouari, M. Boukari, D. Mama, F. L. Dovonon, Y. V. Yoxi, L. E. Toro-Espitia. 2015. Geochemical processes analysis in kandi basin in Benin, west Africa: a combined hydrochemistry and stable isotopes approach. Quaternary International, 369, 99 - 109.

Oral and poster presentations

K. A. R. Kpegli, Sjoerd E. A. T. M. Van Der Zee, A. Alassane, M. Boukari, 2018. Estimate of river leakage and its sensitivity to various hydraulic and storage properties: a case study from southern Benin using a numerical model approach. Oral presentation. International Association of Hydrogeologists Congress, 10-14 September 2018, Daejeon, South Korea.

A. Alassane, K. A. R. Kpegli, M. Boukari, L. Gourcy, Y. Travi, K. Zouari, S. Terzer-Wassmuth, L.J. Araguas-Araguas, 2018. Isotopic characteristics of rain as input signal in aquifers of southern Benin (west Africa) and highlights of the event ENSO (EI Nino/southern oxillation) 2014-2016. Oral presentation. International Association of Hydrogeologists Congress, 10-14 September 2018, Daejeon, South Korea.

Kpegli, K. A. R., Alassane, A., Boukari, M., Zee, van der S. E. A. T. M., Zouari, K., Trabelsi, R., Mama, D., 2017. Using a combined classic hydrogeological, hydrochemical and isotopic approach for a conceptual groundwater flow model development in southern Benin. Scientific Poster. International Association of Hydrogeologists Congress, Dubrovnik, Croatia, September 2017.

K. A. R. Kpegli, A. Alassane, L. Dovonon, D. Mama, M. Boukari, K. Zouari. Groundwater flow characterization in kandi basin (Benin, west Africa): a combined classic hydrogeological and isotopic approach. Scientific Poster. International Symposium on Isotope Hydrology: Revisiting Foundations and Exploring Frontiers. May 2015, IAEA Headquarters, Vienna, Austria. 


\title{
SENSE
}

Netherlands Research School for the

Socio-Economic and Natural Sciences of the Environment

\section{I P L O M A \\ for specialised PhD training}

The Netherlands research school for the

Socio-Economic and Natural Sciences of the Environment

(SENSE) declares that

\section{Kodjo Apelete Raoul Kpegli}

\author{
born on 31 December 1988 in Kouvenafidé, Benin \\ has successfully fulfilled all requirements of the \\ educational PhD programme of SENSE.
}

Wageningen, 4 November 2020
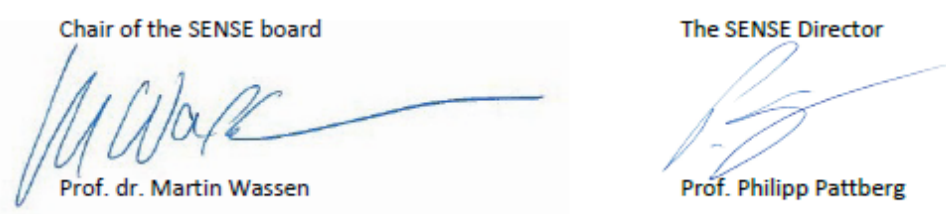

The SENSE Research School hos been accredited by the Royal Netherlands Academy of Arts and Sciences (KNAW)

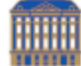

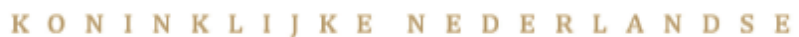

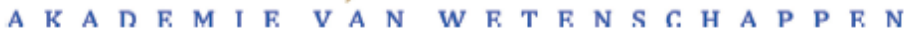




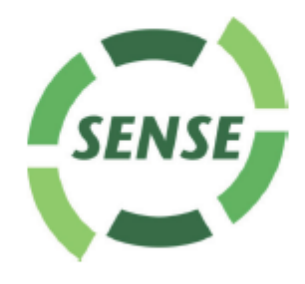

The SENSE Research School declares that Kodjo Apelete Raoul Kpegli has successfully fulfilled all requirements of the educational PhD programme of SENSE with a work load of $48.3 \mathrm{EC}$, including the following activities:

\section{SENSE PhD Courses}

- Environmental research in context (2015)

- Statistical Uncertainty Analysis of Dynamic Models (2015)

- Research in context activity: 'Workshop presentation in Benin for sharing results of the PhD research' (2019)

\section{Other PhD and Advanced MSc Courses}

- Models for Environmental Systems, Wageningen University (2015)

- Handling and processing hydrochemical and isotopic data with the use of GIS (Arc Gis). International Atomic Energy Agency Headquarters, Austria (2015)

- Information Literacy including EndNote, Wageningen Graduate Schools 2015)

- Reviewing a Scientific Paper, Wageningen Graduate Schools (2016)

- Project and time management, Wageningen Graduate Schools (2016)

- Presenting with impact, Wageningen Graduate Schools (2016)

- Summer School for Flow and Transport in Terrestrial Systems, Clausthal University, Germany (2016)

- Training Course on Isotope-enabled Water Balance Modelling for Climate Change Prediction, International Atomic Energy Agency Headquarters, Austria (2019)

\section{External training at a foreign research institute}

- Hydrological model calilbration, Université de Liege, Belgium (2017)

\section{Management and Didactic Skills Training}

- Organizing the regional training course Isotope in contamination studies and tracing of movement of pollutants', Cotonou, Benin (2015)

- Supervising two MSc students with thesis (2016-2017)

- Teaching in the BSc course 'Water sampling techniques, University of Abomey-Calavi, Benin' (2017)

\section{Oral Presentations}

- Analyse hydrogeologique des plateaux de Ketou et Abomey au Benin. Point de These, University of Abomey-Calavi (2015), Abomey-Calavi, Benin

- Estimate of river leakage and its sensitivity to various hydraulic and storage properties: $a$ case study from southern Benin using a numerical model approach. International Association of Hydrogeologists Congress, 10-14 September 2018, Daejeon, South Korea

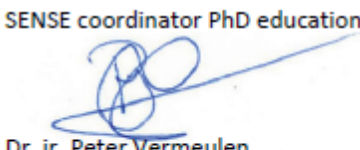

Dr. ir. Peter Vermeulen 
